\title{
The formation, properties and impact of secondary organic aerosol: current and emerging issues
}

\author{
M. Hallquist ${ }^{1}$, J. C. Wenger ${ }^{2}$, U. Baltensperger ${ }^{3}$, Y. Rudich ${ }^{4}$, D. Simpson ${ }^{5,6}$, M. Claeys ${ }^{7}$, J. Dommen ${ }^{3}$, \\ N. M. Donahue ${ }^{8}$, C. George ${ }^{9,10}$, A. H. Goldstein ${ }^{11}$, J. F. Hamilton ${ }^{12}$, H. Herrmann ${ }^{13}$, T. Hoffmann ${ }^{14}$, Y. Iinuma ${ }^{13}$, \\ M. Jang ${ }^{15}$, M. E. Jenkin ${ }^{16}$, J. L. Jimenez ${ }^{17}$, A. Kiendler-Scharr ${ }^{18}$, W. Maenhaut ${ }^{19}$, G. McFiggans ${ }^{20}$, Th. F. Mentel ${ }^{18}$, \\ A. Monod $^{21}$, A. S. H. Prévôt ${ }^{3}$, J. H. Seinfeld ${ }^{22}$, J. D. Surratt ${ }^{23}$, R. Szmigielski ${ }^{7}$, and J. Wildt ${ }^{18}$ \\ ${ }^{1}$ Dept. of Chemistry, Atmospheric Science, University of Gothenburg, 41296 Gothenburg, Sweden \\ ${ }^{2}$ Dept. of Chemistry and Environmental Research Institute, University College Cork, Cork, Ireland \\ ${ }^{3}$ Laboratory of Atmospheric Chemistry, Paul Scherrer Institut, 5232 Villigen PSI, Switzerland \\ ${ }^{4}$ Dept. of Environmental Sciences, Weizmann Institute, Rehovot 76100, Israel \\ ${ }^{5}$ EMEP MSC-W, Norwegian Meteorological Institute, P.B. 32 Blindern, 0313 Oslo, Norway \\ ${ }^{6}$ Dept. of Radio and Space Science, Chalmers University of Technology, 41296, Gothenburg, Sweden \\ ${ }^{7}$ Dept. of Pharmaceutical Sciences, University of Antwerp (Campus Drie Eiken), Universiteitsplein 1, \\ 2610 Antwerp, Belgium \\ ${ }^{8}$ Center for Atmospheric Particle Studies, Carnegie Mellon University, Pittsburgh PA 15213, USA \\ ${ }^{9}$ Université de Lyon, Faculté de Chimie, 69003, France \\ ${ }^{10}$ CNRS, UMR5256, IRCELYON, Institut de recherches sur la catalyse et l'environnement de Lyon, Villeurbanne, \\ 69626, France \\ ${ }^{11}$ Dept. of Environmental Science, Policy and Management, University of California, Berkeley, CA, USA \\ ${ }^{12}$ Dept. of Chemistry, University of York, Heslington, York, YO10 5DD, UK \\ ${ }^{13}$ Leibniz-Institut für Troposphärenforschung, Permoserstrasse 15, 04318 Leipzig, Germany \\ ${ }^{14}$ Johannes Gutenberg-Universität, Institut für Anorganische und Analytische Chemie, Duesbergweg 10-14, \\ 55128 Mainz, Germany \\ ${ }^{15}$ Dept. of Environmental Engineering Sciences, P.O. Box 116450, University of Florida, Gainesville, FL 32611-6450, USA \\ ${ }^{16}$ Atmospheric Chemistry Services, Okehampton, Devon, EX20 1FB, UK \\ ${ }^{17}$ Dept. of Chemistry \& Biochemistry; and CIRES, University of Colorado, UCB 216, Boulder, CO 80309-0216, USA \\ ${ }^{18}$ Institut für Chemie und Dynamik der Geosphäre, ICG, Forschungszentrum Jülich, 52425 Jülich, Germany \\ ${ }^{19}$ Dept. of Analytical Chemistry, Institute for Nuclear Sciences, Ghent University, Proeftuinstraat 86, 9000 Ghent, Belgium \\ ${ }^{20}$ Centre for Atmospheric Sciences, School of Earth, Atmospheric \& Environmental Sciences, University of Manchester, \\ Simon Building, Manchester, M13 9PL, UK \\ ${ }^{21}$ Université Aix-Marseille I, II et III, Case 29, Laboratoire Chimie Provence, UMR-CNRS 6264, 3 place Victor Hugo, 13331 \\ Marseille Cedex 3, France \\ ${ }^{22}$ Depts. of Chemical Engineering and Environmental Science and Engineering, California Institute of Technology, Pasadena, \\ CA 91125, USA \\ ${ }^{23}$ Dept. of Chemistry, California Institute of Technology, Pasadena, CA 91125, USA
}

Received: 20 November 2008 - Published in Atmos. Chem. Phys. Discuss.: 3 February 2009

Revised: 10 June 2009 - Accepted: 11 June 2009 - Published: 29 July 2009 
Abstract. Secondary organic aerosol (SOA) accounts for a significant fraction of ambient tropospheric aerosol and a detailed knowledge of the formation, properties and transformation of SOA is therefore required to evaluate its impact on atmospheric processes, climate and human health. The chemical and physical processes associated with SOA formation are complex and varied, and, despite considerable progress in recent years, a quantitative and predictive understanding of SOA formation does not exist and therefore represents a major research challenge in atmospheric science. This review begins with an update on the current state of knowledge on the global SOA budget and is followed by an overview of the atmospheric degradation mechanisms for SOA precursors, gas-particle partitioning theory and the analytical techniques used to determine the chemical composition of SOA. A survey of recent laboratory, field and modeling studies is also presented. The following topical and emerging issues are highlighted and discussed in detail: molecular characterization of biogenic SOA constituents, condensed phase reactions and oligomerization, the interaction of atmospheric organic components with sulfuric acid, the chemical and photochemical processing of organics in the atmospheric aqueous phase, aerosol formation from real plant emissions, interaction of atmospheric organic components with water, thermodynamics and mixtures in atmospheric models. Finally, the major challenges ahead in laboratory, field and modeling studies of SOA are discussed and recommendations for future research directions are proposed.

\section{Introduction}

Atmospheric aerosols, consisting of liquid or solid particles suspended in air, play a key role in many environmental processes. Aerosols scatter and absorb solar and terrestrial radiation, influence cloud formation and participate in heterogeneous chemical reactions in the atmosphere, thereby affecting the abundance and distribution of atmospheric trace gases (Andreae and Crutzen, 1997; Haywood and Boucher, 2000). As a result, aerosols markedly affect the radiative balance in Earth's atmosphere and play a central role in climate (IPCC, 2007). Atmospheric aerosols also have an important impact on human health and it is now well established that exposure to ambient aerosols is associated with damaging effects on the respiratory and cardiovascular systems (Harrison and Yin, 2000; Davidson et al., 2005; Pope and Dockery, 2006). However, there are significant uncertainties in the true impact of atmospheric aerosols on climate and health because of a lack of knowledge on their sources, composition, properties

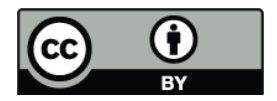

Correspondence to: J. C. Wenger (j.wenger@ucc.ie) and mechanisms of formation (NRC, 2004; Pöschl, 2005; IPCC, 2007).

Atmospheric aerosols are formed from a wide variety of natural and anthropogenic sources. Primary particles are directly emitted from sources such as biomass burning, combustion of fossil fuels, volcanic eruptions and wind-driven suspension of soil, mineral dust, sea salt and biological materials. Secondary particles, however, are formed in the atmosphere by gas-particle conversion processes such as nucleation, condensation and heterogeneous and multiphase chemical reactions. The conversion of inorganic gases such as sulfur dioxide, nitrogen dioxide and ammonia into particulate phase sulfate, nitrate and ammonium is now fairly well understood. However, there is considerable uncertainty over the secondary organic aerosol (SOA) ${ }^{1}$ formed when the atmospheric oxidation products of volatile organic compounds (VOCs) undergo gas-particle transfer. It is estimated that 10000 to 100000 different organic compounds have been measured in the atmosphere (Goldstein and Galbally, 2007). The complexity of the situation is compounded further by the fact that each VOC can undergo a number of atmospheric degradation processes to produce a range of oxidized products, which may or may not contribute to SOA formation and growth. There is also an important difference between processes controlling particle number and processes controlling particle mass; condensation of vapors (sulfuric and nitric acids, ammonia, and secondary organics) onto existing particles may dominate particle mass without necessarily influencing particle number. Both number and mass are important to understand various aspects of the climate and health effects of atmospheric aerosols (Adams and Seinfeld, 2002; Oberdorster et al., 2005). Although clear progress has been made in recent years in identifying key biogenic and anthropogenic SOA precursors, significant gaps still remain in our scientific knowledge on the formation mechanisms, composition and properties of SOA.

The objective of this paper is to review recent advances in our understanding of SOA. It builds upon a number of earlier reviews of organic aerosols in the atmosphere (Jacob, 2000; Jacobson et al., 2000; Turpin et al., 2000; Seinfeld and Pankow, 2003; Gelencsér, 2004; Kanakidou et al., 2005; Fuzzi et al., 2006; Sun and Ariya, 2006; Rudich et al., 2007) and complements the recent work of Kroll and Seinfeld (2008) which focuses specifically on the chemistry of SOA formation. This review begins with an update on the current state of knowledge on the global SOA budget and is followed by an overview of the following topics related to the formation and characterization of SOA: gas-phase oxidation of SOA precursors, gas-particle partitioning and chemical composition. Recent developments in laboratory, field and modeling studies are also presented. These sections provide an effective foundation for the detailed discussions that follow on a range of current and emerging issues related to

\footnotetext{
${ }^{1} \mathrm{~A}$ full list of abbreviations is provided in Sect. 7.
} 
the formation, composition, transformation and properties of SOA. The major challenges ahead are discussed and recommendations for future research directions are proposed.

\section{Global SOA budget}

Estimates of global SOA production have been made by two fundamentally different approaches. The traditional approach is a bottom-up estimate where known or inferred biogenic (most notably isoprene and terpenes) and/or anthropogenic VOC precursor fluxes are combined in global models with laboratory data from oxidation experiments leading to SOA formation in order to obtain a global organic aerosol field (Chung and Seinfeld, 2002; Kanakidou et al., 2005; Henze and Seinfeld, 2006; Henze et al., 2008). An alternative approach is a top-down inverse estimate based on constraining the eventual fate of known precursor emissions to infer the total SOA production rate (Goldstein and Galbally, 2007). These approaches give different results.

Bottom-up estimates give total biogenic SOA (BSOA) fluxes of $12-70 \mathrm{Tg} / \mathrm{yr}$ corresponding to biogenic secondary organic carbon (BSOC) fluxes of $9-50 \mathrm{TgC} / \mathrm{yr}$ for an organic matter to organic carbon ratio $(\mathrm{OM} / \mathrm{OC})$ of 1.4 , which is typically assumed in many modeling studies (Kanakidou et al., 2005). The organic aerosol (OA) in bottom-up models shows a sharp vertical gradient, with much more present in the boundary layer than in the free troposphere (Heald et al., 2005). The sources of biogenic VOCs (BVOCs) are mainly derived from terrestrial ecosystems. However, there are also important emissions of BVOCs from the oceans, in particular of dimethylsulfide, which is oxidized to methanesulfonic acid aerosol (Kettle and Andreae, 2000). Other identified marine SOA components are dicarboxylic acids (Kawamura and Sakaguchi, 1999) and dimethyl- and diethylammonium salts (Facchini et al., 2008). Meskhidze and Nenes (2007) suggested that marine emissions from isoprene could also be a source of SOA. The latter is still an open question, although it has been estimated that the global production of SOA from marine isoprene is insignificant in comparison to terrestrial sources (Arnold et al., 2009). Models also include emissions of primary organic aerosol (POA) of about $35 \mathrm{TgC} / \mathrm{yr}$ (about $9 \mathrm{TgC} / \mathrm{yr}$ of anthropogenic POA and $25 \mathrm{TgC} / \mathrm{yr}$ of POA from open biomass burning (BB) such as forest fires; Bond et al., 2004) and a smaller contribution from anthropogenic SOA (ASOA) in the range $2-12 \mathrm{Tg} / \mathrm{yr}$ $(\sim 1.4-8.6 \mathrm{TgC} / \mathrm{yr}$ with $\mathrm{OM} / \mathrm{OC}=1.4$; Henze et al., 2008). The total organic aerosol budget in bottom-up estimates thus ranges from 50 to $90 \mathrm{TgC} / \mathrm{yr}$, clustering toward the low end. ${ }^{2}$

\footnotetext{
${ }^{2}$ A question arises on how to estimate the range of a summed quantity from the ranges of the summed components. For example if one wants to calculate the range of total SOA from the published estimated ranges for BSOA (9-50 TgC/yr) and ASOA (1.48.6 TgC/yr), one could add the extremes to come up with a total SOA estimate of (10.4-58.6 Tg/yr). However this procedure arti-
}

Recent top-down estimates using several different approaches lead to higher estimates for SOA, with a broad range from 140-910 TgC/yr (Goldstein and Galbally, 2007). These top-down estimates are an order of magnitude larger than the bottom-up estimates, and the extreme outer limits differ by roughly two orders of magnitude. SOA formation of $140-910 \mathrm{TgC} / \mathrm{yr}$ would require $11-70 \%$ of the entire mass of emitted VOCs (including isoprene, which represents $38 \%$ of the VOC budget) to be converted to the particle phase. The upper end of this estimate appears unrealistically high based on available data for SOA yields from chamber experiments (e.g., a few percent from isoprene). However, the difference in range of the top-down and bottom-up estimates clearly suggests that chamber oxidation experiments substantially underestimate total SOA production during the full course of the VOC oxidation process and is an issue that needs to be addressed.

Here, some new evidence based on recently measured aerosol composition will be employed to revise the topdown estimate from Goldstein and Galbally (2007) based on scaling from the sulfate budget, which is believed to provide the tightest constraint of the methods employed in that work. A "hybrid" approach, which combines this revised top-down estimate with bottom-up estimates from various other sources, will then be employed to estimate the BVOC contribution to the total OC budget. The various fluxes and uncertainty ranges used to develop this budget are presented in Table 1.

Particle mass spectrometry measurements on aircraft and at a number of ground-based monitoring locations reveal that most particles throughout the troposphere are mixtures of organics and sulfate $\left(\mathrm{SO}_{4}^{2-}\right)$, with the organic to sulfate ratio (organic/sulfate) ranging between 1:2 and 2:1 (Murphy et al., 2006; Zhang et al., 2007b). From this it can be inferred that organic/sulfate is roughly $1: 1$. Also, several techniques suggest that the OM/OC value typical of the background atmosphere is at least 2:1 (Turpin and Lim, 2001; Aiken et al., 2008). Thus, as the ratio of sulfur to sulfate (S/sulfate) is 1:3,

ficially inflates the uncertainty range. Thus here, and in later estimates, the ranges have been determined by first calculating the mean of the mid-range value (i.e. $(9+50) / 2=29.5$ for BSOA and $(1.4+8.6) / 2=5.0$ for ASOA) and a confidence interval of the difference between the range values (i.e., $50-9=41$ for BSOA and $8.6-1.4=7.2$ for ASOA). Uncertainty propagation rules are then applied to those values to estimate the mid-range value for the sum (i.e. $29.5+5.0=34.5$ for total SOA) and the size of the new confidence interval (i.e. $\operatorname{sqrt}\left(41^{2}+7.2^{2}\right)=41.6$ for total SOA). Finally the range for the summed quantity is calculated as the new mid-range value plus and minus the new confidence interval (i.e. $34.5-41.6 / 2=13.7$ and $34.5+41.6 / 2=55.3$ for total SOA) (D. Fahey, personal communication, 2008, NOAA, Boulder). Although the various range estimates which are being added in this way have been derived in different ways and may have different statistical properties, this method is preferable to other approaches. The fluxes presented here are also rounded to reflect the large uncertainties in these calculations. 
Table 1. Flux estimates (TgC/yr) for the different sources of organic aerosol based on the latest top-down approach. S1 and S2 represent two plausible scenarios, based on global constraints. See text for more details and a description of terms and abbreviations.

\begin{tabular}{|c|c|c|c|c|c|c|c|c|c|}
\hline & $\begin{array}{c}\text { Best } \\
\text { estimate }\end{array}$ & $\begin{array}{l}\text { Low } \\
\text { limit }\end{array}$ & $\begin{array}{l}\text { High } \\
\text { limit }\end{array}$ & $\mathrm{S} 1$ & $\mathrm{~S} 2$ & $\begin{array}{c}\text { Modern } \\
\text { OC }\end{array}$ & $\begin{array}{c}\text { Fossil } \\
\text { OC }\end{array}$ & $\mathrm{HOA}$ & OOA \\
\hline OC Top-down estimate & 150 & 60 & 240 & & & & & & \\
\hline Primary anthropogenic & 5 & 2 & 8 & 2 & 5 & & 5 & 5 & \\
\hline Primary biomass burning & 11 & 5 & 18 & 8 & 15 & 11 & & 6 & 5 \\
\hline Oxidized low volatility anthropogenic & 5 & 1 & 10 & 10 & 5 & & 5 & & 5 \\
\hline Oxidized low volatilty biomass burning & 14 & 1 & 26 & 20 & 15 & 14 & & & 14 \\
\hline Secondary anthropogenic & 10 & 3 & 17 & 10 & 15 & & 10 & & 10 \\
\hline Secondary biomass burning & 17 & 0 & 34 & 20 & 20 & 17 & & & 17 \\
\hline BSOC & 88 & 0 & 180 & 10 & 150 & 88 & & & 88 \\
\hline Sum & 150 & & & 80 & 225 & $\begin{array}{c}130 \\
(87 \%)\end{array}$ & $\begin{array}{c}20 \\
(13 \%)\end{array}$ & $\begin{array}{c}11 \\
(7 \%)\end{array}$ & $\begin{array}{c}139 \\
(93 \%)\end{array}$ \\
\hline
\end{tabular}

the value for $\mathrm{OC} / \mathrm{S}$ in particles throughout the troposphere is about $3: 2$, with a likely range from $3: 1$ to $3: 4$. The global sulfur budget is relatively well known, with most estimates between 50 and $110 \mathrm{TgS} / \mathrm{yr}$ (Barrie et al., 2001). Almost all sulfate is lost through particle deposition, so the sulfate particulate deposition flux is also between 50 and $110 \mathrm{TgS} / \mathrm{yr}$. The same observations giving the value of $3: 2$ for the carbon to sulfur ratio $(\mathrm{C} / \mathrm{S})$ show that typical particles are internally mixed, and thus the mass ratio can be applied to the flux estimate without introducing significant biases. Consequently, the estimate of the global particulate OC deposition flux ranges between 60 and $240 \mathrm{TgC} / \mathrm{yr}$. The best estimate flux is $150 \mathrm{TgC} / \mathrm{yr}$.

The top-down estimates constrain the total, net organic aerosol flux, including primary and secondary emissions of both anthropogenic and biogenic material. To estimate the contribution to SOA from BVOC emissions we must thus subtract from the top-down estimate the contributions from other organic aerosol sources. These include primary emissions, anthropogenic SOA, and SOA formed from lowvolatility vapors co-emitted with POA, for example from biomass burning. Additional constraints come from measurements of the overall oxidation state of the organic aerosol and radiocarbon constraints on the relative contribution of modern and fossil carbon sources.

Bottom-up POA emissions of about $35 \mathrm{TgC} / \mathrm{yr}$ include biomass and fossil-fuel burning (Bond et al., 2004). Here, it is estimated that primary anthropogenic emissions are between 5 and $15 \mathrm{TgC} / \mathrm{yr}$ and biomass-burning emissions are between 15 and $35 \mathrm{TgC} / \mathrm{yr}$. However, recent work on primary emissions has shown that a large fraction of the compounds in concentrated plumes (tailpipes, near fire plumes, etc.) evaporates as the plume dilutes to ambient conditions (Shrivastava et al., 2007), with the vapors then oxidizing to form lower-volatility products (Robinson et al., 2007; Sage et al., 2008). Consequently, between half and two-thirds of the primary emissions in current inventories are likely to go through a cycle of evaporation, oxidation, and recondensation as oxidized, lower-volatility products (Donahue et al., 2009). Our best estimate is that approximately $16 \mathrm{TgC} / \mathrm{yr}$ (9-23 TgC/yr) of the traditional POA remains permanently in the condensed phase while $19 \mathrm{TgC} / \mathrm{yr}(5-33 \mathrm{TgC} / \mathrm{yr})$ undergo gas-phase oxidation before recondensing. The realization that emissions span a continuous range of volatility has created a debate about nomenclature. Semivolatile organic compound emissions with saturation concentrations below about $1000 \mu \mathrm{g} \mathrm{m}^{-3}$ are currently classified as non-volatile POA in most models. To avoid confusing policy makers, some have advocated calling this material "oxidized primary organic aerosol (OPOA)". However, this label is easily mistaken for POA that is heterogeneously oxidized in the particle phase. Furthermore, much of the evaporation is thought to occur rapidly after emission, and most of the oxidation reactions are therefore expected to occur in the gas phase. Other than the low volatility of the emissions, these attributes are those of secondary organic aerosol; therefore, many advocate calling this material SOA as well.

Subtracting the low-volatility emissions from the topdown estimate, the global SOA formation from volatile precursors is about $115 \mathrm{TgC} / \mathrm{yr}$, ranging between 25 and $210 \mathrm{TgC} / \mathrm{yr}$. SOA from volatile precursors thus comprises approximately $70 \%$ of the OC mass, though with broad uncertainty. Furthermore, approximately $90 \%$ of the OC mass is likely to be in an oxidized form, based on the argument presented above.

Ambient aerosol mass spectrometry (AMS) measurements have revealed that OA mass spectra can be separated into several characteristic factors, which can significantly constrain this budget. Depending on the application and location, from two to six factors have been described. The original and simplest approach, which employs two factors to explain the large majority of the observed variance, will be used here. Ambient organic aerosol spectra can be separated into a relatively reduced component (Hydrocarbon-like Organic 
Aerosol, HOA), and a relatively oxidized component (Oxidized Organic Aerosol, OOA) (Zhang et al., 2007b). HOA comprises only about $10 \%$ of the organic carbon (5\% of OA) at background locations (Zhang et al., 2007b). However, direct emissions of partially oxidized POA, such as that produced from biomass burning (Aiken et al., 2008) may appear partially as OOA in the 2-factor solution. If we assume that slightly more than half $(6 \mathrm{TgC} / \mathrm{yr})$ of the biomassburning POA appears as HOA, combined with $5 \mathrm{TgC} / \mathrm{yr}$ anthropogenic POA we estimate a global budget of $11 \mathrm{TgC} / \mathrm{yr}$ HOA and $139 \mathrm{TgC} / \mathrm{yr}$ OOA. This is consistent with the topdown flux estimate constrained by sulfate fluxes and also the ambient split between HOA and OOA.

Volatile anthropogenic precursors, typically substituted aromatics, are estimated to contribute between 1.4 and 8.6 TgC/yr to SOA, as discussed above (Henze et al., 2008). Additional anthropogenic precursors very likely result in several-fold more ASOA (Volkamer et al., 2006; de Gouw et al., 2008; Kleinman et al., 2008; Shrivastava et al., 2008), which is conservatively estimated here as a factor of 2 , giving an estimated ASOA production rate of $10 \mathrm{TgC} / \mathrm{yr}$, ranging from 3-17 TgC/yr. Along with the evaporation of POA emissions described above comes an uncertain flux of intermediate volatility material (Shrivastava et al., 2008). SOA formation from biomass-burning precursors is very uncertain at present and may only make a minor contribution (Capes et al., 2008) or be comparable to the biomass-burning POA (Grieshop et al., 2009). We estimate it here as $2 / 3$ of the biomass-burning POA or $17 \mathrm{TgC} / \mathrm{yr}$, ranging between 0 and $34 \mathrm{TgC} / \mathrm{yr}$. These values combine to yield an estimated $27 \mathrm{TgC} / \mathrm{yr}$ SOA formation from non-BVOC volatile sources, ranging between 3 and $40 \mathrm{TgC} / \mathrm{yr}$.

Subtraction of the estimated anthropogenic and biomass burning SOA from the estimate for total volatile SOA leads to a net BSOA production rate of about $90 \mathrm{TgC} / \mathrm{yr}$, with a very wide potential range. The total flux estimates are summarized in Table 1 . Net BSOA could be nearly zero, or it could be as much as $185 \mathrm{TgC} / \mathrm{yr}$. There are two major differences from the bottom-up modeling estimates of SOA formation. First, those estimates appear to neglect significant non-BVOC sources of SOA. Second, even accounting for those sources, the top-down estimates suggest that modeling studies underestimate BSOA. The best estimate is that bottom-up inventories underestimate BSOA formation by about a factor of 2 . We estimate that BVOC contribute approximately half of the total OC on a global basis, and that modern sources in total comprise about $80 \%$ of the OC.

The values presented here remain highly uncertain. This uncertainty is illustrated in Table 1 where two plausible scenarios, $\mathrm{S} 1$ and $\mathrm{S} 2$, based on global constraints are presented. Scenario $\mathrm{S} 1$ has a relatively low budget $(80 \mathrm{TgC} / \mathrm{yr})$ and only $12 \%$ of the global OA budget is attributed to BVOC oxidation. Instead, the large majority of OOA formation in this scenario comes from oxidation of lower volatility vapors coemitted with combustion sources such as biomass burning and internal combustion engines. On the other hand, scenario $\mathrm{S} 2$, with $225 \mathrm{TgC} / \mathrm{yr}$ total OC production, attributes $2 / 3$ of the total to BVOC emissions. The final columns in Table 1 summarize both the modern versus fossil and HOA versus OOA attribution for the best-estimate scenario, but all three scenarios are broadly consistent within these constraints.

Figure 1 shows the overall VOC and SOA global flux estimates in a simplified manner following Goldstein and Galbally (2007). Organic non-methane carbon emissions are taken to be relatively well known at $1350 \mathrm{TgC} / \mathrm{yr}$. In addition, global production of carbon monoxide from sources other than methane oxidation is also relatively well known, and even accounting for some uncertain production of $\mathrm{CO}_{2}$ through reactions that bypass $\mathrm{CO}$, is thought to account for $300-500 \mathrm{TgC} / \mathrm{yr}$. These numbers suggest that between 800 and $1000 \mathrm{TgC} / \mathrm{yr}$ are returned to Earth's surface through dry and wet deposition of particles and vapors. This constitutes a large majority of the carbon emissions. It is exceedingly difficult to separate wet deposition of particles from wet scavenging of vapors, and dry deposition is even less well constrained. However, the estimates developed above based on relative carbon and sulfur deposition rates are entirely consistent with this global picture, and the total deposition flux is still reasonably constrained by the global mass balance. Ultimately, these mass-balance calculations leave the least certain number to be estimated as a difference. Goldstein and Galbally (2007) suggested that the most uncertain difference was due to SOA formation. However, vapor deposition is possibly the most uncertain term and could account for a majority of the global non-methane carbon flux. There are at least two significant ramifications to this. First, at least two of the most important parameters in the global VOC/SOA budget are very poorly constrained. Second, global models attempting to capture the dynamic behavior of organic aerosol will be very sensitive to these parameters; errors in the deposition calculation of both organic vapors and particles will create significant errors in the SOA production and burden.

This discussion has so far addressed the net SOA flux. As outlined in Sect. 5 of this paper, there is considerable evidence that vapor-particle transformation is dynamic and bidirectional: organic aerosol formation can be induced by gas-phase aging reactions that yield products with lower vapor pressures than their parents, yet on the other hand, the heterogeneous oxidation of organic particles can generate products with higher vapor pressures that evaporate from the particles. At present it is difficult to constrain the potential magnitude of these processes for estimations of SOA flux. For example, assuming an uptake coefficient of 1 for the hydroxyl $(\mathrm{OH})$ radical on organic particles (Lambe et al., 2007; Rudich et al., 2007), the lifetime of organic particles towards heterogeneous oxidation is about 2 days (Molina et al., 2004; Robinson et al., 2006), i.e., the average organic compound within the particle has been oxidized at least once. Murphy et al. (2007) provide a field constraint on the rate of mass 


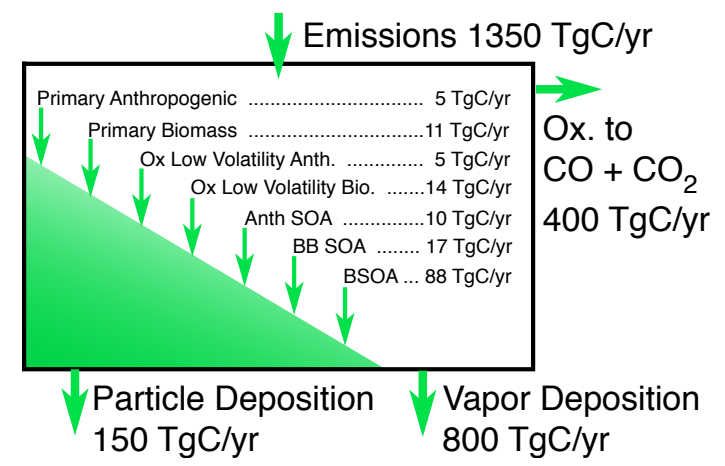

Fig. 1. Global flux estimates of VOC and OA. Fluxes shown are described in the text and aerosol fluxes are summarized in Table 1.

loss from oxygenated organic particles of tropospheric origin in the lower stratosphere. By analyzing the loss of organic mass from these particles, it is shown that particles larger than $\sim 300 \mathrm{~nm}$ lose organic mass over a time scale of around 4-6 months in an environment with high levels of $\mathrm{O}_{3}$ and $\mathrm{OH}$. George et al. (2008) exposed ambient particles to $\mathrm{OH}$ for several equivalent days and found only a minor loss of particle mass by evaporation and only for equivalent exposures longer than 9 days. Further recent work (Capes et al., 2008; DeCarlo et al., 2008; Dunlea et al., 2008) found that a small loss of carbon was compensated by a gain of oxygen to keep the OA mass approximately constant (after accounting for dilution) during the evolution of pollution and biomass burning OA. Together these studies suggest that the evaporation of $\mathrm{OA}$ due to heterogeneous oxidation is unlikely to make a major contribution to the organic aerosol budget.

A further and important caveat to the above budget estimates is the emission rate of BVOC. Guenther et al. (1995) estimated the uncertainty in temperate regions to be a factor of three, and probably more in tropical areas. Although more recent estimates (Guenther et al., 2006), based upon a much larger number of field studies, have produced similar fluxes for isoprene as in the 1995 inventory, it is clearly essential that the global inputs of BVOC are established properly before the SOA budget can be fully understood. The constraints on the SOA budget will, however, certainly improve over the next few years due to the enhanced efforts in using and combining field measurement, laboratory and modeling work in this area.

\section{Formation and characterization of SOA}

\subsection{Atmospheric degradation mechanisms of SOA precursors}

The gas-phase degradation of VOCs is initiated by reaction with hydroxyl $(\mathrm{OH})$ radicals, $\mathrm{O}_{3}$, nitrate $\left(\mathrm{NO}_{3}\right)$ radicals or via photolysis. Under certain conditions in the marine atmosphere, chlorine atoms $(\mathrm{Cl})$ may also initiate the oxidation of VOCs. The relative importance of these competing reactions depends on the structure of the VOC and on the ambient con- ditions (Atkinson and Arey, 2003). The initial oxidation step leads to the generation of a set of organic products containing one or more polar oxygenated functional groups, such as aldehyde $(-\mathrm{C}(=\mathrm{O}) \mathrm{H})$, ketone $(-\mathrm{C}(=\mathrm{O})-)$, alcohol $(-\mathrm{OH})$, nitrate $\left(-\mathrm{ONO}_{2}\right)$, peroxyacyl nitrate $\left(-\mathrm{C}(=\mathrm{O}) \mathrm{OONO}_{2}\right)$, carboxylic acid $(-\mathrm{C}(=\mathrm{O}) \mathrm{OH})$, hydroperoxide $(-\mathrm{OOH})$ and percarboxylic acid $(-\mathrm{C}(=\mathrm{O}) \mathrm{OOH})$ groups, which tend to make the products less volatile and more water soluble. Further oxidation may introduce additional functional groups, such that the "second-generation" set of products (and subsequent generations) may be of even lower volatility and higher solubility. However, the oxidation mechanisms also lead to fragmentation of the carbon chains to form lower molecular weight (MW) oxygenates (which tend to be more volatile), and the gas-phase oxidation, given enough time, would ultimately convert all the carbon in the emitted VOCs into $\mathrm{CO}_{2}$. This is in stark contrast, therefore, with the situation for other secondary aerosol precursors, such as emitted $\mathrm{SO}_{2}$ and $\mathrm{NO}_{\mathrm{x}}$, for which the ultimate thermodynamically-favored products of the gas phase mechanisms $\left(\mathrm{H}_{2} \mathrm{SO}_{4}\right.$ and $\left.\mathrm{HNO}_{3}\right)$ are the forms that are most associated with the particle phase. SOA is therefore formed from the gas-to-particle transfer of partially oxidized organic material, occurring in competition with further oxidation in the gas phase.

As a result of the complexity of the emitted VOC mixture, and of the degradation chemistry, the atmosphere contains many thousands of structurally different organic oxygenates, which possess a wide range of properties (e.g., reactivity, photolability, volatility and aqueous solubility) and different propensities to undergo gas-to-particle transfer. The distribution of products formed, and the dependence of this distribution on ambient conditions such as $\mathrm{NO}_{\mathrm{x}}$ level and relative humidity $(\mathrm{RH})$, is therefore a major factor in determining the influence that a given precursor VOC has on the formation of SOA. In addition, the degradation pathways of VOCs can have varying impacts on ozone formation and on the freeradical budget, and therefore also differing indirect effects on SOA formation, by virtue of the influence that these factors have on VOC oxidation rates in general.

The importance of emitted VOCs as SOA precursors is quite variable, with many emitted compounds generally believed to be very inefficient at generating SOA. However, certain classes of VOCs have long been identified as more likely to lead to SOA formation by virtue of their general high reactivity and types of oxidation product formed. Of particular significance are cyclic compounds, since the products of fragmentation (i.e., ring opening) processes often have the same (or similar) carbon number as the parent compound. Furthermore, in the cases of cycloalkenes, aromatic hydrocarbons and terpenes (the majority of which are cyclic), oxidation occurs predominantly by an addition mechanism, so that the first-generation products generally contain two (or more) polar functional groups. Consequently the oxidation of these classes of compounds is more likely to lead to the generation of low-volatility products than the oxidation of 
similar sized VOCs in other classes. The characterization of SOA formation from the degradation of cyclic hydrocarbons has therefore been the focus of numerous chamber investigations over the years (e.g., Hoffmann et al., 1997; Odum et al., 1997; Griffin et al., 1999).

The more recent identification of oligomers and organosulfates in SOA formed in chambers and the atmosphere (Gao et al., 2004a, b, 2006; Kalberer et al., 2004; Iinuma et al., 2004, 2005, 2007a, b; Tolocka et al., 2004; Baltensperger et al., 2005; Samburova et al., 2005b; Dommen et al., 2006; Surratt et al., 2006, 2007a, b, 2008; Denkenberger et al., 2007; Gómez-González et al., 2008) has established that SOA formation from VOC degradation is not solely driven by the volatility of the gas-phase products formed, but is also influenced by the propensity of degradation products to undergo further reactions in the condensed phase, and how this depends on conditions such as water content, dissolved ions and $\mathrm{pH}$. Condensed-phase reactions that increase the MW can sharply reduce the volatility distribution of the organics. This has substantially altered perceptions of which emitted VOCs can act as SOA precursors, to the point that SOA formation from the degradation of smaller VOCs can no longer be automatically disregarded; for example, even very volatile glyoxal $(\mathrm{CHOCHO})$ can associate with other aldehydes and organic acids in particles to add to SOA mass (Kroll et al., 2005a; Volkamer et al., 2007) or can be sulfated after gem-diol formation (Surratt et al., 2007a, 2008; Gómez-González et al., 2008). Thus even acetylene $\left(\mathrm{C}_{2} \mathrm{H}_{2}\right)$, the smallest hydrocarbon after methane, can produce significant SOA due to the high yield of glyoxal from its degradation (Volkamer et al., 2009). In theory the oxidation of methane can also contribute to SOA if e.g., the radical products such as $\mathrm{CH}_{3} \mathrm{O}_{2}, \mathrm{CH}_{3} \mathrm{O}$, or $\mathrm{HCHO}$ react to form species with much lower volatility.

\subsubsection{Generation of atmospheric degradation mechanisms for VOCs}

Only a very small fraction of the reactions occurring in the atmospheric degradation of VOCs have been studied experimentally. Only for the simplest hydrocarbons and oxygenates (e.g., methane, ethane, ethene, methanol, acetaldehyde, acetone and dimethyl ether) have the kinetics and products of the majority of the elementary reactions involved in their degradation to $\mathrm{CO}_{2}$ and $\mathrm{H}_{2} \mathrm{O}$ been investigated (Atkinson et al., 2006). Even for these compounds, there have been recent unexpected advances in understanding, and some uncertainties remain. For a number of other and more complex VOCs (including isoprene and selected terpenes and aromatic hydrocarbons), some important aspects of their degradation chemistry have been studied experimentally. This information provides a partial basis for defining their degradation chemistry, which can be supplemented by the inclusion of reactions and associated parameters which are inferred from the more detailed understanding of the chemistry of the smaller compounds. For many other VOCs, little or no experimental information exists, and their degradation chemistry needs to be defined almost exclusively by inference. As a result, chemical mechanisms which treat the atmospheric degradation of a large number of significant emitted VOCs (e.g., Jenkin et al., 1997; Carter, 2000; Aumont et al., 2005) necessarily need to make the fundamental assumption that the kinetics and products of a large number of unstudied chemical reactions can be defined on the basis of the known reactions of a comparatively small number of similar chemical species. This is usually done by analogy and with the use of structure-reactivity relationships to provide relatively simple rules to guide mechanism construction (e.g., Jenkin et al., 2003; Saunders et al., 2003; Aumont et al., 2005). To varying extents, such mechanisms also incorporate strategic simplifications to limit their overall size, which would otherwise include as many as $10^{5}-10^{6}$ reactions. The performance of these gas-phase mechanisms can be tested (and, if necessary, refined) using chamber data (e.g., Carter, 2000; Pinho et al., 2005, 2006, 2007). Such procedures have traditionally been focused on providing validated descriptions of ozone formation from the photooxidation of $\mathrm{VOC} / \mathrm{NO}_{\mathrm{x}}$ mixtures, although the development of highly-instrumented chambers (see Table 2 in Sect. 4) has provided data to allow other aspects of the degradation mechanisms, including SOA formation pathways, to be examined and improved.

Mechanisms constructed in this way therefore reflect a number of generic features, which are reasonably well established for smaller VOCs, and used to infer the chemistry for larger VOCs and for their sequential degradation products. The most studied aspect of VOC degradation is the $\mathrm{OH}$-initiated chemistry, for which a simplified schematic is shown in Fig. 2. This shows that the distribution of products formed is mainly governed by the reactions of the intermediate peroxy $\left(\mathrm{RO}_{2}\right)$ and oxy ( $\left.\mathrm{RO}\right)$ radicals, for which a number of competing reactions may exist. At high- $\mathrm{NO}_{\mathrm{x}}$, the chemistry tends to be dominated by radical propagating chemistry, in which $\mathrm{RO}_{2}$ is efficiently converted into $\mathrm{RO}$ via reaction with NO. The fate of the RO radical is strongly dependent on its structure, and therefore on the structure of the parent VOC. It also may depend on the prevailing temperature, if competitive reaction channels exist. As described in detail elsewhere (e.g., Atkinson, 2007), RO may typically react with $\mathrm{O}_{2}$ to form a carbonyl product and $\mathrm{HO}_{2}$, decompose through $\mathrm{C}-\mathrm{C}$ bond scission (leading to a smaller carbonyl product and an organic radical), or isomerize through $\mathrm{H}$-atom shift reactions (leading ultimately to a hydroxycarbonyl product and $\mathrm{HO}_{2}$ ). The reactions of $\mathrm{RO}_{2}$ radicals with NO also have terminating channels which form organic nitrate products $\left(\mathrm{RONO}_{2}\right)$, with the importance of these channels generally increasing as the size of the organic group (and therefore the parent VOC) increases. $\mathrm{RO}_{2}$ radicals also react with $\mathrm{NO}_{2}$ to form peroxynitrates $\left(\mathrm{RO}_{2} \mathrm{NO}_{2}\right)$, although such species only tend to be stable at lower tropospheric temperatures for the specific case of peroxyacyl nitrates (PANs) 
which are formed from peroxyacyl radicals of generic formula $\mathrm{RC}(\mathrm{O}) \mathrm{O}_{2}$. As a result, VOC degradation at high- $\mathrm{NO}_{\mathrm{x}}$ levels tends to generate a product distribution that is dominated by carbonyls, hydroxycarbonyls, organic nitrates and PANs. It should also be noted that the reacting organic species may initially contain oxygenated functional groups, which are retained in the products.

At lower $\mathrm{NO}_{\mathrm{x}}$ levels, the reactions of $\mathrm{RO}_{2}$ with $\mathrm{HO}_{2}$ and with the $\mathrm{RO}_{2}$ radical "pool" become competitive, leading to a progressive change in the product distribution with changing $\mathrm{NO}_{\mathrm{x}}$ level. As shown in Fig. 2, the reaction of simple $\mathrm{RO}_{2}$ radicals (e.g., $\mathrm{CH}_{3} \mathrm{O}_{2}$ ) with $\mathrm{HO}_{2}$ is known to be dominated by termination reactions to form hydroperoxide products $(\mathrm{ROOH})$. The reactions with the $\mathrm{RO}_{2}$ radical pool are partially propagating, to generate $\mathrm{RO}$ radicals (and therefore carbonyls and hydroxycarbonyls), and partially terminating to generate alcohol and carbonyl products. As a result, VOC degradation at very low- $\mathrm{NO}_{\mathrm{x}}$ levels tends to generate a product distribution which is dominated by the formation of hydroperoxides, carbonyls, hydroxycarbonyls and alcohols. Once again, it should be noted that the organic species may initially contain oxygenated functional groups, which are also retained in the products. In the case of peroxyacyl radicals, $\mathrm{RC}(\mathrm{O}) \mathrm{O}_{2}$, the reactions with $\mathrm{HO}_{2}$ and the $\mathrm{RO}_{2}$ pool lead to the formation of percarboxylic acid $(\mathrm{RC}(\mathrm{O}) \mathrm{OOH})$ and carboxylic acid $(\mathrm{RC}(\mathrm{O}) \mathrm{OH})$ products. It should also be noted that the lifetime of the $\mathrm{RO}_{2}$ radicals with respect to reactions with $\mathrm{HO}_{2}$ and the $\mathrm{RO}_{2}$ pool can be very long under atmospheric conditions (i.e., minutes). It is therefore possible that unimolecular rearrangements (e.g., Jorand et al., 2003) or heterogeneous aerosol reactions (Bonn et al., 2007) may also play a role for some peroxy radical classes.

The chemistry initiated by reaction with ozone and $\mathrm{NO}_{3}$ radicals, and via direct photolysis, tends to feed into similar reaction mechanisms by virtue of the formation of $\mathrm{OH}$, $\mathrm{RO}_{2}$ and $\mathrm{RO}$ radicals. Reaction with ozone is significant for unsaturated compounds, and may be the dominant atmospheric fate in certain cases (e.g., for some monoterpenes and sesquiterpenes) (Atkinson and Arey, 2003). As described in detail elsewhere (Johnson and Marston, 2008), the ozoneinitiated chemistry is generally believed to lead to the formation of Criegee intermediates, which typically either decompose to form $\mathrm{OH}$ and an organic fragment (which reacts with $\mathrm{O}_{2}$ to form an $\mathrm{RO}_{2}$ radical), or undergoes bimolecular reactions. In the latter case, the most prevalent reaction partner under atmospheric conditions is believed to be with water, to form carboxylic acids or hydroxyalkyl hydroperoxides. As a result of this complex chemistry, the product distribution (and therefore SOA-formation propensity) is sensitive not only to the presence of $\mathrm{NO}_{\mathrm{x}}$ (Donahue et al., 2005) and water (Bonn et al., 2002; Jonsson et al., 2006), but has also been shown to be influenced in chamber experiments by addition of different scavengers for both $\mathrm{OH}$ and Criegee biradicals. The use of different scavengers for $\mathrm{OH}$ can influence the $\left[\mathrm{RO}_{2}\right] /\left[\mathrm{HO}_{2}\right]$ ratio in the system (e.g., Keywood

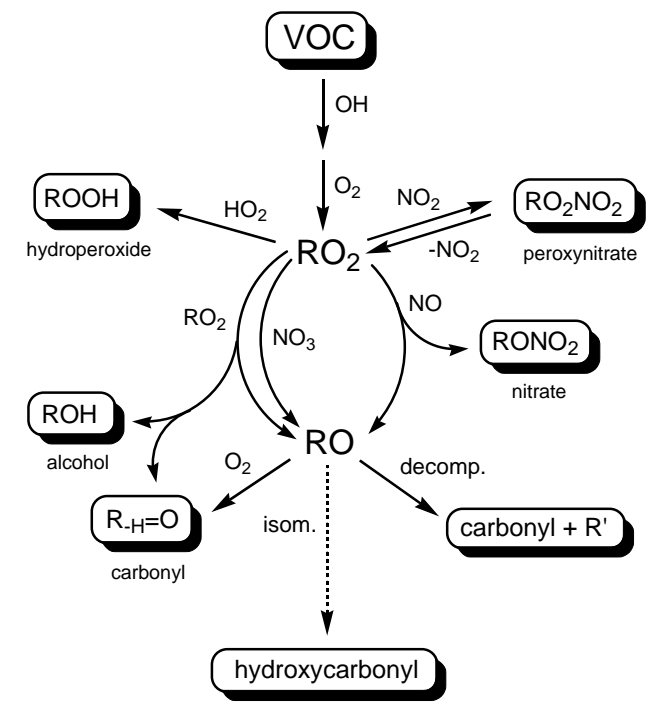

Fig. 2. Simplified schematic of the $\mathrm{OH}$-initiated degradation of generic VOCs to form first-generation products.

et al., 2004; Jenkin, 2004; Docherty et al., 2005; Jonsson et al., 2008a), whereas addition of Criegee biradical scavengers such as carbonyls and acids have been shown to generate various high MW secondary ozonides and acyloxyalkyl hydroperoxides, respectively (e.g., Neeb et al., 1998; Tobias and Ziemann, 2000; Bonn et al., 2002).

\subsubsection{Recent developments and uncertainties in degradation mechanisms for complex VOCs}

The degradation chemistry of selected aromatic hydrocarbons and monoterpenes has in the past received considerable attention (e.g., Calvert et al., 2002; Atkinson and Arey, 2003), owing in part to their established importance as precursors to SOA formation. This effort has been maintained in recent years (e.g., Volkamer et al., 2001, 2002; Olariu et al., 2002; Alvarez et al., 2007; Bejan et al., 2007; Ma et al., 2007a, b; Metzger et al., 2008), leading to a progressive improvement in the understanding of some aspects of their degradation.

The degradation of aromatic hydrocarbons, although usually only initiated significantly by reaction with $\mathrm{OH}$, can proceed via a number of different routes to generate a large variety of structurally complex ring-retaining and ringopened products (e.g., Calvert et al., 2002). Even for wellestablished products (e.g., $\alpha$-dicarbonyls and co-products formed from the major ring-opening channels), however, there is considerable variation in the reported yields, and for many of the studied systems, only ca. $50 \%$ or less of the aromatic loss has been accounted for by observed firstgeneration products. Particular areas where understanding is lacking include uncertainties in the mechanisms of the initial oxidation sequences to first-generation products, and limitations in the available information on the subsequent 
chemistry of many of the classes of products known to be generated. The further degradation chemistry of first- and subsequent-generation products is believed to be particularly important in accounting for secondary radical generation and removal of $\mathrm{NO}_{\mathrm{x}}$ in chamber photooxidation experiments of aromatic/ $\mathrm{NO}_{\mathrm{x}}$ systems (Wagner et al., 2003). In this respect, mechanisms constructed for aromatic hydrocarbons display evidence for a missing radical source in the system, but a simultaneous tendency towards over-production of ozone (e.g., Bloss et al., 2005a, b). This points to a clear gap in understanding, since these features cannot be readily reconciled within traditional understanding of VOC oxidation chemistry. Bloss et al. (2005b) outlined a number of speculative solutions, including the existence of novel isomerization reactions of complex $\mathrm{RO}_{2}$ radical intermediates to regenerate $\mathrm{OH}$ directly, and the possibility that $\mathrm{NO}_{2}$ might react with the SOA formed in the system to generate HONO. Although there was insufficient evidence to support either suggestion, the latter has subsequently received some indirect support from the recognition that photosensitized $\mathrm{NO}_{2}$ to-HONO conversion can occur on organic surfaces (e.g., George et al., 2005; Stemmler et al., 2006). More recently, Metzger et al. (2008) have proposed that the light-induced conversion of $\mathrm{NO}_{2}$ to $\mathrm{HONO}$ occurs at the chamber walls rather than on the SOA itself.

Whereas the uncertainties in aromatic degradation are, to some extent, generic (i.e., an advance in mechanistic understanding is likely to be applicable to aromatics in general), understanding of the degradation of terpenes and related biogenics is further hampered by the enormous variety in their structure and reactivity (atmospheric lifetimes range from minutes to days). In addition to this, three initial reactions, with $\mathrm{OH}, \mathrm{O}_{3}$ and $\mathrm{NO}_{3}$, must be considered in their atmospheric degradation. Under the conditions typically employed in chamber hydrocarbon/ $\mathrm{NO}_{\mathrm{x}}$ photooxidation experiments, the initial reaction with $\mathrm{O}\left({ }^{3} \mathrm{P}\right)$ atoms can also be significant (Pinho et al., 2007). Although kinetic data are available for a wide variety of terpenes (Atkinson and Arey, 2003), experimental information on their degradation pathways is much more limited. Selected product yields (usually for first-generation carbonyls) are available for a number of species, but the most detailed information has been reported for the monoterpenes $\alpha$ - and $\beta$-pinene. Even for these species, however, it is clear that the distribution of firstgeneration products, and the elementary processes leading to their formation, remain far from fully characterized, and that experimental information on the further degradation of firstgeneration products is very sparse indeed (e.g., Pinho et al., 2007).

Detailed chemical mechanisms for such species therefore necessarily contain a substantial proportion of inferred reactions and estimated parameters. In recent years, theoretical methods have been applied with some success to elucidate aspects of the degradation of some complex VOCs, in particular $\alpha$-pinene (e.g., Peeters et al., 2001; Fantechi et al., 2002;
Vereecken et al., 2004, 2007). Such methods invariably identify exotic reaction pathways which are not predicted by the extrapolation methods which are based on relatively simple structure-reactivity relationships as outlined above. Although such alternative pathways have been shown to have a reasonably subtle influence on simulations of oxidant formation (Pinho et al., 2007), they have a notable influence on the precise structures of the products formed, and therefore potentially have a much greater effect on the perceived propensity of product distribution to contribute to SOA formation (Vereecken et al., 2007). It is also clear that SOA formation is often confined to a relatively small fraction of the carbon from any given precursor (Donahue et al., 2009). Thus, it is not obvious that mechanisms derived using simple structurereactivity methods are always appropriate to describe SOA formation, where more exotic, small yield products may play a disproportionate role in SOA production.

From the above discussion, it is clear that, despite considerable investigation, the elementary processes involved in the degradation of complex VOCs, such as aromatic hydrocarbons and terpenes, remain very sparsely characterized. The majority of information relates to the initial oxidation sequences to form first-generation products, with the further degradation of established first-generation products often not characterized at all. It is also becoming clear that chamber datasets for the oxidation of the product compounds (and possibly their degradation products) would be valuable in assessing the performance of detailed degradation mechanisms, and for gaining insights into chemical processes occurring on timescales longer than those addressed by conventional chamber experiments such as those encountered in ambient conditions. This is particularly important for large complex emitted VOCs, which are typically degraded via a large number of sequential (and parallel) steps. Finally, it should be recognized that the chemical mechanisms for the atmospheric degradation of other potential SOA precursors, such as sesquiterpenes, long-chain alkanes and oxygenates, are also in need of improvement.

\subsection{Gas-particle partitioning theory}

The phase partitioning of SOA is generally described using the theoretical foundations on organic aerosol phase partitioning developed by Pankow in the 1990s (Pankow, 1994) and extended by Odum to SOA formation (Odum et al., 1996). The fundamental concept is that SOA comprises a mixture of semivolatile organic compounds that partition between the gas and particle phases. Partitioning of each compound is described by an equilibrium partitioning coefficient $K_{p, i}\left(\mathrm{~m}^{3} \mu \mathrm{g}^{-1}\right)$, or equivalently (Donahue et al., 2006) its inverse, the saturation vapor concentration, $C_{i}^{*}\left(\mu \mathrm{g} \mathrm{m}^{-3}\right)$ :

$\frac{C_{i}^{p}}{C_{i}^{g}}=K_{p, i} C_{O A}=\frac{C_{O A}}{C_{i}^{*}}$ 
where $C_{i}^{g}$ is the mass concentration of species $i$ per unit volume of air $\left(\mu \mathrm{g} \mathrm{m}^{-3}\right)$ in the gas phase, $C_{i}^{p}$ is the mass concentration per unit volume of air $\left(\mu \mathrm{g} \mathrm{m}^{-3}\right)$ in the particulate phase, and $C_{O A}$ is the mass concentration per unit volume of air $\left(\mu \mathrm{g} \mathrm{m}^{-3}\right)$ of the total absorbing particle phase. Both $K_{p, i}$ and $C_{i}^{*}$ can in theory be derived from the saturation vapor pressure of the pure compound if its activity coefficient in the absorbing phase can be determined (Bowman and Karamalegos, 2002; Chang and Pankow, 2006), although Donahue et al. (2006) have suggested that this formulation can be simplified with a modified version of Raoult's law. $C_{O A}$ refers only to the portion of the particulate matter participating in absorptive partitioning (an organic aerosol into which semivolatile organics can partition and possibly the aqueous portion of the particles in the case of highly water-soluble organics). Note that as long as some absorbing mass is present, some fraction of a given semivolatile compound will partition into the particle phase, even if its gas-phase concentration is below its saturation concentration, $C_{i}^{*}$. Equation (1) can be used to obtain the fraction $F_{i}$ of a semivolatile compound in the particle phase:

$F_{i}=\frac{C_{i}^{p}}{C_{i}^{p}+C_{i}^{g}}=\frac{C_{O A} K_{p, i}}{1+C_{O A} K_{p, i}}=\frac{1}{1+C_{i}^{*} / C_{O A}}$

Thus as the amount of absorbing material $\left(C_{O A}\right)$ increases, compounds of greater volatility (larger $C_{i}^{*}$, smaller $K_{p, i}$ ) will increasingly partition into the particle phase. When $C_{i}^{*}=C_{O A}$ half of the semivolatile mass of species $i$ resides in the particle phase. If $C_{O A} \gg C_{i}^{*}$, essentially all of the semivolatile species $i$ is in the particle phase.

In the first basic model of SOA formation in smog chambers using partitioning theory, Odum et al. (1996) represented the process by the generation of $n$ semi- (or non-) volatile products, e.g., $\mathrm{P}_{1}, \mathrm{P}_{2}, \ldots \mathrm{P}_{n}$, and showed that the SOA yield, or mass fraction, $F_{O A}$, defined as the mass of SOA produced $\left(\triangle M_{O A}\right)$ when a certain mass of a precursor hydrocarbon $\left(\Delta M_{H C}\right)$ is oxidized can be derived from Eq. (1) and expressed as:

$F_{O A}=\frac{\Delta M_{O A}}{\Delta M_{H C}}=C_{O A} \sum_{i} \frac{\alpha_{i} K_{p, i}}{1+C_{O A} K_{p, i}} \equiv \sum_{i} \frac{\alpha_{i}}{1+C_{i}^{*} / C_{O A}}$

where $\alpha_{\iota}$ is the mass-based stoichiometric yield (not stoichiometric coefficient) of compound $i$. The "volatility distribution" of the oxidation products is represented by the product yields $\left(\alpha_{\iota}\right)$ and partitioning coefficients $\left(K_{p, i}\right)$. The two-product $(n=2)$ version of Eq. (3) was used by Odum et al. (1996) because adding more products did not improve the fit to the yields obtained from the chamber studies. As a result, the two-product model has been used as the standard means of representing laboratory SOA yield data in many experimental and modeling studies (Seinfeld and Pankow, 2003; Kanakidou et al., 2005). Recently, Chan et al. (2007) have presented a framework to extend the simple product model to take into account the kinetics of both gas- and aerosol-phase processes. In their framework the initial oxidation products may react further to generate secondgeneration products, semivolatile aerosol products may react to generate non-volatile products, etc. This framework has been further discussed in Kroll and Seinfeld (2008).

\subsubsection{The volatility basis set (VBS) approach}

With increasing understanding of the nature and complexity of SOA formation, the limitations of representing laboratory data with a two-product model are now evident. There are two major issues: the wide range of $C_{O A}$ in the atmosphere and the ongoing oxidation of semivolatile organics in both the gas and particle phases. Donahue and co-workers (Donahue et al., 2006; Presto and Donahue, 2006; Pathak et al., 2007) have proposed the use of a "volatility basis set" (VBS) to address these issues. The VBS consists of a group of lumped compounds with fixed $C^{*}$ values, comprising up to 9 "bins" separated by one order of magnitude each in $C^{*}$ at $300 \mathrm{~K}$. Using the VBS, different SOA-forming reactions can be mapped onto the same set of bins over the range of organic aerosol mass concentration typical of ambient conditions $\left(\sim 0.1-100 \mu \mathrm{g} \mathrm{m}^{-3}\right)$ while maintaining mass balance for more volatile co-products as well. Aging reactions within the VBS can be added easily if the kinetics and volatility distribution of the products can be measured or estimated. Figure 3 shows how experimental SOA yield data from the $\alpha$-pinene + ozone reaction can be fitted to the VBS, given a mass balance constraint that the total mass of gaseous and particulate phase products is about 1.4 times the mass of $\alpha$-pinene reacted (the mass gain is from added oxygen). The inset to Fig. 3 shows the partitioning when $26 \mu \mathrm{g} \mathrm{m}^{-3}$ of $\alpha$-pinene is oxidized to give $1 \mu \mathrm{g} \mathrm{m}^{-3}$ of SOA, making clear that under typical ambient conditions most of the firstgeneration products are vapors of a wide range of volatilities.

\subsubsection{Unresolved issues with partitioning}

Several factors complicate the interpretation of partitioning in both experimental work and in the atmosphere. Many of these are addressed in more detail in Sect. 5 of this paper, but here the factors affecting the interpretation of experimental data or implementation in models are highlighted.

1. Complexity. The ensemble of gaseous and particulate phase species involved in SOA formation has enormous complexity, and the identity and properties of only a small percentage of these are known. The compounds relevant to SOA formation are sometimes minor products with yields of only a few percent. These are especially vulnerable to experimental error, and difficult to parameterize in simplified chemical mechanisms.

2. Interpretation of $C_{O A}$. It is not well established what portion of the total organic aerosol mass should be used 
to establish the mass of the condensing phase, $C_{O A}$. It is not certain whether primary organic aerosol mass should be included (Song et al., 2007), or how amorphous or possibly solid fractions affect the OC available for mixing and absorption (e.g., if some of the organic material in a particle is surrounded by a dry ammonium sulfate shell). The role of water-uptake and of inorganics in $C_{O A}$ is also difficult to quantify. This is addressed further in Sect. 5.6.

3. Temperature. It is typically assumed that $C^{*}$ varies with temperature according to the Clausius-Clapeyron equation (Chung and Seinfeld, 2002; Takekawa et al., 2003), though the appropriate values for enthalpies of vaporization, $\Delta H_{v}$, are highly uncertain (Hallquist et al., 1997; Bilde and Pandis, 2001; Chung and Seinfeld, 2002; Pathak et al., 2007; Stanier et al., 2007; Saathoff et al., 2009). As discussed in Donahue et al. (2006), measurements of $\Delta H_{v}$ for specific low-volatility compounds range between 40 and $110 \mathrm{~kJ} / \mathrm{mol}$, whereas data for aggregate organic aerosol suggest an overall temperature dependence equivalent to $\Delta H_{v}$ of ca. $40 \mathrm{~kJ} / \mathrm{mol}$ or less. Donahue et al. (2006) showed that this apparent discrepancy can be reconciled, concluding that models should not confuse two possible approaches; models with few semivolatile components should use artificially low $\Delta H_{v}$ values, while models with numerous components covering a wide range of values for $C^{*}$ should use more realistic $\Delta H_{v}$ values.

4. Thermodynamics and solution theory. Vapor pressures, molar activity coefficients and the mean MW of the condensing phase are all difficult properties to measure or estimate, even for those compounds whose identity is known (e.g., Clegg et al., 2008a, b). Difficulties increase when considering the role of relative humidity on organic partitioning (Chang and Pankow, 2006). The thermodynamics of mixtures in a laboratory experiment and in the atmosphere may also differ, as atmospheric mixtures are presumably much more diverse.

5. Experimental artifacts and difficulties. Aerosols (and vapors) are lost to chamber surfaces in laboratory experiments, complicating the mass balance. Further, SOA is frequently measured as an apparent volume via the particle size distribution, meaning that the condensedphase density must also be determined or assumed.

6. Chemically dynamic system. All of the reaction products important to SOA formation are subject to ongoing chemical degradation. Consequently, the yields $\left(\alpha_{i}\right)$ may not be constant in time during an experiment, or relevant to the atmosphere. Gas-phase products from VOC oxidation depend strongly on ambient composition, most notably through the fate of organic peroxy radicals $\left(\mathrm{RO}_{2}\right)$, which can react with nitrogen oxides

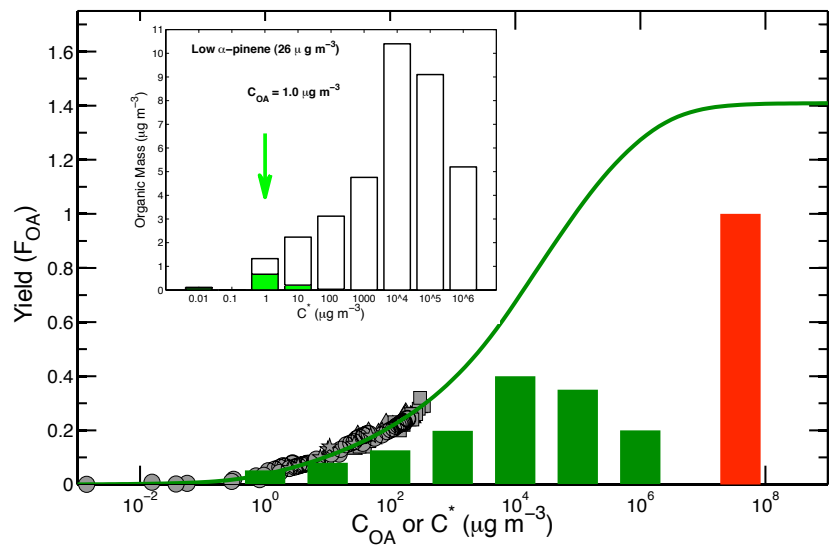

Fig. 3. Volatility Basis Set (VBS) distribution of products from the $\alpha$-pinene + ozone reaction. The $\mathrm{x}$ axis represents both the aerosol mass concentration $C_{O A}$ and the saturation concentration $C^{*}$ of the products, which are both expressed in $\mu \mathrm{g} \mathrm{m}^{-3}$. Product $C^{*}$ values are shown as green bars, normalized by the $\alpha$-pinene, shown in red. The fractional mass yield $F_{O A}$ for a given $C_{O A}$ is shown as a green curve, passing through data shown in gray and discussed in Presto and Donahue (2006). More recent yield data from Shilling et al. (2009) are somewhat higher. The inset shows the partitioning in each VBS bin when $26 \mu \mathrm{g} \mathrm{m}^{-3} \alpha$-pinene is oxidized to give $1 \mu \mathrm{g} \mathrm{m}^{-3} \mathrm{SOA}$, corresponding to a mass yield of around $4 \%$.

(NO, $\left.\mathrm{NO}_{2}\right)$, hydroperoxy radicals $\left(\mathrm{HO}_{2}\right)$, or other $\mathrm{RO}_{2}$. This is commonly described as a VOC: $\mathrm{NO}_{\mathrm{x}}$ dependence. Also, oxygenated organics are often susceptible to photolysis by UV light (Kroll et al., 2005a; Presto et al., 2005a; Zhang et al., 2006). Finally, the semivolatile oxidation products may be formed from first- or highergeneration reactions, and the products themselves may react further in the gas or particle phases to yield compounds of either less (in the case of addition of more functional groups) or greater (in the case in which the carbon backbone of the molecule is cleaved) volatility.

7. Displaced equilibria. A serious limitation of currently applied partitioning approaches is that reactions of either gas or particle-phase compounds will displace the equilibrium given by Eqs. (1) and (2). In this case, the ratio $F_{i}$ is not just a function of $K_{p, i}$ (or $C_{i}^{*}$ ) and $C_{O A}$, but also of the rate at which $C_{i}^{g}$ or $C_{i}^{p}$ are reduced during reactions. Both condensed-phase and heterogeneous reactions may play a role (e.g., Chan et al., 2007; Kroll and Seinfeld, 2008) as outlined in Sect. 5.

\subsection{Measurement of SOA chemical composition}

The determination of SOA composition covers a wide range of analytical techniques and a number of reviews have been published in recent years (McMurry, 2000; Hoffmann and Warnke, 2007; Rudich et al., 2007). The aim of this section is to cover some of the most recent advances in SOA 
analysis. One of the main barriers to a complete characterization of OA and SOA is the sheer number of individual species present. Goldstein and Galbally (2007) showed that for alkanes with 10 carbons there are about 100 possible isomers, increasing to well over 1 million $\mathrm{C}_{10}$ organic species when all typical heteroatoms are included. Many of these species may be present in the atmosphere, and taking this into account, SOA quantification and chemical composition analysis tools generally fall into three categories depending on the degree of characterization required; indirect methods, off-line and on-line techniques. Indirect methods quantify total SOA from the difference between the measured total OA and estimated POA. Off-line high complexity techniques, e.g., gas chromatography/mass spectrometry (GC/MS), liquid chromatography/MS (LC/MS), nuclear magnetic resonance (NMR) and Fourier transform infrared (FTIR) spectroscopy, provide detailed information on individual chemical species or functional groups in SOA but generally require large amounts of sample, resulting in low time resolution (hours to days) and low size resolution. On-line techniques (e.g., aerosol mass spectrometry, AMS) usually provide less specific information on composition, i.e., some level of chemical characterization without details on individual species, but have the advantage of fast acquisition times, providing near real-time data.

Figure 4 highlights how some of the most important current field-deployable techniques compare for three important characteristics: completeness, chemical resolution, and time/size resolution. As described above, techniques that provide molecular speciation, represented by GC/MS in the figure, can only do so for a small mass fraction of the OA (of the order of 10\%) present in ambient aerosol. Time resolutions are typically of many hours although recently a $1 \mathrm{~h} \mathrm{GC/MS}$ instrument has been demonstrated (Williams et al., 2006, 2007), but without any size resolution. Improvements in this type of speciated techniques are highly desirable and are being actively pursued (e.g. Goldstein et al., 2008) but it is very unlikely that in the foreseeable future a technique or combination of techniques can provide the fully speciated and quantitative composition of all the OA with a time resolution of minutes or better and some size resolution. Thermal-optical EC/OC analyzers can quantify total $\mathrm{OC}$ with $1 \mathrm{~h}$ time resolution but without size-resolution. The PILS-WSOC technique, which involves the use of a particle-into-liquid sampler (PILS) combined with analysis for water-soluble organic compounds (WSOC), can be used to quantify water-soluble $\mathrm{OC}$ with a time resolution of minutes and without size resolution (and also water-insoluble OC by difference from e.g. a thermal-optical instrument, but then limited to $1 \mathrm{~h}$ time resolution). A family of complementary techniques (AMS, FTIR and NMR spectroscopy) attempts to analyze most of the OA mass while providing resolution of some chemical classes or functional groups. Of these techniques AMS has much higher time and size resolution (e.g. DeCarlo et al., 2008) and can provide elemental composi-

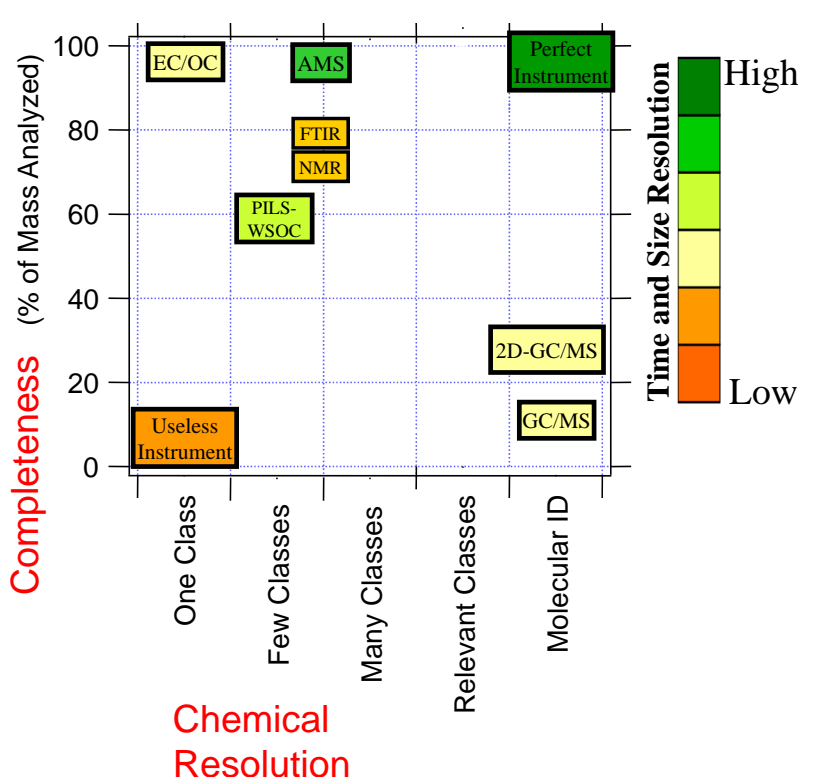

Fig. 4. Three-dimensional representation of some techniques currently used for the analysis of the organic content of aerosol, highlighting their complementary nature. Definition of the acronyms is provided in the text and in the list of abbreviations.

tion (Aiken et al., 2008), but the chemical characterization provided by FTIR and NMR spectroscopy is more directly related to functional groups (e.g. Maria et al., 2003; Decesari et al., 2007). Thus a perfect field instrument with all the ideal characteristics does not exist, and at present a combination of techniques is required for a more complete characterization of OA and SOA.

\subsubsection{Off-line high complexity SOA measurements}

Generally the detailed analysis of SOA is performed in the laboratory using aerosol samples collected onto filters followed by extraction of the organic compounds using techniques such as solvent extraction (Cheng and $\mathrm{Li}, 2004$ ), supercritical fluid extraction (Chiappini et al., 2006) or thermal desorption (Greaves et al., 1985; Veltkamp et al., 1996) to release the semivolatile species. A range of solvents and pre-treatments can be used, such as derivatization, to increase the range of species analyzed and often the specific solvent can be used as an empirical definition of the species present e.g., "water-soluble organic compounds" (WSOC). Thermal desorption has gained increasing popularity over the last few years for the measurement of semivolatile, thermally stable organic aerosol components and can be used without any sample preparation when combined with high resolution chromatographic techniques (Hays and Lavrich, 2007).

First-generation VOC oxidation products are generally polar substances containing hydroxyl, carboxyl, keto and/or aldehyde groups. Further reaction of first-generation photooxidation products through oxidation and sulfation of 
hydroxyl and/or keto or aldehyde groups renders these products even more polar. The presence of hydroxyl, carboxyl, keto, aldehyde, sulfate and nitrooxy groups in SOA constituents requires that suitable analytical methods are employed and developed for their detection and characterization at the molecular level. The most commonly employed analytical techniques for the molecular characterization of SOA constituents are hyphenated techniques that combine a powerful chromatographic and mass spectrometric technique such as GC/MS with prior conversion into volatile derivatives and use of electron ionization (EI) or chemical ionization (CI), and LC/MS with use of electrospray ionization (ESI) or atmospheric pressure chemical ionization (APCI) and detection in the negative $(-)$ or positive $(+)$ ion mode. While the chromatographic separation and sensitive MS detection of polar SOA constituents can, in most cases, be readily achieved, the molecular characterization of unknown SOA constituents remains a demanding analytical task for various reasons. Complementary MS techniques involving high-resolution (HR), soft ionization MS and tandem MS are needed; detailed interpretation of MS data requires specific knowledge and only allows one to propose chemical structures (or tentative structures), which still need to be confirmed through organic synthesis of the proposed compound, or isolation of the compound and subsequent NMR analysis.

GC/MS is one of the most widely used techniques to separate, identify and quantify individual species within aerosol particles (Kotianova et al., 2004; and references therein). A system with $1 \mathrm{~h}$ time resolution has been recently demonstrated (Williams et al., 2006). Unfortunately, the complexity of SOA can be a barrier to this type of analysis resulting in constantly overlapping peaks, as well as the majority of the eluted mass being present as an "unresolved complex mixture" (e.g., Williams et al., 2007). In addition, the oxidized nature of SOA makes it unsuitable for conventional GC analysis, however the range of amenable species can be increased using derivatization (e.g., Yu et al., 1998, 1999; Kubátová et al., 2000; Docherty and Ziemann, 2001; Ho and Yu, 2002; Edney et al., 2003, 2005; Claeys et al., 2004a, b, 2007; Jaoui et al., 2005; Surratt et al., 2006; Szmigielski et al., 2007a, b; Healy et al., 2008).

Recent studies using a higher chromatographic resolution technique, two-dimensional GC coupled to time-of-flight (TOF) MS (GCxGC-TOFMS) have resulted in the separation of over 10000 organic species in urban aerosol samples, some of which could be mechanistically linked to aromatic oxidation processes (Welthagen et al., 2003; Hamilton et al., 2004). GCxGC analysis of the SOA formed in a simulation chamber study of the photooxidation of toluene indicated the presence of over 250 semivolatile oxidation products demonstrating the difficulties associated with linking gas phase precursors and their SOA contribution in ambient aerosols (Hamilton et al., 2005). This technique has recently been incorporated into a field deployable thermal desorption aerosol GCxGC instrument with a flame ionization detector (2-D-TAG) which operates on a hour cycle, providing detailed OA composition at a higher time resolution than previously possible (Goldstein et al., 2008).

LC is becoming increasingly popular for the analysis of polar compounds in aerosol and is routinely used for the analysis of carboxylic acids (Anttila et al., 2005; Römpp et al., 2006; Warnke et al., 2006). State-of-the art coupled LC/MS techniques (such as ion-trap, TOF and triple quadrupole MS) now offer similar or better detection limits than LC-fluorescence techniques and have improved greatly in terms of reliability, sensitivity and ease of use over the past 10 years. LC is particularly suited to high-MW species and very polar molecules, without the need for derivatization prior to analysis. LC/MS is finding increasing use in the analysis of the small polar fraction of SOA formed in simulation chamber studies (Larsen et al., 2001; Gao et al., 2004a, b; Surratt et al., 2006, 2007a, 2008; Iinuma et al., 2007a, b; Ng et al., 2008). LC/MS analyses have also been used to indicate that sulfate as well as nitrate groups could be incorporated in SOA as outlined in Sect. 5.1 below (Iinuma et al., 2007a, b; Surratt et al., 2007a, 2008; Gómez-González et al., 2008). The LC columns employed in most studies are of the reversed phase $\mathrm{C} 18$ or $\mathrm{C} 8$ type; however, stationary phase material containing di- or trifunctionally bonded $\mathrm{C} 18$ chains that prevent stationary phase collapse when aqueous eluent systems are used have proved useful in the analysis of polar sulfated SOA from the photooxidation of isoprene (Gómez-González et al., 2008; Surratt et al., 2008). Hamilton et al. (2008) recently used cationization agents to extend the range of species that could be identified and improve structural characterization. In parallel with GC separations, the low resolution afforded by a single LC separation can be overcome using comprehensive two-dimensional LC as recently demonstrated for the chemical characterization of organosulfates in $\beta$-pinene SOA (Iinuma et al., 2007b). Pol et al. (2006) also recently used LCxLC coupled to ESITOFMS to quantitatively identify carboxylic acids in rural and urban aerosol samples. LC has also been used to separate aerosol extracts into three fractions, based on polarity for subsequent analysis by GC/MS (Lewis et al., 1995; Shimmo et al., 2004).

Electrophoretic separations have also been used for the analysis of SOA components. Capillary electrophoresis (CE) can be applied to the analysis of charged species or compounds that are in equilibrium with a charged form, and are thus generally suited to carboxylic acids as summarized in a recent review (Dabek-Zlotorzynska et al., 2008). CE can also be coupled to MS and has been used to investigate the organic acids and acidic oligomers in SOA formed in simulation chamber studies (Iinuma et al., 2004, 2005; Müller et al., 2007). Ion chromatography (IC) has also been used for the separation of organic aerosol components, especially for the analysis of very acidic, short-chain carboxylic or dicarboxylic acids, such as oxalic acid and glyoxylic acid (Jaffrezo et al., 1998; Kerminen et al., 2000; Röhrl and Lammel, 
2001). Mass spectrometric detection is usually not applied with IC because of the necessity to use buffers that are often not compatible with MS detection. However, there exist methods for the coupling of IC with MS detection that have been used to investigate chamber SOA and the corresponding gas-phase molecules (Fisseha et al., 2004).

One way to reduce the complexity of the analysis is to focus on groups or types of species present in the SOA, rather than trying to analyze for individual species. This simplifies the analysis of large datasets, and by analyzing the whole bulk OA mass it overcomes the disadvantage of identifying only a small fraction of the OA mass, a problem associated with GC/MS studies for example (Rogge et al., 1993). Ion exchange chromatography has been used to separate WSOC into three fractions depending on polarity, (a) neutral/basic compounds, (b) mono and di-carboxylic acids and (c) polycarboxylic acids, followed by subsequent analysis using proton NMR (Decesari et al., 2000). Using this simplified approach, it was determined that atmospheric aerosol in the Po valley in Italy exhibits a seasonal profile, with mono- and dicarboxylic acids dominating in the summer and polycarboxylic acids in spring, winter and autumn (Decesari et al., 2001). NMR profiles of the atmospheric aerosol were found to be similar to those obtained from terrestrial fulvic acids, for example Suwannee River fulvic acid (SRFA, Cappiello et al., 2003), which has been used as a surrogate for ambient aerosol in studies of physico-chemical properties (Parsons et al., 2004; Topping et al., 2005b; Dinar et al., 2006b). This technique has been used in numerous studies, including source identification (Decesari et al., 2007) and a recent improvement involves the derivatization of the carboxylic group with diazomethane to allow a direct determination of carboxylic acids in WSOC (Tagliavini et al., 2006). Some complexities of the compound classification using this technique have been recently discussed in the literature (Collett et al., 2005; Decesari et al., 2005). However, it has the potential to separate biomass burning from marine and secondary organic aerosols as shown for a large number of monitoring stations around the world (Decesari et al., 2007).

A final type of off-line analysis is based on collection of aerosol on impactors or filters followed by analysis by FTIR spectroscopy, to determine the concentration of different organic functional groups such as saturated aliphatic (C-C-H), unsaturated aliphatic $(\mathrm{C}=\mathrm{C}-\mathrm{H})$, aromatic $(\mathrm{C}=\mathrm{C}-\mathrm{H})$, organosulfur (C-O-S), carbonyl $(\mathrm{C}=\mathrm{O})$, organic hydroxyl $(\mathrm{C}-$ $\mathrm{OH}$ ), etc. (Blando et al., 1998; Havers et al., 1998a; Maria et al., 2003; Sax et al., 2005; Polidori et al., 2008). A particular strength of this technique may be the ability to measure the total concentrations of certain functional groups, such as amines or organosulfur species, which are difficult to quantify with other field methods. FTIR spectroscopic analysis has been applied to field samples (e.g. Maria et al., 2003; Polidori et al., 2008; Coury and Dillner, 2008, 2009; Russell et al., 2009). Maria et al. (2003) used aerosol concentrators to obtain sub $1 \mathrm{~h}$ time resolution with this technique from aircraft platforms. The OA concentration determined by FTIR spectroscopy showed good agreement with AMS measurements in several studies (Gilardoni et al., 2007; Russell et al., 2009). Sequential solvent rinsing can be used to further separate the organic compounds by polarity (Maria et al., 2002, 2003; Polidori et al., 2008). The OM/OC ratio can also be estimated from these measurements (Gilardoni et al., 2009).

\subsubsection{On-line techniques}

The analytical techniques described above are based on a time integrating sampling step (using filters, impactors, etc.) followed by post-analysis. This creates the inherent risk of positive and negative artifacts due to adsorption, evaporation, and chemical reactions during the multi-step collection and analysis procedure (e.g., Turpin et al., 2000; Schauer et al., 2003; Subramanian et al., 2004; Dzepina et al., 2007). This type of sampling also severely limits both spatial and temporal sampling densities. Therefore, on-line techniques which provide real-time measurements have revolutionized the chemical analysis of aerosols. The two main types of online techniques currently in use are AMS and PILS-WSOC.

Since the first studies using aerosol mass spectrometers (McKeown et al., 1991), the number of on-line MS techniques has rapidly increased, and has been the subject of several reviews (Noble and Prather, 2000; Sullivan and Prather, 2005; Canagaratna et al., 2007; Murphy et al., 2007). The general principle involves the introduction of airborne particles into the instrument, followed by vaporization and ionization of the material before analysis of the ions using MS. Particle beams can be introduced in the ion source under vacuum using nozzles, capillaries or aerodynamic lenses. For the quantitative field investigation of organic aerosol components and other non-refractory material, a subset of these mass spectrometers has proven most useful.

The AMS instruments (commercialized by Aerodyne Inc.) have proven very useful for field measurements of atmospheric aerosol (Jayne et al., 2000; Jimenez et al., 2003; Canagaratna et al., 2007). The AMS combines thermal desorption (flash evaporation) of the aerosol components and EI of the desorbed components. Data are generally reported as sulfate, nitrate, ammonium, chloride and organic content (Allan et al., 2003; Jimenez et al., 2003). The EI energy of $70 \mathrm{eV}$, especially after vaporization at $600^{\circ} \mathrm{C}$, results in significant fragmentation of the OA fraction and single species can hardly be identified. However, the AMS data can provide information on the bulk composition of the OA, in an analogous manner to some of the off-line techniques such as NMR and FTIR spectroscopy. Statistical multivariate techniques can be used to identify components in the total OA spectra (e.g., Zhang et al., 2005a, b; Lanz et al., 2007, 2008), as discussed below. The high time resolution $(>10 \mathrm{~Hz})$ of the method enables direct flux measurements with the eddy covariance technique, which is promising for biogenic SOA 
quantification and aerosol deposition measurements (Nemitz et al., 2008).

Recently, the quadrupole in the AMS instrument has been replaced with a time-of-flight mass analyzer (ToF-AMS) (Drewnick et al., 2005; DeCarlo et al., 2006). The highresolution version (up to $m / \Delta m \sim 5000$ ) of the ToF-AMS (HR-ToF-AMS) instrument allows the separation of ions with the same nominal mass but different elemental composition, for example at $m / z 43$ the following fragments could be resolved: $\mathrm{CHNO}^{+}, \mathrm{C}_{2} \mathrm{H}_{3} \mathrm{O}^{+}, \mathrm{CH}_{3} \mathrm{~N}_{2}^{+}, \mathrm{C}_{2} \mathrm{H}_{5} \mathrm{~N}^{+}$and $\mathrm{C}_{3} \mathrm{H}_{7}^{+}$. This facilitates the identification of minor elements (e.g., $\mathrm{N}$, P) that were previously obscured among larger ions in the unit resolution spectra, and provides better differentiation of spectra of POA sources and SOA components, thus enhancing statistical techniques (Ulbrich et al., 2009). An ion trap has also been recently coupled with the well characterized AMS inlet and vaporization-ionization system providing the ability to perform $\mathrm{MS}^{n}$ measurements (Kürten et al., 2007). A recently developed method (Aiken et al., 2007) allows the determination of $\mathrm{O} / \mathrm{C}, \mathrm{N} / \mathrm{C}$, and $\mathrm{H} / \mathrm{C}$ atomic ratios of organic matter directly and with high time resolution. The $\mathrm{O} / \mathrm{C}$ ratio of SOA produced in "traditional" high concentration chamber experiments from various precursors ( $\alpha$-pinene, aromatics, isoprene) is in the range $0.28-0.43$ (Aiken et al., 2008). These ratios are lower than those found in the atmosphere and are attributed to less aging and the high precursor concentrations used in the experiment which allows less oxidized species to partition into the aerosol (Aiken et al., 2008; Shilling et al., 2009; Huffman et al., 2009). For urban aerosol the $\mathrm{O} / \mathrm{C}$ atomic ratio increases with aging of the aerosol and reaches 1 for the aged SOA fraction (OOA1). A direct correlation between the measured $\mathrm{O} / \mathrm{C}$ and $\mathrm{OM} / \mathrm{OC}$ ratios was found yielding the relationship

$\mathrm{OM} / \mathrm{OC}=(1.26 \times \mathrm{O} / \mathrm{C})+1.18$

Mixed urban aerosols have OM/OC ratios of 1.6-1.8, which is on the higher side of the range of $1.6 \pm 0.2$ reported by Turpin and Lim (2001). Aged regional organic aerosols have $\mathrm{OM} / \mathrm{OC}$ ratios of ca. 2.1 which is in good agreement with the value of $2.1 \pm 0.2$ recommended for non-urban aerosols (Turpin and Lim, 2001). In the water soluble fraction of organic aerosol OM/OC ratios of 1.8-1.93 were obtained for ambient SOA using ${ }^{1} \mathrm{H}-\mathrm{NMR}$ (Decesari et al., 2007).

Laser-ablation mass spectrometers can analyze individual particles by using a laser to vaporize and ionize single particles followed by TOFMS (McKeown et al., 1991; Noble and Prather, 1996; Murphy, 2007) and allow the analysis of positive and negative ions simultaneously (Hinz et al., 1996). An instrument of this type, the aerosol TOF mass spectrometer (ATOFMS), is commercially available from TSI Inc. The OA fraction produces characteristic fragmentation patterns, but matrix effects make quantification difficult. Murphy et al. (2006) calibrated the organic/sulfate ratios of their Particle Analysis by Laser Mass Spectrometry (PALMS) instrument by comparison with the AMS instrument, and showed that
$30 \%$ to over $80 \%$ of the aerosol mass in the free troposphere is carbonaceous material over the regions they have studied, which may be related to SOA production but also to biomass burning or reduced cloud scavenging of organic-dominated particles. Under certain conditions (e.g., matrix composition, instrument tuning), fragmentation in laser-ablation instruments can be reduced and higher-MW compounds, such as oligomers formed in chamber experiments, can be identified with this technique (Gross et al., 2006; Denkenberger et al., 2007).

Over the last decade there have been numerous other online mass spectrometers incorporating a range of desorption and ionization methods. Some of these designs have been used in field studies, while others have been limited to laboratory applications, primarily due to sensitivity limitations. Of note among the instruments that have only been used for laboratory applications is the photoelectron resonance capture ionization AMS (PERCI-AMS) instrument, where particles are deposited onto a resistively heated wire and the vaporized material is ionized with low energy electrons (LaFranchi et al., 2004; Zahardis et al., 2006). Some important laboratory findings about SOA and heterogeneous chemistry have arisen from work with the thermal desorption particle beam mass spectrometer (TDPBMS), which captures particles in a cryo-cooled surface and then desorbs them by slow heating allowing volatility separation before MS analysis (Docherty and Ziemann, 2003; Lim and Ziemann, 2005). A similar volatility separation technique, involving a rapidly switching thermodenuder, has recently been developed for field sampling with the AMS instrument (Huffman et al., 2008, 2009). Warscheid and Hoffmann $(2001,2002)$ have used APCI, where particles are vaporized in a heated tube and organic compounds chemically ionized using a corona discharge, producing mostly molecular ion species. This instrumentation allows structural analysis of single species using an ion trap MS (ITMS). Other soft ionization techniques based on photoionization (Northway et al., 2007; Dreyfus and Johnston, 2008) or CI (Hearn and Smith, 2006) have been developed and are starting to be applied to ambient measurements. The analysis of the elemental composition of sub- $20 \mathrm{~nm}$ particles has recently become possible with the nano aerosol mass spectrometer (NAMS) (Wang et al., 2006), while their molecular composition can be analyzed by thermal desorption chemical ionization mass spectrometry (TDCIMS) (Smith et al., 2005). Recently the commercially available PTR/MS (proton transfer reaction mass spectrometry) instrument, which detects organic compounds in the gasphase using $\mathrm{H}_{3} \mathrm{O}^{+}$as the chemical ionization reagent, was successfully applied to the identification of organic species in the particle phase (Hellén et al., 2008b).

Particle into liquid samplers (PILS) collect particles into water for subsequent analysis (e.g., IC) (Weber et al., 2001; Orsini et al., 2003; Sullivan et al., 2004; Sorooshian et al., 2006a). A continuous measurement of WSOC (as well as inorganic and organic ions by IC) with a time resolution of 
minutes has been coupled to a PILS instrument and deployed in several aircraft campaigns (e.g., Sorooshian et al., 2006a, b, 2007a, b; Peltier et al., 2007a; Weber et al., 2007). The main sources of WSOC are SOA and biomass burning OA (Sullivan et al., 2006). Miyazaki et al. (2006) showed that WSOC in Tokyo correlated well with SOC estimated with the EC-tracer method, while water-insoluble organic compounds (WIOC) correlated well with EC and CO in that study. Kondo et al. (2007) and Docherty et al. (2008) have shown that the WSOC measurement is very similar to the total AMS OOA in Tokyo and Riverside, respectively. Based on measurements made in Cairo, Favez et al. (2008) suggested that anthropogenically-dominated SOA may have a higher insoluble fraction. Recently, a measurement of WSOC following PILS collection has also been demonstrated in the field, and was found to be in very good agreement with semicontinuous OC measurements (a slope close to unity was obtained within the uncertainties of both measurements). However, a non-zero intercept was also determined, which is possibly related to the inability of the total organic carbon (TOC) analyzer to digest larger insoluble particles (Peltier et al., 2007b). Another very promising recent development is the simultaneous measurement of particle and gas-phase WSOC by Hennigan et al. (2008, 2009). During the summer in Atlanta at elevated RH levels (>70\%), a significant increase in WSOC partitioning to the particle phase was observed and followed the predicted water uptake by fine particles. These results suggest that SOA formation involving partitioning to liquid water may be a significant pathway that is often not considered. Sorooshian et al. (2007a, b) have pioneered the analysis of organic acids by IC analysis following PILS collection. These authors report that organic acids averaged $3.4 \%$ of the water-soluble PM mass during an airborne study in the Houston area. Organic acids were most abundant above clouds, presumably as a result of aqueous phase chemistry in cloud droplets, followed by subsequent droplet evaporation above cloud tops with the main product of this chemistry being oxalic acid. Suppressed organic acid formation was observed in clouds with relatively acidic droplets and lower liquid water content.

\subsubsection{Analysis of high molecular weight compounds}

During the last decade an increasing number of studies have reported that macromolecular species make a significant contribution to the mass of organic compounds present in atmospheric aerosol. The largest fraction of these species showed considerable similarities in structural properties to humic and fulvic acids and were thus termed humic-like substances (HULIS) (Havers et al., 1998a, b; Zappoli et al., 1999; Decesari et al., 2000; Gelencsér et al., 2000a, b; Kiss et al., 2002). HULIS can affect many aerosol properties, including hygroscopicity, cloud condensation nuclei $(\mathrm{CCN})$ activity, surface tension and optical parameters (Gysel et al., 2004; Kiss et al., 2005; Dinar et al., 2006b, 2007, 2008a, b; Hoffer et al., 2006; Salma et al., 2006; Taraniuk et al., 2007; Wex et al., 2007). HULIS are operationally defined fractions of the aerosol and their quantification thus depends to some extent on the applied extraction, isolation and detection method. This fraction consists of polyacidic compounds of aliphatic and aromatic structures with additional substituted functional groups. Their molecular mass was determined to be between $150-500 \mathrm{Da}$ (Kiss et al., 2003). In a comprehensive review, Graber and Rudich (2006) concluded that, although it is difficult to distinguish atmospheric HULIS from terrestrial and aquatic humic substances on a chemical level, there are significant differences in physical properties such as hygroscopicity and CCN activity. This has been substantiated in a series of studies on the microphysical properties of HULIS extracted from real aerosol samples (Dinar et al., 2006a, b, 2007; Asa-Awuku and Nenes, 2007; Taraniuk et al., 2007; Wex et al., 2007). There is indication that HULIS can be of primary origin, e.g., wood combustion, but may also be associated with secondary particle-phase production (Gelencsér et al., 2002; Samburova et al., 2005a, b; Feczko et al., 2007; Surratt et al., 2007a, 2008). LC separations are well suited to the analysis of HULIS in atmospheric aerosols and a comprehensive review of extraction and analysis techniques is given in Graber and Rudich (2006). Separation using reverse-phase high-performance LC (HPLC) and size-exclusion chromatography (SEC) has indicated that aerosol HULIS is of lower molecular mass than terrestrial and aquatic humic substances, possibly due to the presence of mineral acids and mono- and dicarboxylic acids which prevent the formation of large supramolecular structures. Samburova et al. (2005a, b) used SEC coupled to UV spectroscopy and laser desorption ionization MS (LDI-MS) to determine an upper value of $700 \mathrm{Da}$ for the molecular mass of HULIS in atmospheric aerosol and showed that this corresponds to around $9-30 \%$ of the total organic carbon for an urban background site.

Higher-MW reaction products (i.e., products with MWs higher than those of first- and higher- generation oxidation products) have been identified in laboratory SOA produced from the atmospheric oxidation of a wide range of compounds, including 1,3,5-trimethylbenzene, cycloalkenes, $\alpha$-pinene and isoprene (Gao et al., 2004a, b; Iinuma et al., 2004, 2007a; Kalberer et al., 2004, 2005; Tolocka et al., 2004; Bahreini et al., 2005; Hastings et al., 2005; Dommen et al., 2006; Surratt et al., 2006; Szmigielski et al., 2007a; Hamilton et al., 2006), as well as the hydration of glyoxal (Hastings et al., 2005). These higher-MW reaction products have been denoted as "oligomers"; however, it is worth noting that higher-MW products identified in SOA and ambient aerosol do not only contain oligomers, which according to the IUPAC recommendations denotes products which comprise a plurality of monomeric units derived from molecules of lower molecular mass (IUPAC, 1996). In addition to oligomers, higher-MW products also comprise other classes of compounds such as organosulfates and nitrooxy 
organosulfates (Romero and Oehme, 2005; Reemtsma et al., 2006; Iinuma et al., 2007a, b; Gómez-González et al., 2008; Surratt et al., 2007a, 2008), and dimers such as hemiacetals formed between 2-methyltetrols and $\mathrm{C}_{5}$-dihydroxycarbonyl (Surratt et al., 2006). A word of caution is also appropriate here with regard to the use of the term "humic-like substances" (HULIS), which may comprise a complex mixture of several classes of polyfunctional compounds, including oligomers, organosulfates and nitrooxy organosulfates. In earlier work (MacCarthy et al., 1990) it has been stated that the term "structure of humic substances" must not be interpreted in the conventional chemical context because such fine detail was simply beyond reach at that time. Owing to the considerable developments of MS techniques based on ESI, tandem MS and high-resolution MS over the last two decades, the analytical tools are now available to efficiently address the polyfunctional chemical structures of polar HULIS in complex mixtures such as SOA and ambient aerosol.

Initial evidence for oligomer formation was provided by off-line LDI-MS (Kalberer et al., 2004), but this approach did not provide detailed structural information. Tolocka et al. (2004) applied matrix-assisted laser desorption-ionization (MALDI), ESI and CIMS. CI was found to cause decomposition of the parent oligomer, but MALDI and ESI provided similar oligomer distributions. Tandem MS using a quadrupole TOF (Q-TOF) indicated that the dimers, trimers and tetramers were composed of known gas phase reaction products from the ozonolysis of $\alpha$-pinene. Gao et al. (2004a) used LC coupled to a quadrupole mass spectrometer (LC/QMS) and direct infusion into an ion trap mass spectrometer (ITMS), both of which were equipped with ESI, to detect oligomers with masses up to $1600 \mathrm{Da}$ in SOA formed during cyclohexene ozonolysis and estimated that they accounted for around $10 \%$ of the total mass fraction. Fragmentation patterns for structural analysis were performed in negative ionization mode but a wider range of species could be detected in positive ionization mode as $[\mathrm{M}+\mathrm{Na}]^{+}$adducts.

On-line MS techniques have also been used to follow the temporal evolution of oligomers in simulation chamber studies. Gross et al. (2006) used an aerosol time of flight mass spectrometer (ATOFMS) with a minute time resolution to follow the increasing MW of oligomers formed during the photooxidation of $\alpha$-pinene and 1,3,5-trimethylbenzene. Single particle ATOFMS has also been used for the identification and real-time monitoring of oligomers in aged ambient atmospheric aerosol in California, USA (Denkenberger et al., 2007). Müller et al. (2008) have applied on-line APCI tandem MS (APCI-MS ${ }^{n}$ ) to investigate oligomer formation in real-time and used $\mathrm{MS}^{n}$ for structural characterization.

Fourier transform ion cyclotron resonance MS (FTICRMS) has ultra-high mass accuracy (sub ppm) and a very high mass resolution $(>100000)$ allowing determination of molecular composition even at higher mass-to-charge ratios. Reinhardt et al. (2007) used FTICRMS to investigate the molecular composition of oligomeric species in $\alpha$-pinene SOA and applied Kendrick mass analysis, a tool employed in petroleomics, where nomimal mass is plotted against the Kendrick mass defect to visualise the highly complex dataset as homologous series of oligomers with increasing numbers of $\mathrm{CH}_{2}$ groups and $\mathrm{O}$. It was found that the monomer units had a higher $\mathrm{O} / \mathrm{C}$ ratio than the dimers and trimers, indicating that condensation reactions involving the loss of water are important in the formation of oligomers. Reemtsma et al. (2006) have also applied FTICRMS to the analysis of ambient urban aerosol and reported that the high-MW species observed resemble fulvic acids and are often sulfated and/or nitrated. High-resolution mass analyzers in combination with (-)ESI have recently been employed to support the elemental composition of organosulfates and nitrooxy organosulfates present in BSOA and ambient aerosol. TOF mass analyzers of the reflector type with a mass resolution $>10000$ were used in most of these studies (Romero and Oehme, 2005; Iinuma et al., 2007a, b; Surratt et al., 2008) but another mass analyzer with ultra-high mass resolution $(>100000)$ in addition to the ion cyclotron, i.e., the Orbitrap (Gómez-González et al., 2008) has also been employed in the analysis of organosulfates and nitrooxy organosulfates.

\section{Recent developments in laboratory, field and modeling studies}

\subsection{Laboratory studies}

The large majority of our knowledge about SOA formation from VOC oxidation derives from laboratory studies. Most of these studies make use of large simulation chambers (smog chambers), ranging in volume from $1-270 \mathrm{~m}^{3}$ (see Table 2), although some complementary studies have been conducted in aerosol flow reactors (e.g., Bonn et al., 2002; Berndt et al., 2003; Jonsson et al., 2006, 2008a, b). In general, chamber experiments are carried out in batch mode, though some use a continuous flow mode. They are designed to mimic atmospheric conditions as closely as possible so that nonlinearities and other complicating factors are shared in the experiment and in the real atmosphere. Flow reactor experiments, on the other hand, are more often designed to isolate specific fundamental terms in a chemical mechanism, and are primarily not used to explicitly mimic the ambient atmosphere.

At their heart, almost all SOA experiments are based on a mass balance, typically expressed as in Eq. (3). As noted above though, there are many complicating factors in the interpretation of experimental yields, several of which have yet to be completely resolved. With these factors in mind, the objective of laboratory SOA formation experiments can be refined to a dual purpose. First is to constrain the yields $\left(\alpha_{i}\right)$ 
Table 2. Selected laboratory chamber facilities for the study of secondary organic aerosols.

\begin{tabular}{|c|c|c|c|c|c|}
\hline Location & Type & $\begin{array}{l}\text { Volume } \\
\left(\mathrm{m}^{3}\right)\end{array}$ & Material & $\begin{array}{l}\text { Temperature } \\
(\mathrm{K})\end{array}$ & Reference $^{\mathrm{a}}$ \\
\hline $\begin{array}{l}\text { California Institute } \\
\text { of Technology, USA }\end{array}$ & $\begin{array}{l}\text { Indoor } \\
\text { Photoreactor }\end{array}$ & 28 (dual) & FEP & $290-303$ & $\begin{array}{l}\text { Cocker et al. (2001b) } \\
\mathrm{Ng} \text { et al. (2008) }\end{array}$ \\
\hline $\begin{array}{l}\text { Carnegie Mellon } \\
\text { University, USA }\end{array}$ & $\begin{array}{l}\text { Indoor } \\
\text { Photoreactor }\end{array}$ & 10 & PTFE/FEP & $288-313$ & $\begin{array}{l}\text { Stanier et al. (2007) } \\
\text { Robinson et al. (2007) }\end{array}$ \\
\hline $\begin{array}{l}\text { Forschungszentrum Jülich, } \\
\text { Germany (SAPHIR) }\end{array}$ & $\begin{array}{l}\text { Outdoor } \\
\text { Photoreactor }\end{array}$ & 270 & FEP & ambient & Rohrer et al. (2005) \\
\hline $\begin{array}{l}\text { Forschungszentrum } \\
\text { Jülich, Germany }\end{array}$ & Dark Chamber & 250 & PTFE/FEP & ambient & $\begin{array}{l}\text { Mentel et al. (1996) } \\
\text { Folkers et al. (2003) }\end{array}$ \\
\hline $\begin{array}{l}\text { Forschungszentrum } \\
\text { Karlsruhe (AIDA) }\end{array}$ & Dark Chamber & $4-84$ & Metal & $183-323$ & $\begin{array}{l}\text { Saathoff et al. (2003) } \\
\text { Jonsson et al. (2007) }\end{array}$ \\
\hline $\begin{array}{l}\text { Fundación Centro de Estudios } \\
\text { Ambientales del Mediterráneo, } \\
\text { Spain (EUPHORE) }\end{array}$ & $\begin{array}{l}\text { Outdoor } \\
\text { Photoreactor }\end{array}$ & 200 & FEP & ambient & $\begin{array}{l}\text { Klotz et al. (1998) } \\
\text { Martin-Reviejo and } \\
\text { Wirtz (2005) }\end{array}$ \\
\hline $\begin{array}{l}\text { Leibniz Institute for Tropospheric } \\
\text { Research, Germany }\end{array}$ & $\begin{array}{l}\text { Indoor } \\
\text { Photoreactor }\end{array}$ & 19 & FEP & $289-308$ & Iinuma et al. (2007b) \\
\hline $\begin{array}{l}\text { Paul Scherrer Institute, } \\
\text { Switzerland }\end{array}$ & $\begin{array}{l}\text { Indoor } \\
\text { Photoreactor }\end{array}$ & 27 & FEP & $288-313$ & $\begin{array}{l}\text { Paulsen et al. (2005) } \\
\text { Kalberer et al. (2004) }\end{array}$ \\
\hline University College Cork, Ireland & $\begin{array}{l}\text { Indoor } \\
\text { Photoreactor }\end{array}$ & 6.5 & FEP & $293-305$ & $\begin{array}{l}\text { Temime et al. (2007) } \\
\text { Healy et al. (2008) }\end{array}$ \\
\hline University of Manchester, UK & $\begin{array}{l}\text { Indoor } \\
\text { Photoreactor }\end{array}$ & 18 & FEP & $288-313$ & \\
\hline $\begin{array}{l}\text { Univ. of California, } \\
\text { Riverside, USA (CE-CERT) }\end{array}$ & $\begin{array}{l}\text { Indoor } \\
\text { Photoreactor }\end{array}$ & 90 (dual) & FEP & $278-323$ & $\begin{array}{l}\text { Carter et al. (2005) } \\
\text { Song et al. (2005) }\end{array}$ \\
\hline $\begin{array}{l}\text { Univ. of California, } \\
\text { Riverside, USA (APRC) }\end{array}$ & $\begin{array}{l}\text { Indoor } \\
\text { Photoreactor }\end{array}$ & 6-8 (several) & PTFE/FEP & ambient & $\begin{array}{l}\text { Tobias and Ziemann (1999) } \\
\text { Matsunaga et al. (2009) }\end{array}$ \\
\hline $\begin{array}{l}\text { Univ. of North } \\
\text { Carolina, USA }\end{array}$ & $\begin{array}{l}\text { Outdoor } \\
\text { Photoreactor }\end{array}$ & $\begin{array}{l}120,137 \text { (dual) } \\
150 \text { (dual) }\end{array}$ & FEP & ambient & $\begin{array}{l}\text { Lee et al. (2004) } \\
\text { Li et al. (2007) }\end{array}$ \\
\hline $\begin{array}{l}\text { US Environmental } \\
\text { Protection Agency }\end{array}$ & $\begin{array}{l}\text { Indoor } \\
\text { Photoreactor }\end{array}$ & 14.5 & FEP/TFE & $293-298$ & $\begin{array}{l}\text { Edney et al. (2005) } \\
\text { Offenberg et al. (2007) }\end{array}$ \\
\hline $\begin{array}{l}\text { CSIRO Energy Technology } \\
\text { Australia }\end{array}$ & $\begin{array}{l}\text { Indoor } \\
\text { Photoreactor }\end{array}$ & 18 & FEP & ambient & $\begin{array}{l}\text { Hynes et al. (2005) } \\
\text { Angove et al. (2006) }\end{array}$ \\
\hline $\begin{array}{l}\text { National Institute for Environmental } \\
\text { Studies, Japan }\end{array}$ & $\begin{array}{l}\text { Indoor } \\
\text { Photoreactor }\end{array}$ & 6 & PTFE/FEP & ambient & Sato et al. (2007) \\
\hline
\end{tabular}

${ }^{a}$ Selected references with emphasis on SOA (maximum 2 per laboratory).

of a set of (semi- or non-) volatile products $\left(\mathrm{P}_{i}\right)$ as a function of the appropriate variables (temperature, relative humidity, $\mathrm{NO}_{\mathrm{x}}$ and hydrocarbon mixing ratios, UV intensity, etc.), recognizing that $\mathrm{P}_{i}$ are usually surrogate or lumped species that "average" over the real properties of multiple real product species. Second is to elucidate fundamental aspects such as chemical mechanisms and phase partitioning of a given mixture of products in an experiment and then extend that knowledge to the atmosphere. Here several variables potentially influence both the chemical mechanisms and the phasepartitioning thermodynamics. The most notable is temperature, followed by water vapor. A description of the influence of water vapor is found in Sect. 5.6. The effect of temperature on SOA formation has received comparatively little attention (Takekawa et al., 2003; Jonsson et al., 2007, 2008b; Pathak et al., 2007, 2008; Saathoff et al., 2009). However, the results obtained to date provide evidence for a temperature effect, both on gas-particle partitioning and on the chemical mechanism.

\subsubsection{Aerosol yield}

To obtain constraints on $C_{i}^{*}$ and $\alpha_{i}$, data are required spanning a range of $C_{O A}$. Historically, multiple chamber experiments (each lasting one or more days) were carried out to 
obtain $F_{O A}$ versus "final" $C_{O A}$ (Odum et al., 1996; Hoffmann et al., 1997; Griffin et al., 1999), though more recently individual chamber experiments have been used to obtain "dynamic" $C_{O A}$, using the increase in $C_{O A}$ as $C_{H C}$ decreases due to oxidation (see e.g., Hurley et al., 2001; $\mathrm{Ng}$ et al., 2006; Presto et al., 2006). The simple fitting of $F_{O A}$ versus $C_{O A}$ data in this manner is valid only if the set of reaction products and yields remains the same, either through a succession of experiments or during an individual experiment.

At least three approaches have been applied to fitting or reproducing SOA data based on this foundation: (1) Explicit enumeration of reaction products in a reaction mechanism including partitioning (Jenkin, 2004), (2) empirical determination of both $\alpha_{i}$ and $C_{i}^{*}$ in a $n$-product model, most often with $n=2$ (Odum et al., 1996), and (3) fitting of $\alpha_{i}$ only for a fixed "basis set" of $C_{i}^{*}$ (Presto and Donahue, 2006). In all cases, the objective is to constrain the amount and volatility of the reaction products, especially those that partition to the particulate phase. The methods are all empirical, so they cannot constrain volatility outside of the range of $C_{O A}$ in the data; consequently, a recent focus has been to develop SOA formation data over atmospherically relevant $C_{O A}$ ranges $\left(0.1-100 \mu \mathrm{g} \mathrm{m}^{-3}\right.$, Presto and Donahue, 2006; Shilling et al., 2009). There are two separate issues: first is the ability of fit parameters to reproduce data $\left(F_{O A}\right)$, and second is the interpretation of those parameters. As an example, Fig. 5 shows data from $\alpha$-pinene + ozone experiments using 2-butanol as an $\mathrm{OH}$ radical scavenger (Griffin et al., 1999; Cocker et al., 2001a; Presto and Donahue, 2006; Pathak et al., 2007). The $\log x$ axis allows the wide atmospheric range $\left(0.1-100 \mu \mathrm{g} \mathrm{m}^{-3}\right)$ to be observed. The function shown is a basis-set fit; as the data are in quite good agreement over this range, the fit interpolates well. Regardless of the fitting approach, the data themselves reveal that a significant fraction of the overall product mass has a volatility $\left(C^{*}\right)$ in the 5$500 \mu \mathrm{g} \mathrm{m}^{-3}$ range, because the observed values of $F_{O A}$ rise sharply over this range. Likewise, the mass yield of products less volatile than $1 \mu \mathrm{g} \mathrm{m}^{-3}$ can be no more than about 0.05 . However, these conclusions about product volatility distributions assume that the composition of the VOC oxidation products does not vary as $C_{O A}$ changes by several orders of magnitude. This may be a reasonable assumption for ozone + alkene reactions such as ozone $+\alpha$-pinene, but recent results suggest that this may not be the case for more complex photooxidation systems (Chan et al., 2007; Duplissy et al., 2008). It should also be noted that recent experiments point out the challenge in establishing the yield at very low values of $C_{O A}$ (Shilling et al., 2009).

Obviously this parameterization needs to be performed for each selected condition. Here the influence of $\mathrm{NO}_{\mathrm{x}}$ on gasphase oxidation mechanisms for SOA formation has received increasing attention (Kroll et al., 2005b, 2006; Presto et al., 2005b; Ng et al., 2007a, b; Zhang et al., 2006). Explicit mechanisms can of course directly handle such dependencies, but for lumped mechanisms Presto and Donahue (2006)

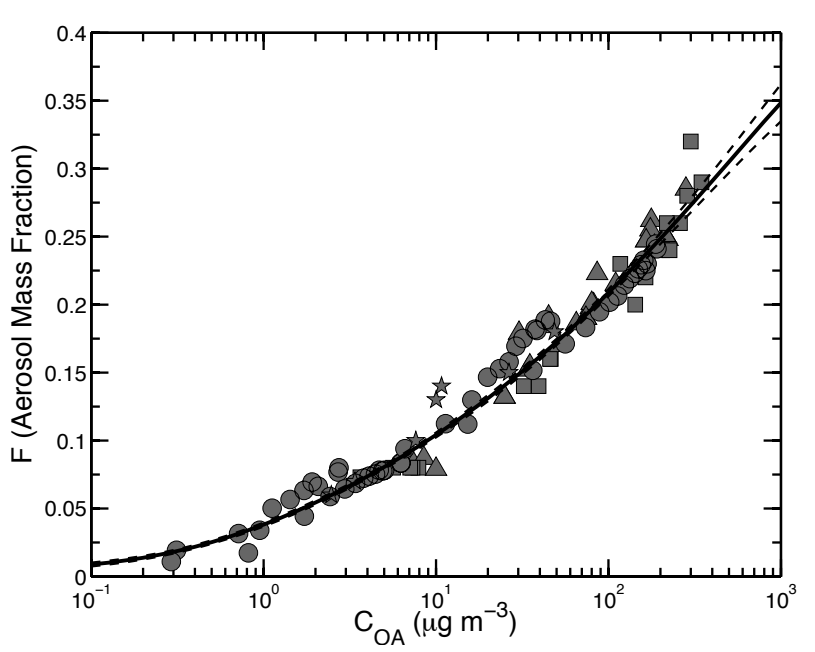

Fig. 5. Aerosol mass fraction $\left(F_{O A}\right)$ for SOA generated in the reaction of $\alpha$-pinene and ozone under low- $\mathrm{NO}_{\mathrm{x}}$ conditions using 2butanol as an $\mathrm{OH}$ scavenger. Data points are taken from; Griffin et al. (1999) (triangles); Cocker et al. (2001a) (squares); Presto and Donahue (2006) (circles); Pathak et al. (2007) (stars).

proposed a simple parameterization of this dependence based on the $\mathrm{RO}_{2}+\mathrm{NO}$ branching ratio, $\beta$. Low- and high- $\mathrm{NO}_{\mathrm{x}}$ product yields $(\alpha)$ are based on photochemical chamber studies carried out under extremes of $\mathrm{NO}_{\mathrm{x}}$ concentration. The overall product yields are then parameterized as the linear combination,

$(\alpha)=\beta(\alpha)^{\text {high }-\mathrm{NO}_{\mathrm{x}}}+(1-\beta)(\alpha)^{\text {low }-\mathrm{NO}_{\mathrm{x}}}$

$\mathrm{Ng}$ et al. (2007a) and Henze et al. (2008) applied a similar formulation for the generation of SOA from aromatics. However, the effect of $\mathrm{NO}_{\mathrm{x}}$ on SOA mass yield is complex. For most light precursors, including alkylbenzenes, isoprene, and monoterpenes, SOA formation at high $\mathrm{NO}_{\mathrm{x}}$ appears to be reduced (Johnson et al., 2004, 2005; Kroll et al., 2005b, 2006; Presto et al., 2005b). In the ozonolysis of limonene, which contains two double bonds, SOA formation is broadly similar at all $\mathrm{NO}_{\mathrm{x}}$ levels (Zhang et al., 2006). Finally, for photooxidation of sesquiterpenes, SOA formation is enhanced at high $\mathrm{NO}_{\mathrm{x}}(\mathrm{Ng}$ et al., 2007b). It should be noted that adding $\mathrm{NO}_{\mathrm{x}}$ during dark reactions will enhance oxidation of the reactant by the $\mathrm{NO}_{3}$ radical (Hallquist et al., 1999; Spittler et al., 2006). Obviously, the $\mathrm{NO}_{3}$ radical initiated oxidation of VOCs can be a source of SOA during nighttime conditions, as outlined in Sect. 3.1. The reaction of VOCs with $\mathrm{Cl}$ atoms is also a potential source of SOA in the marine boundary layer (e.g., Cai et al., 2008). For further discussion of the chemical mechanisms of SOA formation, see Sect. 3.1 and the recent reviews by Kroll and Seinfeld (2008) and Johnson and Marston (2008). 


\subsubsection{Chemical time scales versus precursor and SOA levels}

An important challenge is associated with scales: chemical timescales compared with experimental timescales, mass and concentration scales in experiments versus the ambient atmosphere, and the physical scales of the experiments themselves. In most experiments, this means that much higher concentrations of a precursor, $C_{H C}$, must be oxidized than one ever finds in the atmosphere in order to generate enough SOA: experiments at the typical $C_{H C}$ of an individual hydrocarbon alone would generate trivial levels of $C_{O A}$ that would be very hard to quantify experimentally, and thus are not experimentally appropriate. Consequently this may also influence the choice of oxidant level where experimental interpretation is more straightforward when the product formation timescale is much shorter than the particle deposition timescale. This sometimes motivates experimentalists to utilize oxidant levels well over typical ambient levels; however, great care must be taken to ensure that the resulting chemical mechanism and products remain relevant to the atmosphere. At a low organic aerosol level, only the least volatile VOC oxidation products effectively partition into the aerosol phase. As the mass concentration of organic aerosol rises in a chamber experiment, compounds of higher volatility progressively partition into the aerosol phase. To best simulate partitioning under ambient conditions, organic aerosol levels in chamber SOA studies should be within the range typically encountered in the atmosphere, roughly from 0.1 to $100 \mu \mathrm{g} \mathrm{m}^{-3}$. However, higher mass experiments can be of considerable value too as they help constrain the full volatility distribution of the oxidation products for modeling of extended atmospheric transport and aging. The production of high mass yields is also advantageous when trying to identify individual constituents of SOA that may be used as markers of particular sources of SOA in ambient aerosol, as described in Sects. 4.2 and 5.1.

The organic aerosol level $C_{O A}\left(\mu \mathrm{g} \mathrm{m}^{-3}\right)$ affects both the degree of partitioning of the array of semivolatile products as well as the kinetics of SOA formation (Chan et al., 2007; Kroll et al., 2007; Kroll and Seinfeld, 2008). Also, when $C_{O A}$ is small, there is an induction period associated with subsaturation of the semivolatile product relative to the amount required for condensation. During this induction period, a substantial fraction of condensable material may be lost to the walls, resulting in lower yields (Kroll et al., 2007). In interpreting yields from such a series of experiments, it is important to note that the SOA generated at a certain value of $\Delta M_{H C}$ is not necessarily the same for different starting hydrocarbon concentrations (Chan et al., 2007). In short, to produce the same value for $\Delta M_{H C}$, a longer time is required for a smaller value of initial $C_{H C}$. When generation of semivolatile products involves multiple oxidation steps, as it often does, during that longer time more SOA can form. The result is that at a given $\Delta M_{H C}$, the measured SOA yield can be larger for smaller initial hydrocarbon concentrations. Care must be exercised in interpreting SOA production data from experiments carried out at different initial concentrations when the parent VOC is not completely reacted, or indeed whenever multiple generations of oxidation occur in an experiment. The effect of the initial organic aerosol level on the kinetics of SOA formation is accentuated even more if the semivolatile oxidation products undergo gas-phase decomposition reactions to give more volatile species (Kroll et al., 2007).

\subsubsection{Recent changes in yield estimates}

Recent simulation chamber experiments have shown rather dramatic changes in the yield parameters for important SOA precursor compounds, as illustrated in Fig. 6. Newer data typically show much more aerosol formation than found in papers published prior to 2005 (Ng et al., 2006, 2007a, b; Pathak et al., 2007). For example, Ng et al. (2007a) showed that under low- $\mathrm{NO}_{\mathrm{x}}$ conditions the yield of SOA from aromatic compounds could be more than $30 \%$, regardless of $C_{O A}$. Under high- $\mathrm{NO}_{\mathrm{x}}$ conditions the same aromatic compounds had much reduced yields, but still significantly higher than found in the earlier studies of Odum et al. (1996). These large increases in yield estimates have been attributed by $\mathrm{Ng}$ et al. (2007a) to improvements in the methodology used in the chambers: faster-reacting systems to avoid wall-loss of formed SOA, experiments that were conducted at either high or low $\mathrm{NO}_{\mathrm{x}} / \mathrm{HO}_{2}$ ratios throughout, and a greater recognition of the kinetic factors controlling experimental yield values (Chan et al., 2007). An important new development has been the recognition that isoprene, a compound previously thought to be unimportant for SOA formation under atmospherically relevant conditions (Pandis et al., 1991), can also produce SOA and likely in very significant quantities (Claeys et al., 2004a, b; Edney et al., 2005; Kroll et al., 2005b, 2006; Dommen et al., 2006; Henze and Seinfeld, 2006; Surratt et al., 2006; Tsigaridis and Kanakidou, 2007).

\subsubsection{Density and SOA morphology}

An estimate of particle density (and an assumption of sphericity) is needed when volume measurements of SOA are converted into mass concentration, such as in SOA yield calculations using differential mobility analyzer (DMA) measurements of the size distribution. Without all of the significant components of the SOA being identified, the estimation of the density based on the chemical composition is highly uncertain. A number of methods to determine particle density have been reported in the literature (McMurry et al., 2002; DeCarlo et al., 2004). Typically for SOA an effective density is derived by combining measurements of aerodynamic and mobility diameters (McMurry et al., 2002; DeCarlo et al., 2004; Zelenyuk et al., 2006; Kostenidou et al., 2007), or aerodynamic and optical diameters (Murphy et al., 2004; Cross et al., 2007). The effective densities thus determined are equivalent to the material density in the case 
of spherical particles but may differ significantly from the material density and other definitions of effective density for particles with irregular shapes (DeCarlo et al., 2004).

Laboratory measurements of SOA formed from anthropogenic and biogenic precursors yield aerosol effective densities in the range $1.06-1.45 \mathrm{~g} \mathrm{~cm}^{-3}$ and $0.64-1.65 \mathrm{~g} \mathrm{~cm}^{-3}$, respectively (Bahreini et al., 2005; Alfarra et al., 2006; Kostenidou et al., 2007). A density of $1.4 \mathrm{~g} \mathrm{~cm}^{-3}$ has been determined for isoprene (Dommen et al., 2006; $\mathrm{Ng}$ et al., 2008) and aromatic (Alfarra et al., 2006; Ng et al., 2007a) SOA by comparing mobility diameter measurements from a differential mobility analyzer with the vacuum aerodynamic diameter measured with an on-line aerosol mass spectrometer. In the absence of direct measurements, it is recommended that a value of $1.4 \mathrm{~g} \mathrm{~cm}^{-3}$ is used for the SOA density, particularly when determining SOA mass yields from measured volume concentrations, as performed in several recent studies (e.g., $\mathrm{Ng}$ et al., 2007a, b; Healy et al., 2008). The influence of experimental conditions and other parameters on SOA density is largely unknown. The effective density of SOA from cycloalkene ozonolysis was found to be higher in the absence of seed aerosol than in the presence of $\left(\mathrm{NH}_{4}\right)_{2} \mathrm{SO}_{4}$ seed aerosol (Bahreini et al., 2005). Alfarra et al. (2006) showed that, for non-seeded experiments with 1,3,5-trimethylbenzene and $\alpha$-pinene, SOA densities are independent of the particle size for mobility diameters in the range 140 to $300 \mathrm{~nm}$. Shilling et al. (2009) reported that the effective organic density was as high as $1.73 \pm 0.13 \mathrm{~g} \mathrm{~cm}^{-3}$ for a loading of $0.46 \mu \mathrm{g} \mathrm{m}^{-3}$, but decreased with increasing aerosol load, in line with decreasing degree of oxidation. The effects of parameters such as temperature and relative humidity on SOA density remain little characterized to date. It is recommended that future studies report the exact experimental conditions (precursor and oxidant concentration, seed concentration and composition, relative humidity, temperature) to enable reliable evaluations and comparisons to be made.

Changes in the density of organic aerosol due to chemical reaction with ozone and $\mathrm{OH}$ have been investigated in a number of recent laboratory studies. Katrib et al. (2005) studied the effect of ozone on the density of an oleic acid outer layer on polysterene latex cores and found that the layer density increased with increasing ozone exposure, consistent with the layer becoming more oxidized. Similarly George et al. (2007) showed that the density of bis(2-ethylhexyl) sebacate particles exposed to $\mathrm{OH}$ radicals increases with increasing exposure to the oxidant. It has also been shown that the density of HULIS extracted from aged atmospheric aerosol is higher than the density of HULIS present in fresh aerosols. The aged aerosol also exhibited a higher value for the $\mathrm{O} / \mathrm{C}$ ratio (Dinar et al., 2006a). It is thus likely that the density of atmospheric organic aerosol will increase during its atmospheric residence time. Measurements of organic aerosol density in the atmosphere could thus provide information on atmospheric processing of particles.

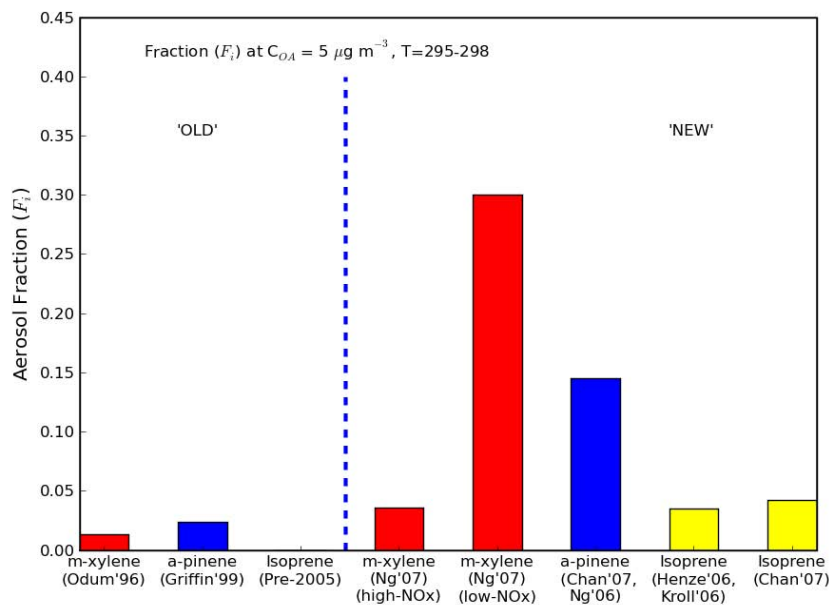

Fig. 6. Comparison of "old" and "new" SOA partitioning fractions ( $F_{i}$ values, see Eq. 2) for an assumed background aerosol concentration of $C_{O A}=5 \mu \mathrm{g} \mathrm{m}^{-3}$. Data from Odum'96, Griffin'99 have been adjusted to a temperature of $295 \mathrm{~K}$ (from an assumed $305 \mathrm{~K}$, experiments were $303-310 \mathrm{~K})$, density $1.48 \mathrm{~g} \mathrm{~cm}^{-3}$ for $\mathrm{m}$-xylene, following $\mathrm{Ng}$ et al. (2007), $1.25 \mathrm{~g} \mathrm{~cm}^{-3}$ for $\alpha$-pinene. (Read e.g., Kroll'06 as Kroll et al. (2006). Cited papers are those giving yieldcurve parameters. Consult these for original experimental data.)

Field data on effective densities of the organic aerosol component are not routinely reported. Cross et al. (2007) determined the organic aerosol effective density by combining measurements of light scattering and aerosol vacuum aerodynamic diameters. The effective density of organic aerosol was found to be $1.27 \mathrm{~g} \mathrm{~cm}^{-3}$ at Chebogue Point during the ICARTT study in summer 2004, when OA was highly oxygenated and thus likely dominated by SOA (Zhang et al., 2007a; de Gouw et al., 2008). Clearly, more detailed studies of the effective density of ambient organic aerosol and how it changes with aging and processing in the atmosphere are required.

The physical and chemical morphology of SOA has not been extensively investigated to date. Model results reported by Marcolli et al. (2004) suggest that tropospheric particles in a highly mixed state are generally not solid. Thus the presence of SOA in atmospheric particles should preferentially lead to particles that are liquid or waxy. However ambient organic-dominated particles with high SOA content in Mexico City have been shown to be non-spherical (Salcedo et al., 2007) and to bounce as much as sulfate from the AMS vaporizer (Salcedo et al., 2006) which suggests that they may be solid. SOA has been suggested to form coatings on aqueous inorganic aerosol and thus influence the reactivity of the aerosol surface (Anttila et al., 2007). On short time scales particle hygroscopicity (Chan et al., 2006) and CCN activity could also possibly be affected as described in Sect. 5.6. In addition, the viscosity of organic particles can be enhanced by oxidation and oligomerization which may also inhibit liquid-phase reactions. 


\subsection{Field studies}

Measurements of SOA in the field are subject to the balance between completeness and chemical resolution, as described in Sect. 3.3. In many cases, the detection of SOA in ambient atmospheric aerosol relies on measurement of suitable marker compounds identified from laboratory experiments. A list of marker compounds, indicative of different sources of SOA is given in Table 3. The identification of BSOA marker compounds is further elaborated in Sect. 5.1. Here, the strategies and methods employed for quantification of SOA in selected recent field studies will be surveyed.

\subsubsection{Indirect SOA quantification methods}

Until recently there were no methods that could directly quantify the SOA mass separately from the POA mass. Two indirect SOA estimation techniques based on tracers have been used for more than a decade. The elemental carbon (EC) tracer method (Turpin and Huntzicker, 1995) is based on measurements of EC and organic carbon (OC), which can now be performed with a time resolution of $1 \mathrm{~h}$. If a

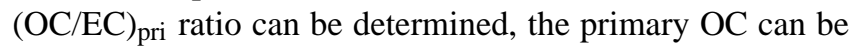
estimated from the $\mathrm{EC}$ measurement and the $\mathrm{OC}_{\mathrm{sec}}$ can be calculated as $\mathrm{OC}-\mathrm{OC}_{\text {pri. }}$. (e.g., Castro et al., 1999; Cabada et al., 2004). A variant of this method using the ratio of organic aerosol to carbon monoxide has been proposed recently, which takes advantage of the higher time resolution of carbon monoxide measurements (Takegawa et al., 2006; Docherty et al., 2008). The main weakness of these methods is the difficulty of estimating a representative value for $(\mathrm{OC} / \mathrm{EC})_{\text {pri }}$ or $(\mathrm{OA} / \mathrm{CO})_{\text {pri }}$. The common method of assuming that ambient SOA is negligible during the morning rush hours has been shown to lead to a significant overestimation of these primary ratios and underestimation of SOA in several studies (Zhang et al., 2005b; Docherty et al., 2008). The primary ratio also depends on the fraction of diesel versus gasoline traffic which can change with time of the day and day of the week (Harley et al., 2005), and the ambient organic mass concentrations according to partitioning theory (Robinson et al., 2007). Furthermore, in areas where both wood (or other biomass) burning and traffic emissions are significant, it becomes almost impossible to estimate SOA using the OC/EC method because of the very different OC/EC ratios of these particle sources (Szidat et al., 2006).

A more sophisticated approach for POA estimation uses the chemical mass balance (CMB) of molecular tracers (Schauer et al., 1996; Shrivastava et al., 2007; Ke et al., 2008). It has been pointed out that condensed-phase organic tracers may be lost by heterogeneous oxidation (Robinson et al., 2006), potentially resulting in a low bias for these methods. The CMB approach tended to identify a high fraction of SOA only during "air pollution episodes" although a recent study performed in the Los Angeles Basin (Docherty et al., 2008) produced results consistent with those of other techniques. Kleindienst et al. (2007) have recently extended the
CMB method to the direct estimation of SOA by using tracers identified in chamber studies, and report that SOA from isoprene, $\alpha$-pinene, $\beta$-caryophyllene, and toluene accounted for $40 \%$ of the measured OC concentration at a suburban site in the southeastern USA. The advantage of the method is that it can be used for very large datasets covering a whole year and longer. However, the time resolution is rather low. The main disadvantage of these tracer methods is that the ratio of the tracer to organic mass needs to be constant for various conditions (low- $\mathrm{NO}_{\mathrm{x}}$, high- $\mathrm{NO}_{\mathrm{x}}$, at low and at high OA concentrations). One also needs to estimate/extrapolate the total SOA using low tracer concentrations (typically up to a couple of percent of the total SOA concentration).

\subsection{2 ${ }^{14} \mathrm{C}$ analysis and associated EC/OC tracer method}

The analysis of ${ }^{14} \mathrm{C}$ in atmospheric aerosols using accelerator mass spectrometry (Hellborg and Skog, 2008) allows the "age" of the organic carbon to be differentiated. ${ }^{14} \mathrm{C}$ is a radioactive isotope of carbon with a half life of 5730 years. The combustion of fossil fuels, which are millions of years old, produces organic species with no ${ }^{14} \mathrm{C}$. Aerosols that have a modern carbon age contain material of biological origin, either biogenic SOA, biomass burning OA (either primary or secondary), primary biological particles, and also particles from anthropogenic sources such as meat cooking. Atomic bomb tests led to higher ${ }^{14} \mathrm{C}$ in the atmosphere which result in different ${ }^{14} \mathrm{C}$ levels in wood of different ages (Lewis et al., 2004). Usage of chemical markers such as levoglucosan, cellulose, sugars, or GC/MS analyzed VOC profiles is required to separate the different possible sources of modern carbon listed above.

The use of ${ }^{14} \mathrm{C}$ analysis coupled with a discrimination of the carbon content into $\mathrm{OC}$ and $\mathrm{EC}$ has been used to determine that the EC fraction in Central Europe is generally dominated by fossil fuel (Szidat et al., 2006). It was also found that fossil-fuel combustion accounts for only ca. $30 \%$ of OC in Zürich, Switzerland, throughout the year, even in the city center (Szidat et al., 2006). Biomass burning in wintertime and SOA in summertime seems to account for the majority of the remaining OC. Results obtained at other sites in Switzerland are generally consistent with those from Zürich. The only exception to date, was the site at Roveredo, located in an Alpine valley, where more than $80 \%$ of the organic mass was estimated to originate from wood burning (Alfarra et al., 2007; Szidat et al., 2007; Sandradewi et al., 2008).

The EU CARBOSOL Project (Carbonaceous Aerosols over Europe, Legrand and Puxbaum, 2007; Pio et al., 2007) combined weekly measurements of EC, OC, inorganic ions, elemental composition, levoglucosan, cellulose and radioactive tracers across a network of six sites in southern central Europe. Gelencsér et al. (2007) combined all of these sources of information in an effort to calculate the relative contributions of the different primary and secondary sources of aerosol. Consistent with the results of Szidat et al. (2006), 
Table 3. Selected marker compounds for identification of anthropogenic and biogenic sources of SOA. The marker compounds used to identify SOA from isoprene and $\alpha$-/ $\beta$-pinene are more extensively described in Sect. 5.1.

\begin{tabular}{|c|c|c|c|}
\hline Precursor type & Sources & $\begin{array}{l}\text { Oxidation product types } \\
\text { identified in SOA }\end{array}$ & Examples observed in ambient aerosol \\
\hline \multicolumn{4}{|l|}{ Anthropogenic } \\
\hline Aromatics & $\begin{array}{l}\text { Gasoline, } \\
\text { Solvent } \\
\text { usage }\end{array}$ & $\begin{array}{l}\text { Cyclic anhydrides } \\
\text { Aromatic nitrophenols } \\
\text { Dicarbonyls } \\
\text { Carboxylic acids }\end{array}$ & $\begin{array}{l}\text { furandione }^{\mathrm{a}} \\
\text { 5-methyl-2-nitrophenol } \\
\text { methylglyoxal }\end{array}$ \\
\hline Alkanes & $\begin{array}{l}\text { Gasoline, } \\
\text { Diesel }\end{array}$ & $\begin{array}{l}\text { Aldehydes } \\
\text { Carboxylic acids } \\
\text { Furanones }\end{array}$ & $\begin{array}{l}\text { nonanal } \\
\text { decanoic acid } \\
\text { dihydro-5-ethyl-2(3H)-furanone }\end{array}$ \\
\hline $\begin{array}{l}\text { Fatty } \\
\text { Acids }\end{array}$ & Meat cooking & $\begin{array}{l}\text { Dicarboxylic acids } \\
\text { Esters } \\
\text { Oxo-acids }\end{array}$ & $\begin{array}{l}\text { azelaic acid }^{\mathrm{b}} \\
\text { iso-propyl palmitate } \\
\text { 9-oxononanoic acid }\end{array}$ \\
\hline $\begin{array}{l}\text { Polycyclic Aromatic } \\
\text { Hydrocarbons (PAHs) }\end{array}$ & Combustion & $\begin{array}{l}\text { Oxygenated PAHs } \\
\text { Nitrated PAHs }\end{array}$ & $\begin{array}{l}\text { 9-fluoren-9-one } \\
\text { nitro-chrysene }\end{array}$ \\
\hline Plasticisers & Plastics & Phthalates & dibutyl-phthalate \\
\hline \multicolumn{4}{|l|}{ Biogenic } \\
\hline Isoprene & Vegetation & $\begin{array}{l}\text { Methyl tetrols } \\
\text { Carboxylic acids } \\
\text { Organosulfates }\end{array}$ & $\begin{array}{l}\text { 2-methylthreitol } \\
\text { 2-hydroxymethylsuccinic acid } \\
\text { 2,3,4-trihydroxy-2-methylbutyl hydrogen sulfate } \\
\text { 2-methyltetrol sulfate esters }\end{array}$ \\
\hline Monoterpenes & Vegetation & $\begin{array}{l}\text { Aldehydes } \\
\text { Carboxylic acids } \\
\text { Organosulfates } \\
\text { Oligomer }\end{array}$ & $\begin{array}{l}\text { pinonaldehyde }^{\mathrm{f}} \\
\text { pinonic acid } \\
\text { 2,3-dihydroxypinane mixed nitrate/sulfate derivatives } \\
\beta \text {-pinene dimerg }\end{array}$ \\
\hline Sesquiterpenes & Vegetation & Carboxylic acids & $\beta$-caryophyllinic acid ${ }^{\mathrm{h}}$ \\
\hline
\end{tabular}

${ }^{\mathrm{a}}$ Hamilton et al. (2004), ${ }^{\mathrm{b}}$ Pol et al. (2006), ${ }^{\mathrm{c}}$ Goldstein et al. (2008), ${ }^{\mathrm{d}}$ Claeys et al. (2004a), ${ }^{\mathrm{e}}$ Surratt et al. (2008), ${ }^{\mathrm{f}}$ Williams et al. (2007), $\mathrm{g}$ Wozniak et al. (2008), ${ }^{\mathrm{h}}$ Lewandowski et al. (2007).

it was found that wintertime residential wood burning was a significant contributor to measured OC levels at all CARBOSOL sites, whereas in summertime another modern-C source, likely BSOA, is the dominant contributor.

In Northern Europe studies have been much more limited, despite early attention from scientists. More than 20 years ago, the pioneering study of Currie et al. (1986) found that residential wood combustion accounted for on average $65 \%$ of carbon in fine aerosol at the town of Elverum $120 \mathrm{~km}$ north of Oslo during wintertime. Several recent studies have confirmed the dominance of wood combustion in wintertime for many areas (Yttri et al., 2005, 2009; Glasius et al., 2006; Hedberg et al., 2006; Hellén et al., 2008a; Saarikoski et al., 2008), although recent results from Gothenburg in Southern Sweden showed a lower wood-burning signal (Szidat et al., 2009). Very few summertime data are available, but Szidat et al. (2009) also found that Gothenburg showed a similar OC composition to that found for Zürich.

In the United States, a recent study found that modern carbon accounted for about $50 \%$ of carbon at 2 urban sites,
$70-97 \%$ of carbon at 4 near-urban sites, and $80-100 \%$ of carbon at six remote sites, as annual averages (Schichtel et al., 2008). These findings are consistent with the earlier studies by Lewis et al. (2004) and Hildemann et al. (1994), and with the high fractions of biogenic SOC deduced from molecular marker methods (Kleindienst et al., 2007; Lewandowski et al., 2008).

In comparison to the marker method, ${ }^{14} \mathrm{C}$ is measured for the total organic carbon (or total carbon/water soluble organic carbon) and thus provides information directly about a larger fraction of the organic mass without the need for extrapolation from small tracer concentrations. However, the SOA fraction cannot be analyzed alone and one relies on OC/EC ratios of traffic and/or biomass burning sources. In the case of WSOC, the contributions of biomass burning need to be taken into account. As for the tracer method, the time resolution offered by ${ }^{14} \mathrm{C}$ analysis is low and the high costs associated with long measurement periods may be prohibitive. 


\subsubsection{Highly time-resolved studies}

A number of recent studies have used the PILS-WSOC (Sullivan et al., 2004) and AMS (Canagaratna et al., 2007) techniques to quantify $\mathrm{OM}$ with a time resolution as low as minutes and seconds, respectively. These techniques have some ability to separate SOA from POA based on water-solubility or mass spectral patterns, and the identification of SOA by both methods has been shown to be very similar in Tokyo (Kondo et al., 2007), although recent results suggest that in some environments the non-WSOC fraction of SOA can be very significant (Favez et al., 2008). These methods allow correlation with time-series of other atmospheric tracers also collected at high resolution, resulting in lower uncertainty in the identification of the OA components and the quantification of POA emission or SOA formation ratios (e.g., $\mathrm{POA} / \mathrm{CO}, \mathrm{SOA} /\left(\mathrm{NO}_{2}+\mathrm{O}_{3}\right)$.

De Gouw et al. (2005) used AMS data from the NEAQS 2002 ship-based study off the coast of the Eastern USA to show that $\mathrm{OA} / \mathrm{C}_{2} \mathrm{H}_{2}$ had low values in fresh emissions and grew tenfold due to photochemical processing within a timescale of one day, clearly showing that SOA formation in these polluted airmasses quickly overwhelmed POA emissions. The formed SOA correlated strongly with tracers of anthropogenic pollution such as isopropyl nitrate, and did not correlate with the available biogenic tracers, despite the expectation of a large contribution of BSOA to OA levels in this region (Chen et al., 2006). These results have been largely confirmed by the analysis of the more extensive dataset from the ICARTT study (de Gouw et al., 2008). Volkamer et al. (2006) extended the rapid formation of SOA to very short timescales in the urban environment and showed that a state-of-the-art SOA model underpredicted the observed SOA by almost an order of magnitude after a few hours of photochemistry. Weber et al. (2007) found a large biogenic fraction of organic carbon and especially of its water-soluble fraction using ${ }^{14} \mathrm{C}$ analysis, in line with other studies, which appears to be in contradiction to the high correlation with anthropogenic tracers observed in the same study. One possible explanation for this discrepancy is that SOA formation from biogenic VOC was greatly enhanced by anthropogenic emissions. To settle this question, methods to distinguish anthropogenic and biogenic SOA that allow for a higher time resolution than ${ }^{14} \mathrm{C}$ analysis would be highly beneficial.

Zhang et al. (2005a, b) used AMS data from Pittsburgh to develop the first quantification of OA components using the full AMS organic spectrum, and showed that two prominent components accounted for most of the mass in this study. Oxygenated organic aerosol (OOA), a component with a mass spectrum typical of highly oxygenated species, was identified as a surrogate for SOA and correlated strongly with sulfate, a secondary inorganic tracer. OOA was observed to be formed in a relatively constant proportion to ozone during a case study dominated by photochemistry, similar to results from Mexico City (Volkamer et al., 2006; Herndon et al., 2008). Hydrocarbon-like organic aerosol (HOA) had a spectrum typical of reduced species (hydrocarbons or species with a hydrocarbon backbone) and correlated strongly with combustion tracers $\left(\mathrm{CO}, \mathrm{NO}_{\mathrm{x}}, \mathrm{EC}\right)$, and was considered a surrogate for POA. OOA was larger than HOA at these urban locations, consistent with a dominance of highly polar species followed by non-polar species observed in Pittsburgh using FTIR spectroscopy (Polidori et al., 2008). Zhang et al. (2005b) illustrate the main limitation of the EC tracer method, namely that the typical method of determining $(\mathrm{OC} / \mathrm{EC})_{\text {pri }}$ from ambient data during periods of suspected "dominant" POA influence can lead to large positive biases due to the prevalence of a significant SOA background. Zhang et al. (2007b) applied an improved multicomponent spectral analysis method (MCA) to 37 AMS datasets from the polluted regions of the Northern Hemisphere, and confirmed the ubiquity and importance of OOA even in urban areas and its overwhelming dominance in rural and remote sites. Lanz et al. (2007) applied the positive matrix factorization (PMF) method to AMS spectra and largely confirmed the results of Zhang et al. (2005a, b), for a dataset in Zürich, while providing more detail on the POA and SOA components. In this study, it was shown that OOA contained two different components, a low volatility fraction (OOA1) highly correlated with sulfate and a fraction of higher volatility (OOA2) correlated with nitrate with enhanced concentrations during the night (due to lower temperatures than daytime). Similar OOA1 and OOA2 components correlating with sulfate and nitrate, respectively, were also found in Pittsburgh (Ulbrich et al., 2009). DeCarlo et al. (2008) reported a rapid gain of oxygen by OOA in the outflow of Mexico City, with the atomic $\mathrm{O} / \mathrm{C}$ of OA reaching $\sim 0.8$ after 1 day of photochemistry. Also in wintertime, Lanz et al. (2008) found that OOA (probably mostly SOA) contributed to more than 50\% of OA present in Zürich. In this case, no split into OOA1 and OOA2 occurred, and the highest correlation was found with the sum of nitrate and sulfate. OOA2 did not show a temporally varying aerosol partitioning under these winter conditons. The combination of these AMS results with ${ }^{14} \mathrm{C}$ analyses (Szidat et al., 2006) reveals that both in summer and winter, SOA is mostly non-fossil in origin. In summer, this could be due to the oxidation of biogenic emissions (terpenes and isoprene) but in winter it is most likely that other sources, such as the oxidation of gaseous emissions from wood burning, make an important contribution (Lanz et al., 2008). Indeed, one might expect that the semivolatiles present in wood burning emissions could form SOA with a similar efficiency as those present in diesel emissions (Robinson et al., 2007; Grieshop et al., 2009). The work of Weimer et al. (2008) adds some complexity to these issues by showing that emissions from one type of wood burning stove can be similar to OOA. Although these results do not appear to be representative of wildfire emissions, additional evidence 
should be used to attribute OOA to SOA when the influence of wood smoke is significant.

The major advantages of using AMS data are the high time and size resolution and that analysis of the whole organic mass is performed. The latter reduces the possible errors that are inferred by the extrapolation from tracer concentrations. The combination of AMS data with the ${ }^{14} \mathrm{C}$ analyses even allows the distinction of SOA from fossil and non-fossil precursors. However, the statistical analysis of the AMS data assumes a constant mass spectrum for the different sources over a given time. Most analyses cover only a couple of weeks, the duration of a field campaign, because the deployment of such an instrument over a long time period, e.g., one year, is rather labor intensive and expensive. Finally as mentioned, the separation and attribution to sources need to be performed carefully. So far, SOA from different sources could not be distinguished. As already mentioned, OOA might not always represent SOA because of possible contributions of wood burning and also by heterogeneous oxidation of primary particles.

In summary, the study of SOA in the ambient atmosphere is complicated because it is usually not separated from other components. New methods for the quantification of the various organic components are still needed in this field. At present, the most suitable approach is to combine the available methods during field campaigns to allow for a more complete analysis than with just one method at the time.

\subsection{Modeling studies}

There have been a number of important developments in the tools and parameterizations used for atmospheric modeling since the review of Kanakidou et al. (2005). The modeling changes include (i) large revisions in understanding of SOA yields brought about by newer experimental procedures, (ii) a suggested new framework (the VBS approach discussed above), better suited to tackling the complexities of SOA formation, reaction, and volatility, and (iii) advances in the understanding of thermodynamics of mixed inorganic-organic systems. In addition, there has been a significant increase in the quantity and quality of ambient measurements available with which to evaluate both models and emission inventories.

\subsubsection{Model approaches}

In principle, models of SOA formation need to represent oxidation reactions of gas-phase organic species, which lead to compounds of lower volatility through addition of functional groups, but can also yield products of higher volatility by cleavage of carbon-carbon bonds. In addition, models need to include reactions of the semivolatile species in the particle phase, which tend to give products of even lower volatility. To date, two approaches to representing SOA formation have been largely used in atmospheric models:
1. Empirical models constrained by laboratory data. The two-product gas-aerosol partitioning model, with parameters derived from laboratory data and with extrapolation to different temperatures using an assumed (or measured) effective value of the latent heat of vaporization of the SOA.

2. Explicit and semi-explicit models in which gas-phase mechanisms predict formation of semivolatile products, with gas-particle partitioning computed from explicit calculation of $K_{p}^{i}$ for each semivolatile compound depending on the composition of the organic aerosol absorbing mass.

The simpler Odum-type models, with laboratory-derived values of $\alpha_{i}$ and $K_{p}^{i}$ have been incorporated into atmospheric chemical transport and general circulation models for a number of years (e.g., Andersson-Sköld and Simpson, 2001; Schell et al., 2001; Chung and Seinfeld, 2002; Koo et al., 2003; Pun et al., 2003; Tsigaridis and Kanakidou, 2003; Heald et al., 2005; Henze and Seinfeld, 2006; Lane et al., 2007; Simpson et al., 2007; Henze et al., 2008). These models are simple enough to be implemented for global scale modeling of SOA. However, this simple approach cannot account for the complexity and dynamics of SOA systems, so alternative approaches are likely in next-generation models.

The most complex of the explicit models include thousands of reactions, such as the Master Chemical Mechanism (Jenkin et al., 2004; Johnson et al., 2004, 2005, 2006), or NCAR Self-Generating Mechanism (Aumont et al., 2005; Camredon et al., 2007). These schemes can account for multiple generations of oxidation and the progression of the volatility distribution as the generations unfold. Although no chemical transport model currently treats particle-phase reactions explicitly, these can be included as soon as a reasonable mechanism becomes available, and indeed some boxmodel simulations (for smog chambers) have begun exploring the importance of such reactions (Li et al., 2007; Capouet et al., 2008). More compact explicit model approaches (or surrogate schemes) have been designed for inclusion in 3-D atmospheric models, including CACM and derivatives (Griffin et al., 2002a, b, 2003, 2005; Pun et al., 2002; Vutukuru et al., 2006; Chen et al., 2006, 2007), EMEP/Kam2(X) (Andersson-Sköld and Simpson, 2001; Simpson et al., 2007) and ORILAM-SOA (Tulet et al., 2006).

Challenges associated with implementing explicit and semi-explicit models include: (a) Establishing the basic science of the detailed gas-phase oxidation chemistry and resulting semivolatile products; (b) Determining accurate values of saturation concentrations (vapor pressures) for the semivolatile compounds of interest; (c) Calculating $K_{p}^{i}$ values that account for the molecular properties (activity coefficients, etc.) of the absorbing organic/water mixture; and (d) Determining particle-phase reactions of importance. Each of the current explicit models deals with these challenges to 
a different extent. Since it is unlikely that all of the challenges listed above will be overcome to such an extent that explicit models can be used without experimental verification (e.g., Clegg et al., 2008a, b), laboratory chamber data must continue to serve as the fundamental basis that constrains all SOA models, followed by evaluation using field data.

Most SOA modeling has focused on the partitioning of organic products onto pre-existing nonacidic particles or by nucleation, leading to new particles. Until now, only a few SOA models have considered heterogeneous or multiphase reactions (Johnson et al., 2005; Ervens et al., 2008), and the existing SOA models are not feasible for use with heterogeneous reactions involving neutral to highly acidic aerosol. Jang et al. (2006a) recently developed a predictive SOA model that unites particle-phase heterogeneous reactions and the gasphase kinetics of precursor VOCs with the thermodynamic processes of organic and inorganic species. The predictive SOA model takes into account both partitioning and heterogeneous reactions. The SOA mass resulting from heterogeneous reactions $\left(O M_{H}\right)$ is estimated using the concentration of organic compounds partitioned into the inorganic layer and heterogeneous rate constants expressed by a semiempirical model (Jang et al., 2005), which considers particle acidity and molecular structures. This $O M_{H}$ model is incorporated into the modified partitioning SOA model originally developed by Schell et al. (2001), and has been used to interpret smog chamber experiments for $\alpha$-pinene. The importance of acidity for both smog chamber and atmospheric modeling is still very unclear however (Kroll and Seinfeld, 2008) and it is not apparent in field data (Zhang et al., 2007b; Peltier et al., 2007a), and no regional or global models have attempted to include such parameterizations.

The VBS approach offers an attractive framework for SOA models that lie intermediate between the two-parameter Odum model and fully explicit models. In the VBS approach, oxidation of the parent hydrocarbon leads to an array of semivolatile products, which evolve through several generations of reactions (Donahue et al., 2006). The gasparticle distribution of the semivolatile products evolves as the amount of aerosol in each volatility bin increases; the SOA yield at any time is then the summation of condensedphase concentrations in each of the volatility bins. Rates of oxidation can be accounted for reasonably well based on established rate constants, and product volatilities, as reflected by $C^{*}$ values, can be determined by fitting the model to laboratory data (Lane et al., 2008; Shrivastava et al., 2008). The importance of volatility with respect to so-called primary emissions was demonstrated with the VBS approach by Robinson et al. (2007), who highlighted the link between anthropogenic emissions of semi- and intermediate volatility precursors and the oxygenated organic aerosol (OOA) observed by AMS instruments. The challenges facing the VBS framework are to obtain accurate coupling parameters and to determine the appropriate number of bins (for example with different oxygen to carbon ratios, polarities, or water solubi- lities) for lumped compounds in large-scale models and how to account for changing chemical regimes when specifying yields of different product distributions.

\subsubsection{Model predictions of SOA formation vs. ambient data}

Long-term measurements of $\mathrm{OC}$ in the atmosphere are now available from a number of sites in the USA and Europe (e.g., IMPROVE network in the USA, the EMEP EC/OC campaign and EUSAAR in Europe). Most comparisons between modeled and observed levels of $\mathrm{OC}$ at such sites suffer from the fact that the origin of the measured OC is unknown - typically with no information on the relative contributions of primary or secondary organics, or of anthropogenic or biogenic sources. In many cases discrepancies may be due to problems with emission inventories, especially in wintertime where wood-burning contributions can dominate ambient OC levels at the surface in populated areas. Some recent studies though have suggested that there are indeed problems in predicting SOA in the atmosphere with current models (de Gouw et al., 2005; Heald et al., 2005; Volkamer et al., 2006; Kleinman et al., 2008). Even the most complex chemical schemes display problems: in the study of SOA formation in the UK (Johnson et al., 2006) all partitioning coefficients in the modified Master Chemical Mechanism (MCMv3.1) had to be increased by a species-independent factor of 500 in order to capture observed OA levels, likely reflecting the need for further volatility-reducing processes in the mechanism, or missing SOA precursors. The recent study of Simpson et al. (2007) also showed a significant (factor 35) underprediction of SOA levels for sites in central-southern Europe (as derived using ${ }^{14} \mathrm{C}$, levoglucosan, cellulose and EC/OC ratios by Gelencsér et al., 2007). However, the same model showed a very good agreement with total carbon levels at northern European sites, illustrating that the extent of model-measurement agreement may also depend on where and when a model is applied, and not just upon its formulation. Model evaluations using total carbon may also hide SOA underestimation if the POA is overestimated (Zhang et al., 2007a).

The recent review from Kroll and Seinfeld (2008) discusses potential reasons for model-measurement discrepancies in detail. Potential factors include actual differences in chemistry between chamber experiments and the atmosphere, incomplete treatment of SOA chemistry in models, and omission of important (unrecognized) precursors in models. Even for those compounds that are known (or suspected) to be important in SOA formation, critical information is missing. Indeed, for many, if not most, of the identified SOA compounds, measured vapor pressures are unavailable, and one must employ a semi-empirical model to estimate vapor pressures. Several such methodologies exist (e.g., Asher et al., 2002; Asher and Pankow, 2006; Camredon and Aumont, 2006), but uncertainties for specific compounds 
can cover several orders of magnitude (Clegg et al., 2008a). The importance of these uncertainties was demonstrated by the Simpson et al. (2007) study which made use of two sets of vapor pressure estimates for BSOA formation, both sets derived from a combination of theory and chamber experiments. These two simulations gave dramatic differences in modeled BSOA and OC estimates. Difficulties with other thermodynamic quantities are discussed further in Sect. 5.7. Among the potentially important precursors, much attention has been devoted recently to "intermediate volatility" and semivolatile organics, such as those in diesel exhaust and biomass burning (Robinson et al., 2007; Weitkamp et al., 2007; Grieshop et al., 2009). Indeed, Chan et al. (2009) recently demonstrated that polycyclic aromatic hydrocarbons found in diesel exhaust can produce SOA upon photooxidation under low- and high- $\mathrm{NO}_{\mathrm{x}}$ conditions. Aqueous pathways are also possible (Warneck, 2003; Carlton et al., 2006; Ervens et al., 2008), but very uncertain. There is also strong evidence for the presence of an ambient pool of hydrocarbons that is largely unaccounted for in models (Lewis et al., 2000; Di Carlo et al., 2004; Holzinger et al., 2005).

\section{Current and emerging issues in SOA research}

\subsection{Molecular characterization of biogenic SOA constituents}

Molecular characterization of organic aerosol constituents is important because it allows one to gain insights into aerosol sources and the underlying mechanisms of SOA formation and transformation (or aging). Common terms to denote analytically accessible organic compounds that provide this valuable information in a complex matrix such as ambient aerosol are "tracer" or "marker". During the past few years considerable progress has been made in the molecular characterization of individual SOA constituents from the photooxidation of isoprene, $\alpha-/ \beta$-pinene and other selected BVOCs that can serve as tracers for organic aerosol characterization.

\subsubsection{SOA tracers for the photooxidation of isoprene}

The chemical structures and names of isoprene SOA constituents that have recently been discovered are listed in Table 4.

\section{2-methyltetrols, 2-methylglyceric acid, $\mathrm{C}_{5}$-alkene triols, and related oligomeric products}

In the case of isoprene, identified SOA tracers are 2methyltetrols (i.e., the diastereoisomers, 2-methylthreitol and 2-methylerythritol), 2-methylglyceric acid and three isomeric $\mathrm{C}_{5}$-alkene triols identified in field samples from the Amazon basin, Brazil, and from a mixed deciduous/coniferous forest site at K-puszta, Hungary. GC/MS with prior trimethylsilylation was used for their analysis, chemi- cal structures were proposed based on EI and methane CI MS data, and confirmed through synthesis of authentic reference compounds (Claeys et al., 2004a, b; Wang et al., 2004).

Their discovery by Claeys et al. (2004a, b) came as a great surprise to the atmospheric science community because it was previously thought that the photooxidation of isoprene did not result in SOA. Laboratory experiments with irradiated isoprene/ $/ \mathrm{NO}_{\mathrm{x}} /$ air mixtures in the presence and absence of $\mathrm{SO}_{2}$ (which is oxidized to sulfuric acid) confirmed that both the 2-methyltetrols and 2-methylglyceric acid are formed by oxidation of isoprene (Edney et al., 2005). In addition, this study, as well as a recent study by Surratt et al. (2007b), revealed that sulfuric acid is crucial in their formation and results in an enhanced SOA yield and in increased 2-methyltetrol concentrations. Additional insights into the mechanism leading to the 2-methyltetrols were obtained in a laboratory study by Böge et al. (2006). They concluded that the $\mathrm{OH}$ radical $/ \mathrm{O}_{2}$ reaction route of isoprene involving permutation reactions of peroxy radicals can be important only in low- $\mathrm{NO}_{\mathrm{x}}$ environments. In addition, they proposed a second mechanism leading to the formation of the 2-methyltetrols that holds for high- $\mathrm{NO}_{\mathrm{x}}$ conditions.

Surratt et al. (2006) then investigated the chemical composition of SOA from the photooxidation of isoprene over a full range of $\mathrm{NO}_{\mathrm{x}}$ levels and seed aerosol conditions through a series of controlled laboratory chamber experiments. SOA composition was studied using a wide range of complementary experimental techniques, including mass spectrometric methods and an iodometric-spectrometric method. Formation of higher-MW products was observed to be an important SOA formation pathway in all cases; however, the nature of these products was found to be strongly dependent on the $\mathrm{NO}_{\mathrm{x}}$ level. Under low- $\mathrm{NO}_{\mathrm{x}}$ conditions, organic peroxides contributed significantly to the SOA mass and decreased with time, indicating photochemical aging. Major products identified were 2-methyltetrols and $\mathrm{C}_{5}$-alkene triols, indicating that these compounds can serve as suitable tracers for the photooxidation of isoprene under low- $\mathrm{NO}_{\mathrm{x}}$ conditions. Minor products that could be tentatively identified included 2-methyltetrol oxyformate derivatives, $\mathrm{C}_{5}$-trihydroxy monocarboxylic acids and hemiacetal dimers formed between 2methyltetrols and a $\mathrm{C}_{5}$-dihydroxycarbonyl. Interestingly, the latter higher-MW products were also found in fine $\left(\mathrm{PM}_{2.5}\right)$ aerosol collected from the Amazonian rainforest, demonstrating the atmospheric relevance of the low- $\mathrm{NO}_{\mathrm{x}}$ chamber experiments. The major products identified in the high- $\mathrm{NO}_{\mathrm{x}}$ SOA were acidic oligoesters with 2-methylglyceric acid as a key monomeric unit and residues formed by esterification of hydroxyl groups with acetic and/or formic acid (Surratt et al., 2006; Szmigielski et al., 2007a). Jaoui et al. (2008) recently observed the diester formed from the esterification of two 2-methylglyceric acid residues in ambient aerosol collected from the Southeastern USA, thus providing a tracer for SOA formation from isoprene photooxidation under high$\mathrm{NO}_{\mathrm{x}}$ conditions. 
Table 4. Isoprene SOA constituents discovered since 2004: chemical structures, names and derivatives; laboratory studies in which isoprene SOA tracers were investigated, and specific conditions; and field studies in which the tracers have been identified or detected, and, in some cases, also quantified.

\begin{tabular}{|c|c|c|c|c|c|}
\hline \multirow{2}{*}{$\begin{array}{l}\text { Chemical structure } \\
\text { trivial name (IUPAC name) } \\
\text { derivatives }\end{array}$} & \multicolumn{4}{|c|}{ Laboratory studies: reaction conditions, reference } & \multirow{2}{*}{$\begin{array}{l}\text { Field studies: site; type of aerosol }\left[\mathrm{PM}_{1}, \mathbf{P M}_{2.5}, \mathbf{P M}_{10} \text {, size- }\right. \\
\text { fractionated aerosol (SFA), or total aerosol (TA)]; reference }\end{array}$} \\
\hline & VOC conc. & oxidant $^{b}$ & $\begin{array}{l}\text { seed aerosol / } \\
\text { atomizing solution }\end{array}$ & reference & \\
\hline \multirow{3}{*}{$\begin{array}{l}\text { 2-methyltetrol } \\
\text { (2-methyl-1,2,3,4-tetrahydroxy- } \\
\text { butane) } \\
+2 \mathrm{~S}, 3 \mathrm{~S} \text { stereoisomer }\end{array}$} & $\begin{array}{l}-1680 / 1610 \mathrm{ppb} \\
\text { isoprene }\end{array}$ & $\begin{array}{l}-647 / 648 \mathrm{ppb} \mathrm{NO} \\
-629 / 627 \mathrm{ppb} \mathrm{NO}_{\mathrm{x}} \\
-268 /<1 \mathrm{ppb} \mathrm{\textrm {SO } _ { 2 }} \\
\end{array}$ & $-\left(\mathrm{NH}_{4}\right)_{2} \mathrm{SO}_{4}$ & $\begin{array}{l}\text { - Edney et al. } \\
(2005)\end{array}$ & \multirow{4}{*}{ 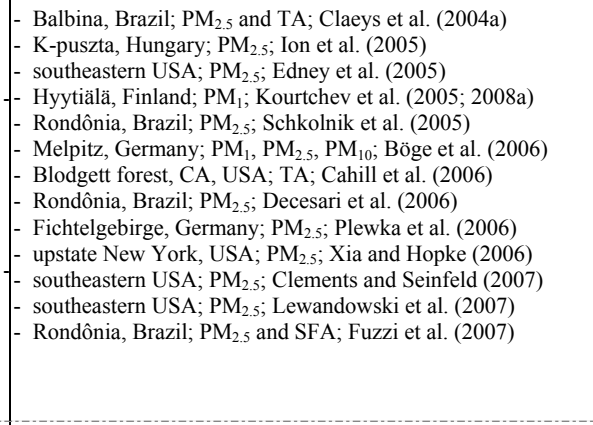 } \\
\hline & $\begin{array}{l}-5 \text { ppm isoprene } \\
-1.5 \text { ppm 2- } \\
\text { methyl-2- } \\
\text { vinyloxirane or } \\
2 \text {-methyl-3- } \\
\text { butene-1,2-diol }\end{array}$ & $\begin{array}{l}1.5 \mathrm{ppm}_{2} \mathrm{O}_{2} / / \\
\text { without } \\
\text { photooxidation }\end{array}$ & $\begin{array}{l}-30 / 50 \mathrm{mM} \\
\left(\mathrm{NH}_{4}\right)_{2} \mathrm{SO}_{4} / \mathrm{H}_{2} \mathrm{SO}_{4}\end{array}$ & $\begin{array}{l}\text { Böge et al. } \\
\text { (2006) }\end{array}$ & \\
\hline & $\begin{array}{l}-100 \text { or } 500 \mathrm{ppb} \\
\text { isoprene }\end{array}$ & $\begin{array}{l}3 \text { ppm } \mathrm{H}_{2} \mathrm{O}_{2} / / \\
\text { low- } \mathrm{NO}_{\mathrm{x}}\end{array}$ & $\begin{array}{l}-15 \mathrm{mM}\left(\mathrm{NH}_{4}\right)_{2} \mathrm{SO}_{4} \\
-15 / 15 \mathrm{mM} \\
\left(\mathrm{NH}_{4}\right)_{2} \mathrm{SO}_{4} / \mathrm{H}_{2} \mathrm{SO}_{4}\end{array}$ & $\begin{array}{l}\text { Surratt et al. } \\
(2006)\end{array}$ & \\
\hline $\begin{array}{l}\text { 2-methylerythritol }(2 \mathrm{~S}, 3 \mathrm{R}) \\
+2 \mathrm{R}, 3 \mathrm{~S} \text { stereoisomer }\end{array}$ & & & & & \\
\hline - oxyformate derivatives & $\begin{array}{l}- \text { see 2- } \\
\text { methyltetrol }\end{array}$ & & & $\begin{array}{l}\text { Surratt et al. } \\
\text { (2006) }\end{array}$ & \\
\hline $\begin{array}{l}\text { - hemiacetal dimers with a } \mathrm{C}_{5-} \\
\text { dihydroxycarbonyl }\end{array}$ & $\begin{array}{l}\text { see } 2- \\
\text { methyltetrol }\end{array}$ & & & - Surratt et al. & - Rondônia, Brazil; $\mathrm{PM}_{2.5}$; Surratt et al. (2006) \\
\hline \multirow[t]{5}{*}{$\begin{array}{l}\text { - sulfate and mixed nitrate/sulfate } \\
\text { derivatives }\end{array}$} & - $500 \mathrm{ppb}$ isoprene & $\begin{array}{l}-3 \mathrm{ppm} \mathrm{H}_{2} \mathrm{O}_{2} / / \\
\text { low- } \mathrm{NO}_{\mathrm{x}}\end{array}$ & $\begin{array}{l}-15 \mathrm{mM}\left(\mathrm{NH}_{4}\right)_{2} \mathrm{SO}_{4} \\
-15 / 15 \mathrm{mM} \\
\left(\mathrm{NH}_{4}\right)_{2} \mathrm{SO}_{4} / \mathrm{H}_{2} \mathrm{SO}_{4}\end{array}$ & \multirow{5}{*}{$\begin{array}{l}\text { - Surratt et al. } \\
(2007 \mathrm{a}) \\
\end{array}$} & \multirow[t]{5}{*}{$\begin{array}{l}\text { - southeastern USA; } \mathrm{PM}_{2.5} ; \text { Surratt et al. (2007a; 2008) } \\
\text { - K-puszta, Hungary; } \mathrm{PM}_{2.5} ; \text { Gómez-González et al. (2008) }\end{array}$} \\
\hline & $-500 \mathrm{ppb}$ isoprene & $\begin{array}{l}-3 \mathrm{ppm} \mathrm{H}_{2} \mathrm{O}_{2} / \\
891-963 \mathrm{ppb} \mathrm{NO}_{\mathrm{x}} \\
/ / \text { high-NO }\end{array}$ & $\begin{array}{l}-15 \mathrm{mM}\left(\mathrm{NH}_{4}\right)_{2} \mathrm{SO}_{4} \\
-15 / 15 \mathrm{mM} \\
\left(\mathrm{NH}_{4}\right)_{2} \mathrm{SO}_{4} / \mathrm{H}_{2} \mathrm{SO}_{4}\end{array}$ & & \\
\hline & $-500 \mathrm{ppb}$ isoprene & $\begin{array}{l}\mathrm{HONO} / 366-382 \\
\mathrm{ppb}_{\mathrm{NO}} / / \text { high- } \\
\mathrm{NO}_{\mathrm{x}}\end{array}$ & $-15 \mathrm{mM}\left(\mathrm{NH}_{4}\right)_{2} \mathrm{SO}_{4}$ & & \\
\hline & $\begin{array}{l}2500 \mathrm{ppb} \\
\text { isoprene }\end{array}$ & $-200 \mathrm{ppb} \mathrm{NO}_{\mathrm{x}}$ & {$\left[\begin{array}{l}-15 / 15 \mathrm{mM} \\
\left(\mathrm{NH}_{4}\right)_{2} \mathrm{SO}_{4} / \mathrm{H}_{2} \mathrm{SO}_{4} \\
-0.92 \mathrm{mM} \mathrm{H}_{2} \mathrm{SO}_{4}\end{array}\right]$} & & \\
\hline & $\begin{array}{l}1598 \mathrm{ppb} \\
\text { isoprene }\end{array}$ & $-475 \mathrm{ppb} \mathrm{NO}_{\mathrm{x}}$ & $\begin{array}{l}-60 \mathrm{ppb} \mathrm{SO} \\
-\quad 200 \mathrm{ppb} \mathrm{SO} \\
\end{array}$ & & \\
\hline $\begin{array}{l}\text { - sulfate derivatives of hemiacetal } \\
\text { dimers with a } \\
\mathrm{C}_{5} \text {-dihydroxycarbonyl }\end{array}$ & $\begin{array}{l}-1598 \mathrm{ppb} \\
\text { isoprene }\end{array}$ & $-475 \mathrm{ppb} \mathrm{NO}$ & 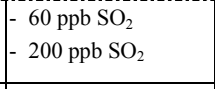 & Surratt et al. & - southeastern USA; $\mathrm{PM}_{2.5}$; Surratt et al. (2008) \\
\hline \multirow{4}{*}{$\begin{array}{l}\text { - 2-methylglyceric acid } \\
\text { (2,3-dihydroxy-2-methylpropanoic } \\
\text { acid) }\end{array}$} & $\begin{array}{l}-2 \text {-methyl-2- } \\
\text { vinyloxirane }\end{array}$ & $-\mathrm{H}_{2} \mathrm{O}_{2} / \mathrm{H}_{2} \mathrm{O}$ & - none & $\begin{array}{l}\text { - Claeys et al. } \\
(2004 b)\end{array}$ & \multirow{4}{*}{$\begin{array}{l}\text { - K-puszta, Hungary; } \mathrm{PM}_{2.5} ; \text { Claeys et al. (2004b) } \\
\text { - K-puszta, Hungary; } \mathrm{PM}_{2.5} ; \text { Ion et al. (2005) } \\
\text { - } \text { southeastern USA; } \mathrm{PM}_{2.5} ; \text { Edney et al. (2005) } \\
\text { - southeastern USA; } \mathrm{PM}_{2.5} ; \text { Yu et al. (2005) } \\
\text { - } \text { southeastern USA; } \mathrm{PM}_{2.5} ; \text { Lewandowski et al. (2007) } \\
\text { - Jülich, Germany; } \mathrm{PM}_{2.5} ; \text { Kourtchev et al. (2008b) }\end{array}$} \\
\hline & - see 2-methyltetrol & & & - Edney et al. & \\
\hline & $\begin{array}{l}500 \mathrm{ppb} \text { isoprene } \\
\text { or methacrolein }\end{array}$ & $\begin{array}{l}-3 \text { ppm } \mathrm{H}_{2} \mathrm{O}_{2} / \\
850-963 \mathrm{ppb} \mathrm{NO}_{\mathrm{x}} \\
/ / \text { high- } \mathrm{NO}_{\mathrm{x}}\end{array}$ & $\begin{array}{l}-15 \mathrm{mM}\left(\mathrm{NH}_{4}\right)_{2} \mathrm{SO}_{4} \\
-15 / 15 \mathrm{mM} \\
\left(\mathrm{NH}_{4}\right)_{2} \mathrm{SO}_{4} / \mathrm{H}_{2} \mathrm{SO}_{4}\end{array}$ & $\begin{array}{l}\text { - Surratt et al. } \\
(2006) \\
- \text { Szmigielski et al. } \\
(2007 a)\end{array}$ & \\
\hline & $-500 \mathrm{ppb}$ isoprene & $\begin{array}{l}\mathrm{HONO} / 366-382 \\
\mathrm{ppb} \mathrm{NO}_{\mathrm{x}} / / \text { high- } \\
\mathrm{NO}_{\mathrm{x}}\end{array}$ & $-15 \mathrm{mM}\left(\mathrm{NH}_{4}\right)_{2} \mathrm{SO}_{4}$ & & \\
\hline $\begin{array}{l}- \text { oligoesters }(n=2-4) \text { and } \\
\text { corresponding nitrate, acetate and } \\
\text { formate derivatives and mixed } \\
\text { derivatives thereof }\end{array}$ & $\begin{array}{l}\text { methylglyceric } \\
\text { acid }\end{array}$ & & & $\begin{array}{l}\text { - Surratt et al. } \\
(2006) \\
- \text { Szmigielski et al. } \\
(2007 \text { a })\end{array}$ & - southeastern USA; $\mathrm{PM}_{2.5} ;$ Jaoui et al. (2008) \\
\hline - sulfate derivative & 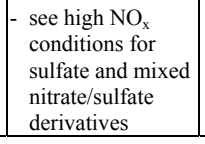 & & & $\begin{array}{l}\text { - Surratt et al. } \\
(2007 \mathrm{a})\end{array}$ & $\begin{array}{l}\text { - southeastern USA; } \mathrm{PM}_{2.5} ; \text { Surratt et al. (2007a; 2008) } \\
\text { - K-puszta, Hungary; } \mathrm{PM}_{2.5} ; \text { Gómez-González et al. (2008) }\end{array}$ \\
\hline
\end{tabular}


Table 4. Continued.

\begin{tabular}{|c|c|c|c|c|c|}
\hline (Z-2-methyl-1,3,4-trihydroxybut- & - see 2-methyltetrol & & & $\begin{array}{l}\text { Surratt et al. } \\
(2006)\end{array}$ & $\begin{array}{l}\text { - Rondônia, Brazil; } \mathrm{PM}_{2.5} ; \text { Wang et al. (2005) } \\
\text { - K-puszta, Hungary; } \mathrm{PM}_{2.5} ; \text { Ion et al. (2005) } \\
\text { - Hyytiälä, Finland; PM } \text { P }_{1} ; \text { Kourtchev et al. (2005; 2008a) } \\
\text { - Blodgett forest, CA, USA; TA; Cahill et al. (2006) } \\
\text { - Jülich, Germany; PM }{ }_{2.5} ; \text { Kourtchev et al. (2008b) }\end{array}$ \\
\hline $\begin{array}{l}- \text { glyoxal (ethanedione) and } \\
\text { methylglyoxal (propane-1,2- } \\
\text { dione) sulfate derivatives }\end{array}$ & $\begin{array}{l}\text { see high } \mathrm{NO}_{\mathrm{x}} \\
\text { conditions for } \\
\text { sulfate and mixed } \\
\text { nitrate/sulfate } \\
\text { derivatives }\end{array}$ & - none & $\begin{array}{l}-24 \mathrm{mM}\left(\mathrm{NH}_{4}\right)_{2} \mathrm{SO}_{4} \\
- \\
-24 / 38 \mathrm{mM} \\
\left(\mathrm{NH}_{4}\right)_{2} \mathrm{SO}_{4} / \mathrm{H}_{2} \mathrm{SO}_{4} \\
-25 / 113 \mathrm{mM} \\
-\left(\mathrm{NH}_{4}\right)_{2} \mathrm{SO}_{4} / \mathrm{H}_{2} \mathrm{SO}_{4}\end{array}$ & $\begin{array}{l}\text { Surratt et ail. } \\
\text { (2007a) }\end{array}$ & $\begin{array}{l}\text { - southeastern USA; } \mathrm{PM}_{2.5} ; \text { Surratt et al. (2007a; 2008) } \\
\text { - K-puszta, Hungary; } \mathrm{PM}_{2.5} ; \text { Gómez-González et al. (2008) }\end{array}$ \\
\hline $\begin{array}{l}-\mathrm{C}_{5} \text {-alkane triol (1,2,3-trihydroxy- } \\
2 \text {-methyl-butane) mixed } \\
\text { nitrate/sulfate derivative }\end{array}$ & $\begin{array}{l}\text { see sulfate } \\
\text { derivatives of } \\
\text { hemiacetal dimers } \\
\text { with a } \\
\text { C }_{5} \text {-dihydroxy- } \\
\text { carbonyl }\end{array}$ & & & $\begin{array}{l}\text { Surratt et al. } \\
\text { (2008) }\end{array}$ & - southeastern USA; $\mathrm{PM}_{2.5} ;$ Surratt et al. (2008) \\
\hline
\end{tabular}

${ }^{\mathrm{a}}$ structure of stereoisomer not shown; ${ }^{\mathrm{b}} \mathrm{H}_{2} \mathrm{O}_{2}$, $\mathrm{HONO}$ and $\mathrm{NO}_{\mathrm{x}}$ serve as $\mathrm{OH}$ radical sources in photooxidation experiments.

Importantly, most of the isoprene SOA tracers discussed above have been measured in several field studies conducted at forested sites on three different continents (see Table 4). With regard to the 2-methyltetrols, the atmospheric concentrations during summer in forested sites were in the range $0.02-365 \mathrm{ng} \mathrm{m}^{-3}$, with the highest concentrations found in Research Triangle Park (NC, USA), a suburban site in the Southeastern USA. 2-methyltetrols show a diel variation with the highest concentrations during day-time, consistent with their formation from isoprene which is light- and temperature-dependent (Ion et al., 2005; Kourtchev et al., 2008a). As expected, the 2-methyltetrols follow a seasonal trend with the highest concentrations during the warmest months (Xia and Hopke, 2006).

\section{Organosulfates and nitrooxy organosulfates from isoprene SOA}

Romero and Oehme (2005) and Reemtsma et al. (2006) first reported organosulfates in ambient aerosol based on the use of (-)ESI-MS; however, their sources and source processes remained unclear. Surratt et al. $(2007 \mathrm{a}, \mathrm{b})$ then detected organosulfates, as well as nitrooxy organosulfates from isoprene SOA products and showed that they are formed by esterification of hydroxyl groups or keto groups (after gem-diol formation) with sulfuric acid (Table 4). Organosulfates and nitrooxy organosulfates should be regarded as processed (or aged) products because their formation involves the participation of sulfuric acid, and in the case of nitrooxy organosulfates also that of $\mathrm{NO}_{\mathrm{x}}$. Both sulfuric acid and $\mathrm{NO}_{\mathrm{x}}$ are mainly anthropogenic in origin, resulting in the organosulfates and nitrooxy organosulfates of isoprene having a mixed biogenic/anthropogenic origin. Isoprene organosulfates and nitrooxy organosulfates were detected at sites in the southeastern USA and Europe (Surratt et al., 2007a, 2008; GómezGonzález et al., 2008). Major organosulfates formed from isoprene SOA detected in ambient aerosol include derivatives of the 2-methyltetrols, glyoxal and methylglyoxal.

It is suggested that organosulfates and nitrooxy organosulfates, which are very polar acidic products, correspond to a substantial fraction of the humic-like substances of ambient aerosol. Considering their very polar character, they may enhance the capacity of ambient aerosol to act as cloud condensation nuclei. Quantitative data on organosulfates and nitrooxy organosulfates from the photooxidation of isoprene are not available yet. Considering that the 2-methyltetrols may be present as sulfate, nitrate and mixed sulfate/nitrate derivatives in ambient aerosol, it is likely that these derivatives are measured in their hydrolyzed form (i.e., containing hydroxyl groups instead of sulfate and/or nitrooxy groups) 
when trimethylsilylation GC/MS is employed (Surratt et al., 2007a), owing to the fact that the trimethylsilylation reagent contains an acidic catalyst. Analytical methods need to be developed that allow the simultaneous measurement of isoprene SOA products in their original forms (i.e., comprising the free non-esterified forms as well as organosulfates and nitrooxy organosulfates).

Previous laboratory studies have employed high levels of seed aerosol acidity, which in most cases are not atmospherically relevant, when oxidizing isoprene and other BVOCs to generate SOA. Since a large number of organosulfates and nitrooxy organosulfates have been observed in ambient aerosol, it is expected that organosulfate formation is likely dependent upon the sulfate aerosol mass concentration; however, the form of this dependency remains unclear. Surratt et al. (2007a) found that organosulfates and nitrooxy organosulfates of isoprene could form from non-acidified sulfate seed aerosol; however, the number of organosulfate and nitrooxy organosulfate products increased with increasing sulfuric acid concentration in the atomization solution. It is suggested that further work be done in understanding whether sulfate aerosol mass concentration, level of acidity, ionic strength, or all of these factors, affect the organosulfate formation potential from isoprene (as well as from other BVOCs) and whether other oxidants, such as $\mathrm{O}_{3}$ and/or $\mathrm{NO}_{3}$, can produce organosulfates of isoprene, as well as other tracer compounds. Recent work by $\mathrm{Ng}$ et al. (2008) has shown that the $\mathrm{NO}_{3}$-initiated oxidation of isoprene in the presence of non-acidified and acidified sulfate seed aerosol can also yield organosulfates and nitrooxy organosulfates of isoprene.

\subsubsection{SOA tracers for the photooxidation of $\alpha$-/ $\beta$-pinene}

The chemical structures and names of $\alpha$-pinene SOA constituents that have recently been elucidated are listed in Table 5.

\section{3-hydroxyglutaric acid and 3-methyl-1,2,3-butanetri- carboxylic acid}

In the case of $\alpha$ - and $\beta$-pinene, it has been well established that both cis-pinic and cis-pinonic acids are major ozonolysis products, which are also produced in reactions with the $\mathrm{OH}$ radical. However, chemical analyses of irradiated $\alpha$ or $\beta$-pinene/ $\mathrm{NO}_{\mathrm{x}}$ mixtures that involve reactions with $\mathrm{OH}$, as well as with ozone, reveal the presence of highly oxidized, acyclic, polar compounds, along with the ozonolysis products (Jaoui et al., 2005). Since these highly oxidized compounds were also observed in the fine fraction of ambient PM samples, considerable efforts have been undertaken to elucidate the chemical structures of the $\alpha$ - $/ \beta$-pinene SOA compounds with MWs 148 and 204. The MW 148 compound was elucidated as the $\mathrm{C}_{5}$-hydroxydicarboxylic acid 3-hydroxyglutaric acid (Claeys et al., 2007), while the
MW 204 compound was established as the $\mathrm{C}_{8}$-tricarboxylic acid 3-methyl-1,2,3-butanetricarboxylic acid (Szmigielski et al., 2007b). Both compounds were identified with authentic standards using GC/EI-MS with prior derivatization, and in the case of 3-methyl-1,2,3-butanetricarboxylic acid also with LC/(-)ESI-MS. Their formation can be explained by further reaction of cis-pinonic acid, involving participation of the $\mathrm{OH}$ radical and $\mathrm{NO}_{\mathrm{x}}$. The detection of these compounds in field samples (Table 5) at high atmospheric concentrations illustrates that complex multi-generation chemistry characterizes the photooxidation of $\alpha-/ \beta$-pinene in the ambient atmosphere. Future laboratory chamber studies over a relatively long time scale should provide more detailed insights into the evolution of $\alpha-/ \beta$-pinene SOA constituents.

\section{Organosulfates and nitrooxy organosulfates from $\alpha$-/ $\beta$-pinene SOA}

Organosulfates and nitrooxy organosulfates from $\alpha-/ \beta$ pinene SOA products have been recently reported by Liggio and Li (2006a, b), Surratt et al. (2007a, 2008) and Iinuma et al. (2007b), Table 5. As in the case of isoprene SOA, the organosulfates and nitrooxy organosulfates from $\alpha-/ \beta$ pinene SOA products have a mixed biogenic/anthropogenic origin and should be regarded as processed (or aged) products. Liggio and Li (2006a, b) noted in laboratory experiments that pinonaldehyde is rapidly taken up on acidic sulfate aerosols, resulting in the formation of organosulfates, i.e., pinonaldehyde with a rather high vapor pressure (Hallquist et al., 1997) will be effectively transported into the condensed phase. Major compounds detected in ambient $\mathrm{PM}_{2.5}$ aerosol are nitrooxy organosulfates from $\alpha$-pinene SOA with a dihydroxypinane skeleton and a MW of 295. Laboratory and field experiments suggest that night-time $\mathrm{NO}_{3}$ chemistry is important for the formation of these compounds (Surratt et al., 2007a, 2008; Iinuma et al., 2007b; GómezGonzález et al., 2008); however, it should be noted that these compounds have also been observed in photooxidation (i.e., $\mathrm{OH}$-initiated) experiments conducted in the presence of $\mathrm{NO}_{\mathrm{x}}$ and highly acidified sulfate seed aerosol (Surratt et al., 2008). Other organosulfates of $\alpha-/ \beta$-pinene SOA products found in ambient $\mathrm{PM}_{2.5}$ aerosol include: derivatives of 3hydroxyglutaric acid (Gómez-González et al., 2008; Surratt et al., 2008), 2,10-dihydroxypinane (linuma et al., 2007b; Surratt et al., 2008) and hydroxypinonic acid (Surratt et al., 2008). The organosulfates from $\alpha-/ \beta$-pinene SOA products are amphiphilic (i.e., both hydrophilic and hydrophobic) and may play an important role in aerosol microphysics. Only semi-quantitative data have been obtained so far using a surrogate standard (camphorsulfonic acid) for the organosulfate derivatives of dihydroxypinanes (Iinuma et al., 2007b). An upper limit estimate of the contribution from organosulfates to the particulate $\mathrm{OM}$ could be derived from the analysis of aerosol samples for total sulfur and water-soluble sulfate. Water-soluble sulfate is commonly measured by ion 
Table 5. $\alpha-/ \beta$-pinene SOA constituents discovered since 2005: chemical structures and names; laboratory studies in which $\alpha-/ \beta$-pinene SOA tracers were investigated and specific conditions; and field studies in which the tracers have been identified or detected, and, in some cases, also quantified.

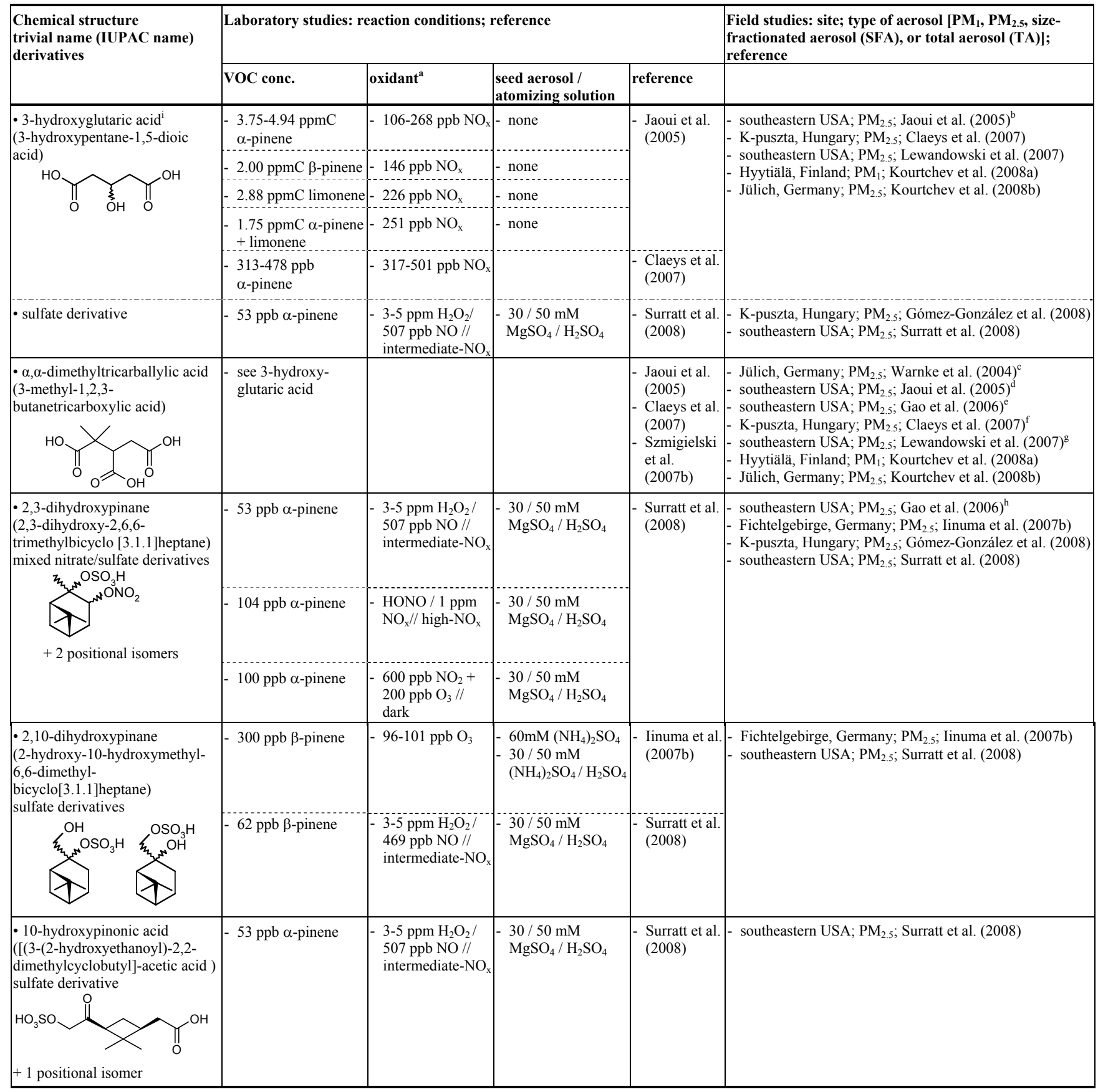

${ }^{\mathrm{a}} \mathrm{H}_{2} \mathrm{O}_{2}$, $\mathrm{HONO}$ and $\mathrm{NO}_{\mathrm{x}}$ serve as $\mathrm{OH}$ radical sources in phootoxidation experiments. $\mathrm{NO}_{2}+\mathrm{O}_{3}$ reaction serves as $\mathrm{NO}_{3}$ radical source in dark experiments. The VOC is only injected after the latter reaction is close to completion. ${ }^{\mathrm{b}}$ Reported as 3-isopropyl-1,2-dihydroxybutanol; ${ }^{\mathrm{c}}$ reported as MW 204; ${ }^{\mathrm{d}}$ reported as 3-carboxy heptanedioic acid; ${ }^{\mathrm{e}}$ reported as norpinic diperoxy acid; ${ }^{\mathrm{f}}$ reported as 2-hydroxy-4-isopropyladipic acid; $\mathrm{g}$ reported as 2-hydroxy-4-isopropyladipic acid; $\mathrm{h}$ reported as nitro-pinonaldehyde sulfate/nitro-pinonaldehyde sulfonate/nitrooxypinonaldehyde sulfonate derivatives $;{ }^{i}$ also reported from oxidation of limonene. 
chromatography (IC) and organosulfates are not included in this type of measurement. Total sulfur can be measured by Xray emission techniques, such as X-ray fluorescence (XRF) or particle-induced X-ray emission spectrometry (PIXE), and this measurement will include the sulfur from water-soluble sulfate and other inorganic sulfur species (e.g., sulfite), the insoluble sulfur which may be associated with primary biogenic particles (Graham et al., 2003), and also the sulfur of the organosulfates. Subtracting the IC sulfate-sulfur from the XRF or PIXE sulfur will thus provide an upper limit for the sulfur that may be associated with organosulfates (assuming that sulfite sulfur and primary biogenic sulfur are negligible). It should be realized that XRF, PIXE, and IC analyses have an associated uncertainty of the order of $5 \%$ or more, so that the uncertainty that is associated with the difference will be quite substantial. For the site of K-puszta, Hungary, and a 2003 summer period, which was very dry and warm (Ion et al., 2005), the calculations indicated that organosulfates could be responsible for $20 \%$ of the total $\mathrm{PM}_{10}$ sulfur concentration and $30 \%$ of the $\mathrm{PM}_{10} \mathrm{OM}$ (Maenhaut et al., 2008; Surratt et al., 2008). Using a similar approach, it was estimated that organosulfates accounted for $6-14 \%$ of the total $\mathrm{PM}_{2.5}$ sulfur concentration at the same site during summer 2006 (Lukács et al., 2009).

\subsubsection{SOA tracers for the photooxidation of BVOCs other than isoprene and $\alpha-/ \beta$-pinene}

Efforts have also been undertaken during the past five years to establish suitable tracers for SOA from the photooxidation of BVOCs other than isoprene and $\alpha-/ \beta$-pinene, which have lower but still significant emission rates, such as $d$-limonene and $\beta$-caryophyllene. Several compounds with a high molar yield were characterized in $d$-limonene/ $\mathrm{NO}_{\mathrm{x}} \mathrm{SOA}$ by Jaoui et al. (2006), including maleic acid, 4-isopropenyl-1-methyl1-hydroxy-2-oxocyclohexane, ketonorlimonic acid and ketolimonic acid. Based on analysis of $\mathrm{PM}_{2.5}$ aerosol collected at Research Triangle Park (North Carolina, USA) during summer 2003, two compounds, i.e., 3-carboxyheptanedioic acid (MW 204) and an unknown product with a MW of 190 , which were not present in $\alpha-/ \beta$-pinene SOA, were proposed as specific tracers for $d$-limonene SOA. With regard to the sesquiterpene $\beta$-caryophyllene, $\beta$-caryophyllinic acid was tentatively identified as a tracer and detected at a level up to $7 \mathrm{ng} \mathrm{m}^{-3}$ in $\mathrm{PM}_{2.5}$ summer aerosol collected at Research Triangle Park, North Carolina, USA (Jaoui et al., 2007).

As in the case of isoprene and $\alpha-/ \beta$-pinene SOA products, organosulfates have also been characterized for $d$-limonene SOA generated in the presence of highly acidic seed aerosol (Iinuma et al., 2007a); more specifically, a sulfate adduct of endolim oxide (limonaldehyde; MW 282) was identified in ozonolysis SOA, as well as higher-MW oligomeric products (MWs 482 and 466) consisting of monomeric residues connected through a sulfate bridge. A recent study by Surratt et al. (2008) found that organosulfates/nitrooxy organosulfates of all monoterpenes studied, which included $d$-limonene, $l$-limonene, $\alpha$-terpinene, $\gamma$-terpinene, terpinolene, $\beta$-phellandrene, and $\Delta^{3}$-carene, also form in the presence of highly acidified sulfate seed aerosol when photooxidized in the absence/presence of $\mathrm{NO}_{\mathrm{x}}$; however, unlike the organosulfates/nitrooxy organosulfates of $\alpha-/ \beta$-pinene, the organosulfates/nitrooxy organosulfates of these monoterpenes have so far not been detected in ambient aerosol. A selected number of $\mathrm{NO}_{3}$-initiated oxidation experiments for $\alpha$-pinene, $d$-limonene, and $l$-limonene were also conducted in the presence of highly acidified sulfate seed aerosol, resulting in the detection of organosulfates/nitrooxy organosulfates of these BVOCs. Finally, very polar organosulfates derived from oxidation products of unsaturated fatty acids and plant leaf volatiles were tentatively identified by Gómez-González et al. (2008) in $\mathrm{PM}_{2.5}$ summer aerosol collected from Kpuszta, Hungary.

\subsection{Condensed phase reactions and oligomerization}

The role of condensed phase reactions in the formation and growth of SOA has been the subject of considerable interest over the last 5-10 years. Reactions of atmospheric oxidation products that increase the carbon number (accretion reactions) also cause the vapor pressure to be lowered by several orders of magnitude. This can have consequences for the ability of VOC oxidation products to form new particles (homogeneous nucleation), affect the growth rate of aerosol particles and also influence the total amount of SOA formed by incorporation of volatile oxidation products into the particle phase. An additional motivation to search for supplementary SOA formation pathways is the serious underestimation of SOA production in current atmospheric modeling approaches (Volkamer et al., 2006; Andreani-Aksoyoglu et al., 2008), as discussed in Sect. 4.3.2. Furthermore, because chemical reactions are taking place in the particle phase, the chemical composition of the existing aerosols, e.g., their acidity or ionic strength, could potentially influence SOA formation, representing a chemical coupling between previously unrelated parameters. There is additional interest in condensed phase reactions because they might help to explain the formation of other higher-MW products detected in atmospheric aerosol, such as HULIS (Gelencsér et al., 2002; Limbeck et al., 2003). HULIS are often detected in ambient atmospheric aerosols, cloud and fog water and show characteristics similar to those of humic and fulvic acids, especially their ultraviolet (UV) and fluorescence spectra (Havers et al., 1998a, b; Zappoli et al., 1999). However, the origin of this class of organic molecules is still unclear, as outlined in Sect. 3.3.3.

Numerous laboratory studies have shown evidence for the reactive uptake of volatile organic species during SOA formation as well as the formation of higher-MW organics in SOA. The first studies were based on indirect evidence, i.e., increased SOA mass concentration observed in the presence 
of acidic seed aerosol (Tobias et al., 2000; Jang et al., 2002, 2004; Limbeck et al., 2003). Although it was proposed that polymerization reactions of volatile carbonyls may account for the observed SOA mass increase, there was no direct evidence to support this at the time. Subsequent studies utilized mass spectrometry for the direct detection of higherMW products, and showed that oligomers, characterized by a highly regular mass difference pattern of $12,14,16$ or $18 \mathrm{Da}$, constituted a considerable portion of the SOA (Kalberer et al., 2004; Tolocka et al., 2004; Gao et al., 2004a, b). It should be noted that the terms oligomer and oligomerization, as opposed to polymer and polymerization, are normally used in this context because, in the reaction systems studied to date, the MW range of the products is limited (IUPAC, 1996). As outlined in Sect. 3.3.3, the MS techniques which have been successfully applied for oligomer detection are mostly based on soft ionization techniques; either off-line techniques after a filter sampling/extraction step (Gao et al., 2004a, b; Iinuma et al., 2004; Surratt et al., 2006) or by on-line MS (Gross et al., 2006; Hearn and Smith, 2006; Surratt et al., 2006; Denkenberger et al., 2007; Heaton et al., 2007). Oligomerization processes of SOA components have even been observed using microscopic techniques (McIntire et al., 2005). Oligomers have been identified in SOA produced from the atmospheric oxidation of cyclic alkenes including terpenes (Gao et al., 2004a, b; Iinuma et al., 2004, 2007a; Tolocka et al., 2004; Baltensperger et al., 2005; Heaton et al., 2007; Müller et al., 2008), small open-chain alkenes including isoprene (Dommen et al., 2006; Sadezky et al., 2006; Surratt et al., 2006; Szmigielski et al., 2007a) and aromatic VOC precursors (Kalberer et al., 2004; Sato et al., 2007). In addition to these classical SOA precursor systems, other compounds which are present in atmospheric aerosols have also been investigated as possible contributors to oligomers, such as levoglucosan (Holmes and Petrucci, 2006) and oleic acid, although the motivation for investigating the chemical processing of oleic acid is often the search for an appropriate model system for heterogeneous reactions (Hearn et al., 2005; Hung et al., 2005; Mochida et al., 2006; Reynolds et al., 2006; Zahardis et al., 2006; Zahardis and Petrucci, 2007).

\subsubsection{Molecular weight and analytical restrictions}

One of the most important characteristics of oligomers in SOA is the MW range, since it not only affects vapor pressure and solubility of the compounds, but is also part of the definition of "higher-MW compounds". Even for this basic feature the different investigations performed to date have identified species with a wide range of values, Table 6 . However, it is likely that the wide MW range is a result of different operating conditions (e.g., oxidant, $\mathrm{NO}_{\mathrm{x}}$ regime, aerosol loading, and seed aerosol conditions) employed in the various studies.

Determination of the MW range of oligomers in SOA can be problematic. Several MS techniques (such as AMS based on EI or LDI) are not able to ionize larger organic molecules
Table 6. Molecular weight range of oligomers detected in laboratory studies of biogenic (BSOA) and anthropogenic SOA (ASOA) formation.

\begin{tabular}{|c|c|c|}
\hline Precursor system & $\begin{array}{l}\text { Molecular } \\
\text { weight range }\end{array}$ & Reference \\
\hline $\operatorname{BSOA}\left(\alpha\right.$-pinene $\left./ \mathrm{O}_{3}\right)$ & $200-900$ & Tolocka et al. (2004) \\
\hline $\operatorname{BSOA}\left(\alpha\right.$-pinene/O $\left.{ }_{3}\right)$ & $250-1600$ & Gao et al. $(2004 a, b)$ \\
\hline $\operatorname{BSOA}\left(\alpha\right.$-pinene $\left./ \mathrm{O}_{3}\right)$ & up to 800 & Iinuma et al. $(2004,2005)$ \\
\hline $\operatorname{BSOA}\left(\alpha\right.$-pinene $\left./ \mathrm{O}_{3}\right)$ & $300-400$ & Müller et al. (2008) \\
\hline $\begin{array}{l}\operatorname{BSOA}(\alpha-\text { pinene } / O H / h v \text {, } \\
\text { isoprene/OH/h } v)\end{array}$ & up to $600-700$ & Kalberer et al. (2006) \\
\hline \multirow[t]{3}{*}{ BSOA (isoprene/OH/hv) } & up to $500-600$ & Dommen et al. (2006) \\
\hline & & Surratt et al. (2006) \\
\hline & & Szmigielski et al. (2007a) \\
\hline BSOA (limonene/O 3 ) & 300-900 & Iinuma et al. (2007a) \\
\hline $\mathrm{BSOA}\left(\beta\right.$-pinene $\left./ \mathrm{O}_{3}\right)$ & up to 600 & Iinuma et al. (2007b) \\
\hline $\mathrm{BSOA}$ (terpenes/O 3 ) & $300-440$ & Heaton et al. (2007) \\
\hline $\begin{array}{l}\text { BSOA (Z-3-hexenyl } \\
\left.\text { acetate/ } / \mathrm{O}_{3}\right)\end{array}$ & up to 500 & Hamilton et al. (2008) \\
\hline $\begin{array}{l}\operatorname{ASOA}\left(\mathrm{C}_{5}-\mathrm{C}_{8}\right. \\
\text { cycloalkenes })\end{array}$ & $>250$ & Gao et al. (2004a) \\
\hline $\begin{array}{l}\text { ASOA }(1,3,5 \text {-trimethyl- } \\
\text { benzene/OH/hv) }\end{array}$ & up to 1000 & $\begin{array}{l}\text { Baltensperger et al. (2005), } \\
\text { Kalberer et al. (2004) }\end{array}$ \\
\hline ASOA (cyclohexene/O ${ }_{3}$ ) & $>200$ & Sato $(2005)$ \\
\hline $\begin{array}{l}\text { ASOA (cyclohexene, } \\
\text { methylenecyclohexane/ } \mathrm{O}_{3} \text { ) }\end{array}$ & up to 300 & Müller et al. (2007) \\
\hline ASOA (toluene/OH/h $v)$ & $200-500$ & Sato et al. (2007) \\
\hline
\end{tabular}

without fragmentation, and thus have a tendency to underestimate MW. In contrast, the application of soft ionization techniques (e.g., ESI-MS) can lead to artificially high MWs due to ion-molecule reactions in the ion source of the mass spectrometer. Furthermore, thermal treatment of the organic aerosol prior to ionization and analysis, which is a common step in on-line aerosol characterization (e.g., thermodenuder systems), might result in artificial oligomer formation (or decomposition) by influencing the equilibrium of condensation reactions. In general, the MW regimes reported more recently tend to be lower than the first estimates and are now mostly below 500. When chromatographic separations are performed before MS detection, ion source artifacts are excluded and the majority of oligomers possess MWs mostly below 400 (Hamilton et al., 2006; Surratt et al., 2006; Müller et al., 2007; Szmigielski et al., 2007a; Reinnig et al., 2008), which indicates the predominance of dimers and perhaps some trimers as oligomeric components in BSOA. However, it should be noted that chromatographic separation, ionization and detection all become more difficult as the size and polarity of the products increases and it is possible that higher oligomers may remain undetected. One example of the analytical difficulties encountered in recent studies concerns the oligomerization behavior of glyoxal. Glyoxal is formed during the photooxidation of biogenic and anthropogenic VOCs, is soluble in water (in form of the dihydrate) and can undergo hemiacetal/acetal formation. Therefore, several theoretical and experimental studies have been performed to evaluate the contribution of the $\mathrm{C}_{2}$-dialdehyde to 
SOA (Hastings et al., 2005; Kroll et al., 2005a; Liggio et al., 2005a, b; Loeffler et al., 2006; Offenberg et al., 2006; Carlton et al., 2007; Hu et al., 2007; Kua et al., 2008; Galloway et al., 2009; Nozière et al., 2009; Shapiro et al., 2009). Although all of these studies support the hypothesis that glyoxal oligomerization contributes to SOA, the MW (or MW distribution) of glyoxal oligomers has yet to be determined. The difficulties lie in the reversibility of the oligomerization reactions, i.e., when chromatographic separation techniques are applied the oligomers can hydrolyze and only the most stable oligomers will survive the separation and can be detected.

\subsubsection{Oxygen content}

Another characteristic of SOA oligomers is their very high oxygen content, at least when they are formed from biogenic precursors. HRMS delivers detailed information about the elemental composition of the oligomers and the results of several investigations published recently are shown in Table 7. All studies consistently report oxygen-to-carbon $(\mathrm{O} / \mathrm{C})$ ratios of about 0.4 to 0.5 , showing that, on average, every second carbon atom is bonded to an oxygen atom. The exception is cyclohexene, which has the same functionality as the terpenes listed in Table 7 (i.e., one double bond) but with a smaller number of carbon atoms, where the observed $\mathrm{O} / \mathrm{C}$ ratio of the oligomers can even reach 0.8 . Interestingly, where data are available, the monomers appear to exhibit a higher maximum $\mathrm{O} / \mathrm{C}$ ratio than observed in the oligomers, suggesting that condensation reactions might be involved in the oligomer formation process (Reinhardt et al., 2007; Walser et al., 2008). The measurement techniques used (HRMS) provide very reliable information on the elemental composition of the oligomers and potential chemical reaction pathways have to be able to account for the very high oxygen content of the products. It should also be noted that these experiments are mostly done at high precursor concentrations. As the $\mathrm{O} / \mathrm{C}$ ratio tends to increase with decreasing aerosol load (Duplissy et al., 2008; Shilling et al., 2009) the O/C ratio may even be higher under atmospheric conditions.

\subsubsection{Chemical nature and formation pathways}

Although knowledge of the exact elemental composition of oligomers is important, it does not reveal their chemical nature. As a result, the formation pathways of oligomers in SOA remain unclear. SOA precursors typically produce a large range of oxidation products, resulting in a considerable number of possible reaction pathways. Table 8 lists some of the suggested high molecular weight products and their proposed formation pathways identified in SOA from alkene and terpene precursors.

The first six of the suggested products all contain a peroxide group, often as the linking functionality between the monomeric units (except the hydroperoxides). In general, the proposed peroxide structures contain a large number of
Table 7. Measured O/C ratio of BSOA oligomers.

\begin{tabular}{lll}
\hline Precursor & O/C ratio & Reference \\
\hline$\alpha$-pinene & $0.4-0.57$ & Reinhardt et al. (2007) \\
$\alpha$-pinene & $0.3-0.5$ & Müller et al. (2008) \\
Limonene & $0.43-0.5$ & Walser et al. (2008) \\
Limonene & 0.45 & Heaton et al. $(2007)^{\mathrm{a}}$ \\
$\beta$-pinene & 0.45 & Heaton et al. $(2007)^{\mathrm{a}}$ \\
$\Delta^{3}$-carene & 0.43 & Heaton et al. $(2007)^{\mathrm{a}}$ \\
Sabinene & 0.37 & Heaton et al. $(2007)^{\mathrm{a}}$ \\
Cyclohexene & $0.42-0.8$ & Müller et al. $(2008)$ \\
Cyclohexene & $0.54-0.8$ & Hamilton et al. (2006) \\
\hline
\end{tabular}

a Overall $\mathrm{O} / \mathrm{C}$ ratio for monomers and oligomers.

oxygen atoms, which is in line with the high $\mathrm{O} / \mathrm{C}$ ratio measurements discussed above. The next subgroup are the noncovalently bonded dimers of organic acids, which are likely to exist in the particle phase and may also be involved in the early steps of new particle formation processes. However, since SOA oligomers have been shown to survive chromatographic separation, which is very unlikely for non-covalently bonded oligomers, other covalently bonded candidates must exist (Müller et al., 2009). Another subgroup of oligomeric products contains esters and anhydrides, both derivatives of carboxylic acids, which are known to be formed in large amounts in laboratory studies of SOA formation. In principle, classical esterification reactions between an alcohol moiety and a carboxylic acid group could be the pathway for ester formation, as recently proposed for oligoesters formed in isoprene high- $\mathrm{NO}_{\mathrm{x}} \mathrm{SOA}$ (Surratt et al., 2006; Szmigielski et al., 2007a). However, other precursor molecules for ester formation are also possible (epoxides, anhydrides). Finally the last two suggested product groups are connected to carbonyl chemistry (especially aldehyde chemistry); the formation of hemiacetals/acetals, which is often connected with initial hydrolysis of the carbonyl to form the carbonyl hydrate, and the aldol reaction, the only pathway to form carbon-carbon bonds between the monomeric building blocks.

Figure 7 schematically shows the different chemical pathways that have been proposed to yield covalently bonded oligomers and other higher-MW products. The upper part of the figure contains oligomerization reactions that are believed to take place in the gas phase, i.e., reaction pathways involving radicals. Although some of these reactions (e.g., peroxy radical recombinations) could also happen in the ambient atmosphere (Madronich and Calvert, 1990), the reactions involving the stabilized Criegee intermediate (SCI) as reactant are unlikely to take place under atmospheric conditions, since reaction with water molecules is considered the most important reaction pathway for these species. However, in laboratory experiments performed under low humidity conditions these pathways might have contributed to the oligomers observed in simulation chambers (Sadezky et al., 2006). Furthermore, the formation pathways yielding 
Table 8. Suggested products and formation pathways for oligomers and other higher-MW products in SOA.

\begin{tabular}{|c|c|c|}
\hline Suggested products & Suggested formation pathway & References \\
\hline Oligoperoxides & Stabilized Criegee Intermediate (SCI) self-reaction & Sadezky et al. (2006) \\
\hline Peroxyhemiacetals & Hydroperoxides + carbonyls (aldehydes) & $\begin{array}{l}\text { Docherty et al. (2005), } \\
\text { Tobias and Ziemann (2000, 2001), } \\
\text { Tobias et al. (2000), } \\
\text { Surratt et al. (2006) }\end{array}$ \\
\hline Alkoxyhydroperoxides & $\mathrm{SCI}+$ alcohols & $\begin{array}{l}\text { Tobias and Ziemann (2000), } \\
\text { Ziemann (2003) }\end{array}$ \\
\hline Acyloxyhydroperoxides & SCI + carboxylic acids & $\begin{array}{l}\text { Tobias and Ziemann (2001), } \\
\text { Tobias et al. (2000) }\end{array}$ \\
\hline Secondary ozonides & SCI + carbonyls (aldehydes) & $\begin{array}{l}\text { Heaton et al. (2007), } \\
\text { Tobias and Ziemann (2001), } \\
\text { Tobias et al. (2000), } \\
\text { Walser et al. (2008) }\end{array}$ \\
\hline ROOR-type peroxides & Peroxyradical self-reaction & $\begin{array}{l}\mathrm{Ng} \text { et al. }(2008) \\
\text { Ziemann }(2002)\end{array}$ \\
\hline Dicarboxylic acid dimers & Formation of non-covalent diacid adducts & $\begin{array}{l}\text { Hoffmann et al. (1998), } \\
\text { Jenkin (2004), } \\
\text { Sloth et al. (2004) }\end{array}$ \\
\hline Esters & $\begin{array}{l}\text { Unknown (alcohol+ carboxylic acid, anhydride+ } \\
\text { alcohol, epoxide + carboxylic acid)? }\end{array}$ & $\begin{array}{l}\text { Hamilton et al. (2006, 2008), } \\
\text { Müller et al. (2007, 2008), } \\
\text { Reinnig et al. (2008), } \\
\text { Surratt et al. (2006), } \\
\text { Szmigielski et al. (2007a) }\end{array}$ \\
\hline Anhydrides & Unknown & Hamilton et al. (2006) \\
\hline Hemiacetals/acetals & Carbonyls + (alcohol) & $\begin{array}{l}\text { Liggio and Li (2006a, b), } \\
\text { Surratt et al. (2006), } \\
\text { Tolocka et al. (2004b), } \\
\text { Iinuma et al. (2004) }\end{array}$ \\
\hline Aldol condensation products & Carbonyls & $\begin{array}{l}\text { Barsanti and Pankow (2005), } \\
\text { Czoschke and Jang (2006b), } \\
\text { Garland et al. (2006), } \\
\text { Liggio and Li (2006a, b), } \\
\text { Nozière et al. (2007), } \\
\text { Tolocka et al. (2004b) }\end{array}$ \\
\hline
\end{tabular}

higher-MW products in the gas phase might very well be involved in new particle formation processes such as nucleation, especially under laboratory conditions.

The lower right part of Fig. 7 contains reactions that are believed to take place within the condensed phase. Here, gasparticle transfer precedes the oligomer forming reaction and, if the partitioning coefficient indicates that the monomer will exist mainly in the gas phase, the oligomerization process can be treated as reactive uptake. As indicated in Fig. 7, these reactions are generally acid-catalyzed, suggesting that a form of chemical coupling exists between aerosol composition and the formation of SOA. Within this context, the most widely investigated processes involve the acid catalyzed reactions of aldehydes or ketones (aldol reaction/condensation, acetal formation) on the surface and in the bulk of particles, see
Sect. 5.3. However, oligomers were observed also in the absence of acidic seed aerosols (Kalberer et al., 2004; Baltensperger et al., 2005; Dommen et al., 2006; Surratt et al., 2006; Szmigielski et al., 2007a). In addition, the water content (water activity) of aerosols will also influence the uptake of organic compounds. Therefore, a straightforward interpretation of the acidity influence is difficult to achieve. Similar issues are found in the interpretation of data obtained from field studies using on-line MS techniques (Denkenberger et al., 2007; Zhang et al., 2007a). Nevertheless, as an initial summation of the work that has been performed to date, one might conclude that particles with higher acidity are likely to promote the formation of larger oligomers. However, the relative importance of these oligomerization processes under ambient atmospheric conditions remains to be quantified. 


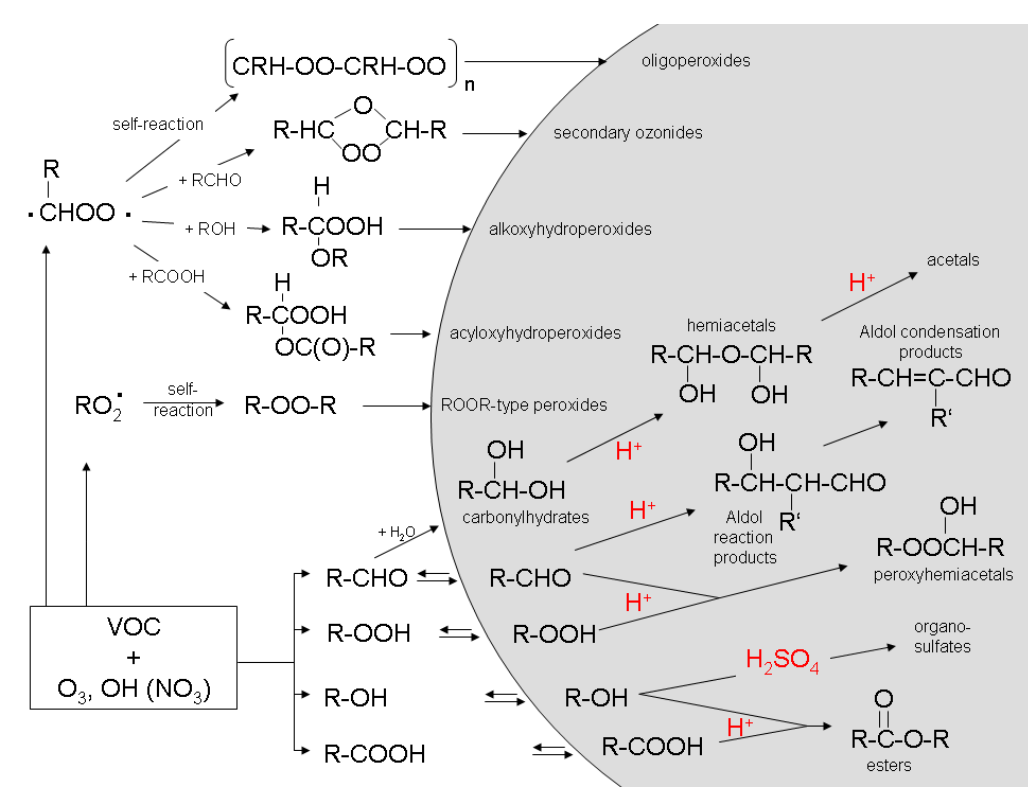

Fig. 7. Possible chemical reaction pathways for the formation of oligomers and other higher-MW products observed in SOA.

It is reasonable to assume that the range of proposed oligomeric species and reaction pathways listed in Table 8 are a direct result of the wide range of VOC oxidation products generated from the different SOA precursors. However, the experimental conditions also play a major role in influencing the chemical pathways. For example, Surratt et al. (2006) showed that SOA generated from the photooxidation of isoprene under low- $\mathrm{NO}_{\mathrm{x}}$ conditions contained organic peroxides (possible peroxyhemiacetals) and hemiacetals as the higher-MW products, whilst under high- $\mathrm{NO}_{\mathrm{x}}$ conditions, oligoesters were identified as the main higher-MW species. Thus, even for the same SOA precursor, changes in $\mathrm{NO}_{\mathrm{x}}$ can significantly influence the types of oligomers formed.

A major problem for the unambiguous identification of the oligomeric products, and hence the unambiguous identification of the chemical processes leading to oligomers, is the lack of reference compounds. Biogenic alkenes, for example, possess complicated structures and the synthesis of potential products, especially larger products (e.g., dimers) or very reactive products (e.g., peroxides), is extremely time consuming and demanding. Recently, the individual dimeric oxidation products (esters) of cyclohexene were synthesized and their mass spectra and retention behavior compared with oligomers formed in chamber experiments (Müller et al., 2008). When reference compounds are not available the application of soft ionization MS/MS techniques can give clues to the chemical nature of the products, however, the fragmentation pathways of even-electron ions (as typically formed with soft ionization) can often be quite similar for different analytes, hence restricting the capability of such studies for structural elucidation. Here the detailed interpretation of EI mass spectra in combination with derivatization GC/MS can be helpful, e.g., in the identification of esters as oligomers formed from isoprene oxidation under high- $\mathrm{NO}_{\mathrm{x}}$ conditions (Szmigielski et al., 2007a). Obviously, the explicit identification of the other suggested products of acid-catalyzed chemistry (e.g., aldol condensation products) would be extremely valuable for the final evaluation of these SOA formation pathways but again appropriate reference compounds are lacking. Another group of SOA related accretion reaction products which could recently be identified in laboratory and field experiments are organosulfates, as outlined in Sect. 5.1.

Light-induced chemical reactions are another possible formation pathway for oligomers in SOA. A number of species in organic aerosols absorb light in the visible and UVA wavelength range and photosensitized chemical processes leading to a change in the MW distribution of SOA components are possible. However, laboratory investigations into such reactions are just beginning and at the present time, not even preliminary conclusions about their significance can be made. It is also unclear which oligomerization processes take place exclusively in the atmospheric aqueous phase and how far cloud processing of water-soluble organics can explain the formation of higher-MW species. This topic is discussed in more detail in Sect. 5.4.

\subsubsection{Quantification}

Quantification of the relative mass contribution of oligomers to SOA is made difficult by a lack of reference compounds and universal measurement techniques. Nevertheless, for laboratory experiments several estimates have been made which indicate that, depending on the type of precursor, precursor concentrations and duration of the experiments, between 25 and $70 \%$ of the SOA mass can be made up of oligomeric products (Gao et al., 2004a, b; Kalberer et al., 
2004; Dommen et al., 2006; Surratt et al., 2006; Hu et al., 2007; Müller et al., 2007). However, many of these estimates were made indirectly, e.g., based on a change of the volatility (increase of the remaining volume fraction after thermal treatment), and are therefore subject to a high level of uncertainty. Considering that the experimental conditions (precursor concentrations, seed aerosols etc.) probably have a major influence on oligomer formation (Chan et al., 2007; Kroll et al., 2007), there is insufficient data for an extrapolation of laboratory data to the ambient atmosphere to be made.

\subsubsection{Time scale}

A further remarkable characteristic is the time scale for oligomer formation. Laboratory studies have shown that at least some of the oligomers are formed quite rapidly (Hoffmann et al., 1998; Heaton et al., 2007). In fact, the chemistry of reactive intermediates, such as peroxides, ozonides or radicals, could be responsible for this observed temporal behavior of oligomer formation. In addition to this almost instantaneous build-up of oligomers, several chamber studies of the chemical composition, volatility and hygroscopicity of SOA indicate that accretion reactions also take place on a longer time scale (vanReken et al., 2005; Gross et al., 2006; Kalberer et al., 2006; Paulsen et al., 2006; Varutbangkul et al., 2006). These somehow contradictory results are probably one reason why no clear picture of oligomerization currently exists, since it indicates the existence of several different chemical pathways which happen on different time scales that lead to a diverse range of higher-MW products - one rapid formation pathway involving reactive intermediates (closed shell or radical intermediates) and one much slower pathway (e.g., involving the reaction of carbonyls, alcohols or acids). While knowledge about the latter processes is essential for the evaluation of the role of oligomerization for organic aerosol aging, the first process could be important for the understanding of new particle formation, both in the laboratory and the field.

It has been demonstrated that the time scale of SOA formation is particularly important for reactive small molecules like glyoxal, for which the rate of aerosol loss directly competes with rapid gas-phase losses. Volkamer et al. (2009) found the rate of SOA formation from glyoxal in a photochemical reaction was enhanced by a factor of 500 compared to a dark reaction system. The SOA formation rate was also strongly dependent on the chemical composition of seed aerosol. Volkamer et al. (2009) concluded that organic photochemical reactions of glyoxal in aerosol water form low volatility products at a rate that can exceed the rate of organosulfate formation; the presence of nucleophiles and sulfuric acid can reduce the rate of SOA formation in the photochemical system compared to that observed in a dark system (see also Table 9).

Obviously the time scale of oligomer formation is also important when repartitioning and the reversibility of oligomer formation is discussed. Grieshop et al. (2007) observed that SOA from alpha-pinene ozonolysis repartitions reversibly upon dilution, but on a much longer time scale than has been observed in single component aerosols of similar size. It is suggested that the surprisingly slow evaporation rate may be due to mixture effects, mass transfer limitations, or the decomposition of weakly bound oligomers. However the mechanism could not be determined from the experimental data.

\subsubsection{Theoretical approaches}

Several modeling approaches have been developed in which heterogeneous reactions including oligomer formation are treated explicitly. One of the theoretical treatments of oligomer formation involves evaluation of the thermodynamic favorability of their formation from different precursors. Barsanti and Pankow published a series of papers on the thermodynamics of accretion reactions dealing with different monomer functionalities (Barsanti and Pankow, 2004, 2005,2006 ), concluding that, for example, accretion reactions involving certain aldehydes and carboxylic acids can be thermodynamically favorable in the condensed phase. The first attempts to include a simplified representation of condensed organic phase accretion reactions (peroxyhemiacetal adduct formation from aromatic VOC oxidation) into detailed chemical models showed a reduced requirement for the otherwise necessary scaling of the physico-chemical parameters (partitioning coefficients) and a better description of the temporal behavior of SOA formation in simulation chambers (Johnson et al., 2005). In addition to providing a better description of chamber data (Capouet et al., 2008), models have also been used to estimate the relative contribution of oligomers to SOA generated from the photooxidation of toluene (Hu et al., 2007) and calculate the most stable oligomeric structures formed from glyoxal (Kua et al., 2008). Another major motivation for the incorporation of particle-phase chemistry is again the evaluation of the influence of particle acidity on SOA formation (Jang et al., 2006a; Pun and Seigneur, 2007). Based on pseudo-first-order approaches, in which the first-order equilibrium constants of the reacting monomers exhibit a semi-empirically derived $\mathrm{pH}$ dependence, both studies show that oligomer formation can increase SOA formation by orders of magnitude and consequently conclude that $\mathrm{pH}$ is a critical parameter. Condensational growth models have also been used to show qualitatively that even relatively volatile VOC oxidation products can induce condensation growth of aerosols by the formation of non-volatile oligomers (Vesterinen et al., 2007). Certainly all modeling exercises are limited by the incomplete knowledge of the chemistry of oligomer formation. However, theoretical models of gas- and particle-phase processes can provide a framework for the evaluation of laboratory data and allow conclusions to be drawn about the relevance under atmospheric conditions (Chan et al., 2007; Vesterinen et al., 2007; Kroll and Seinfeld, 2008). 
Table 9. Summary of laboratory studies of the impact of acidic inorganic sulfates on SOA yields.

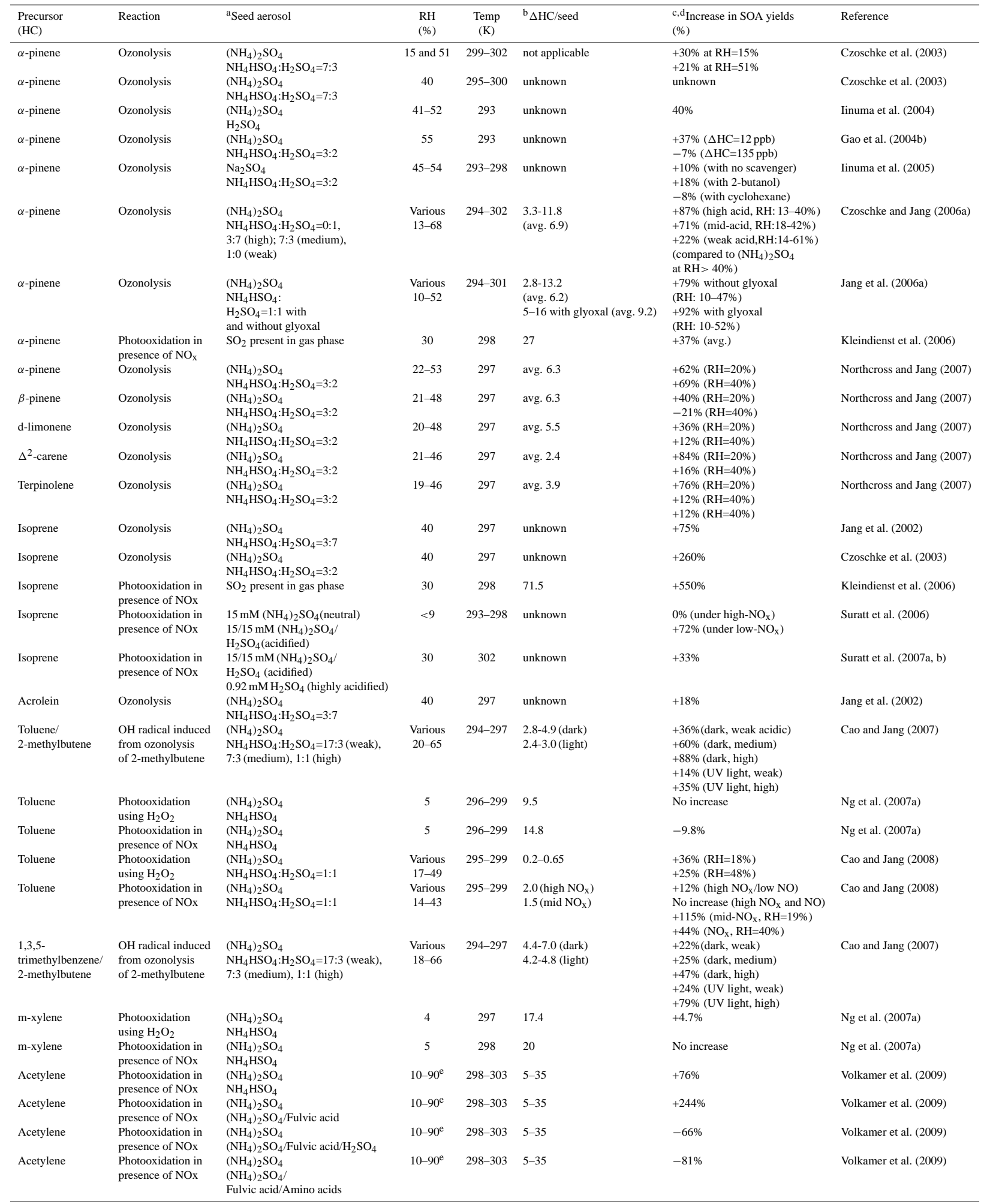

a The description of the seed aerosol composition was based on the aqueous inorganic seed solution prior to nebulization of the inorganic solution to the chamber. ${ }^{b}$ The mass ratio of the consumed hydrocarbon $(\Delta H C)$ to inorganic seed aerosol (no unit). ${ }^{c}$ The SOA yield is defined as SOA mass/ $\triangle H C$. ${ }^{d}$ The increased SOA yield is estimated by (SOA yield with acidic seed - SOA yield with non-acidic seed)/SOA yield with non-acidic seed $\times 100$. ${ }^{\text {e }}$ Yield demonstrated to scale with liquid water content; acid effect quantified at a liquid water content of $10 \mu \mathrm{g} \mathrm{m}^{-3}$. 


\subsubsection{Atmospheric significance}

Although oligomers have been observed in numerous laboratory studies of SOA formation, the relevance of these higher-MW compounds to ambient atmospheric aerosol remains uncertain as the available data appears to be ambiguous. Several studies have detected oligomers in ambient aerosol using off-line mass spectrometry (Baltensperger et al., 2005; Samburova et al., 2005b; Kalberer et al., 2006; Streibel et al., 2006) while Denkenberger et al. (2007) observed oligomers in airborne particles in California using on-line aerosol mass spectrometry. In contrast, oligomers were not detected by LC/(-)ESI-MS analysis of fine organic aerosol collected from the southeastern USA and Europe, although a number of organosulfates/nitrooxy organosulfates, polyacids, and hydroxyacids were identified in the samples (Gao et al., 2006; Iinuma et al., 2007b; Surratt et al., 2007a, 2008; Gómez-González et al., 2008). Clearly, more data is needed before the atmospheric significance of oligomer formation can be assessed. Quantitative information about the amount and relative contribution of these higher-MW compounds to the organic fraction of tropospheric aerosols is also required. The situation is further complicated by the fact that the organic aerosol fraction also undergoes oxidative chemical processing through degradation and chemical modification of the particle-phase constituents by atmospheric oxidants (Rudich et al., 2007). These processes are expected to result in alterations of the physical (volatility, light absorption, light scattering) and physico-chemical properties (water solubility, CCN activity) of atmospheric aerosols and the evaluation of the relative importance of these processes (i.e., oligomerization, oxidative processing, change in hygroscopicity etc.) has to be addressed in future research on organic aerosols.

\subsection{Interaction of atmospheric organic compounds with sulfuric acid}

A number of laboratory studies have shown that atmospheric organics, such as carbonyls, can be transformed to higherMW products via heterogeneous acid-catalyzed reactions between the gas and particle phases (Jang and Kamens, 2001; Jang et al., 2002, 2003a, b, 2004, 2005; Garland et al., 2006; Liggio and Li, 2006a, b; Iinuma et al., 2007a, b; Surratt et al., 2007a, 2008; Gómez-González et al., 2008). These laboratory studies suggest that heterogeneous acid-catalyzed reactions in the particle phase are important mechanisms for SOA formation and that particle acidity has an impact on SOA yield.

\subsubsection{Homogeneous nucleation}

There is evidence to suggest that the interaction of sulfuric acid with atmospheric organics is expected to play an important role in the nucleation of new particles in the atmosphere. For example, Zhang et al. (2004) showed co-nucleation of sulfuric acid and aromatic acids to be a mechanism for forming atmospheric new organic particles. A theory that provides a mechanistic explanation for new particle formation through activation of stable sulfate clusters by organic vapors has also been proposed (Anttila et al., 2004; Kerminen et al., 2004; Kulmala et al., 2006). It is suggested that the nucleation mechanism involves an activation mode which can initiate spontaneous and rapid growth of clusters through heterogeneous acid-catalyzed reactions and polymerization. Verheggen et al. (2007) observed enhancement of the nucleation rate of sulfuric acid by organic species through empirically determining the nucleation rate of $\alpha$-pinene SOA in the presence of acidic sulfate aerosol created by $\mathrm{SO}_{2}$ oxidation. The theoretical study by Nadykto and Yu (2007) also shows that the interaction between sulfuric acid and atmospheric carboxylic acids, such as acetic acid and formic acid, leads to the formation of stable hydrogen-bonded complexes. Citing the recent simulation study using the US EPA's Community Multiscale Air Quality (CMAQ) model for groundbased and aircraft aerosol measurements, Fan et al. (2006) report that the enhanced nucleation effect of secondary condensable organics is important in nucleation when sulfate and organics are abundant.

\subsubsection{Laboratory studies of aerosol growth by acid-catalyzed reactions of carbonyls}

In order to evaluate the potential importance of carbonyl heterogeneous chemistry and understand the reaction mechanisms of carbonyls in the aerosol phase, a range of carbonyls have been exposed to acidic sulfate either as an acidic film or a pre-existing acidic inorganic seed using either flow reactors (Jang et al., 2003a; Nozière and Riemer, 2003; Zhao et al., 2005, 2006; Nozière et al., 2006) or a Teflon film chamber (Jang and Kamens, 2001; Kroll et al., 2005a). The majority of studies showed that, in general, aldehydes, such as hexanal and octanal, resulted in higher aerosol yields via heterogeneous acid-catalyzed reactions than ketones such as 2octanone and 2,4-pentanedione (Jang et al., 2003). Specifically, $\alpha, \beta$-unsaturated aldehydes (e.g., 2,4-hexadienal and 2-hexenal) and $\alpha$-oxocarbonyls (e.g., glyoxal) were more reactive than aliphatic carbonyls in heterogeneous reactions (Jang et al., 2003b, 2005). Particle acidity, together with both humidity and inorganic seed aerosol composition, affect the aerosol growth of aldehydes to varying degrees. Overall, the aerosol production via acid-catalyzed reactions appears to be increased at low humidity and when the seed aerosol contains a high fraction of sulfuric acid. Liggio and Li (2006a, b) showed that the reactive uptake of pinonaldehyde, a principal oxidation product of $\alpha$-pinene, was highly dependent upon the aerosol acidity and did not occur on neutral ammonium sulfate aerosols. Kroll et al. (2005a) also investigated the reactive uptake of a series of small carbonyls onto aqueous seed particles containing ammonium sulfate and mixed ammonium sulfate/sulfuric acid and only found significant 
aerosol growth for glyoxal. Furthermore, no major enhancement in particle growth was observed for the acidic seed, suggesting that the large glyoxal uptake was not a result of particle acidity but rather of ionic strength of the seed. These results are in contrast to those reported by Jang et al. (2006a) and further work is clearly required to resolve this discrepancy.

The proposed reaction mechanisms for acid-catalyzed reactions of aldehydes include hydration, hemiacetal/acetal formation, trioxane formation, aldol condensation, carbocationic rearrangement, and cross-linking in aerosol media, as shown in Fig. 7. In the presence of strong acids, further reactions of hemiacetals lead to acetals, which are comparatively stable and can be isolated by neutralization (Deyrup, 1934). Such hemiacetals/acetals are easily decomposed during conventional GC/MS analysis. In a recent study, Garland et al. (2006) used NMR spectroscopy to characterize the acetal and trioxane resulting from the exposure of hexanal to submicron sulfuric acid aerosol. In addition to acid-catalyzed reactions of atmospheric organic compounds, organosulfate formation has been demonstrated to be an important mechanism in SOA formation, as discussed in Sect. 5.1.

\subsubsection{Laboratory studies of the impact of acidic inorganic sulfate on SOA yields}

A number of laboratory studies have investigated the effects of acidic inorganic sulfate on the yield of SOA, Table 9. The majority of studies have focussed on $\alpha$-pinene and isoprene and typically show an increase in SOA yield when the seed aerosol is acidified. Kleindienst et al. (2006) also reported that the SOA yields from the photoxidation of $\alpha$-pinene and isoprene are significantly enhanced in the presence of gasphase $\mathrm{SO}_{2}$, which produces acidic aerosol. The effect of relative humidity and composition of seed aerosol on SOA yields from the ozonlysis of $\alpha$-pinene was investigated by Czoschke and Jang (2006a). Their study showed that higher yields are obtained when seed composition has either a higher $\mathrm{H}_{2} \mathrm{SO}_{4}$ fraction or a higher acidity due to lower relative humidity. Northcross and Jang (2007) studied SOA formation from the ozonolysis of various terpenes ( $\alpha$-pinene, $\beta$-pinene, $\Delta^{3}$ carene, terpinolene and $d$-limonene) in the presence of inorganic seed. The results indicated that the impact of acidity on SOA yields is also influenced by the molecular structure of SOA products: for example, oxidation products with multifunctional carbonyls significantly increase SOA yields in the presence of acidic sulfate aerosols.

The effects of particle acidity on SOA yields from aromatics have received considerably less attention. $\mathrm{Ng}$ et al. (2007a) reported negligible increases in SOA yields from the photooxidation of toluene and $\mathrm{m}$-xylene in the presence of acidified sulfate seed aerosol, as shown in Table 9. In contrast, recent work by Cao and Jang $(2007,2008)$ reported that SOA yields from toluene and 1,3,5-trimethylbenzene were enhanced by acidified sulfate seed aerosols, not only for ex- periments without photoirradiation but also for those with UV-Visible irradiation. A possible explanation for such a discrepancy between the two laboratories is due to the difference in available proton concentrations used in the experiments; however, this requires further investigation. Using a new colorimetric technique for the measurement of particle acidity, Jang et al. (2008) showed that the acidity of the submicron acidic sulfate aerosol coated with $\alpha$-pinene ozone SOA significantly decreases over time, possibly due to organic sulfate formation. The mass ratio of organic aerosol to acidic inorganic seed in the chamber experiments performed by Cao and Jang $(2007,2008)$ is nearly one order of magnitude lower than those used by $\mathrm{Ng}$ et al. (2007a), i.e., 0.51.0 in the former and 2.5-6.9 in the latter. The mass ratio of available organic products to acidic sulfates obviously enhances heterogeneous acid-catalyzed reactions in aerosol. In the ambient aerosol, the mass ratios of particle organic carbon to inorganic species vary from 0.3 to $>1$ (Hughes et al., 1999; Drewnick et al., 2004; Russell et al., 2004; Zhang et al., 2007a). In addition, the interpretation of acidity effects on SOA yields should also consider humidity and inorganic seed compositions, especially the neutralization of sulfuric acid by ammonia. Table 9 lists the mass ratio of the consumed hydrocarbon $(\triangle \mathrm{HC})$ to inorganic seed along with relative humidity and seed composition. These parameters have recently been incorporated into a SOA model and coupled with inorganic and organic thermodynamic parameters (Jang et al., 2006a; Pun and Seigneur, 2007). However, organic acidity generated in the same photochemical process by which SOA is formed may be sufficient to catalyze these heterogeneous reactions. Takahama et al. (2006) reported from the Pittsburgh Air Quality Study that they were not able to detect significant enhancements of SOA production due to inorganic acidity in Western Pennsylvania most of the time.

\subsubsection{Effects of particle acidity on partitioning of semivolatile organic compounds}

Particle acidity may also affect gas-particle partitioning by the formation of higher-MW products in aerosols. Cao (2008) showed that the gas-particle partitioning coefficients for deuterated alkanes $\left(d_{40}\right.$-nonadecane and $d_{42}$ eicosane) on acidic SOA were considerably lower than those for neutral SOA. The oligomeric matter in aerosol can increase the activity coefficient of hydrophobic semivolatile compounds and also the average MW of organic matter in aerosol, thus leading to less favorable partitioning of alkanes to SOA. A similar effect has been observed in outdoor simulation chamber experiments (Lee et al., 2004) where SOA produced from the photooxidation of $\alpha$-pinene in the presence of pre-existing diesel soot induces the off-gassing of long-chain surrogate deuterated alkanes $\left(d_{40}\right.$-nonadecane and $d_{42}$-eicosane), by significantly reducing their partitioning coefficients. The partitioning coefficients of deuterated long-chain alkanes decrease by one order of magnitude as 
diesel exhaust is photochemically aged both with and without $\alpha$-pinene. Such studies imply that aging of ambient aerosols can enrich highly oxidized and oligomerized organic species by atmospheric oxidation as well as off-gassing of hydrophobic compounds. However, the concentrations of the latter could also be reduced by reactions in the aerosol phase and should be the subject of future investigations.

\subsection{Chemical and photochemical processing of organics in the atmospheric aqueous phase}

A number of studies have been performed on the chemical processing of organic compounds in the atmospheric aqueous phase (i.e., rain, clouds, fogs and aqueous aerosol particles), in order to determine their impact on atmospheric chemistry. They have shown that the aqueous phase processing of organics yields products with lower volatility than those obtained from analogous gas phase reactions. Aqueous phase processes are, therefore, potentially important sources of higher-MW compounds and may contribute to the formation of organic matter in the particle phase. It was suggested that SOA can be produced through cloud and fog processing of carbonyls, monocarboxylic acids, alcohols and organic peroxides to form dicarboxylic acids, functionalized acids, functionalized carbonyls, esters, polyols, amines, amino acids, and organosulfur compounds. Subsequently, a number of studies have been performed on the transformation of various oxygenated organic species in the aqueous phase and at its interface in order to elucidate the key processes and mechanisms involved (Blando and Turpin, 2000; Warneck, 2003; Ervens et al., 2004a, b, 2008; Herrmann et al., 2005; Altieri et al., 2006, 2008, 2009; Carlton et al., 2006; Lim et al., 2005; Poulain et al., 2007; Tilgner et al., 2008; El Haddad et al., 2009; Liu et al., 2009).

\subsubsection{Aqueous phase oxidation of organic compounds}

A number of field studies have shown that the high amount of organic acids (such as oxalic, malonic, malic, succinic, glutaric, formic and acetic acids) found in atmospheric waters and aerosols originate from aqueous phase processes (Legrand et al., 2003, 2005, 2007; Yao et al., 2003; Crahan et al., 2004; Yu et al., 2005; Sorooshian et al., 2007b). It has also been suggested that in-cloud biological activity is an important process (Yao et al., 2003; Amato et al., 2005), but its contribution has not yet been quantified. A larger number of studies have focused on the aqueous phase chemistry. The processing of organic compounds in atmospheric waters can be initiated by numerous oxidizing radicals, including $\mathrm{OH}, \mathrm{NO}_{3}, \mathrm{HO}_{2}$, and also radical anions such as $\mathrm{O}_{2}^{-}, \mathrm{Cl}_{2}^{-}$, $\mathrm{Br}_{2}^{-}, \mathrm{SO}_{4}^{-}$, and finally, non-radical reactants such as ozone and $\mathrm{H}_{2} \mathrm{O}_{2}$. The $\mathrm{OH}$ radical is one of the major sinks for organic compounds, and its presence in atmospheric waters has been confirmed in numerous studies (e.g., Faust and Allen, 1993; Arakaki and Faust, 1998; Anastasio and McGregor,
2001; Arakaki et al., 2006). The major sources for aqueous phase $\mathrm{OH}$ radicals are highly dependent on the surrounding air masses (Herrmann et al., 2000; Deguillaume et al., 2004). For the anthropogenically influenced boundary layer, due to the significant presence of HONO, Anastasio and McGregor (2001) showed that nitrite photolysis in the aqueous phase was a major source of $\mathrm{OH}$ compared to other sources, including gas-to-droplet partitioning,

$\mathrm{NO}_{2}^{-}+\mathrm{H}_{2} \mathrm{O}+h v(\lambda<400 \mathrm{~nm}) \rightarrow \mathrm{OH}+\mathrm{NO}+\mathrm{OH}^{-}$

However, for clouds in the free troposphere this formation pathway is of minor importance compared to the aqueous phase photolysis of nitrate ions (Arakaki et al., 2006)

$\mathrm{NO}_{3}^{-}+\mathrm{H}_{2} \mathrm{O}+h v(\lambda<355 \mathrm{~nm}) \rightarrow \mathrm{OH}+\mathrm{NO}_{2}+\mathrm{OH}^{-}$

the photo-Fenton reaction (at $\mathrm{pH} \leq 4$ ), which is a photochemical cycle (Arakaki and Faust, 1998)

$\mathrm{FeOH}^{2+}+h v(\lambda<370 \mathrm{~nm}) \rightarrow \mathrm{OH}+\mathrm{Fe}^{2+}$

$\mathrm{Fe}^{2+}+\mathrm{H}_{2} \mathrm{O}_{2} \rightarrow \mathrm{OH}+\mathrm{FeOH}^{2+}$

and, to a lesser extent, the aqueous phase photolysis of $\mathrm{H}_{2} \mathrm{O}_{2}$ (Arakaki and Faust, 1998; Parazols et al., 2006)

$\mathrm{H}_{2} \mathrm{O}_{2}+(\lambda<320 \mathrm{~nm}) \rightarrow 2 \mathrm{OH}$

Experimental and theoretical studies confirm that dissolved organic compounds play a major role in the cycling of $\mathrm{OH}$ radicals to $\mathrm{HO}_{2} / \mathrm{O}_{2}^{-}$radicals and/or $\mathrm{H}_{2} \mathrm{O}_{2}$ (Lelieveld and Crutzen, 1990; Arakaki and Faust, 1998; Monod and Carlier, 1999; Blando and Turpin, 2000; Herrmann et al., 2000, 2005; Anastasio and McGregor, 2001; Herrmann, 2003; Deguillaume et al., 2004; Ervens et al., 2003a, 2004a; Arakaki et al., 2006; and references therein).

The kinetics of the oxidation of more than 100 organic compounds by different radicals and anions $\left(\mathrm{OH}, \mathrm{NO}_{3}, \mathrm{Cl}\right.$, $\mathrm{Cl}_{2}^{-}, \mathrm{Br}_{2}^{-}, \mathrm{SO}_{4}^{-} ; \mathrm{CO}_{3}^{-}$) have been extensively studied in the aqueous phase. The reviews by Buxton et al. (1988) and Herrmann (2003) have confirmed that the $\mathrm{OH}$ radical is the most efficient oxidizing agent under atmospheric conditions. Arguing that the ionic strength can vary widely from rain drops and cloud/fog droplets to deliquescent aerosols, Herrmann (2003) showed that the ionic strength has a significant effect on the oxidation rate constants and depends on different parameters such as the type of salt, the oxidizing radical, and the chemical structure of organics. However, very few studies have investigated this effect, although it should be an important parameter for oligomerization. The aqueous phase oxidation of organic compounds has mainly been investigated at $298 \mathrm{~K}$, which is not relevant to the temperatures encountered in cloud/fog waters, and only a limited number of studies have explored the temperature dependence of the rate constants for reaction of $\mathrm{OH}$ with organic compounds at low ionic strength, representative of cloud/fog droplets (Chin and Wine, 1994; Buxton et al., 1997; Ervens 
et al., 2003b; Gligorovski and Herrmann, 2004; Monod et al., 2005; Poulain et al., 2007; Gligorovski et al., 2009). Based on these studies, structure activity relationships have been proposed to predict rate constants for the reaction of $\mathrm{OH}$ radicals with organic compounds at $298 \mathrm{~K}$ (Gligorovski and Herrmann, 2004; Monod et al., 2005; Monod and Doussin, 2008; Morozov et al., 2008; Gligorovski et al., 2009). Nevertheless, many aqueous phase oxidation reactions have yet to be investigated, especially for non-aliphatic compounds, and therefore are not considered in current models. This results in large uncertainties in the contribution of aqueous phase oxidation processes to organic matter.

A number of laboratory studies have investigated the reaction products and mechanisms of aqueous phase oxidation of a number of organic compounds. Although most of these were aimed at studying water treatment methods, or the behavior of sugars in living cells, a few were carried out under atmospheric conditions, i.e., at $\mathrm{pH} \leq 7, \mathrm{O}_{2}$ saturated, under UV-visible irradiation ( $>290 \mathrm{~nm}$ ), and at concentrations relevant to the atmosphere. Not surprisingly, most of these studies revealed that all precursors are transformed more or less directly into carboxylic acids (Table 10). Apart from gaseous $\mathrm{CO}_{2}$, formic, acetic and oxalic acids appear to be the most often encountered end products, in good agreement with field observations. Some studies also showed the importance of intermediate compounds, such as hydroperoxides (Schuchmann and von Sonntag, 1982, 1988; Schuchmann et al., 1989, 1990; Zuo and Hoigné, 1992; Stemmler et al., 2000a, b; Chevallier et al., 2004; Monod et al., 2007; Poulain et al., 2007), which have been scarcely measured in atmospheric waters (Sauer et al., 1996), despite their importance in tropospheric chemistry (Reeves and Penkett, 2003).

A number of photochemical studies observed the formation of higher-MW organic compounds (called here oligomers) in the aqueous phase and are summarized in Table 10. These observations indicate that photochemical processing of organics followed by cloud/fog evaporation is a possible pathway for SOA formation. As shown in Table 10, it appears that oligomers are only formed from complex precursors, i.e., $\geq \mathrm{C}_{2}$ polyfunctional compounds. However, further studies are needed to confirm this, as other parameters can be of importance for oligomerization, such as the presence of transition metal ions (TMI). In the studies of Gelenscér et al. (2003) and Hoffer et al. (2004), the presence of transition metals may have influenced the formation of light absorbing species that were assimilated to oligomers.

The role of transition metals is complex. Iron is the most ubiquitous transition metal in atmospheric waters (Deguillaume et al., 2005), and its photochemical reactivity has been shown to significantly influence the reactivity of organic compounds. Ionic forms of iron and copper increase the amount of hydroperoxides formed from the $\mathrm{OH}$ oxidation of 2-butoxyethanol (Stemmler et al., 2000b); the presence of $\mathrm{Fe}^{\mathrm{II}}$ in aqueous solutions enhances the decomposition of methyl- and ethyl-hydroperoxides (Chevallier et al.,
2004); the organic acids-Fe $\mathrm{F}^{\mathrm{III}}$ complexes catalyze the photochemical decomposition of oxalic, glyoxalic and pyruvic acids (Zuo and Hoigné, 1994). The formation of organic-iron complexes is likely the reason for the light absorbing species observed by Gelenscér et al. (2003) and Hoffer et al. (2004) during the $\mathrm{OH}$-initiated oxidation of 3,5-dihydroxybenzoic acid. Finally, Parazols et al. (2006) suggested that organiciron complexes present in clouds may inhibit, under specific environmental circumstances, the natural Fenton reaction to produce $\mathrm{OH}$ radicals.

Table 10 shows that the number of investigations is limited, and almost none of the studied reactions were duplicated by different groups, except for the $\mathrm{OH}$-initiated oxidation of glyoxal and direct photolysis of pyruvic acid. A reasonable agreement was obtained for the reaction products of $\mathrm{OH}$ oxidation of glyoxal using two very different techniques (Buxton et al., 1997; Carlton et al., 2007). Studying the photolysis of pyruvic acid with very different techniques, Guzmán et al. (2006) and Altieri et al. (2006) both obtained oligomers, but the proposed structures of the products were different, as well as the possible mechanisms explaining their formation. This highlights the need for further experimental work employing a variety of different techniques to identify oligomers and their formation mechanisms.

In general, two different kinds of mechanisms are proposed to explain the formation of oligomers in the aqueous phase; (i) acid catalyzed chemical processes (as described in Sect. 5.2), and (ii) radical processes. Loeffler et al. (2006) observed hemiacetal/acetal formation from semi-hydrated glyoxal and methylglyoxal and showed that acids have little effect on the oligomerization of glyoxal, but bases interrupt oligomer formation by catalyzing glyoxal hydration and disproportionation to glycolic acid. Holmes and Petrucci (2006) showed that oligomers up to $1458 \mathrm{Da}$ were obtained from acid catalyzed processes such as hydration, hemiacetal/acetal formation, aldol condensation, and polymerization from levoglucosan in the aqueous phase. Studying the photolysis of pyruvic acid and the $\mathrm{OH}$ oxidation of methylglyoxal, Altieri et al. $(2006,2008)$ showed the formation of similar oligomers (up to $600 \mathrm{Da}$ ). This was explained by the fact that the oxidation of methylglyoxal leads to pyruvic acid and other acids that were also observed during the photolysis of pyruvic acid. A detailed study of the oligomeric structure showed the repeated contribution of a monomer $\mathrm{C}_{3} \mathrm{H}_{4} \mathrm{O}_{2}$, which was attributed to hydracrylic acid. Altieri et al. (2008) proposed acid catalyzed esterification involving the addition of hydracrylic acid to each organic acid formed photochemically to explain the observed oligomers.

Alternatively, there is evidence that radical processes may also contribute to the formation of oligomers in the aqueous phase. Guzmán et al. (2006) reported that the photolysis of pyruvic acid leads to the formation of dimers and trimers from combination reactions of the nascent alkyl radicals (Fig. 8), even under oxygen concentrations relevant to those of the atmosphere. 
Table 10. A summary of aqueous phase oxidation processes that result in oligomer formation.

\begin{tabular}{|c|c|c|c|c|c|c|}
\hline \multirow[t]{2}{*}{ Reaction } & \multicolumn{3}{|c|}{ Conditions $^{\mathrm{a}}$} & \multicolumn{2}{|c|}{ Reaction products ${ }^{b}$} & \multirow[t]{2}{*}{ Reference } \\
\hline & $\begin{array}{l}\text { Radical } \\
\text { generation }\end{array}$ & $\begin{array}{l}{[\text { organic }]_{0}} \\
(\mathrm{mM})\end{array}$ & $\mathrm{pH}$ & $\begin{array}{l}\text { Primary and } \\
\text { secondary products }\end{array}$ & oligomers & \\
\hline Pyruvic acid $+\mathrm{h} v^{\mathrm{c}}$ & - & $5-100$ & $1.0^{\mathrm{d}}$ & $\mathrm{CO}_{2 \mathrm{~g}}$ & $\begin{array}{l}\text { Dimers and trimers observed } \\
\text { by UV-VIS spectroscopy }\end{array}$ & Guzmán et al. (2006) \\
\hline Pyruvic acid $+h v$ & - & 5 and 10 & $2.7-3.1$ & & $\begin{array}{l}\text { Observed by LC/ESI-MS } \\
\text { (up to } 400 \mathrm{Da} \text { ) }\end{array}$ & Altieri et al. (2006) \\
\hline Methylglyoxal+OH & $\mathrm{H}_{2} \mathrm{O}_{2}+\mathrm{h} v$ & 2 & $4.2-4.5^{\mathrm{f}}$ & $\begin{array}{l}\text { Pyruvic, glyoxylic, formic, } \\
\text { acetic and oxalic acids }\end{array}$ & $\begin{array}{l}\text { Observed by LC/ESI-MS and } \\
\text { FT-ICR-MS (up to } 600 \mathrm{Da} \text { ) }\end{array}$ & Altieri et al. (2008) \\
\hline Glyoxal+OH & $\mathrm{H}_{2} \mathrm{O}_{2}+\mathrm{h} v$ & 2 & $4.1-4.8^{\mathrm{f}}$ & $\begin{array}{l}\text { glyoxylic and formic } \\
\text { acids, oxalic acids }\end{array}$ & $\begin{array}{l}\text { Observed by LC/ESI-MS } \\
\text { (up to } 600 \mathrm{Da} \text { ) }\end{array}$ & Carlton et al. (2007) \\
\hline Glyoxal+OH & Pulse radiolysis ${ }^{\mathrm{e}}$ & 1 & $2.0-6.0$ & glyoxylic acid, $\mathrm{H}_{2} \mathrm{O}_{2}$ & Not measured & Buxton et al. (1997) \\
\hline Methacrolein $+\mathrm{OH}$ & $\mathrm{H}_{2} \mathrm{O}_{2}+\mathrm{h} \nu^{\mathrm{g}}$ & 0.4 and 5 & $4.5-5.6^{\mathrm{f}}$ & $\begin{array}{l}\text { Methylglyoxal, formaldehyde, } \\
\text { hydroxyacetone, methacrylic } \\
\text { and acetic acids, pyruvic, } \\
\text { glyoxylic, and oxalic acids }\end{array}$ & $\begin{array}{l}\text { Observed by LC/ESI-MS } \\
\text { (up to } 400 \mathrm{Da} \text { ) }\end{array}$ & $\begin{array}{l}\text { Liu et al. (2009), } \\
\text { El Haddad et al. (2009) }\end{array}$ \\
\hline Pyruvic acid $+\mathrm{OH}$ & $\mathrm{H}_{2} \mathrm{O}_{2}+\mathrm{h} v^{\mathrm{h}}$ & 5 and 10 & $2.7-3.1$ & $\begin{array}{l}\text { Glyoxylic acid, acetic } \\
\text { acid, oxalic acids }\end{array}$ & $\begin{array}{l}\text { Observed by LC/ESI-MS } \\
\text { (up to } 500 \mathrm{Da} \text { ) }\end{array}$ & $\begin{array}{l}\text { Carlton et al. (2006), } \\
\text { Altieri et al. (2006) }\end{array}$ \\
\hline P-methylphenol+OH/NO 3 & Laser Flash Photolysis & 0.002 & 0.5 & 4-methylcatechol & $\begin{array}{l}\text { Dimers and trimers } \\
\text { Observed by SPE-LC/MS }\end{array}$ & Hoffmann (2007) \\
\hline $\mathrm{N}$-methylpyrrolidone+OH & $\mathrm{H}_{2} \mathrm{O}_{2}+\mathrm{h} v^{i}$ & 0.5 & Free $^{f}$ & $\begin{array}{l}\text { N-Methylsuccinimide, } \\
\text { 5-hydroxy-N-methylpyrrolidone, } \\
\text { formylpyrrolidone, } \\
\text { N-hydroxymethylpyrrolidone, } \\
\text { 2-pyrrolidone, } \\
\text { methylamine, } \\
\text { acetamide, } \\
\text { N-methylformamide, } \\
\text { NHPMP, } \\
\text { 2-hydroxy-N-methylsuccinimide, } \\
\text { formamide, } \\
\text { N-methylacetamide, } \\
\text { dimethylacetamide, } \\
\text { butanoic acid }\end{array}$ & $\begin{array}{l}\text { Observed by LC/ESI-MS } \\
\text { (up to } 300 \mathrm{Da} \text { ) }\end{array}$ & Poulain et al. (2007) \\
\hline $\begin{array}{l}\text { 3,5-dihydroxybenzoic } \\
\text { acid+OH }\end{array}$ & Fenton $^{\mathrm{j}}$ & 0.02 & $4.5^{\mathrm{k}}$ & Not measured & Observed by UV-VIS spectroscopy & $\begin{array}{l}\text { Gelencsér et al. (2003), } \\
\text { Hoffer et al. (2004) }\end{array}$ \\
\hline Levoglucosan & Fenton $^{\mathrm{j}}$ & 1 & $4.5^{\mathrm{k}}$ & D-glucose & $\begin{array}{l}\text { Observed by MALDI/TOF-MS and } \\
\text { ATR-FTIR (up to } 1458 \mathrm{Da} \text { ) }\end{array}$ & $\begin{array}{l}\text { Holmes and Petrucci } \\
(2006)\end{array}$ \\
\hline
\end{tabular}

a Unless specified, all the studies were carried out in steady state photochemical experiments, under aerated conditions, at $25^{\circ} \mathrm{C}$. [organic $]_{0}=$ initial organic concentrations. ${ }^{\mathrm{b}}$ For simplification, only non-hydrated forms are noted (although formaldehyde is totally hydrated in the aqueous phase), and only neutral forms of the acids are noted (although their forms depend on $\mathrm{pH}$ and $\mathrm{p} K_{a}$ ). ${ }^{\mathrm{c}} \mathrm{Photolysis}$ at $\lambda=313$ and $320 \mathrm{~nm}$, at $20^{\circ} \mathrm{C}$. ${ }^{\mathrm{d}}$ Buffered with perchloric acid. ${ }^{\mathrm{e}}$ Pulse radiolysis in $\mathrm{N}_{2} \mathrm{O} / \mathrm{O}_{2}$ aqueous solutions. ${ }^{\mathrm{f}}$ Unbuffered solutions. ${ }^{\mathrm{g}}$ Photolysis using simulated solar spectrum at $\lambda>300 \mathrm{~nm}$. ${ }^{\mathrm{h}}$ Photolysis at $\lambda=254 \mathrm{~nm}$. ${ }^{\mathrm{i}}$ Photolysis using spectrum $\lambda>250 \mathrm{~nm} .{ }^{\mathrm{j}}$ Fenton reaction was operated using 0.1 and $0.005 \mathrm{mM}$ of $\mathrm{H}_{2} \mathrm{O}_{2}$ and $\mathrm{FeCl}_{3}$ respectively. ${ }^{\mathrm{k}}$ Buffered with sulfuric acid.

Dimers and trimers were observed by Hoffmann (2007) during the $\mathrm{OH}$-oxidation of p-methylphenol (Table 10). This can be explained by the fact that phenoxyl radicals formed during $\mathrm{H}$-abstraction or addition of $\mathrm{OH}$ radicals to phenolic compounds are stabilized by mesomeric effects, their reactivity towards $\mathrm{O}_{2}$ is very low, and the recombination of two radicals (Fig. 9) is possible (von Sonntag and Schuchmann, 1997).

Liu et al. (2009) also suggested that oligomers produced during the $\mathrm{OH}$-initiated oxidation of methacrolein were formed via organic radical processes. Furthermore, Michaud et al. (2009) evaporated droplets containing oligomers derived from photooxidized methacrolein and obtained significant amounts of stable organic aerosols. These experiments showed for the first time that oligomers formed in the aqueous phase can result in SOA under atmospheric conditions, and that the resulting SOA has properties slightly different from those obtained from the gas-phase photooxidation of biogenic compounds (Michaud et al., 2009).

Aqueous phase photochemistry may lead to the formation of polyfunctional organic compounds in diluted droplets, which play an important role in condensation reactions leading to oligomers and SOA when the organic concentrations increase during cloud evaporation. However, the scientific knowledge of photochemical processes of organics, and especially polyfunctional compounds, in the atmospheric aqueous phases is still quite limited and needs further investigation. 


\subsubsection{Gas-liquid interactions leading to SOA production}

Processes at the air-water interface can play a key role in the uptake and reactions of atmospheric gases with liquid droplets. Atmospheric species may react at the interface without actually being taken up into the bulk (FinlaysonPitts and Pitts, 2000). The uptake and oxidation of $\mathrm{SO}_{2}$ cannot be explained by liquid-phase chemistry alone (Jayne et al., 1990; Donaldson, et al., 1995; Finlayson-Pitts and Pitts, 2000; Knipping et al., 2000) and it proceeds via the formation of a bound complex at the air-water interface (Jayne et al., 1990; Donaldson et al., 1995; Finlayson-Pitts and Pitts, 2000). Similarly, the atmospheric uptake of acetaldehyde (Jayne et al., 1992; Davidovits et al., 1995) and glyoxal (Schweitzer et al., 1998) cannot be described solely by liquid-phase chemistry and are best explained in terms of enhanced reactivity at the gas-liquid interface.

In particular, the presence of light has recently been shown to enhance the reactivity at the gas-liquid interface. George et al. (2005) studied the effect of light (in the range 300$500 \mathrm{~nm}$ ) on the uptake kinetics of $\mathrm{NO}_{2}$ on various surfaces taken as proxies for organic surfaces encountered in the troposphere. Based on these experiments a mechanism was suggested, in which photosensitized electron transfer is occurring. This photoenhancement is stronger on humic acids, on which the light-activated reduction of $\mathrm{NO}_{2}$ was observed to be a major source of gaseous HONO (Stemmler et al., 2006). Soil and other humic acid containing surfaces exhibit a hitherto unaccounted organic surface photochemistry in producing reductive surface species which react selectively with $\mathrm{NO}_{2}$. The interactions of aerosols consisting of humic acids with gaseous $\mathrm{NO}_{2}$ were also investigated under different light conditions in aerosol flow tube experiments at ambient pressure and temperature. The results show that $\mathrm{NO}_{2}$ is also converted on the humic acid aerosol into HONO, and that this reaction produces volatile products from the aerosol that can be detected in the gas phase at the reactor exit. The formation of HONO on the humic acid aerosol is strongly activated by light.

Similarly, a significant photoenhancement of the uptake of ozone on benzophenone and phenol solid films was also observed under simulated atmospheric conditions with respect to relative humidity, pressure, temperature and $\mathrm{O}_{3}$ concentration using a coated flow tube reactor (Jammoul et al., 2008). As a consequence of the photoenhanced heterogeneous chemistry, the contact angle increased, showing an increase of the organic film hydrophobicity for the benzophenone-phenol mixture upon combined exposure to light and ozone along with the appearance of a new absorption band up to $450 \mathrm{~nm}$. Appearance (or red-shifting) of UV-visible features during SOA formation and aging was also observed during the processing of particles obtained by the oxidation of limonene where solar radiation may play a significant role in the processing of SOA in the atmosphere (Walser et al., 2007, 2008). Light absorbing oligomers were also observed from the aldol condensation of carbonyls in sulfuric acid solutions (Nozière and Esteve, 2005, 2007). Amino acid- and ammonium sulfate-catalyzed reactions in water and ionic solutions were also suggested to produce light-absorbing "humic-like" compounds (Nozière et al., 2007).

\subsubsection{Evaluation of the importance of in-cloud processed SOA}

A number of models have been used to investigate multiphase organic chemistry, including gas- and aqueous-phase photochemistry and gas/aqueous phase transfer. In good agreement with field studies, simulating several evaporationcondensation cycles, these multiphase models showed that, compared to cloudless conditions, significant additional amounts of SOA containing carboxylic acids are formed after the cloud dissipates. For example, Warneck $(2003,2005)$ proposed that oxalic acid, present in aerosols in the remote marine atmosphere (in particular Central Pacific Ocean), mainly originates from multiphase photooxidation of ethane, ethene and acetylene. This source of oxalic acid includes gas phase photooxidation of the VOCs, followed by gas/aqueous phase transfer of the oxygenated products (glyoxal, glycolaldehyde) in cloud droplets, which then are photooxidized in the aqueous phase, leading to oxalic acid, which remains in the condensed phase after cloud evaporation, thus forming SOA. Due to the absence of other sources in the remote marine atmosphere, SOA formation from in-cloud processing may be the only pathway for oxalic acid occurrence in aerosols at such sites (Warneck, 2003, 2005). In the same way, simulating sulfate and organic multiphase chemistry (up to $\mathrm{C}_{6}$ ) through several cloud processing cycles (up to 8 cycles), Ervens et al. (2004a) showed that significant amounts of SOA containing sulfate and organic acids are formed after the cloud dissipates. In both clean and polluted atmospheres, oxalic, glutaric, adipic, and pyruvic acids are the main contributors to the organic acid fraction of the aerosol mass. In agreement with observations, the oxalate fraction in processed particles exceeds the fractions of other dicarboxylic acids since it represents an end product in the oxidation of several organic gas phase species. The study suggests that cloud processing may act as a significant source of small functionalized mono- and dicarboxylic acids, some fraction of which can be retained in the aerosol phase following droplet evaporation.

Gelencsér and Varga (2005) and Chen et al. (2007) investigated the multiphase behavior of organic compounds up to $\mathrm{C}_{10}$ polyfunctional compounds. Gelencsér and Varga (2005) determined an aerosol yield parameter for multiphase SOA formation as a function of the Henry's Law constant and found that the SOA yield is significant above $\mathrm{H}=1000 \mathrm{M} \mathrm{atm}^{-1}$. Among the potential precursors for this process are oxygenated compounds such as primary oxidation products of biogenic and anthropogenic hydrocarbons, 


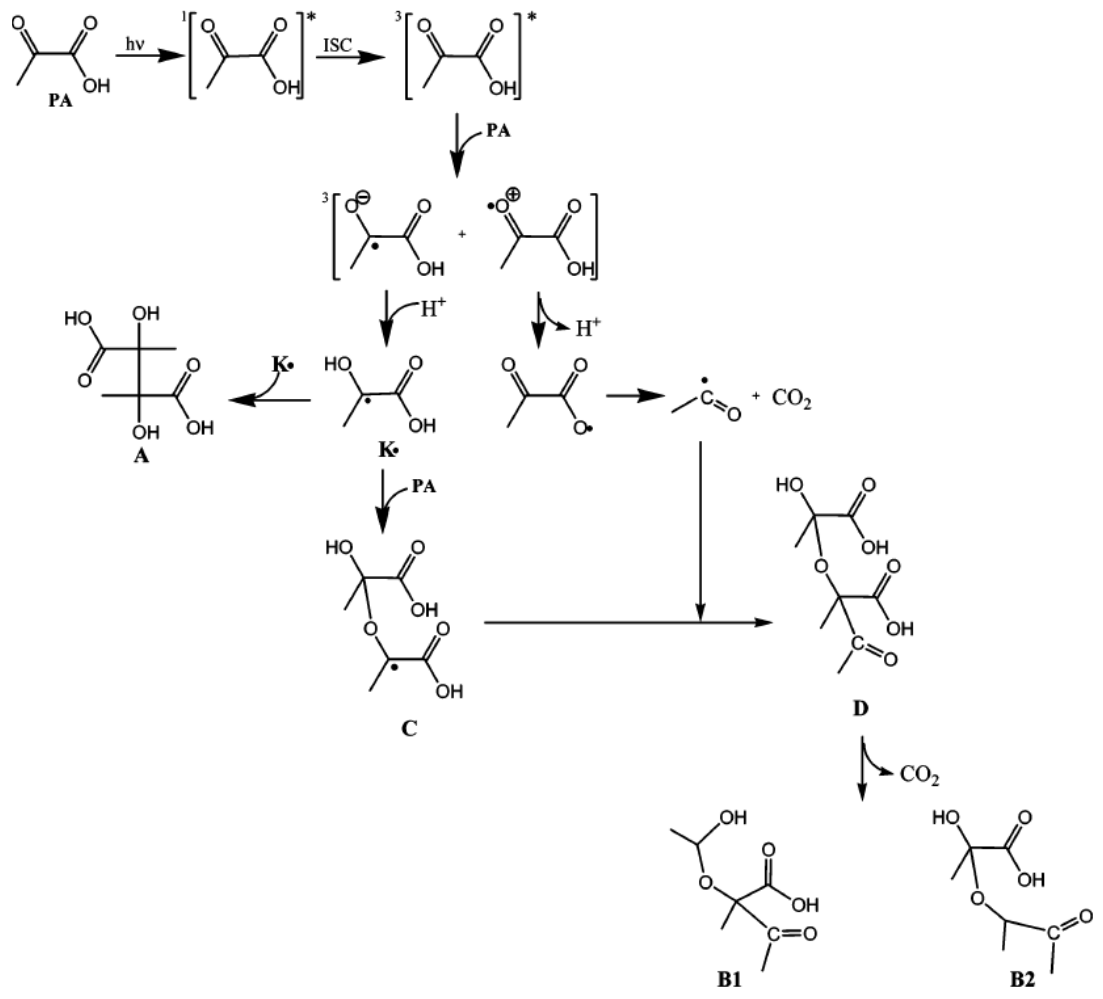

Fig. 8. Radical processes explaining the formation of oligomers during the photolysis of pyruvic acid in the aqueous phase under atmospheric conditions (Guzmán et al., 2006). PA = pyruvic acid; ISC = intersystem crossing; K· = ketyl radical; A =2,3-dimethyltartaric acid; $\mathrm{D}=$ multifunctional dicarboxylic acid. The rapid decarboxylation of $\mathrm{D}$ may form two products, $\mathrm{B} 1$ and $\mathrm{B} 2$.

including, for example, pinonaldehyde. Multiphase SOA formation was found to be less efficient than in-cloud sulfate production per unit mass concentration of the precursor. However, considering the vast amounts of VOCs that are emitted by vegetation and oxidized in the troposphere, in-cloud SOA formation may significantly contribute to atmospheric SOA production on a global scale (Gelencsér and Varga, 2005). Chen et al. (2007) applied 0-D and 3-D models which both showed a significant increase of SOA formation when the aqueous-phase organic chemistry in clouds is considered. A $27 \%$ increase was obtained using the 0-D model in a rural scenario with strong monoterpene emissions. Overall, this study suggests that SOA formation due to aqueousphase organic chemistry in clouds could be important at locations that are strongly influenced by monoterpene emissions. However, key limitations of this study were the simple treatment of organic reactions in the aqueous phase for organic compounds of carbon number greater than four (only based on their phase transfer). Another limitation was the lack of treatment of aqueous phase oligomerization processes for both biogenic and anthropogenic compounds. This should therefore amplify the importance of SOA formation due to aqueous-phase organic chemistry in clouds.

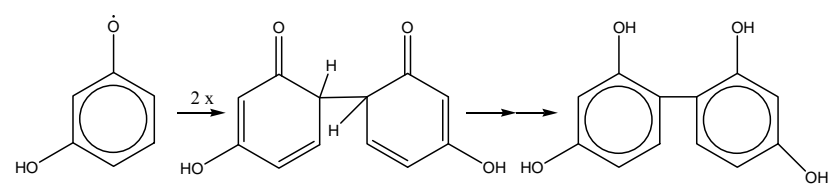

Fig. 9. Formation of dimers by recombination of two phenoxyl radicals during the $\mathrm{OH}$-initiated oxidation of phenolic compounds (von Sonntag and Schuchmann, 1997).

Lim et al. (2005) and Ervens et al. (2008) investigated the multiphase behavior of isoprene. Lim et al. (2005) studied cloud processing of isoprene in an air parcel transported for 5 days over the tropical Amazon, followed by 5 days over the Atlantic Ocean where cloud and cloudless periods alternated. Following each cloud period, aqueous-phase species continued evaporating from cloud droplets. In particular, the low volatility organic acids (i.e., glycolic, pyruvic, glyoxylic, and oxalic acid) remained in the aerosol phase during the cloudless period. Under these conditions, Lim et al. (2005) found that the contribution of cloud processing to the global SOA budget is considerable, with an important contribution of oxalic acid, in good agreement with observations. By taking into account the SOA yields obtained in the model, a global isoprene emission flux of $500 \mathrm{Tg} / \mathrm{yr}$ results in an SOA 
source strength from cloud processing of $1.6 \mathrm{Tg} / \mathrm{yr}$, which is a significant contribution to global biogenic SOA, as described in Sect. 2.1. Moreover, Fu et al. (2008) calculated the global source of SOA from the irreversible uptake of dicarbonyls (glyoxal and methylglyoxal), yielding contributions of $11 \mathrm{Tg} \mathrm{C} / \mathrm{yr}$, including $2.6 \mathrm{Tg} \mathrm{C} / \mathrm{yr}$ from glyoxal and $8 \mathrm{Tg}$ C/yr from methylglyoxal whereas $90 \%$ of this source takes place in clouds.

Ervens et al. (2008) developed a parcel model where an exhaustive multiphase chemical mechanism was complemented by the oligomer formation from glyoxal described by Altieri et al. (2006) and Carlton et al. (2006, 2007). It was shown that substantial amounts of SOA were formed from isoprene through in-cloud processes. Sensitivity tests of liquid water content, cloud contact-time, aerosol/droplet number concentration, $\mathrm{pH}$, and gas-particle partitioning of semivolatile organics showed that the $\mathrm{NO}_{\mathrm{x}}$ levels are most influential in the control of the carbon yield of the in-cloud processed SOA. Ervens et al. (2008) concluded that in regions with high $\mathrm{NO}_{\mathrm{x}}$ and isoprene emissions, together with abundant clouds (e.g., Northeastern US or Southeast Asia) the additional SOA formed through in-cloud processes might significantly contribute to SOA. However, the authors only considered the oligomer formation from glyoxal. Other potential oligomerization processes from polyfunctional compounds such as pyruvic acid (Guzmán et al., 2006; Altieri et al., 2008), or methacrolein (El Haddad et al., 2009; Liu et al., 2009) were not considered. This should result in an underestimation of the total SOA formed. Furthermore, the model calculations by Ervens et al. (2008) did not take into account the photochemical degradation of diacids and particularly oxalate and its complexes with TMI (Deguillaume et al., 2005), and therefore, probably overestimate the SOA formation.

Despite large uncertainties, the above mentioned models indicate that in-cloud aqueous phase processes of organics are probably largely contributing to the global sources of SOA. Photochemical reactions play an important role in the processing of organics. However, the scientific knowledge of photochemical processes of organics in the atmospheric aqueous phases and at the surface of droplets and aerosols is still quite limited and needs further investigations. In particular, the radical photochemistry occurring at the surface and in the bulk diluted aqueous solutions should be further studied for polyfunctional organic compounds. Special attention should be paid to radical photochemistry occurring in concentrated media where the activity coefficients are different from unity, in order to simulate the conditions of evaporating droplets and/or deliquescent aerosols. The influence of parameters relevant to the atmosphere such as $\mathrm{pH}$, TMI content and ionic strength, which are likely to be highly variable in the atmospheric aqueous phases and greatly affect oligomerization processes, should also be examined.

\subsection{Aerosol formation from real plant emissions}

The importance of BSOA is discussed in Sect. 2 and has been further demonstrated in several studies (Szidat et al., 2006; Lanz et al., 2007; Simpson et al., 2007; Schichtel et al., 2008) which reported that up to $90 \%$ of the total SOA in many regions of the European continent during summer months originates from biogenic sources. Long-term studies in the boreal forests in Finland show that biogenic oxidation products aid the formation of new particles and thus contribute not only to atmospheric particle mass but also to atmospheric particle number (O'Dowd et al., 2002). Similarly, in coastal regions biogenic organo-iodine compounds and biogenic iodine emissions contribute significantly to new particle formation (O'Dowd et al., 2002; Laaksonen et al., 2008). Kerminen et al. (2005) estimated that new particle formation over boreal forests could currently exert a cooling of $0.2-0.9 \mathrm{~W} \mathrm{~m}^{-2}$ via the effect on cloud formation. Increase of tree emissions under conditions of rising temperature and $\mathrm{CO}_{2}$ concentrations and subsequent enhanced particle formation, could thus constitute an important negative feedback of vegetation on climate change via the direct and indirect effects of aerosols (Kulmala et al., 2004). Using a vegetation model Lathiere et al. (2005) predicted the future expansion of boreal and temperate forests that may lead to an increase of monoterpene emissions by a factor of 1.5. Based on the same vegetation scenario, Tsigaridis and Kanakidou (2007) predict an increase of the future biogenic SOA burden of $0.94 \mathrm{Tg}$, i.e., the same order of magnitude as the present anthropogenic sulfate burden. The effects of climate change on vegetation emissions and biogenic SOA formation of these model studies would be in accordance with the negative feedback hypothesis of Kulmala et al. (2004). Nevertheless, large uncertainties in the SOA source strength and the tendency to strongly underestimate SOA concentration in many recent model studies point to a severe lack in the understanding of biogenic SOA sources, despite its obvious importance for climate issues (Kanakidou et al., 2005 and references therein; Fuzzi et al., 2006).

The oxidation of a single monoterpene like $\alpha$-pinene leads to a complex mixture of long-chain and short-chain products, which may or may not contribute to SOA formation. However, the natural atmosphere is an even more highly mixed system (Goldstein and Galbally, 2007), and plant emissions contain a mixture of monoterpenes, sesquiterpenes, and other long- and short-chain compounds, partly containing oxygen. Moreover, these compounds cover a wide range of reactivity towards the atmospheric oxidants $\mathrm{OH}, \mathrm{O}_{3}$ and $\mathrm{NO}_{3}$ (e.g., Atkinson and Arey, 2003). Because of their complexity, such reaction systems cannot be easily simulated in the laboratory. As a result, several recent investigations of biogenic SOA formation have utilized emissions from real plants. These experiments complement laboratory studies of SOA formation from single compounds, and enable the interaction and synergic effects of the different components in the emission 
mixture to be investigated. Moreover, such experiments will yield SOA formation potentials for emissions from individual plant species or plant groups, which can be characteristic of particular eco-systems. Such studies may serve to estimate the total flux of organic carbon into the particulate phase on an eco-system level (Mentel et al., 2009).

McFiggans et al. (2004) oxidized the emissions of macroalgae at elevated ozone levels to generate particles in order to obtain information on new particle formation in coastal areas. According to their findings molecular iodine directly released into the atmosphere from macroalgae may be more important for nucleation than organo-iodine compounds. Joutsensaari et al. (2005) studied particle formation using VOC emissions from white cabbage. In this experiment elevated ozone levels were added directly to the chamber that contained the plants, and enhanced VOC emissions were triggered by exposing the plants to methyl jasmonate. The observed particle formation rates were similar to atmospheric nucleation events, but growth rates were clearly larger. From this observation Joutsensaari et al. (2005) concluded that the condensing species should not significantly contribute to nucleation in the atmosphere and suggested that stress-induced plant emissions may be an important factor in new particle formation. In a second set of experiments the plant chamber was separated from the reaction chamber and enhanced monoterpene emissions were triggered by infesting the cabbage plants with herbivores (Pinto et al., 2007). It was concluded that the monoterpene mixing ratio (ca. $30 \mathrm{ppb}$ ) arising from the cabbage, which contained limonene (30\%) as the main component, was too low to induce new particle formation at ozone levels of less than $100 \mathrm{ppb}$.

Generally, trees are expected to be the major source of VOC that contribute to SOA formation. VanReken et al. (2006) investigated particle formation from ozonolysis of holm oak and loblolly pine emissions using a twin chamber approach. The biogenic emissions were generated in a typical plant chamber and transferred into a second, dark reactor, where ozonolysis and subsequent particle formation took place. The VOC mixing ratios (several ppb) entering the aerosol chamber during these experiments were lower than those used in most chamber studies, and approached the natural canopy levels. Ozone levels were around $50 \mathrm{ppb}$. Particle formation from holm oak and loblolly pine emissions was compared to that obtained in a control experiment performed using $\alpha$-pinene (6 ppb). VanReken et al. (2006) found that holm oak emissions were the least efficient particle source whereas emissions from loblolly pine produced more particles than $\alpha$-pinene. However, the amount of particles formed during the events was variable for the same pine tree and a simple relation between emission pattern and event strength was not evident. This study demonstrated that particle formation from biogenic emissions could be investigated under conditions that approach the ambient atmosphere.

The studies discussed above applied $\mathrm{O}_{3}$ as the main oxidant for particle formation but oxidation by $\mathrm{OH}$ is also an important loss process for VOCs. Mentel et al. (2009) investigated particle formation from emissions of boreal forest species in a twin chamber system using $\mathrm{O}_{3}(50-80 \mathrm{ppb})$ and $\mathrm{OH}$ radicals $\left((3 \pm 2) \times 10^{7} \mathrm{~cm}^{-3}\right)$ as oxidants. At total VOC mixing ratios of less than $10 \mathrm{ppb}, \mathrm{OH}$ radicals were needed to generate new particles under the conditions in the plant/reaction chamber, although almost all sesquiterpenes were already consumed by $\mathrm{O}_{3}$ before $\mathrm{OH}$ generation. An average nucleation rate, $j_{3} \mathrm{~nm}$, of $40 \mathrm{~cm}^{-3} \mathrm{~s}^{-1}$ and an average condensational growth rate of $20 \mathrm{~nm} \mathrm{~h}^{-1}$ were observed, which are larger than those over a boreal forest, but commensurable with the factor of 10 increase in $\mathrm{OH}$ concentrations. Thresholds for new particle formation were significantly lower for the tree emissions than for pure $\alpha$-pinene. The measured SOA volume, average nucleation and condensational growth rates were linearly dependent on the carbon mixing ratio in the reactor. The SOA mass fractional yields obtained for tree emissions were in good quantitative agreement (within 5-10\%) with the data obtained for boreal forests by Tunved et al. (2006).

All studies described above suggest that atmospheric aerosol formation from real plant emissions is different from that observed for the oxidation of single compounds. Studies using plants as an integral VOC source can help to confirm if the simple additivity of single compounds holds for prediction of SOA formation and where more detailed understanding is needed. Moreover, if the plants are stressed, emission strength and emission patterns change and this especially may play a role in threshold controlled processes like new particle formation. These types of results cannot intrinsically be produced by laboratory experiments with single precursors, but of course in field studies. However, in field experiments the stability of conditions is limited and long observation times are needed to reproduce findings. This gap can be filled by controlled simulation experiments with real plants, which reflect the highly mixed natural states, and approach natural VOC concentrations and oxidant levels. The achievement of quantitative results in such simulation experiments is still complicated by the natural, biological variability of plant emissions. However, separation of the plant enclosure and reaction chamber (VanReken et al., 2006) combined with thoroughly controlled conditions for plants and stable parameters in the reaction chamber, can lead to reproducible, quantitative results (Mentel et al., 2009). It seems that plant chamber studies as described above will provide an important additional tool for laboratory and field studies directed toward understanding and quantifying natural processes of particle formation.

\subsection{Interaction of atmospheric organic components with water}

Water vapor in the moist atmosphere may interact with organic aerosol components and their precursors in a number of ways. Ignoring the potential dependence of the kinetics 
of gas phase reactions in the oxidative pathways of organic species on water vapor, these interactions may be classified as:

1. Impact on the loading of organic aerosol by influence of relative humidity on the partitioning of SOA components between the gas and aerosol.

2. Changes in the ambient water content and size of aerosol particles in the sub-saturated moist atmosphere with varying relative humidity.

3. Nucleation of cloud droplets on aerosol particles containing organic material as water vapor concentration increases above a critical threshold and the growing droplet successfully competes for available water vapor.

4. Nucleation of ice crystals on organic aerosol behaving as ice nuclei, or freezing of aerosol containing organic material that had previously activated into liquid droplets.

Of course, these processes will overlap to varying degrees such that hygroscopic growth or cloud droplet activation of aerosol particles will increase the liquid water content and hence the equilibrium concentration of soluble aqueous organic components, for example. However, these classifications will first be considered in turn, before addressing such complications.

\subsubsection{The effect of relative humidity on secondary organic aerosol formation}

Seinfeld et al. (2001) and Seinfeld and Pankow (2003) considered the means by which water vapor may impact on the equilibrium concentration of SOA mass by reference to the conventional formulation of the equilibrium coefficient in absorptive partitioning, $K_{p}$, used in Eqs. (1)-(3). An increase in each component present in the aerosol phase can be accomplished by decreasing the average molecular weight of all condensed species, $\mathrm{MW}_{\text {om }}$, decreasing the component activity coefficient $\zeta_{i}$ or increasing the absorptive particulate mass, $C_{o m}$. Since water has a very low MW it will always tend to increase $K_{p}$ by decreasing $\mathrm{MW}_{o m}$. However, the activity coefficient variation with RH will be more complex and depend largely on the hydrophilic nature of the partitioning organic components.

If water is incorporated as a partitioning component into the standard partitioning theories, with an assumed activity coefficient of one, changes in $\mathrm{RH}$ are found to have profound effects on aerosol mass. This is simply a result of water being the most abundant semivolatile component in the atmosphere by many orders of magnitude. For example, Fig. 10 shows calculations for a test system of two compounds, B and C interacting with water. The resulting $\mathrm{RH}$ dependence is large owing to the low molecular mass of water (i.e., the high atmospheric molar abundance compared with the $C^{*}$ value of water expressed in molar terms compared with the lower molar abundance of the higher MW organic components relative to their $C^{*}$ values). It is clear in Fig. 10 that there is a much stronger relative dependence of condensed organic mass on $\mathrm{RH}$ at low organic molecular abundance $\left(2 \mu \mathrm{g} \mathrm{m}^{-3} \mathrm{~B}\right.$ and $\left.1 \mu \mathrm{g} \mathrm{m}^{-3} \mathrm{C}\right)$ than at high abundance $\left(200 \mu \mathrm{g} \mathrm{m}^{-3} \mathrm{~B}\right.$ and $100 \mu \mathrm{g} \mathrm{m}^{-3} \mathrm{C}$ ) and therefore that the precursor concentration at which SOA formation experiments are conducted will influence the observed RH dependence.

In contrast to these predictions, chamber studies have only reported modest RH effects on SOA mass (Cocker et al., 2001a, b), though substantial effects on particle mass and number have been reported in flow-tube studies (Jonsson et al., 2006). A challenge in these studies is that water can participate as a reactant in the gas-phase chemistry leading to SOA formation, so deconvolving RH effects on the phasepartitioning thermodynamics and water effects on the chemistry can be a challenge. Hygroscopic growth experiments provide an important additional constraint, as it is the presence of water in the organic phase that suppresses the organic vapor pressures in the theoretical calculations. To the extent that hygroscopic growth of pure organics is relatively low, the activity coefficient of water in the organic phase is greater than unity. Not only does this reduce the water fraction in the organic phase, but, via the Gibbs-Duhem relationship, it raises the organic vapor pressures as well. For example, the 1,3,5-trimethylbenzene SOA experiments reported by Baltensperger et al. (2005) show much lower hygroscopic growth at $85 \% \mathrm{RH}$ than one would predict for water forming an ideal solution with $\mathrm{MW}_{\text {organic }}=180 \mathrm{~g} \mathrm{~mol}^{-1}$, especially early in the experiment, consistent with an activity coefficient for water in the SOA of considerably more than 1 . That in turn means that there will be less water in the organic mixture at a given $\mathrm{RH}$, which finally will reduce the effect of $\mathrm{RH}$ on the organic vapor pressures. The generality of such results should be investigated. A broader discussion of the role of water in absorptive partitioning through its effects on condensed molar mass and its contribution to the overall condensed mass may be found in Barley et al. (2009) and of the effects of non-ideality and phase separation of hydrophobic and hydrophilic components in absorptive partitioning in Erdakos and Pankow (2004).

\subsubsection{Hygroscopic growth}

The hygroscopicity of a particle describes its equilibrium water content at a known humidity. Hygroscopicity is an absolute quantity, referenced to the known dry state. In the laboratory, it may be measured with a hygroscopicity tandem differential mobility analyzer (HTDMA) or by single particle techniques such as the electrodynamic balance (EDB) or optical tweezers (Hanford et al., 2008). The HTDMA compares the mobility diameter at dry conditions with that at enhanced RH, from which a (diameter related) hygroscopic growth factor (GF) is determined. The water fraction of the 
particle is then calculated assuming particle sphericity (and volume additivity on dissolution or adsorption of water). In the EDB the particle is levitated by adjusting a voltage for compensating the increase in gravitational force on water uptake; this method thus determines a mass related water uptake. The EDB requires particles with a diameter of at least about $5 \mu \mathrm{m}$, and is thus only suited for the laboratory. The HTDMA is used both in the laboratory and in the field. Swietlicki et al. (2008) provided a recent review on HTDMA measurements in the field. Zardini et al. (2008) reported a comparison of HTDMA and EDB data for mixtures of ammonium sulfate and different carboxylic acids.

Soluble inorganic particles exhibit a distinct deliquescence $\mathrm{RH}$, where particles suddenly change their state from a dry particle to a saturated solution, associated with a sudden change in the diameter. On further increase of RH the particle becomes more diluted, resulting in a further increase in the diameter. On decreasing the RH the particle does not crystallize at the deliquescence RH (DRH) but rather stays liquid in a supersaturated solution, exhibiting hysteresis, until it crystallizes at lower RH known as the efflorescence RH (ERH).

Marcolli et al. (2004), Marcolli and Krieger (2006) and Meyer et al. (2009) showed that organic compounds can reduce the DRH of mixed particles compared with particles containing only inorganic components, thus enabling the inorganic components to be partly solubilized below their DRH. The ERH of particles mixed of ammonium sulfate and limonene or $\alpha$-pinene SOA have been found not to differ significantly from the ERH of pure ammonium sulfate particles (Takahama et al., 2007). However, aged ambient aerosol particles, as typically found at remote sites such as the highAlpine site Jungfraujoch, do not show efflorescence at RH as low as 10\% (Weingartner et al., 2002). From such field measurements it may be implied that, for atmospheric aerosols, the presence of SOA will enable the water uptake of the inorganic fraction at RH values lower than the DRH of the inorganic component.

The hygroscopic growth of SOA has recently been investigated in several simulation chamber studies (Baltensperger et al., 2005; Varutbankul et al., 2006; Duplissy et al., 2008). No efflorescence or deliquescence has been found in these studies. Hygroscopic growth has been found to increase with aging time under the chamber conditions (Baltensperger et al., 2005; Duplissy et al., 2008), with such an increase being consistent with oxidation of the SOA particles during aging. Oligomerization is another process thought to take place during aging. In chamber experiments, dimers and trimers have a lower O/C ratio than monomers (Reinhardt et al., 2007). In line with this observation, Altieri et al. (2008) reported that the ratio of organic matter to organic carbon $(\mathrm{OM} / \mathrm{OC})$ in the oligomers (1.0-2.5) was lower than the OM/OC in the organic acid monomers formed, suggesting that the oligomers are less hygroscopic than the organic acid monomers in the investigated system. An increase in hygroscopicity with time

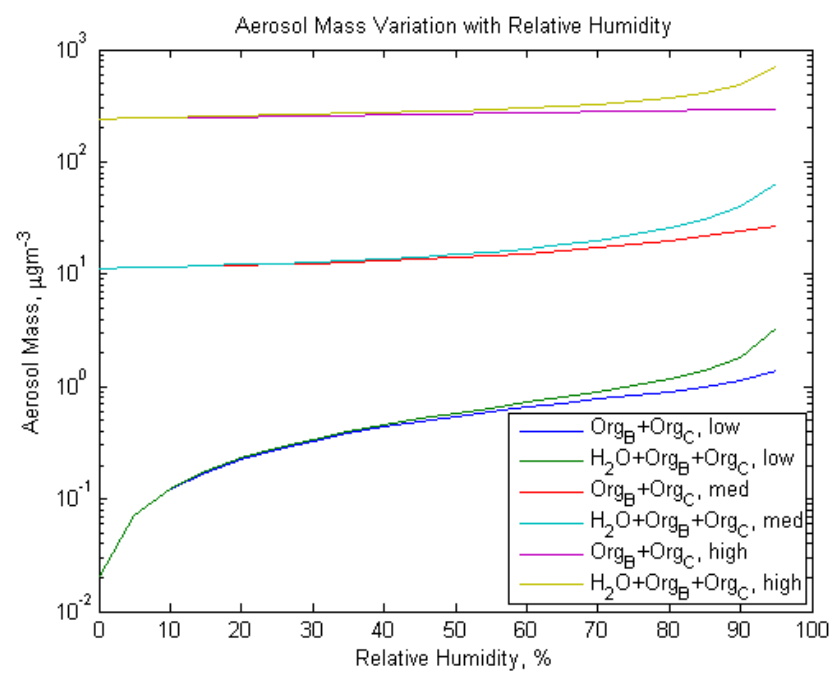

Fig. 10. Condensed mass predicted in the partitioning of water and two organic components, $\mathrm{B}$ and $\mathrm{C}$, assuming ideality. $\mathrm{B}$ and $\mathrm{C}$ have molar-based $C^{*}$ values of 0.4 and $0.004 \mu \mathrm{mol} \mathrm{m}^{-3}$. Using molar masses of $250 \mathrm{~g} \mathrm{~mol}^{-1}$ for both $\mathrm{B}$ and $\mathrm{C}$, this is equivalent to massbased $C^{*}$ values of 100 and $1 \mu \mathrm{gm}^{-3}\left(\log C^{*}\right.$ mass based bins 2 and 0 ). The three pairs of curves show the effect of varying the total organic abundances of $0.008,0.08,0.8 \mu \mathrm{mol} \mathrm{m}^{-3}(2,20$ and $200 \mu \mathrm{gm}^{-3}$ ) of component B and $0.004,0.04,0.4 \mu \mathrm{mol} \mathrm{m}^{-3}(1,10$ and $100 \mu \mathrm{gm}^{-3}$ ) of component $\mathrm{C}$ (low, medium and high cases).

may indicate that oxidation overwhelms oligomerization in the aging of particles formed by self-nucleation. Furthermore, an increased hygroscopic growth was found for a decreasing chamber VOC precursor concentration (Duplissy et al., 2008). This may be explained by partitioning of higher volatility (less polar) compounds into the aerosol at high concentrations, as described in Sect. 4.3.2. Decreasing the VOC precursor, hence molecular abundance of partitioning organics and aerosol loading down to atmospherically relevant values thus results in an increase of the hygroscopic growth factor.

Hygroscopic growth has also been investigated for HULIS, which are frequently used as model compounds for SOA. Both HULIS extracted from atmospheric aerosols and standard material such as SRFA have been investigated (Gysel et al., 2004; Baltensperger et al., 2005; Dinar et al., 2007; Ziese et al., 2008). In general, these samples showed similar hygroscopic growth.

The water content can be calculated by accounting for the ionic and molecular interactions (solving the water equation within an energy minimization) or can be evaluated by use of relationships derived from mixing rules, such as that of Zdanovskii, Stokes and Robinson (ZSR) (Stokes and Robinson, 1966). Whichever method is used to evaluate multicomponent water content, the prediction must include the water associated with all components. Such binary aqueous solution data may be readily available for inorganic 
systems of atmospheric importance, but are seldom available for atmospherically-representative organic compounds, necessitating the use of models to predict the water activity in the aqueous organic solution. A number of approaches have been used, including; (i) explicit considerations of compound interactions requiring compound specific laboratory data, e.g., the extended ZSR approach of Clegg and Simonson (2001); (ii) empirically-fitted approaches such as UNIQUAC (Ming and Russell, 2002); (iii) more generalized group contribution techniques such as UNIFAC (Topping et al., 2005a, b). Various developments have been made to UNIFAC in order to most appropriately treat atmospherically relevant components through development of new group interaction parameters (Peng et al., 2001), based on emerging laboratory data. The contribution to the water content by a number of organic components may be directly evaluated within the organic activity coefficient model, and combined with the water associated with the inorganic components in a coupled model (Topping et al., 2005b). Such models may (Ming and Russell, 2002; Erdakos et al., 2006a, b) or may not (Topping et al., 2005b) explicitly account for interactions between inorganic and organic solutes. The AIOMFAC model reported by Zuend et al. (2008) is based on LIFAC with improved treatments of the mid-range interaction terms enabling superior treatment of inorganic and a limited number of organic components (alcohols and polyols) in multicomponent aerosol. A recent detailed comparison with laboratory measurements has shown that both coupled and uncoupled treatments of inorganic and organic components capture water uptake behavior adequately (Hanford et al., 2008). Alternatively, the contributions may be lumped and treated in an additive manner as in the ZSR technique, which may be applied as outlined below.

The hygroscopic growth factor of a mixture $\left(\mathrm{GF}_{\text {mixed }}\right)$ is estimated from the growth factors of the individual components of the aerosol and their respective volume fractions, $\varepsilon$ :

$\mathrm{GF}_{\text {mixed }}=\left(\sum_{k} \varepsilon_{k} \mathrm{GF}_{k}^{3}\right)^{1 / 3}$

where the summation is performed over all compounds present in the particles. The model assumes that the particles are spherical, there is ideal mixing behavior (i.e., no volume change upon mixing) and independent water uptake by the organic and inorganic components. The volume fractions $\varepsilon_{i}$ of the components in the particles are calculated as

$\varepsilon_{i}=\frac{\left(w_{i}\right) /\left(\rho_{i}\right)}{\sum_{k}\left(w_{k} / \rho_{k}\right)}$

where $w_{i}$ is the measured mass fraction and $\rho_{i}$ the density of component $i$.

A number of laboratory studies have shown that the ZSR relationship is generally valid within experimental error (e.g., Choi and Chan, 2002; Svenningsson et al., 2006; Varutbangkul et al., 2006; Moore and Raymond, 2008; Sjogren et al., 2008). Relatively few field studies are reported where HTDMA measurements were accompanied by detailed chemical measurements sufficient to perform a hygroscopicity closure (McFiggans et al., 2005; Aklilu et al., 2006; Gysel et al., 2007; Sjogren et al., 2008). McFiggans et al. (2005) and Gysel et al. (2007) showed that, in atmospheric particles, water uptake is to a great extent determined by the inorganic constituents. It was found to be more important that the chemistry and instrumental behavior of the inorganic compounds was well-characterized, e.g., if sulfate was present as ammonium sulfate or ammonium bisulfate and whether ammonium nitrate was present, than if the hygroscopic growth factor chosen for the organic components was accurate.

\subsubsection{Cloud condensation nucleation behavior}

The activation of an aerosol particle into a cloud droplet is determined by the size of the particle and its composition. A complete discussion of the processes controlling warm cloud droplet activation is provided by McFiggans et al. (2006). With respect to the effect of organic components on CCN behavior of atmospheric aerosol, there are several considerations. Organic molecules may influence both the Raoult and Kelvin terms of the Köhler equation by their effect on the water activity and surface tension of the activating aerosol particle.

The cloud forming potential is closely related to the hygroscopic properties of the aerosol, and is typically probed with a cloud condensation nuclei counter (VanReken et al., 2005; Prenni et al., 2007; Duplissy et al., 2008; Engelhart et al., 2008). VanReken et al. (2005) found a decreasing hygroscopicity (increased supersaturation required for activation at a given size) with aging time for SOA from several biogenic precursors and attributed this to an increased degree of oligomerization, while Duplissy et al. (2008) reported a decreasing required supersaturation with aging time, in line with the simultaneously observed increasing hygroscopic growth determined with an HTDMA. Similarly, Engelhart et al. (2008) reported that $\alpha$-pinene SOA experienced a decrease of the particle activation diameter of approximately $3 \mathrm{~nm} \mathrm{~h}^{-1}$ during aging.

Recently the semi-empirical " $\kappa$-Köhler theory" (Petters and Kreidenweis, 2007 and references therein) was introduced to describe the hygroscopic growth as a function of relative humidity (so-called humidograms). Here, $\kappa$ is a single free parameter of the " $\kappa$-Köhler theory", capturing all compound properties as well as the degree of dissociation and deviations from ideal behavior as a function of water activity, thus determining the hygroscopic growth. Whilst it is unlikely that general agreement may be obtained with this approach to link sub-saturated and supersaturated beha-vior, it may have value under well-defined conditions. Seve-ral studies have found that, within error, reconciliation of growth factor and CCN activation from chamber studies of SOA can be achieved using such an approach with the surface 
tension of water (e.g., Duplissy et al., 2008). Engelhart et al. (2008) reported that the CCN activity of $\alpha$-pinene and mixed monoterpene SOA can be modeled by a very simple implementation of Köhler theory, assuming complete dissolution of the particles, no dissociation into ions, a molecular weight of $180 \mathrm{~g} \mathrm{~mol}^{-1}$, a density of $1.5 \mathrm{~g} \mathrm{~cm}^{-3}$, and a surface tension to within $10-15 \%$ of water. However, Prenni et al. (2007) found that measured droplet activation conditions were inconsistent with hygroscopicity measured below water saturation and Köhler theory expressions based on Raoult's law for several parameterizations of water activity for SOA formed in ozonolysis of $\alpha$-pinene and other precursors. Dinar et al. (2007) found that the approach works reasonably well for SRFA samples but is limited in use for the HULIS extracts from smoke- and pollution-derived aerosol particles, stating that the difficulties arose from uncertainties with the GF measurements at high relative humidity, leading to large errors in the predicted CCN activity. It is also possible that surface tension could have played a role in the activation of the HULIS extracts. More research is needed to elucidate the reasons for these different observations.

Surface-active compounds may have a significant potential to increase the predicted cloud number concentration and thus radiative forcing in cloud simulations, when compared with simplified simulations assuming the properties of ammonium sulfate (Ervens et al., 2005; McFiggans et al., 2006) and may thus be of high atmospheric relevance. Cloud activation behavior prediction using theoretical calculation of surface tension was shown to give reasonable agreement with laboratory measurements for pure component organic particles generated in the laboratory (Rissman et al., 2007). However, recent developments in the theory of partitioning of surface active materials between the bulk and surface of growing aqueous droplets (Kokkola et al., 2006; Sorjamaa and Laaksonen, 2006) indicate that, when agreement is achieved in such studies using the simplified approach, this is likely to result from cancellation of errors in the underlying assumptions. Such complete cancellation cannot generally be assumed. In addition, although the critical supersaturation of a particle may be correctly predicted using the simplified approach, there may be significant differences in the prediction of critical diameter. McFiggans et al. (2006) provide a discussion of the potential effects of component-limited solubility and the possible effects of film-forming compounds on $\mathrm{CCN}$ behavior relevant to organic aerosol components. More recent modification of Köhler theory to account for adsorption to wettable but largely insoluble compounds (Sorjamaa and Laaksonen, 2006) has predicted that such processes may account for activation of such components at atmospherically-reasonable supersaturations and further theoretical and laboratory work is needed to investigate this behavior.

Two recent studies have investigated the $\mathrm{CCN}$ behavior of mixed inorganic/organic particles from different perspectives. Dinar et al. (2008a) suggested that the formation of ammonium salts due to reaction of ammonia with slightly soluble organic acids (such as adipic acid) can affect the CCN activity and hygroscopic growth of aerosols with a significant organic component. The findings are relevant to organic components containing carboxylic groups and require the presence of water in the aerosol. It was also found that the effects are stronger for less soluble organic acids. Prisle et al. (2008) showed that it was necessary to consider partitioning of organic molecules between the bulk and surface of an activating cloud droplet to correctly predict measured CCN behavior of the sodium salts of $\mathrm{C}_{8}$ to $\mathrm{C}_{14}$ fatty acids, confirming the predictions made by surface partitioning theory.

\subsubsection{Ice nucleation}

In general ice nucleation can occur in the atmosphere in two fundamental ways: through homogeneous freezing of liquid solution droplets and through heterogeneous interaction on a particulate nucleus. Homogeneous nucleation, or freezing, occurs at temperatures below about $240 \mathrm{~K}$, while heterogeneous freezing may occur at much higher temperatures and just slightly below $273 \mathrm{~K}$. For both processes, nucleating efficiency not only depends on temperature but also on the chemical composition of the droplets or particles. On the other hand, when the nucleation of ice from supercooled aqueous solutions is described as a function of the water activity of a solution, the ice nucleation process becomes independent of the chemical composition (Koop, 2004), indicating the nature of the solute is unimportant for the freezing process. There is further evidence that a similar dependence is also true for heterogeneous ice nucleation in the immersion mode (Zobrist et al., 2008a) and for dust particles with soluble coatings in the deposition/immersion model (Archuleta et al., 2005).

The majority of work on organic aerosol components and their influence on homogeneous freezing has mainly focussed on small organic acids. While some laboratory studies indicate that low molecular weight dicarboxylic acids exhibit identical freezing behavior as sulfate (Wise et al., 2004), others have indicated that homogeneous freezing of low molecular weight dicarboxylic acids is not as efficient as for inorganic aerosol components (Prenni et al., 2001). Also field measurements indicate that organics could impede ice nucleation since these measurements have revealed that organic containing aerosols are less abundant than sulfate aerosols in ice cloud particles when compared to interstitial aerosols (DeMott et al., 2003; Cziczo et al., 2004a, b). Based on a modeling approach, Kärcher and Koop (2005) explain this poor partitioning of certain organics into the ice phase primarily by a disparate water uptake and resulting size differences that occur between organic and inorganic particles prior to freezing. The situation is less clear with respect to the influence of organic aerosol components on heterogeneous ice nucleation processes. Zobrist et al. (2006) 
measured the heterogeneous freezing points with several immersed dicarboxylic acids and found that only oxalic acid, in the form of its dihydrate, acts as a heterogeneous ice nucleus with an increase in freezing temperature between 2 and $5 \mathrm{~K}$. Long-chain alcohols have also been found to catalyze the freezing of solutions of ammonium sulfate and sodium chloride (Popovitz-Biro et al., 1994; Seeley and Seidler, 2001; Cantrell and Robinson, 2006; Zobrist et al., 2008a). For the alcohol systems, it is believed that the organic molecules self-assemble at the air-water interface into two-dimensional crystals with a structure similar to the basal plane of ice. In the case of oxalic acid the crystallization of the oxalic acid hydrate within the aqueous solution is assumed to result in organic crystals, which act as immersion mode freezing ice nuclei. Further interesting results with respect to the influence of organics on ice formation were recently published by Beaver et al. (2006), who studied the effects of carbonyl compounds on the ice nucleation of sulfuric acid in the laboratory and observed that the physical properties of the organic compounds (primarily the solubility and melting point) play a dominant role in determining the inferred mode of nucleation (homogeneous or heterogeneous) and the specific freezing temperatures. Highly soluble, low-melting point organics caused a decrease in aerosol ice nucleation temperatures when compared with aqueous sulfuric acid aerosol in agreement with the homogeneous freezing experiments mentioned above. In contrast, sulfuric acid particles exposed to organic compounds of higher molecular weight, of much lower solubility and higher melting temperatures, nucleate ice at temperatures above aqueous sulfuric acid aerosols. Apparently, partial crystallization of organic molecules changes the freezing mode from homogeneous to heterogeneous. The precipitated crystal, possibly an organic solid, might then induce heterogeneous ice nucleation at the liquid/solid interface.

Finally, there is another potential effect of organic aerosol components on ice cloud formation - the influence of organic surface layers. For example, organic films on the aerosol surface have been used as one explanation for supersaturations with respect to ice exceeding $100 \%$ observed in the tropical tropopause (Jensen et al., 2005). The idea is that dense organic films might reduce the accommodation coefficient for the uptake of water, resulting in aerosols with more concentrated solutions, with lower activities, and correspondingly inhibited homogeneous freezing. Alternatively, if water rich aerosols were fully covered with organic surfactants, nucleation might be suppressed if it started preferentially at the surface (Tabazadeh et al., 2003; Peter et al., 2006). In addition, there have been recent studies on ice nucleation on pure SOA particles as well as on mineral dust particles coated with SOA (Möhler et al., 2008). SOA significantly reduced the ice nucleation efficiency in both the homogeneous and the heterogeneous ice nucleation case, requiring very large supersaturations before ice particles could be observed. Similar results were obtained for soot particles covered by or- ganic carbon (Möhler et al., 2005). These effects were very recently interpreted by the possible presence of a highly viscous or glassy state in solutions of larger organic molecules (Murray, 2008; Zobrist et al., 2008b). Furthermore, Prenni et al. (2009) investigated the ice nucleation behavior of SOA particles generated by the ozonolysis of 25 different alkenes. None of these SOA particles showed measurable signatures of heterogeneous ice nucleation at a temperature of $243 \mathrm{~K}$. However, the laboratory studies mentioned above are performed at precursor concentrations significantly greater than those commonly occurring in the atmosphere, influencing the chemical composition of SOA. As already mentioned above, in Sects. 3.2. and 4.1.2, as the mass concentration of organic aerosol rises in a chamber experiment, compounds of higher volatility (and different chemical functionalities) progressively partition into the aerosol phase, potentially changing the physico-chemical behavior of the organic phase. Such effects have already been observed experimentally for the cloud activation potential of SOA for atmospheric mass loadings (King et al., 2009) and it remains to be explored if they also play a role for the ice-forming properties of organics. Similarly, changes of chemical functionalities of organics as a consequence of homogeneous or heterogeneous aging or organic aerosol components are not covered in conventional chamber experiments.

In summary, it remains unclear how important the chemical nature of the organic compounds is with respect to their ability to serve as ice nuclei or their potential to impede or even inhibit ice formation, since the implications of individual solubility, melting temperature, surface activity or glassforming properties of organics are not quantitatively understood. Certainly additional laboratory work and field measurements in clouds in the upper troposphere are needed in the future to understand the role of organics in ice nucleation.

\subsection{Thermodynamics and mixtures in atmospheric models}

Under the non-ideal conditions expected to be encountered under self-nucleating conditions in simulation chambers, or in organic component condensation in chambers or the atmosphere, the activity coefficients of the condensing organic compounds, $\gamma_{i}$, are required in the calculation of the $K_{p, i}$ (or $C_{i}^{*}$ ) values. The UNIFAC group contribution method is widely used for calculating activity coefficients in liquid nonelectrolyte mixtures, including organic compounds and water. Several studies have made use of UNIFAC in calculating the formation and hygroscopic properties of organic particulates (e.g., Jang et al., 1997; Pankow et al., 2001; Peng et al., 2001; Seinfeld et al., 2001; Erdakos and Pankow, 2004; Erdakos et al., 2006a, b). Semi-empirical group contribution methods such as UNIFAC are broadly suitable for atmospheric applications because a small number of functional groups can be used to represent a large number of organic components. The group interaction parameters account for 
differences in the molecular interactions between pairs of functional groups in solution under the assumption that their contributions to the component activity coefficients are additive and independent.

Because field evidence suggests that organic aerosol components invariably do not exist in the absence of inorganic components, a wide variety of approaches have been used to treat multicomponent particles. The models of Clegg et al. (2001) and Ming and Russell (2002) may be used if the concentrations of organic compounds in mixed aqueous salt aerosol are so low that water may be considered the solvent. Similarly, if the particles comprise organic and water solutions with inorganic salts present at concentrations sufficiently low for the organic/water mixture to be considered the solvent, the formulations of Kikic et al. (1991) or Erdakos et al. (2006a, b) may be appropriate.

Raatikainen and Laaksonen (2005) presented an evaluation of the capabilities of multi-component activity coefficient models for atmospheric applications. These included: (i) models combining group contribution models for organic components and ionic interaction models for inorganics: Ming and Russell (2002) combining UNIFAC (including modifications to account for differences in molecule polarity) and the Pitzer, Simonsen, Clegg (PSC) mole fraction ion interaction model and Topping et al. (2005a, b) combining UNIFAC and the PSC model, (ii) an extension of UNIFAC to include group interaction parameters for ions and (iii) a modified version of LIFAC (Yan et al., 1999), a group contribution version of the LIQUAC model of Li et al. (1994).

The Raatikainen and Laaksonen (2005) version contains optimized interaction parameters for atmospherically relevant components such as dicarboxylic acids and hydroxycarboxylic acids. All the above models are capable of predicting activity coefficients in single-phase multicomponent mixtures with reasonable but varying degrees of skill. However, phase separation is not easily treated in these formulations. A general method for predicting activity coefficients for solutions containing significant amounts of organic compounds, inorganic electrolytes and water does not exist; nor do the data require the construction of such a general framework applicable across the full range of atmospheric organic compounds.

It has been assumed in some studies that two stable liquid phases are present in the ambient aerosol (equivalent to fully externally mixed particle populations): one hydrophilic containing mostly water and inorganic electrolytes, the other hydrophobic comprising mainly organic components. This assumption allows the hydrophilic phase to be treated as an aqueous electrolyte solution, and the less polar hydrophobic phase as a non-electrolyte solution. The system can then be treated by previously-reported activity coefficient methods, e.g., in line with Griffin et al. (2003). The model of Griffin et al. (2003) does not include inorganic components in the nonaqueous phase and allows organics to partition to both condensed phases. However, it does not account adequately for the interaction of organics and inorganics within this phase. Consequently, the validity of this assumption is not general and it is desirable to develop approaches that do not rely on such a priori conditions. In general, all components may be present to some degree in all phases. In particular, high polarity organic components may be present at significant concentrations in an aqueous phase (e.g., Meyer et al., 2009) and salts may be present in a predominantly organic phase at concentrations that affect all component activities.

Clegg and Seinfeld (2006a) demonstrated that the extended-ZSR approach first proposed in Clegg et al. (2001) is reasonably accurate when carboxylic acids are not allowed to dissociate. When carboxylic acids are allowed to dissociate, the extended-ZSR only yielded reasonable results when the non-dissociating support ion is present at medium to high concentrations (Clegg and Seinfeld, 2006b). This was benchmarked against a complex Pitzer-type model based on all multicomponent equilibrium data.

The X-UNIFAC.3 model of Erdakos et al. (2006b) enables consideration of phase separation by applying correction to the model terms and constraint on parameters in predicting component activity coefficients to avoid activity coefficient re-expression relative to the same reference state in each phase, which would otherwise be necessary. The model is applicable to carboxylic acids and hydroxycarboxylic acids and was demonstrated for a limited number of mixed systems with these compounds, salts and water. There are severe data limitations in the approach limiting the specific model applicability, but the generality of the approach is encouraging.

It can be seen that there are a number of modeling tools capable of making activity coefficient predictions in single phase and multiphase solely organic or mixed organic/inorganic and aqueous solution particles. There is, as yet, no generally applicable model, but appropriate careful selection of model and laboratory SOA formation systems should allow reasonable representation of activity coefficients in partitioning calculations.

\section{Future research directions}

The topics discussed in this review demonstrate the immense progress made in our understanding of SOA over the past 10 years. We now possess much better knowledge of detailed processes and how they affect SOA formation, properties and possible environmental impacts. Despite this, there are still significant gaps in our knowledge which places limitations on our ability to quantify and predict SOA in the ambient atmosphere. In light of the progress made and problems identified, several emerging issues pose challenges which need to be addressed via a combination of laboratory, field and modeling studies. These key issues are discussed below. They are not listed in order of priority but rather as a guide for future research directions. In general, it is pointed out that many of the items on this list require faster and more accurate 
analytical tools which may open avenues for exploring a wider range of phenomena. Other major challenges include an improved understanding of the fundamental processes responsible for SOA formation and how they affect composition, and the design of simulation experiments which more closely reflect the conditions and complexity of the real atmosphere.

\subsection{SOA budget}

Further research in the following areas should help to reduce the large uncertainty associated with the SOA budget.

Missing BVOC - It is plausible that large sources of organic compounds are yet to be identified. This may be a result of current limitations associated with detection and analysis tools and may be addressed, for example, by measuring the entire reactivity of radicals towards organics in order to estimate the total organic burden in the atmosphere in different environments. A complementary approach would be to use less specific detectors in order to detect unidentified compounds in ambient and in plant chamber studies in order to assess the amount and the main functional groups of these species. 2-D separation methods may provide such an avenue for these investigations.

Improved quantification of BSOA in the field - The quantification of BSOA in the field using highly time-resolved techniques has remained a challenge due to the difficulty in separating the relatively low formation rates from variations due to advection and other OA sources. Future highly timeresolved studies (e.g., using AMS, PILS-WSOC) should be performed at locations that are expected to be dominated by BSOA to evaluate the biogenic signal more clearly. New techniques that eliminate the influence of the background $\mathrm{OA}$, such as flux measurements, or that use more specific biogenic tracers such as carbonyl sulfide uptake, may prove to be effective.

Improved quantification of SOA formation from biomass burning - Very recent results indicate that SOA formation from biomass burning emissions can be very important under some circumstances and minor in others. The observed variability is likely to stem from the high variability of the gas, semivolatile, and particle emissions from BB due to combustion conditions (flaming vs. smoldering) and fuel burned, as well as atmospheric variables (injection height, wet removal in pyroconvection). Additional field studies are needed to characterize this potentially important SOA source.

Addressing the discrepancy between ${ }^{14} \mathrm{C}$ analysis and highly time-resolved studies - The apparent contradiction between results based on ${ }^{14} \mathrm{C}$ analysis that attribute most SOA to modern sources and those from highly time-resolved studies that point to anthropogenic pollution as the dominant source of SOA needs to be a focus of future work. New field studies should strive to include both types of measurements to allow a more direct comparison and to address the possibility that the different findings are due to different geo- graphical locations or times. The potential enhancement of BSOA by anthropogenic pollution needs to be evaluated in the field by analyzing BSOA formation during periods of high and low pollution.

Use of data from simulation chambers - Bottom-up estimates of SOA formation fluxes rely on data generated from simulation chamber experiments. However, the yields of SOA from individual precursors appear to be highly dependent on experimental conditions. Further work is clearly required to establish the most appropriate parameters for inclusion in global models. Despite the complexities involved, these data need to be understood in terms of chemical and gas-particle partitioning mechanisms before reliable extrapolation to the ambient atmosphere can be placed on a sound basis. This will require substantial improvements in our understanding of the chemical mechanisms and the thermodynamics of such complex gas-particle mixtures.

Additional SOA precursors - The potential importance of additional sources of SOA (newly discovered and previously unconsidered precursors, such as acetylene and oxygenated BVOCs) should be explored. A large source of missing biogenic VOCs that result in SOA likely also includes plant leaf volatiles (Hamilton et al., 2009) and oxidation products of primary plant material containing unsaturated fatty acid residues.

\subsection{Fundamental understanding of processes leading to SOA formation}

Improved understanding of VOC oxidation - The atmospheric degradation mechanisms for many established SOA precursors (e.g., monoterpenes, aromatics) contain a high level of uncertainty, particularly in relation to the reactivity of certain oxidation products. There is a general lack of information on the degradation reactions of multifunctional oxygenates containing combinations of the key functional groups (i.e., $-\mathrm{C}(=\mathrm{O}) \mathrm{H},-\mathrm{C}(=\mathrm{O})-,-\mathrm{OH},-\mathrm{ONO}_{2}$, $-\mathrm{C}(=\mathrm{O}) \mathrm{OONO}_{2},-\mathrm{C}(=\mathrm{O}) \mathrm{OH},-\mathrm{OOH}$ and $\left.-\mathrm{C}(=\mathrm{O}) \mathrm{OOH}\right)$ and the further degradation of organic nitrates and hydroperoxides is particularly poorly characterized, even though these are comparatively significant product classes which potentially play a role in $\mathrm{SOA}$ formation. The role of $\mathrm{NO}_{3}$-initiated chemistry in SOA formation has largely been neglected and the chemical mechanisms for the atmospheric degradation of other potential SOA precursors, such as sesquiterpenes, longchain alkanes and oxygenated BVOC, are also in need of improvement.

Gas-particle partitioning - The link between the fundamental understanding of gas-particle partitioning and its application to atmospheric or laboratory generated SOA is complex. Several factors complicate the interpretation of data such as the nature of the condensed phase, effect of temperature and the validity of thermodynamics and solution theory for non-ideal partitioning. In addition, the application of fundamental data, such as vapor pressures, molar 
activity coefficients and the mean MW of the condensing phase has proven to be difficult. Further improvements in the use of gas-particle partitioning theory to interpret experimental data, obtained in both laboratory and field studies, are required.

Condensed phase reactions - The wide range of higherMW products detected in laboratory-generated SOA have resulted in many proposed reactions occurring in the condensed phase. Further work is required to investigate the key processes (e.g., oligomerization, organosulfate formation) under conditions relevant to the atmosphere.

Aqueous phase reactions - Chemical and photochemical processes in the atmospheric aqueous phase may lead to the formation of polyfunctional organic compounds in diluted droplets, which play an important role in condensation reactions leading to oligomers and SOA when the organic concentrations increase during cloud evaporation. However, the scientific knowledge of photochemical processes of organics, especially polyfunctional compounds, in the atmospheric aqueous phases is still quite limited and needs further investigation. Future studies should take into account the influence of different parameters relevant to the atmosphere such as $\mathrm{pH}$, TMI content and ionic strength, which are likely to be highly variable in evaporating droplets, and could greatly affect the oligomerization processes.

Detection and quantification of nanoparticles - Nucleation of new particles is recognized as a widespread phenomenon but the exact mechanisms of initiation and growth are not well-known. A major challenge is posed by the minute mass of the nucleation mode particles. Standing issues include identification of the main nucleating agents, the possible role of organics in nucleation, and the contribution of organics to the growth mechanism. New instrumentation dedicated to these issues is urgently required. The missing parameters need to be studied in different environments (urban, rural, remote locations) in order to be able to include nucleation in a meaningful manner in models.

\subsection{Measurements of aerosol composition}

Characterization of water insoluble organic matter (WIOM) - SOA contains both water soluble (WSOM) and water insoluble organic matter (WIOM). Due to availability of separation methods, analytical tools and the importance of WSOM in $\mathrm{CCN}$ activation, much of the effort in speciation and microphysical studies has focused on WSOM but mostly neglected the WIOM, which may constitute a large fraction of the mass in some aerosol types and hence may significantly affect the microphysical, optical and chemical properties. WIOM is left mostly under-characterized. Tools for isolation, characterization and process studies of this important fraction are therefore encouraged.

Organosulfates, HULIS, oligomers and other higher-MW species - Recent field and chamber studies suggest that complex organic matter may consist of organosulfates, amines, organic nitrates, oligomers and other higher-MW compounds. Many of these species remain poorly characterized. Missing information includes the identity, concentration, formation pathways and possible roles in affecting surface tension, optical properties, reactivity and CCN activity of SOA. New analytical methods should be developed to extract, identify and quantify these compounds. While the formation of oligomers has been firmly established in laboratory experiments, it is still uncertain whether they are formed under ambient conditions. There are still abundant unknown SOA constituents, even first-generation products detected in laboratory chamber studies, which are present in ambient and plant chamber aerosol and need to be structurally elucidated. Given their chemical complexity, efforts should be made to isolate and purify key species and to establish their chemical structures, where use could be made of available advanced multidimensional MS and NMR techniques.

High time resolution techniques - The development of measurement techniques with high time resolution would be very beneficial for mobile platforms by providing fast measurements of more components, e.g., tracers or functional groups. The recent methods providing data at high time resolution like mass spectrometry should be developed further to allow for less costly and labor-intensive deployments over longer time periods, a key issue for long-term monitoring. Methods that could be easily deployed and operated at multiple locations are beneficial for field campaigns or for longerterm monitoring. This would allow for better possibilities to evaluate and validate Eulerian type models.

Characterization of SOA formation and aging processes - Recent field results, mostly from anthropogenic pollution, suggest that SOA formation occurs in a timescale of one day after emission of the precursors, while aging of the SOA is rapid at first and continues at a slower rate for at least a week. Measurements of organic aerosol density could be used to provide information on atmospheric processing and aging of particles. Description of transformations (such as kinetics of specific processes, e.g., oligomerization, liquid phase diffusion, water interaction, surface reactions) relevant to SOA formation should be better characterized. Confirmation of this model at other locations and the investigation of whether the processes are similar for biogenic SOA are needed.

Setup of field campaigns - As already done to some extent, large field campaigns need to be specifically designed for the analysis of SOA. This often involves a Lagrangian type approach that allows for the analysis of the airmasses after different time of aging. Mobile platforms (aircraft, Zeppelins, ships, and mobile on-road laboratories) seem to be especially suited for such an approach.

\subsection{Dealing with complexity}

Complex simulation systems - Many laboratory studies employ simplified experimental conditions which neglect the environmental complexity. Important factors often 
overlooked are presence of water, complex reactant mixture and composition, and temperature dependence. This limits the ability to extrapolate laboratory-based data to the atmosphere. With regards to simulation chambers, more complex VOC mixes could be employed. An important future development would be to describe the effect on SOA formation when going from the oxidation of a single precursor to the oxidation of complex mixtures.

Combination of laboratory and field studies - In the field, SOA from different precursors are mixed. The laboratory allows for the analysis of specific precursors and thus SOA detection by different methods can be tested. Future laboratory studies should therefore be performed under conditions that are closer to ambient conditions. The study of SOA from automobile engine exhausts, wood burning, and whole plants in addition to studies of individual precursor gases seems very promising. However, these laboratory studies need to be made at concentrations relevant to the atmosphere.

Data interpretation - As high complexity methods reach maturity it is likely that data interpretation will become the rate-determining step in the analytical procedure. This may require the adoption of data handling technologies associated with image processing and statistical methods, such as principal component analysis, to find ways in which useful and timely information can be extracted from chemical methods with such high levels of detail.

\subsection{Modeling of SOA}

It is obvious that modeling activities must follow experimental and mechanistic understanding, and the most basic problem regarding modeling of SOA is therefore the uncertainty surrounding the main formation mechanisms. However, the mechanistic details obtained from experimental and theoretical work need to be tested in models against ambient data in order to be considered reliable.

Reflecting the latest findings - It is essential that models reflect the latest findings as well as possible, and it can be noted that much of the understanding that has emerged over the past several years concerning the formation of SOA still needs to be incorporated in the SOA models embedded in atmospheric chemical transport models. The new developments that need to be reflected in any class of models include sufficiently detailed gas-phase chemistry, especially the role of $\mathrm{NO}_{\mathrm{x}}$ level, leading to formation of semivolatile products, particulate-phase chemistry, identification of the volatility range of oxidation products, and the roles of organic aerosol level in determining aerosol water content.

Empirical vs. fundamental modeling - A fundamental model would be based on detailed gas-phase mechanisms of VOC oxidation leading to explicit products that are then allowed to partition between the gas and particulate phases according to theoretically predicted partitioning coefficients. This class of models would account for the nature of the condensed phase and include, to the extent we understand such chemistry, particulate-phase reactions, as well as aerosol aging over time scales beyond those accessible in chamber studies. The oxidation products explicitly identified would ideally be the predominant ones that have been identified in laboratory studies. Models of this type, which simulate the time-dependent course of SOA formation as a VOC is oxidized, are well-suited for simulation of chamber experiments, as they test the level of understanding of the fundamental processes involved. While such models have been formulated theoretically, a drawback to their use is that in many cases the majority of semivolatile oxidation products for a particular VOC may not yet have been fully identified. Even if well validated based on chamber data, they may not be the optimal choice for a three-dimensional atmospheric chemical transport model because of their computational demands. Despite increased understanding, the point has not been reached where SOA models can be formulated purely on the basis of chemical reaction mechanisms and thermodynamic predictions, in the absence of laboratory data. Therefore, formulation and testing of SOA models must continue to be based firmly on laboratory chamber data, and tested against real-world ambient data under a wide range of conditions.

Availability of relevant data input - It is evident that laboratory data should preferably reflect conditions either as close to ambient as possible or which allow confident extrapolation to ambient conditions. Ambient data must provide information which can be used for source apportionment, to evaluate the models emissions and chemical processing, which will require some combination of chemical speciation, radiocarbon data and/or functional group analysis. It is important to note that even in their present state or with modest improvements, chemical transport models can still be used to evaluate emission inventories of primary emissions of both particle and precursor VOC - such evaluations are a pre-requisite to any attempt to understand SOA formation in the ambient atmosphere.

\subsection{Impacts of SOA on health and climate}

Health impacts - A recent epidemiological study reveals a stronger association between daily mortality and fine particulate air pollution in summer than in winter (Nawrot et al., 2007). As high PM levels in summer are typically associated with the production of SOA, this finding suggests that SOA may substantially contribute to the observed effect on mortality. However, there are very few studies of the health effects of SOA. This is mainly due to the lack of suitable particle exposure techniques for studies of in vitro toxicity effects of SOA. Techniques that directly investigate the interaction of SOA material with lung cells are just emerging (e.g., Jang et al., 2006b; Baltensperger et al., 2008; De Bruijne et al., 2009). Another possible approach to unravelling the possible health-related aspects of SOA is to identify markers for SOA sources and also for allergens and other inducers of health problems. Reactions occurring at the surfaces of SOA, such 
as nitration, should be studied in relation to these possible health impacts. Studies that combine bio assays and such markers could shed new light on the topic.

Participation of organics in new particle formation - Several studies strongly suggest that biogenic VOCs may be involved in new particle formation in forested environments. This phenomenon has important implications for climatebiosphere interactions, and should be further investigated, including the application of recently developed nanoparticle composition techniques such as NAMS and TDCIMS in forested areas.

Optical properties - The optical properties (scattering and absorption) of fresh and aged SOA (pure or in combination with other species) are not well constrained, hindering assessment of their possible contribution to the aerosol direct effect. New sensitive techniques should be sought to measure these missing properties.

Cloud formation and properties - The complex interaction and influence of SOA in the formation of clouds could be essential. One crucial point is to establish the influence of SOA on the kinetics and thermodynamics of water uptake. In addition, ice nucleation and evaporation of water are two processes where the complex mixtures of SOA are expected to have an impact.

\section{Abbreviations}

$\begin{array}{ll}\text { AMS } & \text { Aerosol Mass Spectrometry } \\ \text { APCI } & \text { Atmospheric Pressure Chemical Ionization } \\ \text { ASOA } & \text { Anthropogenic Secondary Organic Aerosol } \\ \text { ATOFMS } & \text { Aerosol Time-of-Flight Mass Spectrometry } \\ \text { BB } & \text { Biomass Burning } \\ \text { BSOA } & \text { Biogenic Secondary Organic Aerosol } \\ \text { BSOC } & \text { Biogenic Secondary Organic Carbon } \\ \text { BVOC } & \text { Biogenic Volatile Organic Compound } \\ \text { CACM } & \text { Caltech Atmospheric Chemistry Mechanism } \\ \text { CCN } & \text { Cloud condensation Nuclei } \\ \text { CE } & \text { Capillary Electrophoresis } \\ \text { CI } & \text { Chemical Ionization } \\ \text { CIMS } & \text { Chemical Ionization Mass Spectrometry } \\ \text { CMB } & \text { Chemical Mass Balance } \\ \text { DMA } & \text { Differential Mobility Analyzer } \\ \text { DRH } & \text { Deliquescence Relative Humidity } \\ \text { EC } & \text { Elemental Carbon } \\ \text { EDB } & \text { Electrodynamic Balance } \\ \text { EI } & \text { Electron Ionization } \\ \text { EMEP } & \text { European Monitoring and } \\ & \text { Evaluation Programme } \\ \text { ERH } & \text { Efflorescence Relative Humidity } \\ \text { ESI } & \text { Electrospray Ionization } \\ \text { FTICRMS } & \text { Fourier Transform Ion Cyclotron } \\ & \text { Resonance Mass Spectrometry } \\ \text { FTIR } & \text { Fourier Transform Infrared Spectroscopy } \\ \text { GC } & \text { Gas Chromatography }\end{array}$

\begin{tabular}{|c|c|}
\hline GC/MS & $\begin{array}{l}\text { Gas Chromatography/ } \\
\text { Mass Spectrometry }\end{array}$ \\
\hline GF & Growth Factor \\
\hline HOA & Hydrocarbon-like Organic Aerosol \\
\hline HPLC & $\begin{array}{l}\text { High Performance } \\
\text { Liquid Chromatography }\end{array}$ \\
\hline HR & High Resolution \\
\hline HRMS & High Resolution Mass Spectrometry \\
\hline HTDMA & $\begin{array}{l}\text { Hygroscopicity Tandem Differential } \\
\text { Mobility Analyzer }\end{array}$ \\
\hline HULIS & Humic-like Substances \\
\hline $\mathrm{IC}$ & Ion Chromatography \\
\hline ITMS & Ion Trap Mass Spectrometry \\
\hline $\mathrm{LC}$ & Liquid Chromatography \\
\hline $\mathrm{LC} / \mathrm{MS}$ & $\begin{array}{l}\text { Liquid Chromatography/ } \\
\text { Mass Spectrometry }\end{array}$ \\
\hline LDI-MS & $\begin{array}{l}\text { Laser Desorption Ionization- } \\
\text { Mass Spectrometry }\end{array}$ \\
\hline MALDI & $\begin{array}{l}\text { Matrix-Assisted Laser } \\
\text { Desorption Ionization }\end{array}$ \\
\hline MS & Mass Spectrometry \\
\hline MW & Molecular Weight \\
\hline NAMS & Nano Aerosol Mass Spectrometer \\
\hline NMR & Nuclear Magnetic Resonance \\
\hline $\mathrm{OA}$ & Organic Aerosol \\
\hline $\mathrm{OC}$ & Organic Carbon \\
\hline $\mathrm{OM}$ & Organic Matter \\
\hline OOA & Oxygenated Organic Aerosol \\
\hline PAN & Peroxyacyl Nitrate \\
\hline PILS & Particle into Liquid Sampler \\
\hline PIXE & $\begin{array}{l}\text { Particle-Induced X-ray } \\
\text { Emission spectrometry }\end{array}$ \\
\hline $\begin{array}{l}\mathrm{PM}_{1}, \mathrm{PM}_{2.5} \\
\mathrm{PM}_{10}\end{array}$ & $\begin{array}{l}\text { Particulate Matter } \\
\text { with an aerodynamic } \\
\text { diameter }<1,2.5 \\
\text { and } 10 \mu \mathrm{m} \text {, respectively }\end{array}$ \\
\hline POA & Primary Organic Aerosol \\
\hline PTR/MS & $\begin{array}{l}\text { Proton Transfer Reaction/ } \\
\text { Mass Spectrometry }\end{array}$ \\
\hline Q-TOF & Quadrupole-Time-of-Flight \\
\hline $\mathrm{RH}$ & Relative Humidity \\
\hline SCI & Stabilized Criegee Intermediate \\
\hline SEC & Size-Exclusion Chromatography \\
\hline SFA & Size-Fractionated Aerosol \\
\hline $\mathrm{SOA}$ & Secondary Organic Aerosol \\
\hline $\mathrm{SOC}$ & Secondary Organic Carbon \\
\hline SRFA & Suwannee River Fulvic Acid \\
\hline TA & Total Aerosol \\
\hline TDCIMS & $\begin{array}{l}\text { Thermal Desorption Chemical } \\
\text { Ionization Mass Spectrometry }\end{array}$ \\
\hline TMI & Transition Metal Ion \\
\hline TOF & Time-of-Flight \\
\hline UNIFAC & $\begin{array}{l}\text { Universal Functional } \\
\text { Activity Coefficient }\end{array}$ \\
\hline
\end{tabular}




$\begin{array}{ll}\text { VBS } & \text { Volatility Basis Set } \\ \text { VOC } & \text { Volatile Organic Compound } \\ \text { XRF } & \text { X-ray Fluorescence } \\ \text { WIOC } & \text { Water Insoluble Organic Compounds } \\ \text { WIOM } & \text { Water Insoluble Organic Matter } \\ \text { WSOC } & \text { Water Soluble Organic Compounds } \\ \text { WSOM } & \text { Water Soluble Organic Matter }\end{array}$

Acknowledgements. This review is the result of presentations and discussions during the joint VOCBAS-INTROP conference on Biogenic Volatile Organic Compounds: Sources and Fates in a Changing World. The authors would like to thank M. Staudt and his colleagues at the Centre for Evolutionary and Functional Ecology in Montpellier, France, for hosting the event. Financial support from the European Science Foundation INTROP programme is gratefully acknowledged. The authors would also like to acknowledge funding received from; the European Commission (EUROCHAMP, RII3-CT-2004-505968; EUCAARI, 036833-2; POLYSOA, 12709; Marie Curie postdoctoral fellowship to R.S.); European Monitoring and Evaluation Programme (EMEP); the Swedish Research Council Formas (contract 214-2006-1204); Science Foundation Ireland; the Swiss National Science Foundation; the Israel Science Foundation (grants 1527/07 and 196/08) and the Helen and Martin Kimmel Award for Innovative Investigation; Belgian Federal Science Policy Office (BIOSOL project); the Fund for Scientific Research Flanders (FWO); DOE BER/ASP (DEFG0208ER64627); the UK Department for Environment, Food and Rural Affairs (contract AQ0704); NOAA OGP (NA08OAR4310565); US EPA (STAR R833746, RD-83374901); DOE (DEFG02-05ER63983); US National Science Foundation (ATM-0703914).

Edited by: R. MacKenzie

\section{References}

Adams, P. J. and Seinfeld, J. H.: Predicting global aerosol size distributions in general circulation models, J. Geophys. Res., 107(D19), 4370, doi:10.1029/2001JD001010, 2002.

Aiken, A. C., DeCarlo, P. F., and Jimenez, J. L.: Elemental analysis of organic species with electron ionization high-resolution mass spectrometry, Anal. Chem., 79, 8350-8358, 2007.

Aiken, A. C., DeCarlo, P. F., Kroll, J. H., Worsnop, D. R., Huffman, J. A., Docherty, K., Ulbrich, I. M., Mohr, C., Kimmel, J. R., Sueper, D., Zhang, Q., Sun, Y., Trimborn, A., Northway, M., Ziemann, P. J., Canagaratna, M. R., Onasch, T. B., Alfarra, M. R., Prévôt, A. S. H., Dommen, J., Duplissy, J., Metzger, A., Baltensperger, U., and Jimenez, J. L.: O/C and OM/OC ratios of primary, secondary, and ambient organic aerosols with high resolution time-of-flight aerosol mass spectrometry, Environ. Sci. Technol., 42, 4478-4485, 2008.

Aklilu, Y., Mozurkewich, M., Prenni, A. J., Kreidenweis, S. M., Alfarra, M. R., Allan, J. D., Anlauf, K., Brook, J., Leaitch, W. R., Sharma, S., Boudries, H., and Worsnop, D. R.: Hygroscopicity of particles at two rural, urban influenced sites during Pacific 2001: Comparison with estimates of water uptake from particle composition, Atmos. Environ., 40, 2650-2661, 2006.
Alfarra, M. R., Paulsen, D., Gysel, M., Garforth, A. A., Dommen, J., Prévôt, A. S. H., Worsnop, D. R., Baltensperger, U., and Coe, H.: A mass spectrometric study of secondary organic aerosols formed from the photooxidation of anthropogenic and biogenic precursors in a reaction chamber, Atmos. Chem. Phys., 6, 52795293, 2006,

http://www.atmos-chem-phys.net/6/5279/2006/.

Alfarra, M. R., Prévôt, A. S. H., Szidat, S., Sandradewi, J., Weimer, S., Lanz, V. A., Schreiber, D., Mohr, M., and Baltensperger, U.: Identification of the mass spectral signature of organic aerosols from wood burning emissions, Environ. Sci. Technol., 41, 57705777, 2007.

Allan, J. D., Alfarra, M. R., Bower, K. N., Williams, P. I., Gallagher, M. W., Jimenez, J. L., McDonald, A. G., Nemitz, E., Canagaratna, M. R., Jayne, J. T., Coe, H., and Worsnop, D. R.: Quantitative sampling using an Aerodyne aerosol mass spectrometer: 2. Measurements of fine particulate chemical composition in two UK cities, J. Geophys. Res., 108, 4091, doi:10.1029/2002JD002359, 2003.

Altieri, K. E., Carlton, A. G., Lim, H. J., Turpin, B. J., and Seitzinger, S. P.: Evidence for oligomer formation in clouds: Reactions of isoprene oxidation products, Environ. Sci. Technol., 40, 4956-4960, 2006.

Altieri, K. E., Seitzinger, S. P., Carlton, A. G., Turpin, B. J., Klein, G. C., and Marshall, A. G.: Oligomers formed through in-cloud methylglyoxal reactions: Chemical composition, properties, and mechanisms investigated by ultra-high resolution FT-ICR mass spectrometry, Atmos. Environ., 42, 1476-1490, 2008.

Altieri, K. E., Turpin, B. J., and Seitzinger, S. P.: Oligomers, organosulfates, and nitrooxy organosulfates in rainwater identified by ultra-high resolution electrospray ionization FT-ICR mass spectrometry, Atmos. Chem. Phys., 9, 2533-2542, 2009, http://www.atmos-chem-phys.net/9/2533/2009/.

Alvarez, E. G., Viidanoja, J., Munoz, A., Wirtz, K., and Hjorth, J.: Experimental confirmation of the dicarbonyl route in the photooxidation of toluene and benzene, Environ. Sci. Technol., 41, 8362-8369, 2007.

Amato, P., Menager, M., Sancelme, M., Laj, P., Mailhot, G., and Delort, A. M.: Microbial population in cloud water at the Puy de Dome: implications for the chemistry of clouds, Atmos. Environ., 39, 4143-4153, 2005.

Anastasio, C. and McGregor, K. G.: Chemistry of fog waters in California's Central Valley: 1. In situ photoformation of hydroxyl radical and singlet molecular oxygen, Atmos. Environ., 35, 1079-1089, 2001.

Andreae, M. O. and Crutzen, P. J.: Atmospheric aerosols: Biogeochemical sources and role in atmospheric chemistry, Science, 276, 1052-1058, 1997.

Andreani-Aksoyoglu, S., Keller, J., Prévôt, A. S. H., Baltensperger, U., and Flemming, J.: Secondary aerosols in Switzerland and northern Italy: Modeling and sensitivity studies for summer 2003, J. Geophys. Res., 113, D06303, doi:10.1029/2007JD009053, 2008.

Andersson-Sköld, Y. and Simpson, D.: Secondary organic aerosol formation in Northern Europe: a model study, J. Geophys. Res., 106, 7357-7374, 2001.

Angove, D. E., Fookes, C. J. R., Hynes, R. G., Walters, C. K., and Azzi, M.: The characterization of secondary organic aerosol formed during the photodecomposition of 1,3-butadiene in air 
containing nitric oxide, Atmos. Environ., 40, 4597-4607, 2006. Anttila, P., Hyotylainen, T., Heikkila, A., Jussila, M., Finell, J., Kulmala, M., and Riekkola, M. L.: Determination of organic acids in aerosol particles from a coniferous forest by liquid chromatography-mass spectrometry, J. Separation. Sci., 28, 337346, 2005 .

Anttila, T., Kerminen, V.-M., Kulmala, M., Laaksonen, A., and O'Dowd, C. D.: Modelling the formation of organic particles in the atmosphere, Atmos. Chem. Phys., 4, 1071-1083, 2004, http://www.atmos-chem-phys.net/4/1071/2004/.

Anttila, T., Kiendler-Scharr, A., Mentel, T. F., and Tillmann, R.: Size dependent partitioning of organic material: evidence for the formation of organic coatings on aqueous aerosols, J. Atmos. Chem., 57, 215-237, 2007.

Arakaki, T. and Faust, B. C. N.: Sources, sinks, and mechanisms of hydroxyl radical $(\mathrm{OH})$ photoproduction and consumption in authentic acidic continental cloud waters from Whiteface Mountain, New York: the role of the Fe(r) (r=II, III) photochemical cycle, J. Geophys. Res., 103, 3487-3504, 1998.

Arakaki, T., Kuroki, Y., Okada, K., Nakama, Y., Ikota, H., Kinjo, M., Higuchi, T., Uehara, M., and Tanahara, A.: Chemical composition and photochemical formation of hydroxyl radicals in aqueous extracts of aerosol particles collected in Okinawa, Japan, Atmos. Environ., 40, 4764-4774, 2006.

Archuleta, C. M., DeMott, P. J., and Kreidenweis, S. M.: Ice nucleation by surrogates for atmospheric mineral dust and mineral dust/sulfate particles at cirrus temperatures, Atmos. Chem. Phys., 5, 2617-2634, 2005,

http://www.atmos-chem-phys.net/5/2617/2005/.

Arnold, S. R., Spracklen, D. V., Williams, J., Yassaa, N., Sciare, J., Bonsang, B., Gros, V., Peeken, I., Lewis, A. C., Alvain, S., and Moulin, C.: Evaluation of the global oceanic isoprene source and its impacts on marine organic carbon aerosol, Atmos. Chem. Phys., 9, 1253-1262, 2009,

http://www.atmos-chem-phys.net/9/1253/2009/.

Asa-Awuku, A. and Nenes, A.: Effect of solute dissolution kinetics on cloud droplet formation: Extended Kohler theory, J. Geophys. Res., 112, D22201, doi:10.1029/2005JD006934, 2007.

Asher, W. E., Pankow, J. F., Erdakos, G. B., and Seinfeld, J. H.: Estimating the vapor pressures of multi-functional oxygencontaining organic compounds using group contribution methods, Atmos. Environ., 36, 1483-1498, 2002.

Asher, W. E. and Pankow, J. F.: Vapor pressure prediction for alkenoic and aromatic organic compounds by a UNIFAC-based group contribution method, Atmos. Environ., 40, 3588-3600, 2006.

Atkinson, R. and Arey, J.: Gas-phase tropospheric chemistry of biogenic volatile organic compounds: a review, Atmos. Environ., 37, Supplement No. 2, S197-S219, 2003.

Atkinson, R., Baulch, D. L., Cox, R. A., Crowley, J. N., Hampson, R. F., Hynes, R. G., Jenkin, M. E., Rossi, M. J., Troe, J., and IUPAC Subcommittee: Evaluated kinetic and photochemical data for atmospheric chemistry: Volume II - gas phase reactions of organic species, Atmos. Chem. Phys., 6, 3625-4055, 2006, http://www.atmos-chem-phys.net/6/3625/2006/.

Atkinson, R.: Rate constants for the atmospheric reactions of alkoxy radicals: a revised estimation method, Atmos. Environ., 41, 8468-8465, 2007.

Aumont, B., Szopa, S., and Madronich, S.: Modelling the evolution of organic carbon during its gas-phase tropospheric oxidation: development of an explicit model based on a self generating approach, Atmos. Chem. Phys., 5, 2497-2517, 2005, http://www.atmos-chem-phys.net/5/2497/2005/.

Bahreini, R., Keywood, M. D., Ng, N. L., Varutbangkul, V., Gao, S., Flagan, R. C., Seinfeld, J. H., Worsnop, D. R., and Jimenez, J. L.: Measurements of secondary organic aerosol from oxidation of cycloalkenes, terpenes, and m-xylene using an Aerodyne aerosol mass spectrometer, Environ. Sci. Technol., 39, 5674-5688, 2005.

Baltensperger, U., Kalberer, M., Dommen, J., Paulsen, D., Alfarra, M. R., Coe, H., Fisseha, R., Gascho, A., Gysel, M., Nyeki, S., Sax, M., Steinbacher, M., Prévôt, A. S. H., Sjögren, S., Weingartner, E., and Zenobi, R.: Secondary organic aerosols from anthropogenic and biogenic precursors, Faraday Discuss., 130, 265-278, 2005.

Baltensperger, U., Dommen, J., Alfarra, M. R., Duplissy, J., Gaeggeler, K., Metzger, A., Facchini, M. C., Decesari, S., Finessi, E., Reinnig, C., Schott, M., Warnke, J., Hoffmann, T., Klatzer, B., Puxbaum, H., Geiser, M., Savi, M., Lang, D., Kalberer, M., and Geiser, T.: Combined determination of the chemical composition and of health effects of secondary organic aerosols: the POLYSOA Project, J. Aerosol Med. Pulm. D., 21, 145-154, 2008.

Barley, M., Topping, D. O., Jenkin, M. E., and McFiggans, G.: Sensitivities of the absorptive partitioning model of secondary organic aerosol formation to the inclusion of water, Atmos. Chem. Phys., 9, 2919-2932, 2009, http://www.atmos-chem-phys.net/9/2919/2009/.

Barrie, L. A., Yi, Y., Leaitch, W. R., Lohmann, U., Kasibhatla, P., Roelofs, G. J., Wilson, J., McGovern, F., Benkovitz, C., Mélières, M. A., Law, K., Prospero, J., Kritz, M., Bergmann, D., Bridgeman, C., Chin, M., Christensen, J., Easter, R., Feichter, J., Land, C., Jeuken, A., Kjellström, E., Koch, D., and Rasch, P.: A comparison of large-scale atmospheric sulphate aerosol models (COSAM): Overview and highlights, Tellus B, 53, 615-645, 2001.

Barsanti, K. C. and Pankow, J. F.: Thermodynamics of the formation of atmospheric organic particulate matter by accretion reactions-Part 1: aldehydes and ketones, Atmos. Environ., 38, 4371-4382, 2004.

Barsanti, K. C. and Pankow, J. F.: Thermodynamics of the formation of atmospheric organic particulate matter by accretion reactions-Part 2: Dialdehydes, methylglyoxal, and diketones, Atmos. Environ., 39, 6597-6607, 2005.

Barsanti, K. C. and Pankow, J. F.: Thermodynamics of the formation of atmospheric organic particulate matter by accretion reactions-Part 3: Carboxylic and dicarboxylic acids, Atmos. Environ., 40, 6676-6686, 2006.

Beaver, M. R., Elrod, M. J., Garland, R. M., and Tolbert, M. A.: Ice nucleation in sulfuric acid/organic aerosols: implications for cirrus cloud formation, Atmos. Chem. Phys., 6, 3231-3242, 2006, http://www.atmos-chem-phys.net/6/3231/2006/.

Bejan, I., Barnes, I., Olariu, R., Zhou, S. M., Wiesen, P., and Benter, T.: Investigations on the gas-phase photolysis and $\mathrm{OH}$ radical kinetics of methyl-2-nitrophenols, Phys. Chem. Chem. Phys., 9, 5686-5692, 2007.

Berndt, T., Böge, O., and Stratmann, F.: Gas-phase ozonolysis of alpha-pinene: gaseous products and particle formation, Atmos. Environ., 37, 3933-3945, 2003. 
Bilde, M. and Pandis, S. N.: Evaporation rates and vapor pressures of individual aerosol species formed in the atmospheric oxidation of $\alpha$ - and $\beta$-pinene, Environ. Sci. Technol., 35, 3344-3349, 2001.

Blando, J. D., Porcja, R. J., Li, T.-H., Bowman, D., Lioy, P. J., and Turpin, B. J.: Secondary formation and the Smoky Mountain organic aerosol: an examination of aerosol polarity and functional group composition during SEAVS, Environ. Sci. Technol., 32, 604-613, 1998.

Blando, J. D. and Turpin, B. J.: Secondary organic aerosol formation in cloud and fog droplets: a literature evaluation of plausibility, Atmos. Environ., 34, 1623-1632, 2000.

Bloss, C., Wagner, V., Bonzanini, A., Jenkin, M. E., Wirtz, K., Martin-Reviejo, M., and Pilling, M. J.: Evaluation of detailed aromatic mechanisms (MCMv3 and MCMv3.1) against environmental chamber data, Atmos. Chem. Phys., 5, 623-639, 2005a, http://www.atmos-chem-phys.net/5/623/2005/.

Bloss, C., Wagner, V., Jenkin, M. E., Volkamer, R., Bloss, W. J., Lee, J. D., Heard, D. E., Wirtz, K., Martin-Reviejo, M., Rea, G., Wenger, J. C., and Pilling, M. J.: Development of a detailed chemical mechanism (MCMv3.1) for the atmospheric oxidation of aromatic hydrocarbons, Atmos. Chem. Phys., 5, 641664, 2005b, http://www.atmos-chem-phys.net/5/641/2005/.

Bond, T. C., Streets, D. G., Yarber, K. F., Nelson, S. M., Woo, J. H., and Klimont, Z.: A technology-based global inventory of black and organic carbon emissions from combustion, J. Geophys. Res., 109, D14203, doi:10.1029/2003JD003697, 2004.

Bonn, B., Schuster, G., and Moortgat, G. K.: Influence of water vapor on the process of new particle formation during monoterpene ozonolysis, J. Phys. Chem. A, 106, 2869-2881, 2002.

Bonn, B., Korhonen, H., Petäjä, T., Boy, M., and Kulmala, M.: Understanding the formation of biogenic secondary organic aerosol from $\alpha$-pinene in smog chamber studies: role of organic peroxy radicals, Atmos. Chem. Phys. Discuss., 7, 3901-3939, 2007, http://www.atmos-chem-phys-discuss.net/7/3901/2007/.

Bowman, F. M. and Karamalegos, A. M.: Estimated effects of composition on secondary organic aerosol mass concentrations, Environ. Sci. Technol., 36, 2701-2707, 2002.

Buxton, G., Greenstock, C. L., Helman, W. P, and Ross, A. B.: Critical review of rate constants for reactions of hydrated electrons, hydrogen atom and hydroxyl radicals $\left(\mathrm{OH} / \mathrm{O}^{-}\right)$in aqueous solution, J. Phys. Chem. Ref. Data, 17, 513-883, 1988.

Buxton, G. V., Malone, T. N., and Salmon, G. A.: Oxidation of glyoxal initiated by $\mathrm{OH}$ in oxygenated aqueous solution, J. Chem. Soc. Faraday T., 93, 2889-2891, 1997.

Böge, O., Miao, Y., Plewka, A., and Herrmann, H.: Formation of secondary organic particle phase compounds from isoprene gasphase oxidation products: An aerosol chamber and field study, Atmos. Environ., 40, 2501-2509, 2006.

Cabada, J., Pandis, S., Subramanian, R., Robinson, A., Polidori, A., and Turpin, B.: Estimating the secondary organic aerosol contribution to PM2.5 using the EC tracer method, Aerosol Sci. Technol., 38, 140-155, 2004.

Cai, X. Y., Ziemba, L. D., and Griffin, R. J.: Secondary aerosol formation from the oxidation of toluene by chlorine atoms, Atmos. Environ., 42, 7348-7359, 2008.

Cahill, T. M., Seaman, V. Y., Charles, M. J., Holzinger, R., and Goldstein, A. H.: Secondary organic aerosols formed from ox- idation of biogenic volatile organic compounds in the Sierra Nevada Mountains of California, J. Geophys. Res., 111, D16312, doi:10.1029/2006JD007178, 2006.

Calvert, J. G., Atkinson, R., Becker, K. H., Kamens, R. M., Seinfeld, J. H., Wallington, T. J., and Yarwood, G.: The mechanisms of atmospheric oxidation of aromatic hydrocarbons, Oxford University Press, New York, 2002.

Camredon, M. and Aumont, B.: Assessment of vapor pressure estimation methods for secondary organic aerosol modeling, Atmos. Environ., 40(6), 2105-2116, 2006.

Camredon, M., Aumont, B., Lee-Taylor, J., and Madronich, S.: The SOA/VOC/NO $\mathrm{N}_{\mathrm{x}}$ system: an explicit model of secondary organic aerosol formation, Atmos. Chem. Phys., 7, 5599-5610, 2007, http://www.atmos-chem-phys.net/7/5599/2007/.

Canagaratna, M. R., Jayne, J. T., Jimenez, J. L., Allan, J. D., Alfarra, M. R., Zhang, Q., Onasch, T. B., Drewnick, F., Coe, H., Middlebrook, A., Delia, A., Williams, L. R., Trimborn, A. M., Northway, M. J., DeCarlo, P. F., Kolb, C. E., Davidovits, P., and Worsnop, D. R.: Chemical and microphysical characterization of ambient aerosols with the Aerodyne aerosol mass spectrometer, Mass Spectrom. Rev., 26, 185-222, 2007.

Cantrell, W. and Robinson, C.: Heterogeneous freezing of ammonium sulfate and sodium chloride solutions by long chain alcohols, Geophys. Res. Lett., 33, L07802, doi:10.1029/2005GL024945, 2006.

Cao, G.: Secondary organic aerosol formation from toluene oxidation in the presence of inorganic aerosols, Ph.D. thesis, Department of Environmental Sciences and Engineering, The University of North Carolina at Chapel Hill, North Carolina, Chapel Hill, USA, 2008.

Cao, G. and Jang, M.: Effects of particle acidity and UV light on secondary organic aerosol formation from oxidation of aromatics in the absence of $\mathrm{NO}_{\mathrm{x}}$, Atmos. Environ., 35, 7603-7613, 2007.

Cao, G. and Jang, M.: Secondary organic aerosol formation from toluene photooxidation under various $\mathrm{NO}_{\mathrm{x}}$ conditions and particle acidity, Atmos. Chem. Phys. Discuss., 8, 14467-14495, 2008, http://www.atmos-chem-phys-discuss.net/8/14467/2008/.

Capes, G., Johnson, B., McFiggans, G., Williams, P. I., Haywood, J., and Coe, H.: Aging of biomass burning aerosols over West Africa: Aircraft measurements of chemical composition, microphysical properties and emission ratios, J. Geophys. Res., 113, D00C15, doi:10.1029/2008JD009845, 2008.

Capouet, M., Mueller, J. F., Ceulemans, K., Compernolle, S., Vereecken, L., and Peeters, J.: Modeling aerosol formation in alpha-pinene photo-oxidation experiments, J. Geophys. Res., 113, D2, D02308, doi:10.1029/2007JD008995, 2008.

Cappiello, A., De Simoni, E., Fiorucci, C., Mangani, F., Palma, P., Trufelli, H., Decesari, S., Facchini, M. C., and Fuzzi, S.: Molecular characterization of the water-soluble organic compounds in fogwater by ESIMS/MS, Environ. Sci. Technol., 37, 1229-1240, 2003.

Carlton, A. G., Turpin, B. J., Lim, H. J., Altieri, K. E., and Seitzinger, S.: Link between isoprene and secondary organic aerosol (SOA): Pyruvic acid oxidation yields low volatility organic acids in clouds, Geophys. Res. Lett., 33, L06822, doi:10.1029/2005GL025374, 2006.

Carlton, A. G., Turpin, B. J., Altieri, K. E., Seitzinger, S., Reff, A., Lim, H. J., and Ervens, B.: Atmospheric oxalic acid and SOA production from glyoxal: Results of aqueous photooxidation ex- 
periments, Atmos. Environ., 41, 7588-7602, 2007.

Carter, W. P. L.: Documentation of the SAPRC-99 chemical mechanism for VOC reactivity assessment. Final Report to California Air Resources Board Contract 92-329 and Contract 95-308, Air Pollution Research Center and College of Engineering Center for Environmental Research and Technology, University of California Riverside, California, 2000.

Carter, W. P. L., Cocker III, D. R., Fitz, D. R., Malkina, I. L., Bumiller, K., Sauer, C. G., Pisano, J. T., Bufalino, C., and Song, C.: A new environmental chamber for evaluation of gas-phase chemical mechanisms and secondary aerosol formation, Atmos. Environ., 39, (40), 7768-7788, 2005.

Castro, L. M., Pio, C. A., Harrison, R. M., and Smith, D. J. T.: Carbonaceous aerosol in urban and rural European atmospheres: estimation of secondary organic carbon concentrations, Atmos. Environ., 33, 2771-2781, 1999.

Chan, A. W. H., Kroll, J. H., Ng, N. L., and Seinfeld, J. H.: Kinetic modeling of secondary organic aerosol formation: effects of particle- and gas-phase reactions of semivolatile products, Atmos. Chem. Phys., 7, 4135-4147, 2007,

http://www.atmos-chem-phys.net/7/4135/2007/.

Chan, A. W. H., Kautzman, K. E., Chhabra, P. S., Surratt, J. D., Chan, M. N., Crounse, J. D., Kürten, A., Wennberg, P. O., Flagan, R. C., and Seinfeld, J. H.: Secondary organic aerosol formation from photooxidation of naphthalene and alkylnaphthalenes: implications for oxidation of intermediate volatility organic compounds (IVOCs), Atmos. Chem. Phys., 9, 3049-3060, 2009, http://www.atmos-chem-phys.net/9/3049/2009/.

Chan, M. N., Lee, A. K. Y., and Chan, C. K.: Responses of ammonium sulfate particles coated with glutaric acid to cyclic changes in relative humidity: Hygroscopicity and Raman characterization, Environ. Sci. Technol., 40, 6983-6989, 2006.

Chang, E. I. and Pankow, J. F.: Prediction of activity coefficients in liquid aerosol particles containing organic compounds, dissolved inorganic salts, and water - Part 2: Consideration of phase separation effects by an X-UNIFAC model, Atmos. Environ., 40, 6422-6436, 2006.

Chen, J., Mao, H. T., Talbot, R. W., and Griffin, R. J.: Application of the CACM and MPMPO modules using the CMAQ model for the eastern United States, J. Geophys. Res., 111, D23S25, doi:10.1029/2006JD007603, 2006.

Chen, J., Griffin, R. J., Grini, A., and Tulet, P.: Modeling secondary organic aerosol formation through cloud processing of organic compounds, Atmos. Chem. Phys., 7, 5343-5355, 2007, http://www.atmos-chem-phys.net/7/5343/2007/.

Cheng, Y. and Li, S. M.: Analytical method development of longchain ketones in PM2.5 aerosols using accelerated solvent extraction and GC/FID/MSD, Int. J. Environ. An. Ch., 84, 367378, 2004

Chevallier, E., Durand Jolibois, R., Carlier, P., and Monod, A.: "Fenton like" reactions of methylhydroperoxide and ethylhydroperoxide with $\mathrm{Fe}^{2+}$ in liquid aerosols under tropospheric conditions, Atmos. Environ., 38, 921-933, 2004.

Chiappini, L., Perraudin, E., Durand-Jolibois, R., and Doussin, J. F.: Development of a supercritical fluid extraction-gas chromatography-mass spectrometry method for the identification of highly polar compounds in secondary organic aerosols formed from biogenic hydrocarbons in smog chamber experiments, Anal. Bioanal. Chem., 386, 1749-1759, 2006.
Chin, M. and Wine, P. H.: A temperature-dependent competitive kinetics study of the aqueous phase reaction of $\mathrm{OH}$ radicals with formate, formic acid, acetate, acetic acid, and hydrated formaldehyde, C. Helz, CRC press, 85-96, 1994.

Choi, M. Y. and Chan, C. K.: The effects of organic species on the hygroscopic behavior of inorganic aerosols, Environ. Sci. Technol., 36, 2422-2428, 2002.

Chung, S. H. and Seinfeld, J.: Global distribution and climate forcing of carbonaceous aerosols, J. Geophys. Res., 107(D19), 4407, doi:101029/2001JD001397, 2002.

Claeys, M., Graham, B., Vas, G., Wang, W., Vermeylen, R., Pashynska, V., Cafmeyer, J., Guyon, P., Andreae, M. O., Artaxo, P., and Maenhaut, W.: Formation of secondary organic aerosols through photooxidation of isoprene, Science, 303, 1173-1176, 2004a.

Claeys, M., Wang, W., Ion, A. C., Kourtchev, I., Gelencsér, A., and Maenhaut, W.: Formation of secondary organic aerosols from isoprene and its gas-phase oxidation products through reaction with hydrogen peroxide, Atmos. Environ., 38, 4093-4098, 2004b.

Claeys, M., Szmigielski, R., Kourtchev, I., Van der Veken, P., Vermeylen, R., Maenhaut, W., Jaoui, M., Kleindienst, T. E., Lewandowski, M., Offenberg, J. H., and Edney, E. O.: Hydroxydicarboxylic acids: novel markers for secondary organic aerosol from the photooxidation of $\alpha$-pinene, Environ. Sci. Technol., 41, 1628-1634, 2007.

Clegg, S. L. and Simonson, J. M.: A BET model of the thermodynamics of aqueous multicomponent solutions at extreme concentration, J. Chem. Thermodyn., 33, 1457-1472, 2001.

Clegg, S. L., Seinfeld J. H., and Brimblecombe P.: Thermodynamic modeling of aqueous aerosols containing electrolytes and dissolved organic compounds, J. Aerosol Sci., 32, 713-738, 2001.

Clegg, S. L. and Seinfeld, J. H.: Thermodynamic models of aqueous solutions containing inorganic electrolytes and dicarboxylic acids at $298.15 \mathrm{~K}$. I. The acids as non-dissociating components, J. Phys. Chem. A, 110, 5692-5717, 2006a.

Clegg, S. L. and Seinfeld, J. H.: Thermodynamic models of aqueous solutions containing inorganic electrolytes and dicarboxylic acids at 298.15 K. II. Systems including dissociation equilibria, J. Phys. Chem. A, 110, 5718-5734, 2006b.

Clegg, S. L., Kleeman, M. J., Griffin, R. J., and Seinfeld, J. H.: Effects of uncertainties in the thermodynamic properties of aerosol components in an air quality model - Part 2: Predictions of the vapour pressures of organic compounds, Atmos. Chem. Phys., 8, 1087-1103, 2008a, http://www.atmos-chem-phys.net/8/1087/2008/.

Clegg, S. L., Kleeman, M. J., Griffin, R. J., and Seinfeld, J. H.: Effects of uncertainties in the thermodynamic properties of aerosol components in an air quality model - Part 1: Treatment of inorganic electrolytes and organic compounds in the condensed phase, Atmos. Chem. Phys., 8, 1057-1085, 2008b, http://www.atmos-chem-phys.net/8/1057/2008/.

Clements, A. L. and Seinfeld, J. H.: Detection and quantification of 2-methyltetrols in ambient aerosol in the southeastern United States, Atmos. Environ., 41, 1825-1830, 2007.

Cocker, D. R., Clegg, S. L., Flagan, R. C., and Seinfeld, J. H.: The effect of water on gas-particle partitioning of secondary organic aerosol. Part I: alpha-pinene/ozone system, Atmos. Environ., 35, 6049-6072, 2001a.

Cocker, D. R., Flagan, R. C., and Seinfeld, J. H.: State-of-the-art 
chamber facility for studying atmospheric aerosol chemistry, Environ. Sci. Technol., 35, 2594-2601, 2001b.

Collett, J. L., Herckes, P., and Chang, H.: Reply to comment by S. Decesari et al. on "On the use of anion exchange chromatography for the characterization of water soluble organic carbon", Geophys. Res. Lett., 32, L24815, doi:10.1029/2005GL024338, 2005.

Coury, C. and Dillner, A. M.: A method to quantify organic functional groups and inorganic compounds in ambient aerosols using attenuated total reflectance FTIR spectroscopy and multivariate chemometric techniques, Atmos. Environ., 42, 5923-5932, 2008.

Coury, C. and Dillner, A. M.: ATR-FTIR characterization of organic functional groups and inorganic ions in ambient aerosols at a rural site, Atmos. Environ., 43, 940-948, 2009.

Crahan, K. K., Hegg, D., Covert, D. S., and Jonsson, H.: An exploration of aqueous oxalic acid production in the coastal marine atmosphere, Atmos. Environ., 38, 3757-3764, 2004.

Cross, E. S., Slowik, J. G., Davidovits, P., Allan, J. D., Worsnop, D. R., Jayne, J. T., Lewis, D. K., Canagaratna, M., and Onasch, T. B.: Laboratory and ambient particle density determinations using light scattering in conjunction with aerosol mass spectrometry, Aerosol Sci. Technol., 41, 343-359, 2007.

Currie, L. A., Klouda, G., Schjoldager, J., and Ramdahl, T.: The power of ${ }^{14} \mathrm{C}$ measurements combined with chemical characterization for tracing urban aerosol in Norway, Radiocarbon, 28, 673-680, 1986

Cziczo, D. J., Murphy, D. M., Hudson, P. K., and Thomson, D. S.: Single particle measurements of the chemical composition of cirrus ice residue during CRYSTAL-FACE, J. Geophys. Res., 109, D04201, doi:10.1029/2003JD004032, 2004a.

Cziczo, D. J., DeMott, P. J., Brooks, S. D., Prenni, A. J., Thomson, D. S., Baumgardner, D., Wilson, J. C., Kreidenweis, S. M., and Murphy, D. M.: Observations of organic species and atmospheric ice formation, Geophys. Res. Lett., 31, L12116, doi:10.1029/2004GL019822, 2004b.

Czoschke, N. M., Jang, M., and Kamens, R. M.: Effect of acidic seed on biogenic secondary organic aerosol growth, Atmos. Environ., 37, 4287-4299, 2003.

Czoschke, N. M. and Jang, M.: Acidity effects on the formation of $\alpha$-pinene ozone SOA in the presence of inorganic seed, Atmos. Environ., 40, 4370-4380, 2006a.

Czoschke, N. M. and Jang, M.: Markers of heterogeneous reaction products in $\alpha$-pinene ozone secondary organic aerosol, Atmos. Environ., 40, 5629-5639, 2006b.

Dabek-Zlotorzynska, E., Celo, V., and Yassine, M. M.: Recent advances in CE and CEC of pollutants, Electrophoresis, 29, 310 323, 2008.

Davidovits, P., Hu, J. H., Worsnop, D. R., Zahnister, M. S., and Kolb, C. E.: Entry of gas molecules into liquids, Faraday Discuss., 100, 65-82, 1995.

Davidson, C. I., Phalen, R. F., and Solomon, P. A.: Airborne Particulate Matter and Human Health: A Review, Aerosol Sci. Technol., 39, 737-749, 2005.

De Bruijne, K., Bersviller, S., Sexton, K. G., Lake, S., Leith, D., Goodman, R., Jetters, J., Walters, G. W., Doyle-Eisele, M., Woodside, R., Jeffries, H. E., and Jaspers, I.: Design and testing of electrostatic aerosol in vitro exposure system (EAVES): An alternative exposure system for particles, Inhal. Toxicol., 21,
91-101, 2009.

DeCarlo, P. F., Slowik, J. G., Worsnop, D. R., Davidovits, P., and Jimenez, J. L.: Particle morphology and density characterization by combined mobility and aerodynamic diameter measurements. Part 1: Theory, Aerosol Sci. Technol., 38, 1185-1205, 2004.

DeCarlo, P. F., Kimmel, J. R., Trimborn, A., Northway, M. J., Jayne, J. T., Aiken, A. C., Gonin, M., Fuhrer, K., Horvath, T., Docherty, K. S., Worsnop, D. R., and Jimenez, J. L.: Field-deployable, high-resolution, time-of-flight aerosol mass spectrometer, Anal. Chem., 78, 8281-8289, 2006.

DeCarlo, P. F., Dunlea, E. J., Kimmel, J. R., Aiken, A. C., Sueper, D., Crounse, J., Wennberg, P. O., Emmons, L., Shinozuka, Y., Clarke, A., Zhou, J., Tomlinson, J., Collins, D. R., Knapp, D., Weinheimer, A. J., Montzka, D. D., Campos, T., and Jimenez, J. L.: Fast airborne aerosol size and chemistry measurements above Mexico City and Central Mexico during the MILAGRO campaign, Atmos. Chem. Phys., 8, 4027-4048, 2008, http://www.atmos-chem-phys.net/8/4027/2008/.

Decesari, S., Facchini, M. C., Fuzzi, S., and Tagliavini, E.: Characterization of water-soluble organic compounds in atmospheric aerosol: A new approach, J. Geophys. Res., 105, 1481-1489, 2000.

Decesari, S., Facchini, M. C., Matta, E., Lettini, F., Mircea, M., Fuzzi, S., Tagliavini, E., and Putaud, J. P.: Chemical features and seasonal variation of fine aerosol water-soluble organic compounds in the Po Valley, Italy, Atmos. Environ., 35, 3691-3699, 2001.

Decesari, S., Moretti, F., Fuzzi, S., Facchini, M. C., and Tagliavini, E.: Comment on "On the use of anion exchange chromatography for the characterization of water soluble organic carbon” by H. Chang et al., Geophys. Res. Lett., 32, L24814, doi:10.1029/2005GL023826, 2005.

Decesari, S., Fuzzi, S., Facchini, M. C., Mircea, M., Emblico, L., Cavalli, F., Maenhaut, W., Chi, X., Schkolnik, G., Falkovich, A., Rudich, Y., Claeys, M., Pashynska, V., Vas, G., Kourtchev, I., Vermeylen, R., Hoffer, A., Andreae, M. O., Tagliavini, E., Moretti, F., and Artaxo, P.: Characterization of the organic composition of aerosols from Rondônia, Brazil, during the LBASMOCC 2002 experiment and its representation through model compounds, Atmos. Chem. Phys., 6, 375-402, 2006, http://www.atmos-chem-phys.net/6/375/2006/.

Decesari, S., Mircea, M., Cavalli, F., Fuzzi, S., Moretti, F., Tagliavini, E., and Facchini, M. C.: Source attribution of watersoluble organic aerosol by nuclear magnetic resonance spectroscopy, Environ. Sci. Technol., 41, 2479-2484, 2007.

de Gouw, J. A., Middlebrook, A. M., Warneke, C., Goldan, P. D., Kuster, W. C., Roberts, J. M., Fehsenfeld, F. C., Worsnop, D. R., Canagaratna, M. R., Pszenny, A. A. P., Keene, W. C., Marchewka, M., Bertman, S. B., and Bates, T. S.: Budget of organic carbon in a polluted atmosphere: Results from the New England Air Quality Study in 2002, J. Geophys. Res., 110, D16305, doi:10.1029/2004JD005623, 2005.

de Gouw, J. A., Brock, C. A., Atlas, E. L., Bates, T. S., Fehsenfeld, F. C., Goldan, P. D., Holloway, J. S., Kuster, W. C., Lerner, B. M., Matthew, B. M., Middlebrook, A. M., Onasch, T. B., Peltier, R. E., Quinn, P. K., Senff, C. J., Stohl, A., Sullivan, A. P., Trainer, M., Warneke, C., Weber, R. J., and Williams, E. J.: Sources of particulate matter in the northeastern United States in summer: 1. Direct emissions and secondary formation of or- 
ganic matter in urban plumes, J. Geophys. Res., 113, D08301, doi:10.1029/2007JD009243, 2008.

Deguillaume, L., Leriche, M., Monod, A., and Chaumerliac, N.: The role of transition metal ions on $\mathrm{HO}_{\mathrm{x}}$ radicals in clouds: a numerical evaluation of its impact on multiphase chemistry, Atmos. Chem. Phys., 4, 95-110, 2004,

http://www.atmos-chem-phys.net/4/95/2004/.

Deguillaume, L., Leriche, M., Desboeufs, K., Mailhot, G., George, C., and Chaumerliac, N.: Transition metals in atmospheric liquid phases: sources, reactivity, and sensitive parameters, Chem. Rev., 105, 3388-3431, 2005.

DeMott, P. J., Cziczo, D. J., Prenni, A. J., Murphy, D. M., Kreidenweis, S. M., Thomson, D. S., Borys, R., and Rogers, D. C.: Measurements of the concentration and composition of nuclei for cirrus formation, P. Natl. Acad. Sci. USA, 100, 14 655-14660, 2003.

Denkenberger, K. A., Moffet, R. C., Holecek, J. C., Rebotier, T. P., and Prather, K. A.: Real-time, single-particle measurements of oligomers in aged ambient aerosol particles, Environ. Sci. Technol., 41, 5439-5446, 2007.

Deyrup, A. J.: Determination of acidity in ethyl alcohol by velocity of acetal formation, J. Am. Chem. Soc., 56, 60-64, 1934.

Di Carlo, P., Brune, W. H., Martinez, M., Harder, H., Lesher, R., Ren, X. R., Thornberry, T., Carroll, M. A., Young, V., Shepson, P. B., Riemer, D., Apel, E., and Campbell, C.: Missing OH reactivity in a forest: Evidence for unknown reactive biogenic VOCs, Science, 304, 722-725, 2004.

Dinar, E., Mentel, T. F., and Rudich, Y.: The density of humic acids and humic like substances (HULIS) from fresh and aged wood burning and pollution aerosol particles, Atmos. Chem. Phys., 6, 5213-5224, 2006a, http://www.atmos-chem-phys.net/6/5213/2006/.

Dinar, E., Taraniuk, I., Graber, E. R., Katsman, S., Moise, T., Anttila, T., Mentel, T. F., and Rudich, Y.: Cloud Condensation Nuclei properties of model and atmospheric HULIS, Atmos. Chem. Phys., 6, 2465-2482, 2006b, http://www.atmos-chem-phys.net/6/2465/2006/.

Dinar, E., Taraniuk, I., Graber, E., Anttila, T., Mentel, T., and Rudich, Y.: Hygroscopic growth of atmospheric and model humic-like substances, J. Geophys. Res., 112, D05211, doi:10.1029/2006JD007442, 2007.

Dinar, E., Anttila, T., and Rudich, Y.: CCN activity and hygroscopic growth of organic aerosols following reactive uptake of ammonia, Environ. Sci. Technol., 42, 793-799, 2008a.

Dinar, E., Riziq, A. A., Spindler, C., Erlick, C., Kiss, G., and Rudich, Y.: The complex refractive index of atmospheric and model humic-like substances (HULIS) retrieved by a cavity ring down aerosol spectrometer (CRD-AS), Faraday Discuss., 137, 279-295, 2008b.

Docherty, K. S. and Ziemann, P. J.: On-line, inlet-based trimethylsilyl derivatization for gas chromatography of mono- and dicarboxylic acids, J. Chrom. A, 921, 265-275, 2001.

Docherty, K. S. and Ziemann, P. J.: Effects of stabilized Criegee intermediate and $\mathrm{OH}$ radical scavengers on aerosol formation from reactions of $\beta$-pinene with $\mathrm{O}_{3}$, Aerosol Sci. Technol., 37, 877$891,2003$.

Docherty, K. S., Wu, W., Lim, Y. B., and Ziemann, P. J.: Contributions of organic peroxides to secondary aerosol formed from reactions of monoterpenes with $\mathrm{O}_{3}$, Environ. Sci. Technol., 39,
4049-4059, 2005.

Docherty, K. S., Stone, E. A., Ulbrich, I. M., DeCarlo, P. F., Snyder, D. C., Schauer, J. J., Peltier, R. E., Weber, R. J., Murphy, S. M., Seinfeld, J. H., Eatough, D. J., Grover, B. D., and Jimenez, J. L.: Apportionment of primary and secondary organic aerosols in Southern California during the 2005 study of organic aerosols in riverside (SOAR), Environ. Sci. Technol., 42, 7655-7662, 2008.

Dommen, J., Metzger, A., Duplissy, J., Kalberer, M., Alfarra, M. R., Gascho, A., Weingartner, E., Prévôt, A. S. H., Verheggen, B., and Baltensperger, U.: Laboratory observation of oligomers in the aerosol from isoprene/ $\mathrm{NO}_{\mathrm{x}}$ photooxidation, Geophys. Res. Lett., 31, L13805, doi:13810.11029/12006GL026523, 2006.

Donahue, N., Hartz, K., Chuong, B., Presto, A., Stanier, C., Rosenhorn, T., Robinson, A., and Pandis, S.: Critical factors determining the variation in SOA yields from terpene ozonolysis: a combined experimental and computational study, Faraday Discuss., 130, 295-309, 2005.

Donahue, N. M., Robinson, A. L., Stanier, C. O., and Pandis, S. N.: Coupled partitioning, dilution, and chemical aging of semivolatile organics, Environ. Sci. Technol., 40, 2635-2643, 2006.

Donahue, N. M., Robinson, A. L., and Pandis, S. N.: Atmospheric organic particulate matter: from smoke to secondary organic aerosol, Atmos. Environ., 43, 94-106, 2009.

Donaldson, D. J., Guest, J. A., and Goh, M. C.: Evidence for adsorbed $\mathrm{SO}_{2}$ at the aqueous-air interface, J. Phys. Chem., 99, 9313-9315, 1995.

Drewnick, F., Jayne, J. T., Canagaratna, M., Worsnop, D. R., and Demerjian, K. L.: Measurement of ambient aerosol composition during the PMTACS-NY 2001 using an aerosol mass spectrometer. Part II: chemically speciated mass distributions, Aerosol Sci. Technol., 38, 104-117, 2004.

Drewnick, F., Hings, S. S., DeCarlo, P. F., Jayne, J. T., Gonin, M., Fuhrer, K., Weimer, S., Jimenez, J. L., Demerjian, K. L., Borrmann, S., and Worsnop, D. R.: A new Time-of-Flight Aerosol Mass Spectrometer (ToF-AMS) - instrument description and first field deployment, Aerosol Sci. Technol., 39, 637-658, 2005.

Dreyfus, M. A. and Johnston M. V.: Rapid sampling of individual organic aerosol species in ambient air with the photoionization aerosol mass spectrometer, Aerosol Sci. Technol., 42, 18-27, 2008.

Dunlea, E. J., DeCarlo, P. F., Aiken, A. C., Kimmel, J. R., Peltier, R. E., Weber, R. J., Tomlison, J., Collins, D. R., Shinozuka, Y., McNaughton, C. S., Howell, S. G., Clarke, A. D., Emmons, L. K., Apel, E. C., Pfister, G. G., van Donkelaar, A., Martin, R. V., Millet, D. B., Heald, C. L., and Jimenez, J. L.: Evolution of Asian aerosols during transpacific transport in INTEX-B, Atmos. Chem. Phys. Discuss., 8, 15375-15461, 2008, http://www.atmos-chem-phys-discuss.net/8/15375/2008/.

Duplissy, J., Gysel, M., Alfarra, M. R., Dommen, J., Metzger, A., Prévôt, A. S. H., Weingartner, E., Laaksonen, A., Raatikainen, T., Good, N., Turner, S. F., McFiggans, G., and Baltensperger, U.; Cloud forming potential of secondary organic aerosol under near atmospheric conditions, Geophys. Res. Lett., 35, L03818, doi:10.1029/2007GL031075, 2008.

Dzepina, K., Arey, J., Marr, L. C., Worsnop, D. R., Salcedo, D., Zhang, Q., Onasch, T. B., Molina, L. T., Molina, M. J., and Jimenez, J. L.: Detection of particle-phase polycyclic aromatic hydrocarbons in Mexico City using an aerosol mass spectrome- 
ter, Int. J. Mass Spectrom., 263, 152-170, 2007.

Edney, E. O., Kleindienst, T. E., Conver, T. S., McIver, C. D., Corse, E. W., and Weathers, W. S.: Polar organic oxygenates in $\mathrm{PM}_{2.5}$ at a southeastern site in the United States, Atmos. Environ., 37, 3947-3965, 2003.

Edney, E. O., Kleindienst, T. E., Jaoui, M., Lewandowski, M., Offenberg, J. H., Wang, W., and Claeys, M.: Formation of 2-methyl tetrols and 2-methylglyceric acid in secondary organic aerosol from laboratory irradiated isoprene $/ \mathrm{NO}_{\mathrm{x}} / \mathrm{SO}_{2}$ /air mixtures and their detection in ambient $\mathrm{PM}_{2.5}$ samples collected in the eastern United States, Atmos. Environ., 39, 5281-5289, 2005.

El Haddad, I., Liu, Y., Nieto-Gligorovski, L., Michaud, V., TemimeRoussel, B., Quivet, E., Marchand, N., Sellegri, K., and Monod, A.: In-cloud processes of methacrolein under simulated conditions - Part 2: Formation of secondary organic aerosol, Atmos. Chem. Phys. Discuss., 9, 6425-6449, 2009,

http://www.atmos-chem-phys-discuss.net/9/6425/2009/.

Engelhart, G. J., Asa-Awuku, A., Nenes, A., and Pandis, S. N.: $\mathrm{CCN}$ activity and droplet growth kinetics of fresh and aged monoterpene secondary organic aerosol, Atmos. Chem. Phys., 8, 3937-3949, 2008,

http://www.atmos-chem-phys.net/8/3937/2008/.

Erdakos, G. B. and Pankow, J. F.: Gas/particle partitioning of neutral and ionizing compounds to single- and multi-phase aerosol particles. 2. Phase separation in liquid particulate matter containing both polar and low-polarity organic compounds, Atmos. Environ., 38, 1005-1013, 2004.

Erdakos, G. B., Asher, W. E., Seinfeld, J. H., and Pankow, J. F.: Prediction of activity coefficients in liquid aerosol particles containing organic compounds, dissolved inorganic salts, and water Part 1: Organic compounds and water by consideration of shortand long-range effects using X-UNIFAC.1, Atmos. Environ., 40, 6410-6421, 2006a.

Erdakos, G. B., Chang, E. I., Pankow, J. F., and Seinfeld, J. H.: Prediction of activity coefficients in liquid aerosol particles containing organic compounds, dissolved inorganic salts and water - Part 3: Organic compounds, water, and ionic constituents by consideration of short-, mid-, and long-range effects using XUNIFAC.3, Atmos. Environ., 40, 6437-6452, 2006 b.

Ervens, B., George, C., Williams, J. E., Buxton, G. V., Salmon, G. A., Bydder, M., Wilkinson, F., Dentener, F., Mirabel, P., Wolke, R., and Herrmann, H.: CAPRAM 2.4 (MODAC mechanism): an extended and condensed tropospheric aqueous phase mechanism and its application, J. Geophys. Res., 108, 4426, doi:10.1029/2002JD002202, 2003a.

Ervens, B., Gligorovski, S., and Herrmann, H.: Temperature dependent rate constants for hydroxyl radical reactions with organic compounds in aqueous solutions, Phys. Chem. Chem. Phys., 5, 1811-1824, 2003b.

Ervens, B., Feingold, G., Frost, G. J., and Kreidenweis, S. M.: A modeling study of aqueous production of dicarboxylic acids: 1. Chemical pathways and speciated organic mass production, J. Geophys. Res., 109, D15205, doi:10.1029/2003JD004387, 2004a.

Ervens, B., Feingold, G., Clegg, S. L., and Kreidenweis, S. M.: A modelling study of aqueous production of dicarboxylic acids: 2. implications for cloud microphysics, J. Geophys. Res., 109, D15206, doi:10.1029/2004JD004575, 2004b.
Ervens, B., Feingold G., and Kreidenweis, S. M.: Influence of water-soluble organic carbon on cloud drop number concentration, J. Geophys. Res., 110, D18211, doi:10.1029/2004JD005634, 2005.

Ervens, B., Carlton, A. G., Turpin, B. J., Altieri, K. E., Kreidenweis, S. M., and Feingold, G.: Secondary organic aerosol yields from cloud-processing of isoprene oxidation products, Geophys. Res. Lett., 35, L02816, doi:10.1029/2007GL031828, 2008.

Facchini, M. C., Decesari, S., Rinaldi, M., Carbone, C., Finessi, E., Mircea, M., Fuzzi, S., Moretti, F., Tagliavini, E., Ceburnis, D., and O'Dowd, C. D.: Important source of marine secondary organic aerosol from biogenic amines, Environ. Sci. Technol., 42, 9116-9121, 2008.

Fan, J., Zhang, R., Collins, D., and Li, G.: Contribution of secondary condensable organics to new particle formation: a case study in Houston, Texas, Geophys. Res. Lett., 33, L15802, doi:10.1029/2006GL026295, 2006.

Fantechi, G., Vereecken, L., and Peeters, J.: The OH-initiated atmospheric oxidation of pinonaldehyde: Detailed theoretical study and mechanism construction, Phys. Chem. Chem. Phys., 4, 5795-5805, 2002.

Favez, O., Sciare, J., Cachier, H., Alfaro, S. C., and Abdelwahab, M. M.: Significant formation of water-insoluble secondary organic aerosols in semi-arid urban environment, Geophys. Res. Lett., 35, L15801, doi:10.1029/2008GL034446, 2008.

Faust, B. C. and Allen, J. M.: Aqueous-phase photochemical formation of hydroxyl radical in authentic cloudwaters and fogwaters, Environ. Sci. Technol., 27, 1221-1224, 1993.

Feczko, T., Puxbaum, H., Kasper-Giebl, A., Handler, M., Limbeck, A., Gelencsér, A., Pio, C., Preunkert, S., and Legrand, M.: Determination of water and alkaline extractable atmospheric humiclike substances with the TU Vienna HULIS analyzer in samples from six background sites in Europe, J. Geophys. Res., 112, D23S10, doi:10.1029/2006JD008331, 2007.

Finlayson-Pitts, B. J. and Pitts, J. N.: Chemistry of the Upper and Lower Atmosphere: Theory, Experiments and Applications, Academic Press, San Diego, 2000.

Fisseha, R., Dommen, J., Sax, M., Paulsen, D., Kalberer, M., Maurer, R., Hofler, F., Weingartner, E., and Baltensperger, U.: Identification of organic acids in secondary organic aerosol and the corresponding gas phase from chamber experiments, Anal. Chem., 76, 6535-6540, 2004.

Folkers, M., Mentel, T. F., and Wahner, A.: Influence of an organic coating on the reactivity of aqueous aerosols probed by the heterogeneous hydrolysis of $\mathrm{N}_{2} \mathrm{O}_{5}$, Geophys. Res. Lett., 30, 1644, doi:10.1029/2003GL017168, 2003.

Fu, T. M., Jacob, D. J., Wittrock, F., Burrows, J. P., Vrekoussis, M., and Henze, D. K.: Global budgets of atmospheric glyoxal and methylglyoxal, and implications for formation of secondary organic aerosols, J. Geophys. Res., 113, D15303, doi:10.1029/2007JD009505, 2008.

Fuzzi, S., Andreae, M. O., Huebert, B. J., Kulmala, M., Bond, T. C., Boy, M., Doherty, S. J., Guenther, A., Kanakidou, M., Kawamura, K., Kerminen, V.-M., Lohmann, U., Russell, L. M., and Pöschl, U.: Critical assessment of the current state of scientific knowledge, terminology, and research needs concerning the role of organic aerosols in the atmosphere, climate, and global change, Atmos. Chem. Phys., 6, 2017-2038, 2006, http://www.atmos-chem-phys.net/6/2017/2006/. 
Fuzzi, S., Decesari, S., Facchini, M. C., Cavalli, F., Emblico, L., Mircea, M., Andreae, M. O., Trebs, I., Hoffer, A., Guyon, P., Artaxo, P., Rizzo, L. V., Lara, L. L., Pauliquevis, T., Maenhaut, W., Raes, N., Chi, X., Mayol-Bracero, O. L., Soto-Garcia, L. L., Claeys, M., Kourtchev, I., Rissler, J., Swietlicki, E., Tagliavini, E., Schkolnik, G., Falkovich, A. H., Rudich, Y., Fisch, G., and Gatti, L. V.: Overview of the inorganic and organic composition of size-segregated aerosol in Rondônia, Brazil, from the biomass-burning period to the onset of the wet season, J. Geophys. Res., 112, D01201, doi:10.1029/2005JD006741, 2007.

Galloway, M. M., Chhabra, P. S., Chan, A. W. H., Surratt, J. D., Flagan, R. C., Seinfeld, J. H., and Keutsch, F. N.: Glyoxal uptake on ammonium sulphate seed aerosol: reaction products and reversibility of uptake under dark and irradiated conditions, Atmos. Chem. Phys., 9, 3331-3345, 2009,

http://www.atmos-chem-phys.net/9/3331/2009/.

Gao, S., Keywood, M., Ng, N. L., Surratt, J. D., Varutbangkul, V., Bahreini, R., Flagan, R. C., and Seinfeld, J. H.: Low-molecularweight and oligomeric components in secondary organic aerosol from the ozonolysis of cycloalkenes and alpha-pinene, J. Phys. Chem. A, 108, 10 147-10 164, 2004a.

Gao, S., Ng, N. L., Keywood, M., Varutbangkul, V., Bahreini, R., Nenes, A., He, J., Yoo, K. Y., Beauchamp, J. L., Hodyss, R. P., Flagan, R. C., and Seinfeld, J. H.: Particle phase acidity and oligomer formation in secondary organic aerosol, Environ. Sci. Technol., 38, 6582-6589, 2004b.

Gao, S., Surratt, J. D., Knipping, E. M., Edgerton, E. S., Shahgholi, M., and Seinfeld, J. H.: Characterization of polar organic components in fine aerosols in the southeastern United States: Identity, origin, and evolution, J. Geophys. Res., 111, D14314, doi:10.1029/2005JD006601, 2006.

Garland, R. M., Elrod, M. J., Kincaid, K., Beaver, M. R., Jimenez, J. L., and Tolbert, M. A.: Acid-catalyzed reactions of hexanal on sulfuric acid particles: Identification of reaction products, Atmos. Environ., 40, 6863-6878, 2006.

Gelencsér, A., Hoffer, A., Molnar, A., Krivacsy, Z., Kiss, G., and Meszaros, E.: Thermal behavior of carbonaceous aerosol from a continental background site, Atmos. Environ., 34, 823-831, 2000a.

Gelencsér, A., Meszaros, T., Blazso, M., Kiss, G., Krivacsy, Z., Molnar, A., and Meszaros, E.: Structural characterization of organic matter in fine tropospheric aerosol by pyrolysis-gas chromatography-mass spectrometry, J. Atmos. Chem., 37, 173183, $2000 b$.

Gelencsér, A., Hoffer, A., Krivacsy, Z., Kiss, G., Molnar, A., and Meszaros, E.: On the possible origin of humic matter in fine continental aerosol, J. Geophys. Res., 107, 4137, doi:10.1029/2001JD001299, 2002.

Gelencsér, A., Hoffer, A., Kiss, G., Tombácz, E., Kurdi, R., and Bencze, L.: In-situ formation of light-absorbing organic matter in cloud water, J. Atmos. Chem., 45, 25-33, 2003.

Gelencsér, A.: Carbonaceous aerosol, Springer, Netherlands, 2004.

Gelencsér, A. and Varga, Z.: Evaluation of the atmospheric significance of multiphase reactions in atmospheric secondary organic aerosol formation, Atmos. Chem. Phys., 5, 2823-2831, 2005, http://www.atmos-chem-phys.net/5/2823/2005/.

Gelencsér, A., May, B., Simpson, D., Sánchez-Ochoa, A., Kasper-Giebl, A., Puxbaum, H., Caseiro, A., Pio, C., and Legrand, M.: Source apportionment of PM2.5 organic aerosol over Europe: primary/secondary, natural/anthropogenic, fossil/biogenic origin, J. Geophys. Res., 112, D23S04, doi: 10.1029/2006JD008094, 2007.

George, C., Strekowski, R. S., Kleffmann, J., Stemmler, K., and Ammann, M.: Photoenhanced uptake of gaseous $\mathrm{NO}_{2}$ on solid organic compounds: a photochemical source of HONO?, Faraday Discuss., 130, 195-210, 2005.

George, I. J., Vlasenko, A., Slowik, J. G., Broekhuizen, K., and Abbatt, J. P. D.: Heterogeneous oxidation of saturated organic aerosols by hydroxyl radicals: uptake kinetics, condensed-phase products, and particle size change, Atmos. Chem. Phys., 7, 4187-4201, 2007,

http://www.atmos-chem-phys.net/7/4187/2007/.

George, I. J., Slowik, J., and Abbatt, J. P. D.: Chemical aging of ambient organic aerosol from heterogeneous reaction with hydroxyl radicals, Geophys. Res. Lett., 35, L13811, doi:10.1029/2008GL033884, 2008.

Gilardoni, S., Russell, L. M., Sorooshian, A., et al.: Regional variation of organic functional groups in aerosol particles on four U.S. east coast platforms during the International Consortium for Atmospheric Research on Transport and Transformation 2004 campaign, J. Geophys. Res., 112, D10S27, doi:10.1029/2006JD007737, 2007.

Gilardoni, S., Shang, L., Takahama, S., Russell, L. M., Allan, J. D., Steinbrecher, R., Jimenez, J. L., Decarlo, P. F., Dunlea, E. J., and Baumgardner, D.: Characterization of organic ambient aerosol during MIRAGE 2006 on three platforms, Atmos. Chem. Phys. Discuss., 9, 6617-6655, 2009,

http://www.atmos-chem-phys-discuss.net/9/6617/2009/.

Glasius, M., Ketzel, M., Wahlin, P., Jensen, B., Monster, J., Berkowicz, R., and Palmgren, F.: Impact of wood combustion on particle levels in a residential area in Denmark, Atmos. Environ., 40, 7115-7124, 2006.

Gligorovski, S. and Herrmann, H.: Kinetics of reactions of $\mathrm{OH}$ with organic carbonyl compounds in aqueous solution, Phys. Chem. Chem. Phys., 6, 4118-4126, 2004.

Gligorovski, S., Rousse, D., George, C., and Herrmann, H.: Rate constants for the $\mathrm{OH}$ reactions with oxygenated organic compounds in aqueous solution, Int. J. Chem. Kinet., 41, 309-326, 2009.

Goldstein, A. H. and Galbally, I. E.: Known and unexplored organic constituents in the earth's atmosphere, Environ. Sci. Technol., 41, 1514-1521, 2007.

Goldstein, A. H., Worton, D. R., Williams, B. J., Hering, S. V., Kreisberg, N. M., Pani, O., and Górecki, T.: Thermal desorption comprehensive two-dimensional gas chromatography for in-situ measurements of organic aerosols, J. Chrom. A, 1186, 340-347, 2008.

Gómez-González, Y., Surratt, J. D., Cuyckens, F., Szmigielski, R., Vermeylen, R., Jaoui, M., Lewandowski, M., Offenberg, J. H., Kleindienst, T. E., Edney, E. O., Blockhuys, F., Van Alsenoy, C., Maenhaut, W., and Claeys, M.: Characterization of organosulfates from the photooxidation of isoprene and unsaturated fatty acids in ambient aerosol using liquid chromatography/(-) electrospray ionization mass spectrometry, J. Mass Spectrom., 43, 371-382, 2008.

Graber, E. R. and Rudich, Y.: Atmospheric HULIS: How humiclike are they? A comprehensive and critical review, Atmos. Chem. Phys., 6, 729-753, 2006, 
http://www.atmos-chem-phys.net/6/729/2006/.

Graham, B., Guyon, P., Maenhaut, W., Taylor, P. E., Ebert, M., Matthias-Maser, S., Mayol-Bracero, O. L., Godoi, R. H. M., Artaxo, P., Meixner, F. X., Lima Moura, M. A., Eça D’Almeida Rocha, C. H., Van Grieken, R., Glovsky, M. M., Flagan, R. C., and Andreae, M. O.: Composition and diurnal variability of the natural Amazonian aerosol, J. Geophys. Res., 108(D24), 4765, doi:10.1029/2003JD004049, 2003.

Greaves, R. C., Barkley, R. M., and Sievers, R. E.: Rapid sampling and analysis of volatile constituents of airborne particulate matter, Anal. Chem., 57, 2807-2815, 1985.

Grieshop, A. P., Donahue, N. M., and Robinson, A. L.: Is the gas-particle partitioning in alpha-pinene secondary organic aerosol reversible?, Geophys. Res. Lett., 34, L14810, doi:10.1029/2007GL029987, 2007.

Grieshop, A. P., Logue, J. M., Donahue, N. M., and Robinson, A. L.: Laboratory investigation of photochemical oxidation of organic aerosol from wood fires 1: measurement and simulation of organic aerosol evolution, Atmos. Chem. Phys., 9, 1263-1277, 2009 ,

http://www.atmos-chem-phys.net/9/1263/2009/.

Griffin, R. J., Cocker III, D. R., Flagan, R. C., and Seinfeld, J. H.: Organic aerosol formation from the oxidation of biogenic hydrocarbons, J. Geophys. Res., 104, 3555-3567, 1999.

Griffin, R., Dabdub, D., Kleeman, M., Fraser, M., Cass, G., and Seinfeld, J. H.: Secondary organic aerosol - 3. Urban/regional scale model of size and composition-resolved aerosols, J. Geophys. Res., 107, 4334, doi:10.1029/2001JD000544, 2002a.

Griffin, R. J., Dabdub, D., and Seinfeld, J. H.: Secondary organic aerosol. I. Atmospheric chemical mechanism for production of molecular constituents, J. Geophys. Res., 107, 4332, doi: 10.1029/2001JD000541, 2002b.

Griffin, R. J., Nguyen, K., Dabdub, D., and Seinfeld, J. H.: A coupled hydrophobic-hydrophilic model for predicting secondary organic aerosol formation, J. Atmos. Chem., 44, 171-190, 2003.

Griffin, R. J., Nguyen, K., Dabdub, D., and Seinfeld, J. H.: Development and initial evaluation of a dynamic species-resolved model for gas phase chemistry and size-resolved gas/particle partitioning associated with secondary organic aerosol formation, J. Geophys. Res., 110, D05304, doi:10.1029/2004JD005219, 2005.

Gross, D. S., Galli, M. E., Kalberer, M., Prévôt, A. S. H., Dommen, J., Alfarra, M. R., Duplissy, J., Gaeggeler, K., Gascho, A., Metzger, A., and Baltensperger, U.: Real-time measurement of oligomeric species in secondary organic aerosol with the aerosol time-of-flight mass spectrometer, Anal. Chem., 78, 2130-2137, 2006.

Guenther, A., Hewitt, C., Erickson, D., Fall, R., Geron, C., Graedel, T., Harley, P., Klinger, L., Lerdau, M., McKay, W., Pierce, T., Scholes, R., Steinbrecher, R., Tallamraju, R., Taylor, J., and Zimmerman, P.: A global model of natural volatile organic compound emissions, J. Geophys. Res., 100, 8873-8892, 1995.

Guenther, A., Karl, T., Harley, P., Wiedinmyer, C., Palmer, P. I., and Geron, C.: Estimates of global terrestrial isoprene emissions using MEGAN (Model of Emissions of Gases and Aerosols from Nature), Atmos. Chem. Phys., 6, 3181-3210, 2006, http://www.atmos-chem-phys.net/6/3181/2006/.

Guzmán, M. I., Colussi, A. I., and Hoffmann, M. R.: Photoinduced oligomerization of aqueous pyruvic acid, J. Phys. Chem. A, 110, 3619-3626, 2006.
Gysel, M., Weingartner, E., Nyeki, S., Paulsen, D., Baltensperger, U., Galambos, I., and Kiss, G.: Hygroscopic properties of water-soluble matter and humic-like organics in atmospheric fine aerosol, Atmos. Chem. Phys., 4, 35-50, 2004,

http://www.atmos-chem-phys.net/4/35/2004/.

Gysel, M., Crosier, J., Topping, D. O., Whitehead, J. D., Bower, K. N., Cubison, M. J., Williams, P. I., Flynn, M. J., McFiggans, G. B., and Coe, H.: Closure study between chemical composition and hygroscopic growth of aerosol particles during TORCH2, Atmos. Chem. Phys., 7, 6131-6144, 2007, http://www.atmos-chem-phys.net/7/6131/2007/.

Hallquist, M., Wangberg, I., and Ljungstrom, E.: Atmospheric fate of carbonyl oxidation products originating from alpha-pinene and $\Delta^{3}$-carene: Determination of rate of reaction with $\mathrm{OH}$ and $\mathrm{NO}_{3}$ radicals, UV absorption cross sections, and vapor pressures, Environ. Sci. Technol., 31, 3166-3172, 1997.

Hallquist, M., Wangberg, I., Ljungstrom, E., Barnes, I., and Becker, K. H.: Aerosol and product yields from $\mathrm{NO}_{3}$ radical-initiated oxidation of selected monoterpenes, Environ. Sci. Technol., 33, 553-559, 1999.

Hamilton, J. F., Webb, P. J., Lewis, A. C., Hopkins, J. R., Smith, S., and Davy, P.: Partially oxidised organic components in urban aerosol using GCXGC-TOF/MS, Atmos. Chem. Phys., 4, 12791290, 2004,

http://www.atmos-chem-phys.net/4/1279/2004/.

Hamilton, J. F., Webb, P. J., Lewis, A. C., and Reviejo, M. M.: Quantifying small molecules in secondary organic aerosol formed during the photo-oxidation of toluene with hydroxyl radicals, Atmos. Environ., 39, 7263-7275, 2005.

Hamilton, J. F., Lewis, A. C., Reynolds, J. C., Carpenter, L. J., and Lubben, A.: Investigating the composition of organic aerosol resulting from cyclohexene ozonolysis: low molecular weight and heterogeneous reaction products, Atmos. Chem. Phys., 6, 4973 4984, 2006,

http://www.atmos-chem-phys.net/6/4973/2006/.

Hamilton, J. F., Lewis, A. C., Carey, T. J., and Wenger, J. C.: Characterization of polar compounds and oligomers in secondary organic aerosol using liquid chromatography coupled to mass spectrometry, Anal. Chem., 80, 474-480, 2008.

Hamilton, J. F., Lewis, A. C., Carey, T. J., Wenger, J. C., Borrás i Garcia, E., and Muñoz, A.: Reactive oxidation products promote secondary organic aerosol formation from green leaf volatiles, Atmos. Chem. Phys., 9, 3815-3823, 2009, http://www.atmos-chem-phys.net/9/3815/2009/.

Hanford, K. L., Mitchem, L., Reid, J. P., Clegg, S. L., Topping, D. O., and McFiggans, G. B.: Comparative thermodynamic studies of aqueous glutaric acid, ammonium sulfate and sodium chloride aerosol at high humidity, J. Phys. Chem. A, 112, 9413-9422, 2008.

Harley, R. A., Marr, L. C., Lehner, J. K., and Giddings, S. N.: Changes in motor vehicle emissions on diurnal to decadal time scales and effects on atmospheric composition, Environ. Sci. Technol., 39, 5356-5362, 2005.

Harrison, R. M. and Yin, J.: Particulate matter in the atmosphere: which particle properties are important for its effects on health?, Sci. Total Environ., 249, 85-101, 2000.

Hastings, W. P., Koehler, C. A., Bailey, E. L., and De Haan, D. O.: Secondary organic aerosol formation by glyoxal hydration and oligomer formation: Humidity effects and equilibrium shifts 
during analysis, Environ. Sci. Technol., 39, 8728-8735, 2005.

Havers, N., Burba, P., Lambert, J., and Klockow, D.: Spectroscopic characterization of humic-like substances in airborne particulate matter, J. Atmos. Chem., 29(1), 45-54, 1998a.

Havers, N., Burba, P., Klockow, D., and Klockow-Beck, A.: Characterization of humic-like substances in airborne particulate matter by capillary electrophoresis, Chromatographia, 47, 619-624, 1998b.

Hays, M. D. and Lavrich, R. J.: Developments in direct thermal extraction gas chromatography-mass spectrometry of fine aerosols, Trac-Trend. Anal. Chem., 26, 88-102, 2007.

Haywood, J. and Boucher, O.: Estimates of the direct and indirect radiative forcing due to tropospheric aerosols: A review, Rev. Geophys., 38(4), 513-543, 2000.

Heald, C. L., Jacob, D. J., Park, R. J., Russell, L. M., Huebert, B. J., Seinfeld, J. H., Liao, H., and Weber, R. J.: A large organic aerosol source in the free troposphere missing from current models, Geophys. Res. Lett., 32, L18809, doi: 10.1029/2005GL023831, 2005.

Healy, R. M., Wenger, J. C., Metzger, A., Duplissy, J., Kalberer, M., and Dommen, J.: Gas/particle partitioning of carbonyls in the photooxidation of isoprene and 1,3,5-trimethylbenzene, Atmos. Chem. Phys., 8, 3215-3230, 2008,

http://www.atmos-chem-phys.net/8/3215/2008/.

Hearn, J. D., Lovett, A. J., and Smith, G. D.: Ozonolysis of oleic acid particles: evidence for a surface reaction and secondary reactions involving Criegee intermediates, Phys. Chem. Chem. Phys., 7, 501-511, 2005.

Hearn, J. D. and Smith, G. D.: Reactions and mass spectra of complex particles using Aerosol CIMS, Int. J. Mass Spectrom., 258, 95-103, 2006.

Heaton, K. J., Dreyfus, M. A., Wang, S., and Johnston, M. V.: Oligomers in the early stage of biogenic secondary organic aerosol formation and growth, Environ. Sci. Technol., 41, 61296136, 2007.

Hedberg, E., Johansson, C., Johansson, L., Swietlicki, E., and Brorström-Lunden, E.: Is levoglucosan a suitable quantitative tracer for wood burning? Comparison with receptor modeling on trace elements in Lycksele, Sweden, J. Air Waste Manage., 56, 1669-1678, 2006.

Hellborg, R. and Skog, G.: Accelerator mass spectrometry, Mass Spec. Rev., 27, 398-427, 2008.

Hellén, H., Hakola, H., Haaparanta, S., Pietarila, H., and Kauhaniemi, M.: Influence of residential wood combustion on local air quality, Sci. Total Environ., 393, 283-290, 2008a.

Hellén, H., Dommen, J., Gascho, A., Metzger, A., Duplissy, J., Tritscher, T., Prévôt, A. S. H., and Baltensperger, U.: Using proton transfer reaction mass spectrometry for online analysis of secondary organic aerosols, Environ. Sci. Technol., 42, 73477353, 2008b.

Hennigan, C. J., Bergin, M. H., Dibb, J. E., and Weber, R. J.: Enhanced secondary organic aerosol formation due to water uptake by fine particles, Geophys. Res. Lett., 35, L18801, doi:10.1029/2008GL035046, 2008.

Hennigan, C. J., Bergin, M. H., Russell, A. G., Nenes, A., and Weber, R. J.: Gas/particle partitioning of water-soluble organic aerosol in Atlanta, Atmos. Chem. Phys., 9, 3613-3628, 2009, http://www.atmos-chem-phys.net/9/3613/2009/.
Henze, D. K. and Seinfeld, J. H.: Global secondary organic aerosol from isoprene oxidation, Geophys. Res. Lett., 33, L09812, doi:10.1029/2006GL025976, 2006.

Henze, D. K., Seinfeld, J. H., Ng, N. L., Kroll, J. H., Fu, T.-M., Jacob, D. J., and Heald, C. L.: Global modeling of secondary organic aerosol formation from aromatic hydrocarbons: high- vs. low-yield pathways, Atmos. Chem. Phys., 8, 2405-2420, 2008, http://www.atmos-chem-phys.net/8/2405/2008/.

Herndon, S. C., Onasch, T. B., Wood, E. C., Kroll, J. H., Canagaratna, M. R., Jayne, J. T., Zavala, M. A., Knighton, W. B., Mazzoleni, C., Dubey, M. K., Ulbrich, I. M., Jimenez, J. L., Seila, R., de Gouw, J. A., de Foy, B., Fast, J., Molina, L. T., Kolb, C. E., and Worsnop, D. R.: The correlation of secondary organic aerosol with odd oxygen in a megacity outflow, Geophys. Res. Lett., 35, L15804, doi:10.1029/2008GL034058, 2008.

Herrmann, H., Ervens, B., Jacobi, H. W., Wolke, R., Nowacki, P., and Zellner, R.: CAPRAM2.3: A chemical aqueous radical mechanism for tropospheric chemistry, J. Atmos. Chem., 36, 231-284, 2000.

Herrmann, H.: Kinetics of aqueous phase reactions relevant for atmospheric chemistry, Chem. Rev., 103, 4691-4716, 2003.

Herrmann, H., Tilgner, A., Barzaghi, P., Majdik, Z., Gligorovski, S., Poulain, L., and Monod, A.: Towards a more detailed description of tropospheric aqueous phase organic chemistry: CAPRAM 3.0., Atmos. Environ., 39, 4351-4363, 2005.

Hildemann, L. M., Klinedinst, D. B., Klouda, G. A., Currie, L. A., and Cass, G. R.: Sources of urban contemporary carbon aerosol, Environ. Sci. Technol., 28, 1565-1576, 1994.

Hinz, K. P., Kaufmann, R., and Spengler, B.: Simultaneous detection of positive and negative ions from single airborne particles by real-time laser mass spectrometry, Aerosol Sci. Technol., 24, 233-242, 1996.

Ho, S. S. H. and Yu, J. Z.: Feasibility of collection and analysis of airborne carbonyls by on-sorbent derivatization and thermal desorption, Anal. Chem., 74, 1232-1240, 2002.

Hoffer, A., Kiss, G., Blazso, M., and Gelencsér, A.: Chemical characterization of humic-like substances (HULIS) formed from a lignin-type precursor in model cloud water, Geophys. Res. Lett., 31, L06115, doi:10.1029/2003GL018962, 2004.

Hoffer, A., Gelencsér, A., Guyon, P., Kiss, G., Schmid, O., Frank, G. P., Artaxo, P., and Andreae, M. O.: Optical properties of humic-like substances (HULIS) in biomass-burning aerosols, Atmos. Chem. Phys., 6, 3563-3570, 2006, http://www.atmos-chem-phys.net/6/3563/2006/.

Hoffmann, D.: Multiphase chemistry of substituted phenols: analytics and process studies, Ph.D. thesis, Faculty of Chemistry and Mineralology, University of Leipzig, Leipzig, Germany, 2007.

Hoffmann, T., Odum, J. R., Bowman, F., Collins, D., Klockow, D., Flagan, R. C., and Seinfeld, J. H.: Formation of organic aerosols from the oxidation of biogenic hydrocarbons, J. Atmos. Chem., 26, 189-222, 1997.

Hoffmann, T., Bandur, R., Marggraf, U., and Linscheid, M.: Molecular composition of organic aerosols formed in the alphapinene $/ \mathrm{O}_{3}$ reaction: Implications for new particle formation processes, J. Geophys. Res., 103, 25 569-25 578, 1998.

Hoffmann, T. and Warnke, J.: Organic Aerosols, in Volatile Organic Compounds in the Atmosphere, edited by: Koppmann, R., Blackwell Publishing Ltd., Oxford, United Kingdom, 342-387, 2007. 
Holmes, B. J. and Petrucci, G. A.: Water-soluble oligomer formation from acid-catalyzed reactions of levoglucosan in proxies of atmospheric aqueous aerosols, Environ. Sci. Technol., 40, 49834989, 2006.

Holzinger, R., Lee, A., Paw, K. T., and Goldstein, A. H.: Observations of oxidation products above a forest imply biogenic emissions of very reactive compounds, Atmos. Chem. Phys., 5, 6775,2005 , http://www.atmos-chem-phys.net/5/67/2005/.

Hu, D., Tolocka, M., Li, Q., and Kamens, R. M.: A kinetic mechanism for predicting secondary organic aerosol formation from toluene oxidation in the presence of $\mathrm{NO}_{\mathrm{x}}$ and natural sunlight, Atmos. Environ., 41, 6478-6496, 2007.

Huffman, J. A., Ziemann, P. J., Jayne, J. T., Worsnop, D. R., and Jimenez, J. L.: Development and characterization of a fast-stepping/scanning thermodenuder for chemically-resolved aerosol volatility measurements, Aerosol Sci. Technol., 42, 395407, 2008

Huffman, J. A., Docherty, K. S., Aiken, A. C., Cubison, M. J., U1brich, I. M., DeCarlo, P. F., Sueper, D., Jayne, J. T., Worsnop, D. R., Ziemann, P. J., and Jimenez, J. L.: Chemically-resolved aerosol volatility measurements from two megacity field studies, Atmos. Chem. Phys. Discuss., 9, 2645-2697, 2009. http://www.atmos-chem-phys-discuss.net/9/2645/2009/.

Hughes, L. S., Allen, J. O., Kleeman, M. J., Johnson, R. J., Cass, G. R., Gross, D. S., Gard, E. E., Gaelli, M. E., Morrical, B. D., Fergenson, D. P., Dienes, T., Noble, C. A., Liu, D.-Y., Silva, P. J., and Prather, K. A.: Size and composition distribution of atmospheric particles in Southern California, Environ. Sci. Technol., 33, 3506-3515, 1999.

Hung, H. M., Katrib, Y., and Martin, S. T.: Products and mechanisms of the reaction of oleic acid with ozone and nitrate radical, J. Phys. Chem. A, 109, 4517-4530, 2005.

Hurley, M. D., Sokolov, O., Wallington, T. J., Takekawa, H., Karasawa, M., Klotz, B., Barnes, I., and Becker, K. H.: Organic aerosol formation during the atmospheric degradation of toluene, Environ. Sci. Technol, 35, 1358-1366, 2001.

Hynes, R. G., Angove, D. E., Saunders, S. M., Haverd, V., and Azzi, M.: Evaluation of two MCM v3.1 alkene mechanisms using indoor environmental chamber data, Atmos. Environ., 39, 72517262, 2005

Iinuma, Y., Böge, O., Gnauk, T., and Herrmann, H.: Aerosolchamber study of the $\alpha$-pinene $/ \mathrm{O}_{3}$ reaction: Influence of particle acidity on aerosol yields and products, Atmos. Environ., 38, 761-773, 2004.

Iinuma, Y., Böge, O., Miao, Y., Sierau, B., Gnauk, T., and Herrmann, H.: Laboratory studies on secondary organic aerosol formation from terpenes, Faraday Discuss., 130, 279-294, 2005.

Iinuma, Y., Müller, C., Böge, O., Gnauk, T., and Herrmann, H.: The formation of organic sulfate esters in the limonene ozonolysis secondary organic aerosol (SOA) under acidic conditions, Atmos. Environ., 41, 5571-5583, 2007a.

Iinuma, Y., Müller, C., Berndt, T., Böge, O., Claeys, M., and Herrmann, H.: Evidence for the existence of organosulfates from beta-pinene ozonolysis in ambient secondary organic aerosol, Environ. Sci. Technol., 41, 6678-6683, 2007b.

Intergovernmental Panel on Climate Change (IPCC): Climate Change 2007: The Physical Science Basis, Cambridge University Press, UK, 2007.
International Union for Pure and Applied Chemistry (IUPAC): Glossary of basic terms in polymer science, Pure Appl. Chem., 68, 2287-2311, 1996.

Ion, A. C., Vermeylen, R., Kourtchev, I., Cafmeyer, J., Chi, X., Gelencsér, A., Maenhaut, W., and Claeys, M.: Polar organic compounds in rural $\mathrm{PM}_{2.5}$ aerosols from K-puszta, Hungary, during a 2003 summer field campaign: Sources and diel variations, Atmos. Chem. Phys., 5, 1805-1814, 2005, http://www.atmos-chem-phys.net/5/1805/2005/.

Jacob, D. J.: Heterogeneous chemistry and tropospheric ozone, Atmos. Environ., 34, 2131-2159, 2000.

Jacobson, M. C., Hansson, H. C., Noone, K. J., and Charlson, R. J.: Organic atmospheric aerosols: Review and state of the science, Rev. Geophys., 38, 267-294, 2000.

Jaffrezo, J. L., Calas, T., and Bouchet, M.: Carboxylic acids measurements with ionic chromatography, Atmos. Environ., 32, 2705-2708, 1998.

Jammoul, A., Gligorovski, S., George, C., and D’Anna, B.: Photosensitized heterogeneous chemistry of ozone on organic films, J. Phys. Chem. A, 112, 1268-1276, 2008.

Jang, M., Kamens, R. M., Leach, K. B., and Strommen, M. R.: A thermodynamic approach using group contribution methods to model the partitioning of semivolatile organic compounds on atmospheric particulate matter, Environ. Sci. Technol., 31, 28052811, 1997.

Jang, M. and Kamens, R. M.: Atmospheric secondary aerosol formation by heterogeneous reactions of aldehydes in the presence of a sulfuric acid aerosol catalyst, Environ. Sci. Technol., 35, 4758-4766, 2001.

Jang, M. S., Czoschke, N. M., Lee, S., and Kamens, R. M.: Heterogeneous atmospheric aerosol production by acid-catalyzed particle-phase reactions, Science, 298, 814-817, 2002.

Jang, M., Lee, S., and Kamens, R. M.: Organic aerosol growth by acid-catalyzed heterogeneous reactions of octanal in a flow reactor, Atmos. Environ., 37, 2125-2138, 2003 a.

Jang, M., Carroll, B., Chandramouli, B., and Kamens, R. M.: Particle growth by acid-catalyzed heterogeneous reactions of organic carbonyls on preexisting aerosols, Environ. Sci. Technol., 37, 3828-3837, 2003b.

Jang, M., Czoschke, N. M., and Northcross, A. L.: Atmospheric organic aerosol production by heterogeneous acid-catalyzed reactions, Chem. Phys. Chem., 5, 1646-1661, 2004.

Jang, M., Czoschke, N. M., and Northcross, A. L.: Semiempirical model for organic aerosol growth by acid-catalyzed heterogeneous reactions of organic carbonyls, Environ. Sci. Technol., 39, 164-174, 2005.

Jang, M., Czoschke, N. M., Northcross, A. L., Cao, G., and Shaof, D.: SOA formation from partitioning and heterogeneous reactions: model study in the presence of inorganic species, Environ. Sci. Technol., 40, 3013-3022, 2006a.

Jang, M., Ghio, A., and Cao, G.: Exposure of BEAS-2B cells to secondary organic aerosol coated on magnetic nanoparticles, Chem. Res. Toxicol., 19, 1044-1050, 2006b.

Jang, M., Cao, G., and Paul, J.: Colorimetric particle acidity analysis of secondary organic aerosol coating on submicron acidic aerosols, Aerosol Sci. Technol., 42, 409-420, 2008.

Jaoui, M., Kleindienst, T. E., Lewandowski, M., Offenberg, J. H., and Edney, E. O.: Identification and quantification of aerosol polar oxygenated compounds bearing carboxylic or hydroxyl 
groups: 2. Organic tracer compounds from monoterpenes, Environ. Sci. Technol., 39, 5661-5673, 2005.

Jaoui, M., Corse, E., Kleindienst, T. E., Offenberg, J. H., Lewandowski, M., and Edney, E. O.: Analysis of secondary organic aerosol from the photooxidation of d-limonene and their detection in ambient $\mathrm{PM}_{2.5}$ aerosol, Environ. Sci. Technol., 40, 3819-3828, 2006.

Jaoui, M., Lewandowski, M., Kleindienst, T. E., Offenberg, J. H., and Edney, E. O.: $\beta$-caryophyllinic acid: An atmospheric tracer for $\beta$-caryophyllene secondary organic aerosol, Geophys. Res. Lett., 34, L05816, doi:10.1029/2006GL028827, 2007.

Jaoui, M., Edney, E. O., Kleindienst, T. E., Lewandowksi, M., Offenberg, J. H., Surratt, J. D., and Seinfeld, J. H.: Formation of secondary organic aerosol from irradiated $\alpha$-pinene/toluene/ $\mathrm{NO}_{\mathrm{x}}$ mixtures and the effect of isoprene and sulfur dioxide, J. Geophys. Res., 113, D09303, doi:10.1029/2007JD009426, 2008.

Jayne, J. T., Davidovits, P., Worsnop, D. R., Zahnister, M. S., and Kolb, C. E.: Uptake of sulfur dioxide by aqueous surfaces as a function of $\mathrm{pH}$ : the effect of chemical reaction at the interface, J. Phys. Chem., 94, 6041-6048, 1990.

Jayne, J. T., Duan, S. X., Davidovits, P., Worsnop, D. R., Zahnister, M. S., and Kolb, C. E.: Uptake of gas-phase aldehydes by water surfaces, J. Phys. Chem., 96, 5452-5460, 1992.

Jayne, J. T., Leard, D. C., Zhang, X. F., Davidovits, P., Smith, K. A., Kolb, C. E., and Worsnop, D. R.: Development of an aerosol mass spectrometer for size and composition analysis of submicron particles, Aerosol. Sci. Technol., 33, 49-70, 2000.

Jenkin, M. E., Saunders, S. M., and Pilling, M. J.: The tropospheric degradation of volatile organic compounds: A protocol for mechanism development, Atmos. Environ., 31, 81-104, 1997.

Jenkin, M. E., Saunders, S. M., Wagner, V., and Pilling, M. J.: Protocol for the development of the Master Chemical Mechanism, MCM v3 (Part B): tropospheric degradation of aromatic volatile organic compounds, Atmos. Chem. Phys., 3, 181-193, 2003, http://www.atmos-chem-phys.net/3/181/2003/.

Jenkin, M. E.: Modelling the formation and composition of secondary organic aerosol from $\alpha$ - and $\beta$-pinene ozonolysis using MCM v3, Atmos. Chem. Phys., 4, 1741-1757, 2004,

http://www.atmos-chem-phys.net/4/1741/2004/.

Jensen, E. J., Smith, J. B., Pfister, L., Pittman, J. V., Weinstock, E. M., Sayres, D. S., Herman, R. L., Troy, R. F., Rosenlof, K., Thompson, T. L., Fridlind, A. M., Hudson, P. K., Cziczo, D. J., Heymsfield, A. J., Schmitt, C., and Wilson, J. C.: Ice supersaturations exceeding $100 \%$ at the cold tropical tropopause: implications for cirrus formation and dehydration, Atmos. Chem. Phys., 5, 851-862, 2005, http://www.atmos-chem-phys.net/5/851/2005/.

Jimenez, J. L., Jayne, J. T., Shi, Q., Kolb, C. E., Worsnop, D. R., Yourshaw, I., Seinfeld, J. H., Flagan, R. C., Zhang, X. F., Smith, K. A., Morris, J. W., and Davidovits, P.: Ambient aerosol sampling using the Aerodyne Aerosol Mass Spectrometer, J. Geophys. Res., 108, 8425, doi:10.1029/2001JD001213, 2003.

Johnson, D., Jenkin, M. E., Wirtz, K., and Martin-Reviejo, M.: Simulating the formation of secondary organic aerosol from photooxidation of toluene, Environ. Chem., 1, 150-165, 2004.

Johnson, D., Jenkin, M. E., Wirtz, K., and Martin-Reviejo, M.: Simulating the formation of SOA from the photooxidation of aromatic hydrocarbons, Environ. Chem., 2, 35-48, 2005.
Johnson, D., Utembe, S. R., and Jenkin, M. E.: Simulating the detailed chemical composition of secondary organic aerosol formed on a regional scale during the TORCH 2003 campaign in the southern UK, Atmos. Chem. Phys., 6, 419-431, 2006, http://www.atmos-chem-phys.net/6/419/2006/.

Johnson, D. and Marston, G.: The gas-phase ozonolysis of unsaturated volatile organic compounds in the troposphere, Chem. Soc. Rev., 37, 699-716, 2008.

Jonsson, A.. M., Hallquist, M., and Ljungström, E.: Impact of humidity on the ozone initiated oxidation of limonene, $\Delta^{3}$-carene, and $\alpha$-pinene, Environ. Sci. Technol., 40, 188-194, 2006.

Jonsson, Å. M., Hallquist, M., and Saathoff, H.: Volatility of secondary organic aerosols from the ozone initiated oxidation of $\alpha$ pinene and limonene, J. Aerosol Sci., 38, 843-852, 2007.

Jonsson, Å. M., Hallquist, M., and Ljungstrom, E.: Influence of $\mathrm{OH}$ scavenger on the water effect on secondary organic aerosol formation from ozonolysis of limonene, $\Delta^{3}$-carene, and $\alpha$-pinene, Environ. Sci. Technol., 42, 5938-5944, 2008a.

Jonsson, Å. M., Hallquist, M., and Ljungström, E.: The effect of temperature and water on secondary organic aerosol formation from ozonolysis of limonene, $\Delta^{3}$-carene and $\alpha$-pinene, Atmos. Chem. Phys., 8, 6541-6549, 2008b, http://www.atmos-chem-phys.net/8/6541/2008/.

Jorand, F., Heiss, A., Perrin, O., Sahetchian, K., Kerhoas, L., and Einhorn, J.: Isomeric hexyl-ketohydroperoxides formed by reactions of hexoxy and hexylperoxy radicals in oxygen, Int. J. Chem. Kinet., 35, 354-366, 2003.

Joutsensaari, J., Loivamäki, M., Vuorinen, T., Miettinen, P., Nerg, A.-M., Holopainen, J. K., and Laaksonen, A.: Nanoparticle formation by ozonolysis of inducible plant volatiles, Atmos. Chem. Phys., 5, 1489-1495, 2005, http://www.atmos-chem-phys.net/5/1489/2005/.

Kalberer, M., Paulsen, D., Sax, M., Steinbacher, M., Dommen, J., Prévôt, A. S. H., Fisseha, R., Weingartner, E., Frankevich, V., Zenobi, R., and Baltensperger, U.: Identification of polymers as major components of atmospheric organic aerosols, Science, 303, 1659-1662, 2004.

Kalberer, M., Sax, M., and Samburova, V.: Characterization of polymers in nanometer sized atmospheric aerosol particles, Chimia, 59, 43-43, 2005.

Kalberer, M., Sax, M., and Samburova, V.: Molecular size evolution of oligomers in organic aerosols collected in urban atmospheres and generated in a smog chamber, Environ. Sci. Technol., 40, 5917-5922, 2006.

Kanakidou, M., Seinfeld, J. H., Pandis, S. N., Barnes, I., Dentener, F. J., Facchini, M. C., Van Dingenen, R., Ervens, B., Nenes, A., Nielsen, C. J., Swietlicki, E., Putaud, J. P., Balkanski, Y., Fuzzi, S., Horth, J., Moortgat, G. K., Winterhalter, R., Myhre, C. E. L., Tsigaridis, K., Vignati, E., Stephanou, E. G., and Wilson, J.: Organic aerosol and global climate modelling: a review, Atmos. Chem. Phys., 5, 1053-1123, 2005, http://www.atmos-chem-phys.net/5/1053/2005/.

Kärcher, B. and Koop, T.: The role of organic aerosols in homogeneous ice formation, Atmos. Chem. Phys., 5, 703-714, 2005, http://www.atmos-chem-phys.net/5/703/2005/.

Katrib, Y., Martin, S. T., Rudich, Y., Davidovits, P., Jayne, J. T., and Worsnop, D. R.: Density changes of aerosol particles as a result of chemical reaction, Atmos. Chem. Phys., 5, 275-291, 2005, http://www.atmos-chem-phys.net/5/275/2005/. 
Kawamura, K. and Sakaguchi, F.: Molecular distributions of watersoluble dicarboxylic acids in marine aerosols over the Pacific Ocean including tropics, J. Geophys. Res., 104, 3501-3509, 1999.

Ke, L., Liu, W., Wang, Y., Russell, A. G., Edgerton, E. S., and Zheng, M.: Comparison of PM2.5 source apportionment using positive matrix factorization and molecular marker-based chemical mass balance, Sci. Total Environ., 394, 290-302, 2008.

Kerminen, V. M., Ojanen, C., Pakkanen, T., Hillamo R., Aurela, M., and Merilainen, J.: Low-molecular-weight dicarboxylic acids in an urban and rural atmosphere, J. Aerosol Sci., 31, 349-362, 2000.

Kerminen, V.-M., Anttila, T., Lehtinen, K., and Kulmala, M.: Parameterization for atmospheric new-particle formation: application to a system involving sulfuric acid and condensable watersoluble organic vapors, Aerosol Sci. Technol., 38, 1001-1008, 2004.

Kerminen, V. M., Lihavainen, H., Komppula, M., Viisanen, Y., and Kulmala, M.: Direct observational evidence linking atmospheric aerosol formation and cloud droplet activation, Geophys. Res. Lett., 32, L14803, doi:10.1029/2005GL023130, 2005.

Kettle, A. J. and Andreae, M. O.: Flux of dimethylsulfide from the oceans: A comparison of updated data sets and flux models, J. Geophys. Res., 105, 26 793-26 808, 2000.

Keywood, M. D., Kroll, J. H., Varutbangkul, V., Bahreini, R., Flagan, R. C., and Seinfeld, J. H.: Secondary organic aerosol formation from cyclohexene ozonolysis: effect of $\mathrm{OH}$ scavenger and the role of radical chemistry, Environ. Sci. Technol., 38, 33433350, 2004.

Kikic, I., Fermeglia, M., and Rasmussen, P.: UNIFAC prediction of vapor-liquid equilibria in mixed-solvent salt systems, Chem. Eng. Sci., 46, 2775-2780, 1991.

King, S. M., Rosenoern, T., Shilling, J. E., Chen, Q., and Martin, S. T.: Increased cloud activation potential of secondary organic aerosol for atmospheric mass loadings, Atmos. Chem. Phys., 9, 2959-2971, 2009, http://www.atmos-chem-phys.net/9/2959/2009/.

Kiss, G., Varga, B., Galambos, I., and Ganszky, I.: Characterization of water-soluble organic matter isolated from atmospheric fine aerosol, J. Geophys. Res., 107, 8339, doi:10.1029/2001JD000603, 2002.

Kiss, G., Tombacz, E., Varga, B., Alsberg, T., and Persson, L.: Estimation of the average molecular weight of humic-like substances isolated from fine atmospheric aerosol, Atmos. Environ., 37, 3783-3794, 2003.

Kiss, G., Tombacz, E., and Hansson H. C.: Surface tension effects of humic-like substances in the aqueous extract of tropospheric fine aerosol, J. Atmos. Chem., 50, 279-294, 2005.

Kleindienst, T. E., Edney, E. O., Lewandowski, M., Offenberg, J. H., and Jaoui, M.: Secondary organic carbon and aerosol yields from the irradiations of isoprene and $\alpha$-pinene in the presence of $\mathrm{NO}_{\mathrm{x}}$ and $\mathrm{SO}_{2}$, Environ. Sci. Technol, 40, 3807-3812, 2006.

Kleindienst, T. E., Jaoui, M., Lewandowski, M., Offenberg, J. H., Lewis, C. W., Bhave, P. V., and Edney, E. O.: Estimates of the contributions of biogenic and anthropogenic hydrocarbons to secondary organic aerosol at a southeastern US location, Atmos. Environ., 41, 8288-8300, 2007.

Kleinman, L. I., Springston, S. R., Daum, P. H., Lee, Y.-N., Nunnermacker, L. J., Senum, G. I., Wang, J., Weinstein-Lloyd, J.,
Alexander, M. L., Hubbe, J., Ortega, J., Canagaratna, M. R., and Jayne, J.: The time evolution of aerosol composition over the Mexico City plateau, Atmos. Chem. Phys., 8, 1559-1575, 2008, http://www.atmos-chem-phys.net/8/1559/2008/.

Klotz, B., Sorensen, S., Barnes, I., Becker, K. H., Etzkorn, T., Volkamer, R., Platt, U., Wirtz, K., and Martin-Reviejo, M.: Atmospheric oxidation of toluene in a large-volume outdoor photoreactor: in situ determination of ring-retaining product yields, J. Phys. Chem., 102, 10 289-10 299, 1998.

Knipping, E. M., Lakin, M. J., Foster, K. L., Jungwirth, P., Tobias, D. J., Gerber, R. B., Dabdub, D., and Finlayson-Pitts, B. J.: Experiments and simulations of ion-enhanced interfacial chemistry an aqueous $\mathrm{NaCl}$ aerosols, Science, 288, 301-306, 2000.

Kokkola, H., Sorjamaa, R., Peräniemi, A., Raatikainen, A., and Laaksonen, A.: Cloud formation of particles containing humic-like substances, Geophys. Res. Lett., 33, L10816, doi:10.1029/2006GL026107, 2006.

Kondo, Y., Miyazaki, Y., Takegawa, N., Miyakawa, T., Weber, R. J., Jimenez, J. L., Zhang, Q., and Worsnop, D. R.: Oxygenated and water-soluble organic aerosols in Tokyo, J. Geophys. Res., 112, D01203, doi:10.1029/2006JD007056, 2007.

Koo, B. Y., Ansari, A. S., and Pandis, S. N.: Integrated approaches to modeling the organic and inorganic atmospheric aerosol components, Atmos. Environ., 37, 4757-4768, 2003.

Koop, T.: Homogeneous ice nucleation in water and aqueous solutions, Z. Phys. Chem., 218, 1231-1258, 2004.

Kostenidou, E., Pathak, R. K., and Pandis, S. N.: An algorithm for the calculation of secondary organic aerosol density combining AMS and SMPS data, Aerosol Sci. Technol., 41, 1002-1010, 2007.

Kotianova, P., Matisova, E., Puxbaum, H., and Lehotay, J.: Analysis of organic compounds in aerosols. A review, Chem. Anal.Warsaw, 49, 833-844, 2004.

Kourtchev, I., Ruuskanen, T., Maenhaut, W., Kulmala, M., and Claeys, M.: Observation of 2-methyltetrols and related photooxidation products of isoprene in boreal forest aerosols from Hyytiälä, Finland, Atmos. Chem. Phys., 5, 2761-2770, 2005, http://www.atmos-chem-phys.net/5/2761/2005/.

Kourtchev, I., Ruuskanen, T. M., Keronen, P., Sogacheva, L., Dal Maso, M., Reissell, A., Chi, X., Vermeylen, R., Kulmala, M., Maenhaut, W., and Claeys, M.: Determination of isoprene and $\alpha-/ \beta$-pinene oxidation products in boreal forest aerosols from Hyytiälä, Finland: diel variations and possible link with particle formation events, Plant Biol., 10, 138-149, 2008a.

Kourtchev, I., Warnke, J., Maenhaut, W., Hoffmann, T., and Claeys, M.: Polar organic marker compounds in PM2.5 aerosol from a mixed forest site in western Germany, Chemosphere, 73, 13081314, 2008b.

Kroll, J. H., Ng, N. L., Murphy, S. M., Varutbangkul, V., Flagan, R. C., and Seinfeld, J. H.: Chamber studies of secondary organic aerosol growth by reactive uptake of simple carbonyl compounds, J. Geophys. Res., 110, D23207, doi:10.1029/2005JD006004, 2005a.

Kroll, J. H., Ng, N. L., Murphy, S. M., Flagan, R. C., and Seinfeld, J. H.: Secondary organic aerosol formation from isoprene photooxidation under high- $\mathrm{NO}_{\mathrm{x}}$ conditions, Geophys. Res. Lett., 32, L18808, doi:10.1029/2005GL023637, 2005b.

Kroll, J. H., Ng, N. L., Murphy, S. M., Flagan, R. C., and Seinfeld, J. H.: Secondary organic aerosol formation from isoprene 
photooxidation, Environ. Sci. Technol., 40, 1869-1877, 2006.

Kroll, J. H., Chan, A. W. H., Ng, N. L., Flagan, R. C., and Seinfeld, J. H.: Reactions of semivolatile organics and their effects on secondary organic aerosol formation, Environ. Sci. Technol., 41, 3545-3550, 2007.

Kroll, J. H. and Seinfeld, J. H.: Chemistry of secondary organic aerosol: Formation and evolution of low-volatility organics in the atmosphere, Atmos. Environ., 42, 3593-3624, 2008.

Kua, J., Hanley, S. W., and De Haan, D. O.: Thermodynamics and kinetics of glyoxal dimer formation: A computational study, J. Phys. Chem. A, 112, 66-72, 2008.

Kubátová, A., Vermeylen, R., Claeys, M., Cafmeyer, J., Maenhaut, W., Roberts, G., and Artaxo, P.: Carbonaceous aerosol characterization in the Amazon basin, Brasil: novel dicarboxylic acids and related compounds, Atmos. Environ., 34, 5037-5051, 2000.

Kulmala, M., Suni, T., Lehtinen, K. E. J., Dal Maso, M., Boy, M., Reissell, A., Rannik, Ü., Aalto, P., Keronen, P., Hakola, H., Bäck, J., Hoffmann, T., Vesala, T., and Hari, P.: A new feedback mechanism linking forests, aerosols, and climate, Atmos. Chem. Phys., 4, 557-562, 2004,

http://www.atmos-chem-phys.net/4/557/2004/.

Kulmala, M., Lehtinen, K. E. J., and Laaksonen, A.: Cluster activation theory as an explanation of the linear dependence between formation rate of $3 \mathrm{~nm}$ particles and sulphuric acid concentration, Atmos. Chem. Phys., 6, 787-793, 2006, http://www.atmos-chem-phys.net/6/787/2006/.

Kürten, A., Curtius, J., Helleis, F., Lovejoy, E. R., and Borrmann, S.: Development and characterization of an ion trap mass spectrometer for the on-line chemical analysis of atmospheric aerosol particles, Int. J. Mass Spectrom., 265, 30-39, 2007.

Laaksonen, A., Kulmala, M., O’Dowd, C. D., Joutsensaari, J., Vaattovaara, P., Mikkonen, S., Lehtinen, K. E. J., Sogacheva, L., Dal Maso, M., Aalto, P., Petäjä, T., Sogachev, A., Yoon, Y. J., Lihavainen, H., Nilsson, D., Facchini, M. C., Cavalli, F., Fuzzi, S., Hoffmann, T., Arnold, F., Hanke, M., Sellegri, K., Umann, B., Junkermann, W., Coe, H., Allan, J. D., Alfarra, M. R., Worsnop, D. R., Riekkola, M.-L., Hyötyläinen, T., and Viisanen, Y.: The role of VOC oxidation products in continental new particle formation, Atmos. Chem. Phys., 8, 2657-2665, 2008, http://www.atmos-chem-phys.net/8/2657/2008/.

LaFranchi, B. W., Zahardis, J., and Petrucci, G. A.: Photoelectron resonance capture ionization mass spectrometry: a soft ionization source for mass spectrometry of particle-phase organic compounds, Rapid Commun. Mass Sp., 18, 2517-2521, 2004.

Lambe, A. T., Zhang, J., Sage, A. M., and Donahue, N. M.: Controlled $\mathrm{OH}$ radical production via ozone-alkene reactions for use in aerosol aging atudies, Environ. Sci. Technol., 41, 2357-2363, 2007.

Lane, T. E., Pinder, R. W., Shrivastava, M., Robinson, A. L., and Pandis, S. N.: Source contributions to primary organic aerosol: Comparison of the results of a source-resolved model and the chemical mass balance approach, Atmos. Environ., 41, 37583776, 2007.

Lane, T. E., Donahue, N. M., and Pandis, S. N.: Simulating secondary organic aerosol formation using the volatility basis set approach in a chemical transport model, Atmos. Environ., 42, 7439-7451, 2008.

Lanz, V. A., Alfarra, M. R., Baltensperger, U., Buchmann, B., Hueglin, C., and Prévôt, A. S. H.: Source apportionment of sub- micron organic aerosols at an urban site by factor analytical modelling of aerosol mass spectra, Atmos. Chem. Phys., 7, 15031522, 2007,

http://www.atmos-chem-phys.net/7/1503/2007/.

Lanz, V. A., Alfarra, M. R., Baltensperger, U., Buchmann, B., Hueglin, C., Szidat, S., Wehrli, M. N., Wacker, L., Weimer, S., Caseiro, A., Puxbaum, H., and Prévôt, A. S. H.: Source attribution of submicron organic aerosols during wintertime inversions by advanced factor analysis of aerosol mass spectra, Environ. Sci. Technol., 42, 214-220, 2008.

Larsen, B. R., Di Bella, D., Glasius, M., Winterhalter, R., Jensen, N. R., and Hjorth, J.: Gas-phase OH oxidation of monoterpenes: Gaseous and particulate products, J. Atmos. Chem., 38, 231-276, 2001.

Lathiere, J., Hauglustaine, D. A., De Noblet-Ducoudre, N., Krinner, G., and Folberth, G. A.: Past and future changes in biogenic volatile organic compound emissions simulated with a global dynamic vegetation model, Geophys. Res. Lett., 32, L20818, doi:10.1029/2005GL024164, 2005.

Lee, S., Jang, M., and Kamens, R. M.: SOA formation from the photooxidation of $\alpha$-pinene in the presence of freshly emitted diesel soot exhaust, Atmos. Environ., 38, 2597-2605, 2004.

Legrand, M., Preunkert, S., Wagenbach, D., Cachier, H., and Puxbaum, H.: A historical record of formate and acetate from a high elevation Alpine glacier: Implications for their natural versus anthropogenic budgets at the European scale, J. Geophys. Res., 108(D24), 4788, doi:10.1029/2003JD003594, 2003.

Legrand, M., Preunkert, S., Galy-Lacaux, C., Liousse, C., and Wagenbach, D.: Atmospheric year-round records of dicarboxylic acids and sulfate at three French sites located between 630 and $4360 \mathrm{~m}$ elevation, J. Geophys. Res., 110, D13302, doi:10.1029/2004JD005515, 2005.

Legrand, M. and Puxbaum, H.: Summary of the CARBOSOL project: Present and retrospective state of organic versus inorganic aerosol over Europe, J. Geophys. Res., 112, D23S01, doi:10.1029/2006JD008271, 2007.

Lelieveld, J. and Crutzen, P. J.: Influence of cloud photochemical processes on tropospheric ozone, Nature, 343, 227-233, 1990.

Lewandowski, M., Jaoui, M., Kleindienst, T. E., Offenberg, J. H., and Edney, E. O.: Composition of $\mathrm{PM}_{2.5}$ during the summer of 2003 in Research Triangle Park, North Carolina, Atmos. Environ., 41, 4073-4083, 2007.

Lewis, A. C., Kupiszewska, D., Bartle, K. D., and Pilling, M. J.: City center concentrations of polycyclic aromatic hydrocarbons using supercritical fluid extraction, Atmos. Environ., 29, 15311542, 1995.

Lewis, A. C., Carslaw, N., Marriott, P. J., Kinghorn, R. M., Morrison, P., Lee, A. L., Bartle, K. D., and Pilling, M. J.: A larger pool of ozone-forming carbon compounds in urban atmospheres, Nature, 405(6), 778-781, 2000.

Lewis, C. W., Klouda, G., and Ellenson, W.: Radiocarbon measurement of the biogenic contribution to summertime PM2.5 ambient aerosol in Nashville, TN, Atmos. Environ., 38, 6053-6061, 2004.

Li, J. D., Polka, H. M., and Gmehling, J.: A G(E) model for single and mixed-solvent electrolyte systems. 1. Model and results for strong electrolytes, Fluid Phase Equilibr., 94, 89-114, 1994.

Li, Q., Hu, D., Leungsakul, S., and Kamens, R. M.: Large outdoor chamber experiments and computer simulations: (I) Secondary organic aerosol formation from the oxidation of a mixture of $d$ - 
limonene and $\alpha$-pinene, Atmos. Environ., 41(40), 9341-9352, 2007.

Liggio, J., McLaren, R., and Li, S.-M.: Heterogeneous reactions of glyoxal in particulate matter: Identification of acetals and sulfate esters, Environ. Sci. Technol., 39, 1532-1541, 2005a.

Liggio, J., McLaren, R., and Li, S.-M.: Reactive uptake of glyoxal on particulate matter, J. Geophys. Res., 110, D10304, doi:10.1029/2004JD005113, 2005b.

Liggio, J. and Li, S.-M.: Organosulfate formation during the uptake of pinonaldehyde in acidic sulfate aerosols, Geophys. Res. Lett., 33, L13808, doi:10.1029/2006GL026079, 2006 .

Liggio, J. and Li, S.-M.: Reactive uptake of pinonaldehyde on acidic aerosols, J. Geophys. Res., 111, D24303, doi:10.1029/2005jd006978, 2006b.

Lim, Y. B. and Ziemann, P. J.: Products and mechanism of secondary organic aerosol formation from reactions of n-alkanes with $\mathrm{OH}$ radicals in the presence of $\mathrm{NO}_{\mathrm{x}}$, Environ. Sci. Technol., 39, 9229-9236, 2005.

Lim, H. J., Carlton, A. G., and Turpin, B. J.: Isoprene forms secondary organic aerosol through cloud processing: Model simulations, Environ. Sci. Technol, 39(6), 4441-4446, 2005.

Limbeck, A., Kulmala, M., and Puxbaum, H.: Secondary organic aerosol formation in the atmosphere via heterogenous reaction of gaseous isoprene on acidic particles, Geophys. Res. Lett., 30, 1996, doi:10.1029/2003GL017738, 2003.

Liu, Y., El Haddad, I., Scarfogliero, M., Nieto-Gligorovski, L., Temime-Roussel, B., Quivet, E., Marchand, N., PicquetVarrault, B., and Monod, A.: In-cloud processes of methacrolein under simulated conditions - Part 1: Aqueous phase photooxidation, Atmos. Chem. Phys. Discuss., 9, 6397-6424, 2009, http://www.atmos-chem-phys-discuss.net/9/6397/2009/.

Loeffler, K. W., Koehler, C. A., Paul, N. M., and De Haan, D. O.: Oligomer formation in evaporating aqueous glyoxal and methyl glyoxal solutions, Environ. Sci. Technol., 40, 6318-6323, 2006.

Lukács, H., Gelencsér, A., Hoffer, A., Kiss, G., Horváth, K., and Hartyáni, Z:: Quantitative assessment of organosulfates in sizesegregated rural fine aerosol, Atmos. Chem. Phys., 9, 231-238, 2009 ,

http://www.atmos-chem-phys.net/9/231/2009/.

Ma, Y., Luciani, T., Porter, R. A., Russell, A. T., Johnson, D., and Marston, G.: Organic acid formation in the gas-phase ozonolysis of alpha-pinene, Phys. Chem. Chem. Phys., 9, 5084-5087, 2007a.

Ma, Y., Willcox, T. R., Russell, A. T., and Marston, G.: Pinic and pinonic acid formation in the reaction of ozone with alphapinene, Chem. Commun., 13, 1328-1330, $2007 \mathrm{~b}$.

MacCarthy, P., Bloom, P. R., Clapp, C. E., and Malcolm, R. L.: Humic substances in soil and crop sciences: an overview, in: Humic Substances in Soil and Crop Sciences: Selected Readings, American Society of Agronomy, Soil Science Society of America, Madison, Wisconsin, USA, 261-271, 1990.

Madronich, S. and Calvert, J. G.: Permutation reactions of organic peroxy radicals in the troposphere, J. Geophys. Res., 95, 56975715, 1990.

Maenhaut, W., Raes, N., Chi, X., Cafmeyer, J., and Wang W.: Chemical composition and mass closure for $\mathrm{PM}_{2.5}$ and $\mathrm{PM}_{10}$ aerosols at K-puszta, Hungary, in summer 2006, X-Ray Spectrom., 37, 193-197, 2008.

Marcolli, C., Luo, B. P., and Peter, T.: Mixing of the organic aerosol fractions: Liquids as the thermodynamically stable phases, J. Phys. Chem. A, 108, 2216-2224, 2004.

Marcolli, C. and Krieger, U. K.: Phase changes during hygroscopic cycles of mixed organic/inorganic model systems of tropospheric aerosols, J. Phys. Chem. A, 110, 1881-1893, 2006.

Maria, S. F., Russell, L. M., Turpin, B. J., and Porcja, R. J.: FTIR measurements of functional groups and organic mass in aerosol samples over the Caribbean, Atmos. Environ., 36, 5185-5196, 2002.

Maria, S. F., Russell, L. M., Turpin, B. J., Porcja, R. J., Campos, T. L., Weber, R. J., and Huebert, B. J.: Source signatures of carbon monoxide and organic functional groups in Asian Pacific Regional Aerosol Characterization Experiment (ACEAsia) submicron aerosol types, J. Geophys. Res., 108, 8637, doi:10.1029/2003JD003703, 2003.

Martin-Reviejo, M. and Wirtz, K.: Is benzene a precursor for secondary organic aerosol?, Environ. Sci. Technol., 39, 1045-1054, 2005.

Matsunaga, A., Docherty, K. S., Lim, Y. B., and Ziemann, P. J.: Composition and yields of secondary organic aerosol formed from $\mathrm{OH}$ radical-initiated reactions of linear alkenes in the presence of $\mathrm{NO}_{\mathrm{x}}$ : Modeling and measurements, Atmos. Environ., 43, 1349-1357, 2009.

McFiggans, G., Coe, H., Burgess, R., Allan, J., Cubison, M., Alfarra, M. R., Saunders, R., Saiz-Lopez, A., Plane, J. M. C., Wevill, D., Carpenter, L., Rickard, A. R., and Monks, P. S.: Direct evidence for coastal iodine particles from Laminaria macroalgae - linkage to emissions of molecular iodine, Atmos. Chem. Phys., 4, 701-713, 2004,

http://www.atmos-chem-phys.net/4/701/2004/.

McFiggans, G., Alfarra, M. R., Allan, J., Bower, K., Coe, H., Cubison, M., Topping, D., Williams, P., Decesari, S., Facchini, C., and Fuzzi, S.: Simplification of the representation of the organic component of atmospheric particulates, Faraday Discuss., 130, 341-362, 2005.

McFiggans, G., Artaxo, P., Baltensperger, U., Coe, H., Facchini, M. C., Feingold, G., Fuzzi, S., Gysel, M., Laaksonen, A., Lohmann, U., Mentel, T. F., Murphy, D. M., O’Dowd, C. D., Snider, J. R., and Weingartner, E.: The effect of physical and chemical aerosol properties on warm cloud droplet activation, Atmos. Chem. Phys., 6, 2593-2649, 2006, http://www.atmos-chem-phys.net/6/2593/2006/.

McIntire, T. M., Lea, A. S., Gaspar, D. J., Jaitly, N., Dubowski, Y., Li, Q. Q., and Finlayson-Pitts, B. J.: Unusual aggregates from the oxidation of alkene self-assembled monolayers: a previously unrecognized mechanism for SAM ozonolysis?, Phys. Chem. Chem. Phys., 7, 3605-3609, 2005.

McKeown, P. J., Johnston, M. V., and Murphy, D. M.: Online single-particle analysis by laser desorption mass-spectrometry, Anal. Chem., 63, 2069-2073, 1991.

McMurry, P. H.: A review of atmospheric aerosol measurements, Atmos. Environ., 34, 1959-1999, 2000.

McMurry, P. H., Wang, X., Park, K., and Ehara, K.: The relationship between mass and mobility for atmospheric particles: A new technique for measuring particle density, Aerosol Sci. Technol., 36, 227-238, 2002.

Mentel, T. F., Bleilebens, D., and Wahner, A.: A study of nighttime nitrogen oxide oxidation in a large reaction chamber - the fate of $\mathrm{NO}_{2}, \mathrm{~N}_{2} \mathrm{O}_{5}, \mathrm{HNO}_{3}$ and $\mathrm{O}_{3}$ at different humidities, Atmos. 
Environ., 30, 4007-4020, 1996.

Mentel, Th. F., Wildt, J., Kiendler-Scharr, A., Kleist, E., Tillmann, R., Dal Maso, M., Fisseha, R., Hohaus, Th., Spahn, H., Uerlings, R., Wegener, R., Griffiths, P. T., Dinar, E., Rudich, Y., and Wahner, A.: Photochemical production of aerosols from real plant emissions, Atmos. Chem. Phys., 9, 4387-4406, 2009, http://www.atmos-chem-phys.net/9/4387/2009/.

Meskhidze, N. and Nenes, A.: Phytoplankton and cloudiness in the Southern Ocean, Science, 314, 1419-1423, 2006.

Metzger, A., Dommen, J., Gaeggeler, K., Duplissy, J., Prévôt, A. S. H., Kleffmann, J., Elshorbany, Y., Wisthaler, A., and Baltensperger, U.: Evaluation of 1,3,5 trimethylbenzene degradation in the detailed tropospheric chemistry mechanism, MCMv3.1, using environmental chamber data, Atmos. Chem. Phys., 8, 6453-6468, 2008,

http://www.atmos-chem-phys.net/8/6453/2008/.

Meyer, N. K., Duplissy, J., Gysel, M., Metzger, A., Dommen, J., Weingartner, E., Alfarra, M. R., Prévôt, A. S. H., Fletcher, C., Good, N., McFiggans, G., Jonsson, Å. M., Hallquist, M., Baltensperger, U., and Ristovski, Z. D.: Analysis of the hygroscopic and volatile properties of ammonium sulphate seeded and unseeded SOA particles, Atmos. Chem. Phys., 9, 721-732, 2009, http://www.atmos-chem-phys.net/9/721/2009/.

Michaud, V., El Haddad, I., Liu, Y., Sellegri, K., Laj, P., Villani, P., Picard, D., Marchand, N., and Monod, A.: In-cloud processes of methacrolein under simulated conditions - Part 3: Hygroscopic and volatility properties of the formed secondary organic aerosol, Atmos. Chem. Phys. Discuss., 9, 6451-6482, 2009, http://www.atmos-chem-phys-discuss.net/9/6451/2009/.

Ming, Y. and Russell, L. M.: Thermodynamic equilibrium of organic-electrolyte mixtures in aerosol particles, AIChE J., 48, 1331-1348, 2002.

Miyazaki, Y., Kondo, Y., Takegawa, N., Komazaki, Y., Fukuda, M., Kawamura, K., Mochida, M., Okuzawa, K., and Weber, R. J.: Time-resolved measurements of water-soluble organic carbon in Tokyo, J. Geophys. Res., 111, D23206, doi:10.1029/2006JD007125, 2006.

Mochida, M., Katrib, Y., Jayne, J. T., Worsnop, D. R., and Martin, S. T.: The relative importance of competing pathways for the formation of high-molecular-weight peroxides in the ozonolysis of organic aerosol particles, Atmos. Chem. Phys., 6, 4851-4866, 2006, http://www.atmos-chem-phys.net/6/4851/2006/.

Möhler, O., Linke, C., Saathoff, H., Schnaiter, M., Wagner, R., Mangold, A., Krämer, M., and Schurath, U.: Ice nucleation on flame soot aerosol of different organic carbon content, Meteorol. Z., 14, 477-484, 2005.

Möhler, O., Benz, S., Saathoff, H., Schnaiter, M., Wagner, R., Schneider, J., Walter, S., Ebert, V., and Wagner, S.: The effect of organic coating on the heterogeneous ice nucleation efficiency of mineral dust aerosols, Environ. Res. Lett., 3, 025007, doi:10.1088/1748-9326/3/2/025007, 2008.

Molina, M. J., Ivanov, A. V., Trakhtenberg, S., and Molina, L. T.: Atmospheric evolution of organic aerosol, Geophys. Res. Lett., 31, L22104, 10.1029/2004g1020910, 2004.

Monod A. and Carlier, P.: Impact of clouds on tropospheric ozone budget: direct effect of multiphase photochemistry of soluble organic compounds, Atmos. Environ., 33, 4431-4446, 1999.
Monod, A., Poulain, L., Grubert, S., Voisin, D., and Wortham, H.: Kinetics of $\mathrm{OH}$-initiated oxidation of oxygenated organic compounds in the aqueous phase - new rate constants and structurereactivity relationships, Atmos. Environ., 39, 7667-7688, 2005.

Monod, A., Chevallier, E., Durand-Jolibois, R., Doussin, J. F., Picquet-Varrault, B., and Carlier P.: Photooxidation of methylhydroperoxide and ethylhydroperoxide in the aqueous phase under simulated cloud droplet conditions, Atmos. Environ., 41, 24122426, 2007.

Monod, A. and Doussin, J. F.: Structure-activity relationship for the estimation of $\mathrm{OH}$-oxidation rate constant of aliphatic organic compounds in the aqueous phase: alkanes, alcohols, organic acids and bases, Atmos. Environ., 42, 7611-7622, 2008.

Moore, R. H. and Raymond, T. M.: HTDMA analysis of multicomponent dicarboxylic acid aerosols with comparison to UNIFAC and ZSR, J. Geophys. Res., 113, D04206, doi:10.1029/2007JD008660, 2008.

Morozov, I., Gligorovski, S., Barzaghi, P., Hoffmann, D., Lazarou, Y. G., Vasiliev, E., and Herrmann, H.: Hydroxyl radical reactions with halogenated ethanols in aqueous solution: Kinetics and thermochemistry, Int. J. Chem. Kinet., 40, 174-188, 2008.

Müller, C., Iinuma, Y., Böge, O., and Herrmann, H.: Applications of CE-ESI-MS/MS analysis to structural elucidation of methylenecyclohexane ozonolysis products in the particle phase, Electrophoresis, 28, 1364-1370, 2007.

Müller, L., Reinnig, M.-C., Warnke, J., and Hoffmann, Th.: Unambiguous identification of esters as oligomers in secondary organic aerosol formed from cyclohexene and cyclohexene $/ \alpha$ pinene ozonolysis, Atmos. Chem. Phys., 8, 1423-1433, 2008, http://www.atmos-chem-phys.net/8/1423/2008/.

Müller, L., Reinnig, M. C., Hayen, H., and Hoffmann, T.: Characterization of oligomeric compounds in secondary organic aerosol using liquid chromatography coupled to electrospray ionization Fourier transform ion cyclotron resonance mass spectrometry, Rapid Commun. Mass Sp., 23, 971-979, 2009.

Murphy, D. M., Cziczo, D. J., Hudson, P. K., Schein, M. E., and Thomson, D. S.: Particle density inferred from simultaneous optical and aerodynamic diameters sorted by composition, J. Aerosol Sci., 35, 135-139, 2004.

Murphy, D. M., Cziczo, D. J., Froyd, K. D., Hudson, P. K., Matthew, B. M., Middlebrook, A. M., Peltier, R. E., Sullivan, A., Thomson, D. S., and Weber, R. J.: Single-particle mass spectrometry of tropospheric aerosol particles, J. Geophys. Res., 111, D23S32, doi:10.1029/2006JD007340, 2006.

Murphy, D. M., Cziczo, D. J., Hudson, P. K., and Thomson, D. S.: Carbonaceous material in aerosol particles in the lower stratosphere and tropopause region, J. Geophys. Res., 112, D04203, doi:10.1029/2006JD007297, 2007.

Murray, B. J.: Inhibition of ice crystallisation in highly viscous aqueous organic acid droplets, Atmos. Chem. Phys., 8, 54235433, 2008, http://www.atmos-chem-phys.net/8/5423/2008/.

Nadykto, A. B. and Yu, F.: Strong hydrogen bonding between atmospheric nucleation precursors and common organics, Chem. Phys. Lett., 435, 14-18, 2007.

National Research Council (NRC): Research Priorities for Airborne Particulate Matter, IV Continuing Research Progress, National Academy Press, Washington, DC, available at: http://books.nap. edu/catalog.php?record_id=10957, 2004. 
Nawrot, T. S., Torfs, R., Fierens, F., de Henauw, S., Hoet, P. H., van Kersschaever, G., de Backer, G., and Nemery, B.: Stronger associations between daily mortality and fine particulate air pollution in summer than in winter: evidence from a heavily polluted region in western Europe, J. Epidemiol. Commun. H., 61, 146-149, 2007.

Neeb, P., Horie, O., and Moortgat, G. K.: The ethene-ozone reaction in the gas phase, J. Phys. Chem. A., 102, 6778-6785, 1998.

Nemitz, E., Jimenez, J. L., Huffman, J. A., Canagaratna, M. R., Worsnop, D. R., and Guenther, A. B.: An eddy-covariance system for the measurement of surface/atmosphere exchange fluxes of submicron aerosol chemical species - first application above an urban area, Aerosol Sci. Technol., 42, 636-657, 2008.

Ng, N. L., Kroll, J. H., Keywood, M. D., Bahreini, R., Varutbangkul, V., Flagan, R. C., Seinfeld, J. H., Lee, A. and Goldstein, A. H.: Contributions of first- versus second-generation products to secondary organic aerosols formed in the oxidation of biogenic hydrocarbons, Environ. Sci. Technol., 40, 2283-2297, 2006.

Ng, N. L., Kroll, J. H., Chan, A. W. H., Chhabra, P. S., Flagan, R. C., and Seinfeld, J. H.: Secondary organic aerosol formation from m-xylene, toluene, and benzene, Atmos. Chem. Phys., 7, 3909-3922, 2007a, http://www.atmos-chem-phys.net/7/3909/2007/.

Ng, N. L., Chhabra, P. S., Chan, A. W. H., Surratt, J. D., Kroll, J. H., Kwan, A. J., McCabe, D. C., Wennberg, P. O., Sorooshian, A., Murphy, S. M., Dalleska, N. F., Flagan, R. C., and Seinfeld, J. H.: Effect of $\mathrm{NO}_{\mathrm{x}}$ level on secondary organic aerosol (SOA) formation from the photooxidation of terpenes, Atmos. Chem. Phys., 7, 5159-5174, 2007b,

http://www.atmos-chem-phys.net/7/5159/2007/.

Ng, N. L., Kwan, A. J., Surratt, J. D., Chan, A. W. H., Chhabra, P. S., Sorooshian, A., Pye, H. O. T., Crounse, J. D., Wennberg, P. O., Flagan, R. C., and Seinfeld, J. H.: Secondary organic aerosol (SOA) formation from reaction of isoprene with nitrate radicals $\left(\mathrm{NO}_{3}\right)$, Atmos. Chem. Phys., 8, 4117-4140, 2008, http://www.atmos-chem-phys.net/8/4117/2008/.

Noble, C. A. and Prather, K. A.: Real-time measurement of correlated size and composition profiles of individual atmospheric aerosol particles, Environ. Sci. Technol., 30, 2667-2680, 1996.

Noble, C. A. and Prather, K. A.: Real-time single particle mass spectrometry: A historical review of a quarter century of the chemical analysis of aerosols, Mass Spectrom. Rev., 19, 248274, 2000.

Northcross, A. L. and Jang, M.: Increases in heterogeneous SOA yield from ozonolysis of monoterpenes, Atmos Environ., 41, 1483-1493, 2007.

Northway, M. J., Jayne, J. T., Toohey, D. W., Canagaratna, M. R., Trimborn, A., Akiyama, K.-I., Shimono, A., Jimenez, J. L., DeCarlo, P. F., Wilson, K. R., and Worsnop, D. R.: Demonstration of a VUV lamp photoionization source for improved organic speciation in an aerosol mass spectrometer, Aerosol Sci. Technol., 41, 829-839, 2007.

Nozière, B. and Riemer, D. D.: The chemical processing of gas-phase carbonyl compounds by sulfuric acid aerosols, 2,4pentanedione, Atmos. Environ., 37, 841-851, 2003.

Nozière, B. and Esteve, W.: Organic reactions increasing the absorption index of atmospheric sulfuric acid aerosols, Geophys. Res. Lett., 32, L03812, doi:10.1029/2004GL021942, 2005.

Nozière, B., Voisin, D., Longfellow, C. A., Friedli, H., Henry,
B. E., and Hanson, D. R.: The uptake of methyl vinyl ketone, methacrolein, and 2-methyl-3-butene-2-ol onto sulfuric acid solutions, J. Phys. Chem. A, 110, 2387-2395, 2006.

Nozière, B. and Esteve, W.: Light-absorbing aldol condensation products in acidic aerosols: Spectra, kinetics, and contribution to the absorption index, Atmos. Environ., 41, 1150-1163, 2007.

Nozière, B., Dziedzic, P., and Cordova, A.: Formation of secondary light-absorbing "fulvic-like" oligomers: A common process in aqueous and ionic atmospheric particles?, Geophys. Res. Lett., 34, L21812, doi:10.1029/2007GL031300, 2007.

Nozière, B., Dziedzic, P., and Cordova, A.: Products and kinetics of the liquid-phase reaction of glyoxal catalyzed by ammonium ions $\left(\mathrm{NH}_{4}^{+}\right)$, J. Phys. Chem. A, 113, 231-237, 2009.

Oberdorster, G., Oberdorster, E., and Oberdorster, J.: Nanotoxicology: An emerging discipline evolving from studies of ultrafine particles, Environ. Health Persp., 113, 823-839, 2005.

O'Dowd, C. D., Aalto, P., Hameri, K., Kulmala, M., and Hoffmann, T.: Aerosol formation - Atmospheric particles from organic vapors, Nature, 416, 497-498, 2002.

Odum, J. R., Hoffmann, T., Bowman, F., Collins, D., Flagan, R. C., and Seinfeld, J. H.: Gas/particle partitioning and secondary organic aerosol yields, Environ. Sci. Technol., 30, 2580-2585, 1996.

Odum, J. R., Jungkamp, T. P. W., Griffin, R. J., Flagan, R. C., and Seinfeld, J. H.: The atmospheric aerosol forming potential of whole gasoline vapor, Science, 276, 96-99, 1997.

Offenberg, J. H., Kleindienst, T. E., Jaoui, M., Lewandowski, M., and Edney, E. O.: Thermal properties of secondary organic aerosols, Geophys. Res. Lett., 33, L03816, doi:10.1029/2005GL024623, 2006.

Offenberg, J. H., Lewis, C. W., Lewandowski, M., Jaoui, M., Kleindienst, T. E., and Edney, E. O.: Contributions of toluene and alpha-pinene to SOA formed in an irradiated toluene/alphapinene/ $\mathrm{NO}_{\mathrm{x}}$ /air mixture: Comparison of results using $\mathrm{C}-14$ content and SOA organic tracer methods, Environ. Sci. Technol., 41, 3972-3976, 2007.

Olariu, R. I., Barnes, I., Becker, K. H., Klotz, B., and Mocanu, R.: FT-IR study of the ring-retaining products from the reaction of $\mathrm{OH}$ radicals with phenol, o-, m-, p-cresol, Atmos. Environ., 36, 3685-3697, 2002.

Orsini, D. A., Ma, Y. L., Sullivan, A., Sierau, B., Baumann, K., and Weber, R. J.: Refinements to the particle-into-liquid sampler (PILS) for ground and airborne measurements of water soluble aerosol composition, Atmos. Environ., 37, 1243-1259, 2003.

Pandis, S. N., Paulson, S. E., Seinfeld, J. H., and Flagan, R. C.: Aerosol formation in the photooxidation of isoprene and $\beta$ pinene, Atmos. Environ., 25, 997-1008, 1991.

Pankow, J. F.: An absorption model of the gas/aerosol partitioning involved in the formation of secondary organic aerosol, Atmos. Environ., 28(6), 189-193, 1994.

Pankow, J. F., Seinfeld, J. H., Asher, W. E., and Erdakos, G. B.: Modeling the formation of secondary organic aerosol: 1 . The application of theoretical principles to measurements obtained in the $\alpha$-pinene-, $\beta$-pinene-, sabinene-, $\Delta^{3}$-carene-, and cyclohexene-ozone systems, Environ. Sci. Technol., 35, 1164 1172, 2001.

Parazols, M., Marinoni, A., Amato, P., Abida, O., Laj, P., and Mailhot, G.: Speciation and role of iron in cloud droplets at the Puy de Dome station, J. Atmos. Chem., 54, 267-281, 2006. 
Parsons, M. T., Knopf, D. A., and Bertram, A. K.: Deliquescence and crystallization of ammonium sulfate particles internally mixed with water-soluble organic compounds, J. Phys. Chem. A, 108, 11 600-11 608, 2004.

Pathak, R. K., Presto, A. A., Lane, T. E., Stanier, C. O., Donahue, N. M., and Pandis, S. N.: Ozonolysis of $\alpha$-pinene: parameterization of secondary organic aerosol mass fraction, Atmos. Chem. Phys., 7, 3811-3821, 2007, http://www.atmos-chem-phys.net/7/3811/2007/.

Pathak, R., Donahue, N. M., and Pandis, S. N.: Ozonolysis of betapinene: Temperature dependence of secondary organic aerosol mass fraction, Environ. Sci. Technol., 42, 5081-5086, 2008.

Paulsen, D., Dommen, J., Kalberer, M., Prévôt, A. S. H., Richter, R., Sax, M., Steinbacher, M., Weingartner, E., and Baltensperger, U.: Secondary organic aerosol formation by irradiation of 1,3,5trimethylbenzene- $\mathrm{NO}_{\mathrm{x}}-\mathrm{H}_{2} \mathrm{O}$ in a new reaction chamber for atmospheric chemistry and physics, Environ. Sci. Technol., 39, 2668-2678, 2005.

Paulsen, D., Weingartner, E., Alfarra, M. R., and Baltensperger, U.: Volatility measurements of photochemically and nebulizergenerated organic aerosol particles, J. Aerosol Sci., 37, 10251051, 2006.

Peeters, J., Vereecken, L., and Fantechi, G.: The detailed mechanism of the $\mathrm{OH}$-initiated atmospheric oxidation of $\alpha$-pinene: a theoretical study, Phys. Chem. Chem. Phys., 3, 5489-5504, 2001.

Peltier, R. E., Sullivan, A. P., Weber, R. J., Wollny, A. G., Holloway, J. S., Brock, C. A., de Gouw, J. A., and Atlas, E. L.: No evidence for acid-catalyzed secondary organic aerosol formation in power plant plumes over metropolitan Atlanta, Georgia, Geophys. Res. Lett., 34, L06801, doi:10.1029/2006GL028780, 2007a.

Peltier, R. E., Weber, R. J., and Sullivan, A. P.: Investigating a liquid-based method for online organic carbon detection in atmospheric particles, Aerosol Sci. Technol., 41(12), 1117-1127, $2007 b$.

Peng, C., Chan, M. N., and Chan, C. K.: The hygroscopic properties of dicarboxylic and multifunctional acids: measurements and UNIFAC predictions, Environ. Sci. Technol., 35, 4495-4501, 2001

Peter, T., Marcolli, C., Spichtinger, P., Corti, T., Baker, M. B., Koop, T.: When dry air is too humid, Science, 314, 1399-1402, 2006.

Petters, M. D. and Kreidenweis, S. M.: A single parameter representation of hygroscopic growth and cloud condensation nucleus activity, Atmos. Chem. Phys., 7, 1961-1971, 2007, http://www.atmos-chem-phys.net/7/1961/2007/.

Pinho, P. G., Pio, C. A., and Jenkin, M. E.: Evaluation of isoprene degradation in the detailed tropospheric chemical mechanism, MCM v3, using environmental chamber data, Atmos. Environ., 39, 1303-1322, 2005.

Pinho, P. G., Pio, C. A., Carter, W. P. L., and Jenkin, M. E.: Evaluation of alkene degradation in the detailed tropospheric chemistry mechanism, MCM v3, using environmental chamber data, J. Atmos. Chem., 55, 55-79, 2006.

Pinho, P. G., Pio, C. A., Carter, W. P. L., and Jenkin, M. E.: Evaluation of $\alpha$-and $\beta$-pinene degradation in the detailed tropospheric chemistry mechanism, MCM v3.1, using environmental chamber data, J. Atmos. Chem., 57, 171-202, 2007.

Pinto, D. M., Tiiva, P., Miettinen, P., Joutsensaari, J., Kokkola, H., Nerg, A. M., Laaksonen, A., and Holopainen, J. K.: The effects of increasing atmospheric ozone on biogenic monoterpene profiles and the formation of secondary aerosols, Atmos. Environ., 41, 4877-4887, 2007.

Pio, C. A., Legrand, M., Oliveira, T., Afonso, J., Santos, C., Caseiro, A., Fialho, P., Barata, F., Puxbaum, H., Sanchez-Ochoa, A., Kasper-Giebl, A., Gelencsér, A., Preunkert, S., and Schock, M.: Climatology of aerosol composition (organic versus inorganic) at nonurban sites on a west-east transect across Europe, J. Geophys. Res., 112, D23S02, doi:10.1029/2006JD008038, 2007.

Plewka, A., Gnauk, T., Brüggemann, E., and Herrmann, H.: Biogenic contributions to the chemical composition of airborne particles in a coniferous forest in Germany, Atmos. Environ., 40, 103-115, 2006.

Pol, J., Hohnova, B., Jussila, M., and Hyotylainen, T.: Comprehensive two-dimensional liquid chromatography-time-of-flight mass spectrometry in the analysis of acidic compounds in atmospheric aerosols, J. Chromatogr. A, 1130, 64-71, 2006.

Polidori, A., Turpin, B. J., Davidson, C. I., Rodenburg, L. A., and Maimone, F.: Organic PM2.5: Fractionation by polarity, FTIR spectroscopy, and OM/OC ratio for the Pittsburgh aerosol, Aerosol Sci. Technol., 42, 233-246, 2008.

Pope III, C. A. and Dockery, D. W.: Health Effects of Fine Particulate Air Pollution: Lines that Connect, J. Air Waste Manage., 56, 709-742, 2006.

Popovitz-Biro, R., Wang, J., Majewski, J., Shavit, E., Leiserowitz, L., and Lahav, M.: Induced freezing of supercooled water into ice by self-assembled crystalline monolayers of amphiphilic alcohols at the air-water interface, J. Am. Chem. Soc., 116, 11791191, 1994.

Pöschl, U.: Atmospheric Aerosols: Composition, Transformation, Climate and Health Effects, Angew. Chem. Int. Edit., 44, 7520 7540, 2005.

Poulain, L., Monod, A., and Wortham, H.: Development of a new on-line mass spectrometer to study the reactivity of soluble organic compounds in the aqueous phase under tropospheric conditions: application to $\mathrm{OH}$-oxidation of $\mathrm{N}$-methylpyrrolidone, J Photoch. Photobio. A, 187, 10-23, 2007.

Prenni, A. J., DeMott, P. J., Kreidenweis, S. M., Sherman, D. E., Russell, L. M., Ming, Y.: The effects of low molecular weight dicarboxylic acids on cloud formation, J. Phys. Chem. A, 105, 11 240-11 248, 2001.

Prenni, A. J., Petters, M. D., Kreidenweis, S. M., DeMott, P. J., and Ziemann, P. J.: Cloud droplet activation of secondary organic aerosol, J. Geophys. Res., 112, D10223, doi:10.1029/2006JD007963, 2007.

Prenni, A. J., Petters, M. D., Faulhaber, A., Carrico, Ch. M., Ziemann, P. J., Kreidenweis, S. M., and DeMott, P. J.: Heterogeneous ice nucleation measurements of secondary organic aerosol generated from ozonolysis of alkenes, Geophys. Res. Lett., 36, L06808, doi:10.1029/2008GL036957, 2009.

Presto, A. A., Hartz, K. E. H., and Donahue, N. M.: Secondary organic aerosol production from terpene ozonolysis. 1. Effect of UV radiation, Environ. Sci. Technol., 39, 7036-7045, 2005a.

Presto, A. A., Hartz, K. E. H., and Donahue, N. M.: Secondary organic aerosol production from terpene ozonolysis. 2. Effect of $\mathrm{NO}_{\mathrm{x}}$ concentration, Environ. Sci. Technol., 39, 7046-7054, 2005b.

Presto, A. A. and Donahue, N. M.: Investigation of $\alpha$-pinene + 
ozone secondary organic aerosol formation at low total aerosol mass, Environ. Sci. Technol., 40, 3536-3543, 2006.

Prisle, N. L., Raatikainen, T., Sorjamaa, R., Svenningsson, B., Laaksonen, A., and Bilde, M.: Surfactant partitioning in cloud droplet activation: a study of $\mathrm{C} 8, \mathrm{C} 10, \mathrm{C} 12$ and $\mathrm{C} 14$ normal fatty acid sodium salts, Tellus B, 60(3), 416-431, 2008.

Pun, B. K., Griffin, R. J., Seigneur, C., and Seinfeld, J. H.: Secondary organic aerosol. II. Thermodynamic model for gas/particle partitioning of molecular constituents, J. Geophys. Res., 107, 4333, doi:10.1029/2001JD000542, 2002.

Pun, B. K., Wu, S. Y., Seigneur, C., Seinfeld, J. H., Griffin, R. J., and Pandis, S. N.: Uncertainties in modeling secondary organic aerosols: three-dimensional modeling studies in Nashville/Western Tennessee, Environ. Sci. Technol., 37, 36473661, 2003.

Pun, B. K. and Seigneur, C.: Investigative modeling of new pathways for secondary organic aerosol formation, Atmos. Chem. Phys., 7, 2199-2216, 2007,

http://www.atmos-chem-phys.net/7/2199/2007/.

Raatikainen, T. and Laaksonen, A.: Application of several activity coefficient models to water-organic-electrolyte aerosols of atmospheric interest, Atmos. Chem. Phys., 5, 2475-2495, 2005, http://www.atmos-chem-phys.net/5/2475/2005/.

Reemtsma, T., These, A., Venkatachari, P., Xia, X. Y., Hopke, P. K., Springer, A., and Linscheid, M.: Identification of fulvic acids and sulfated and nitrated analogues in atmospheric aerosol by electrospray ionization Fourier transform ion cyclotron resonance mass spectrometry, Anal. Chem., 78, 8299-8304, 2006.

Reeves, C. E. and Penkett, S. A.: Measurements of peroxides and what they tell us, Chem. Rev., 103, 5199-5218, 2003.

Reinhardt, A., Emmenegger, C., Gerrits, B., Panse, C., Dommen, J., Baltensperger, U., Zenobi, R., and Kalberer, M.: Ultrahigh mass resolution and accurate mass measurements as a tool to characterize oligomers in secondary organic aerosols, Anal. Chem., 79, 4074-4082, 2007.

Reinnig, M. C., Müller, L., Warnke, J., and Hoffmann, T.: Characterization of selected organic compound classes in secondary organic aerosol from biogenic VOCs by HPLC/MS ${ }^{n}$, Anal. Bioanal. Chem., 391, 171-182, 2008.

Reynolds, J. C., Last, D. J., McGillen, M., Nijs, A., Horn, A. B., Percival, C., Carpenter, L. J., and Lewis, A. C.: Structural analysis of oligomeric molecules formed from the reaction products of oleic acid ozonolysis, Environ. Sci. Technol., 40, 6674-6681, 2006.

Rissman, T. A., Varutbangkul, V., Surratt, J. D., Topping, D. O., McFiggans, G., Flagan, R. C., and Seinfeld, J. H.: Cloud condensation nucleus $(\mathrm{CCN})$ behavior of organic aerosol particles generated by atomization of water and methanol solutions, Atmos. Chem. Phys., 7, 2949-2971, 2007,

http://www.atmos-chem-phys.net/7/2949/2007/.

Robinson, A. L., Donahue, N. M., and Rogge, W. F.: Photochemical oxidation and changes in molecular composition of organic aerosol in the regional context, J. Geophys. Res., 111, D03302, doi:10.1029/2005JD006265, 2006.

Robinson, A. L., Donahue, N. M., Shrivastava, M. K., Weitkamp, E. A., Sage, A. M., Grieshop, A. P., Lane, T. E., Pierce, J. R., and Pandis, S. N.: Rethinking organic aerosols: semivolatile emissions and photochemical aging, Science, 315, 1259-1262, 2007.

Rogge, W. F., Mazurek, M. A., Hildemann, L. M., Cass, G. R., and Simoneit, B. R. T.: Quantification of urban organic aerosols at a molecular-level - identification, abundance and seasonalvariation, Atmos. Environ., 27, 1309-1330, 1993.

Rohrer, F., Bohn, B., Brauers, T., Brüning, D., Johnen, F.-J., Wahner, A., and Kleffmann, J.: Characterisation of the photolytic HONO-source in the atmosphere simulation chamber SAPHIR, Atmos. Chem. Phys., 5, 2189-2201, 2005,

http://www.atmos-chem-phys.net/5/2189/2005/.

Röhrl, A. and Lammel, G.: Low molecular weight dicarboxylic acids and glyoxylic acid: Seasonal and air mass characteristics, Environ. Sci. Technol., 35, 95-101, 2001.

Romero, F. and Oehme, M.: Organosulfates - a new component of humic-like substances in atmospheric aerosols?, J. Atmos. Chem., 52, 283-294, 2005.

Römpp, A., Winterhalter, R., and Moortgat, G. K.: Oxodicarboxylic acids in atmospheric aerosol particles, Atmos. Environ., 40, 6846-6862, 2006.

Rudich, Y., Donahue, N. M., and Mentel, T. F.: Aging of organic aerosol: Bridging the gap between laboratory and field studies, Annu. Rev. Phys. Chem., 58, 321-352, 2007.

Russell, L. M., Allen, D. T., Collins, D. R., and Fraser, M. P.: Daily, seasonal, and spatial trends in PM2.5 mass and composition in southeast Texas, Aerosol Sci. Technol. 38, 14-26, 2004.

Russell, L. M., Takahama, S., Liu, S., Hawkins, L. S., Covert, D. S., Quinn, P. K., and Bates, T. S.: Oxygenated fraction and mass of organic aerosol from direct emission and atmospheric processing measured on the R/V Ronald Brown during TEXAQS/GoMACCS 2006, J. Geophys. Res., 114, D00F05, doi:10.1029/2008JD011275, 2009.

Saarikoski, S., Timonen, H., Saarnio, K., Aurela, M., Järvi, L., Keronen, P., Kerminen, V.-M., and Hillamo, R.: Sources of organic carbon in fine particulate matter in northern European urban air, Atmos. Chem. Phys., 8, 6281-6295, 2008,

http://www.atmos-chem-phys.net/8/6281/2008/.

Saathoff, H., Moehler, O., Schurath, U., Kamm, S., Dippel, B., and Mihelcic, D.: The AIDA soot aerosol characterization campaign 1999, J. Aerosol Sci., 34, 1277-1296, 2003.

Saathoff, H., Naumann, K.-H., Möhler, O., Jonsson, Å. M., Hallquist, M., Kiendler-Scharr, A., Mentel, Th. F., Tillmann, R., and Schurath, U.: Temperature dependence of yields of secondary organic aerosols from the ozonolysis of $\alpha$-pinene and limonene, Atmos. Chem. Phys., 9, 1551-1577, 2009, http://www.atmos-chem-phys.net/9/1551/2009/.

Sadezky, A., Chaimbault, P., Mellouki, A., Römpp, A., Winterhalter, R., Le Bras, G., and Moortgat, G. K.: Formation of secondary organic aerosol and oligomers from the ozonolysis of enol ethers, Atmos. Chem. Phys., 6, 5009-5024, 2006,

http://www.atmos-chem-phys.net/6/5009/2006/.

Sage, A. M., Weitkamp, E. A., Robinson, A. L., and Donahue, N. M.: Evolving mass spectra of the oxidized component of organic aerosol: results from aerosol mass spectrometer analyses of aged diesel emissions, Atmos. Chem. Phys., 8, 1139-1152, 2008, http://www.atmos-chem-phys.net/8/1139/2008/.

Salcedo, D., Onasch, T. B., Dzepina, K., Canagaratna, M. R., Zhang, Q., Huffman, J. A., DeCarlo, P. F., Jayne, J. T., Mortimer, P., Worsnop, D. R., Kolb, C. E., Johnson, K. S., Zuberi, B., Marr, L. C., Volkamer, R., Molina, L. T., Molina, M. J., Cardenas, B., Bernabé, R. M., Márquez, C., Gaffney, J. S., Marley, N. A., Laskin, A., Shutthanandan, V., Xie, Y., Brune, W., Lesher, 
R., Shirley, T., and Jimenez, J. L.: Characterization of ambient aerosols in Mexico City during the MCMA-2003 campaign with Aerosol Mass Spectrometry: results from the CENICA Supersite, Atmos. Chem. Phys., 6, 925-946, 2006,

http://www.atmos-chem-phys.net/6/925/2006/.

Salcedo, D., Onasch, T. B., Canagaratna, M. R., Dzepina, K., Huffman, J. A., Jayne, J. T., Worsnop, D. R., Kolb, C. E., Weimer, S., Drewnick, F., Allan, J. D., Delia, A. E., and Jimenez, J. L.: Technical Note: Use of a beam width probe in an Aerosol Mass Spectrometer to monitor particle collection efficiency in the field, Atmos. Chem. Phys., 7, 549-556, 2007,

http://www.atmos-chem-phys.net/7/549/2007/.

Salma, I., Ocskay, R., Varga, I., and Maenhaut, W.: Surface tension of atmospheric humic-like substances in connection with relaxation, dilution, and solution pH, J. Geophys. Res., 111, D23205, doi:10.1029/2005JD007015, 2006.

Samburova, V., Szidat, S., Hueglin, C., Fisseha, R., Baltensperger, U., Zenobi, R., and Kalberer, M.: Seasonal variation of high-molecular-weight compounds in the water-soluble fraction of organic urban aerosols, J. Geophys. Res., 110, D23210, doi:10.1029/2005JD005910, 2005a.

Samburova, V., Zenobi, R., and Kalberer, M.: Characterization of high molecular weight compounds in urban atmospheric particles, Atmos. Chem. Phys., 5, 2163-2170, 2005b,

http://www.atmos-chem-phys.net/5/2163/2005/.

Sandradewi, J., Prévôt, A. S. H., Szidat, S., Perron, N., Alfarra, M. R., Lanz, V. A., Weingartner, E., and Baltensperger, U.: Using aerosol light absorption measurements for the quantitative determination of wood burning and traffic emission contributions to particulate matter, Environ. Sci. Technol., 42, 3316-3323, 2008.

Sato, K.: Chemical compositions of secondary organic aerosol from the ozonolysis of cyclohexene in the absence of seed particles, Chem. Lett., 34, 1584-1585, 2005.

Sato, K., Hatakeyama, S., and Imamura, T.: Secondary organic aerosol formation during the photooxidation of toluene: $\mathrm{NO}_{\mathrm{x}}$ dependence of chemical composition, J. Phys. Chem. A, 111, 9796-9808, 2007.

Sauer, F., Schuster, G., Schäfer, C., and Moortgat, G. K.: Determination of $\mathrm{H}_{2} \mathrm{O}_{2}$ and organic peroxides in cloud-and-rain-water on the Kleiner Feldberg during FELDEX, Geophys. Res. Lett., 23, 2605-2608, 1996.

Saunders, S. M., Jenkin, M. E., Derwent, R. G., and Pilling, M. J.: Protocol for the development of the Master Chemical Mechanism, MCM v3 (Part A): tropospheric degradation of nonaromatic volatile organic compounds, Atmos. Chem. Phys., 3, 161-180, 2003, http://www.atmos-chem-phys.net/3/161/2003/.

Sax, M., Zenobi, R., Baltensperger, U., and Kalberer, M.: Time resolved infrared spectroscopic analysis of aerosol formed by photo-oxidation of 1,3,5-trimethylbenzene and $\alpha$-pinene, Aerosol Sci. Technol., 39, 822-830, 2005.

Schauer, C., Rogge, W. F., Hildemann, L. M., Mazurek, M. A., and Cass, G. R.: Source apportionment of airborne particulate matter using organic compounds as tracers, Atmos. Environ., 30, 38373855, 1996.

Schauer, C., Niessner, R., and Pöschl, U.: Polycyclic aromatic hydrocarbons in urban air particulate matter: decadal and seasonal trends, chemical degradation, and sampling artifacts, Environ. Sci. Technol., 37, 2861-2868, 2003.
Schell, B., Ackermann, I. J., Hass, H., Binkowski, F. S., and Ebel, A.: Modeling the formation of secondary organic aerosol within a comprehensive air quality model system, J. Geophys. Res., 106, 28 275-28 293, 2001.

Schichtel, B. A., Malm, W. C., Bench, G., Fallon, S., McDade, C. E., Chow, J. C., and Watson, J. G.: Fossil and contemporary fine particulate carbon fractions at 12 rural and urban sites in the United States, J. Geophys. Res., 113, D02311, doi:10.1029/2007JD008605, 2008.

Schkolnik, G., Falkovich, A. H., Rudich, Y., Maenhaut, W., and Artaxo, P.: New analytical method for the determination of levoglucosan, polyhydroxy compounds, and 2-methylerythritol and its application to smoke and rainwater samples, Environ. Sci. Technol., 39, 2744-2752, 2005.

Schuchmann, M. N. and von Sonntag, C.: Hydroxyl radical-induced oxidation of diethyl ether in oxygenated aqueous solution. A product and pulse radiolysis study, J. Phys. Chem., 86, 19952000, 1982.

Schuchmann, M. N. and von Sonntag, C.: The rapid hydration of the acetyl radical. A pulse radiolysis study of acetaldehyde in aqueous solution, J. Am. Chem. Soc., 110, 5698-5701, 1988.

Schuchmann, M. N., Schuchmann, H. P., and von Sonntag, C.: The pKa value of the $\mathrm{O}_{2} \mathrm{CH}_{2} \mathrm{CO}_{2} \mathrm{H}$ radical: the Taft $\sigma^{*}$ constant of the $-\mathrm{CH}_{2} \mathrm{O}_{2}$ group, J. Phys. Chem., 93, 5320-3, 1989.

Schuchmann, M. N., Schuchmann, H. P., and von Sonntag, C.: Hydroxyl-radical-induced oxidation of acetaldehyde dimethyl acetal in oxygenated aqueous solution. Rapid $\mathrm{O}_{2}$ anion radical release from the $\mathrm{MeC}(\mathrm{OMe})_{2} \mathrm{O}_{2}$ radical, J. Am. Chem. Soc., 112, 403-7, 1990.

Schweitzer, F., Magi, L., Mirabel, P., and George, C.: Uptake rate measurements of methanesulfonic acid and glyoxal by aqueous droplets, J. Phys. Chem. A, 102, 593-600. 1998.

Seeley, L. and Seidler, G.: Two-dimensional nucleation of ice from supercooled water, Phys. Rev. Lett., 87(5), 055702, doi:10.1103/PhysRevLett.87.055702, 2001.

Seinfeld, J. H., Erdakos, G. B., Asher, W. E., and Pankow, J. F.: Modeling the formation of secondary organic aerosols: 2. The predicted effects of relative humidity on aerosol formation in the $\alpha$-pinene-, $\beta$-pinene-, sabinene-, $\Delta^{3}$-carene, and cyclohexeneozone systems, Environ. Sci. Technol., 35, 1806-1817, 2001.

Seinfeld, J. H. and Pankow, J. F.: Organic atmospheric particulate material, Annu. Rev. Phys. Chem., 54, 121-140, 2003.

Shapiro, E. L., Szprengiel, J., Sareen, N., Jen, C. N., Giordano, M. R., and McNeill, V. F.: Light-absorbing secondary organic material formed by glyoxal in aqueous aerosol mimics, Atmos. Chem. Phys., 9, 2289-2300, 2009, http://www.atmos-chem-phys.net/9/2289/2009/.

Shilling, J. E., Chen, Q., King, S. M., Rosenoern, T., Kroll, J. H., Worsnop, D. R., DeCarlo, P. F., Aiken, A. C., Sueper, D., Jimenez, J. L., and Martin, S. T.: Loading-dependent elemental composition of $\alpha$-pinene SOA particles, Atmos. Chem. Phys., 9, 771-782, 2009, http://www.atmos-chem-phys.net/9/771/2009/.

Shimmo, M., Jantti, J., Aalto, P., Hartonen, K., Hyotylainen, T., Kulmala, M., and Riekkola, M. L.: Characterization of organic compounds in aerosol particles from a Finnish forest by on-line coupled supercritical fluid extraction-liquid chromatography-gas chromatography-mass spectrometry, Anal. Bioanal. Chem., 378, 1982-1990, 2004. 
Shrivastava, M. K., Subramanian, R., Rogge, W. F., and Robinson, A. L.: Sources of organic aerosol: Positive matrix factorization of molecular marker data and comparison of results from different source apportionment models, Atmos. Environ., 41, 93539369, 2007.

Shrivastava, M. K., Lane, T. E., Donahue, N. M., Pandis, S. N., and Robinson, A. L.: Effects of gas particle partitioning and aging of primary emissions on urban and regional organic aerosol concentrations, J. Geophys. Res., 113, D18301, doi:10.1029/2007JD009735, 2008.

Simpson, D., Yttri, K., Klimont, Z., Kupiainen, K., Caseiro, A., Gelencsér, A., Pio, C., and Legrand, M.: Modeling carbonaceous aerosol over Europe. Analysis of the CARBOSOL and EMEP EC/OC campaigns, J. Geophys. Res., 112, D23S14, doi:10.1029/2006JD008158, 2007.

Sjogren, S., Gysel, M., Weingartner, E., Alfarra, M. R., Duplissy, J., Cozic, J., Crosier, J., Coe, H., and Baltensperger, U.: Hygroscopicity of the submicrometer aerosol at the high-alpine site Jungfraujoch, $3580 \mathrm{~m}$ a.s.1., Switzerland, Atmos. Chem. Phys., 8, 5715-5729, 2008,

http://www.atmos-chem-phys.net/8/5715/2008/.

Sloth, M., Bilde, M., and Mikkelsen, K. V.: Interaction energies between aerosol precursors formed in the photo-oxidation of alphapinene, Mol. Phys., 102, 2361-2368, 2004.

Smith, J. N., Moore, K. F., Eisele, F. L., Voisin, D., Ghimire, A. K., Sakurai, H., and McMurry, P. H.: Chemical composition of atmospheric nanoparticles during nucleation events in Atlanta, J. Geophys. Res., 110, D22S03, doi:10.1029/2005JD005912, 2005.

Song, C., Na, K. S., and Cocker, D. R.: Impact of the hydrocarbon to $\mathrm{NO}_{\mathrm{x}}$ ratio on secondary organic aerosol formation, Environ. Sci. Technol., 39, 3143-3149, 2005.

Song, C., Zaveri, R. A., Alexander, M. L., Thornton, J. A., Madronich, S., Ortega, J. V., Zelenyuk, A., Yu, X. Y., Laskin, A., and Maughan, D. A.: Effect of hydrophobic primary organic aerosols on secondary organic aerosol formation from ozonolysis of $\alpha$-pinene, Geophys. Res. Lett., 34, L20803, doi:10.1029/2007GL030720, 2007.

Sorjamaa, R. and Laaksonen, A.: The influence of surfactant properties on critical supersaturations of cloud condensation nuclei, J. Aerosol Sci., 37, 1730-1736, 2006.

Sorooshian, A., Brechtel, F. J., Ma, Y., Weber, R. J., Corliss, A., Flagan, R. C., and Seinfeld, J. H.: Modeling and Characterization of a Particle-into-Liquid-Sampler (PILS), Aerosol Sci. Technol., 40, 396-409, 2006a.

Sorooshian, A., Varutbangkul, V., Brechtel, F. J., Ervens, B., Feingold, G., Bahreini, R., Murphy, S. M., Holloway, J. S., Atlas, E. L., Buzorius, G., Jonsson, H., Flagan, R. C., and Seinfeld, J. H.: Oxalic acid in clear and cloudy atmospheres: Analysis of data from the International Consortium for Atmospheric Research on Transport and Transformation 2004, J. Geophys. Res., 111, D23S45, doi:10.1029/2005JD006880, 2006b.

Sorooshian, A., Lu, M.-L., Brechtel, F. J., Jonsson, H., Feingold, G., Flagan, R. C., and Seinfeld, J. H.: On the source of organic acid aerosol layers above clouds, Environ. Sci. Technol., 41, 46474654, 2007a.

Sorooshian, A., Ng, N. L., Chan, A. W. H., Feingold, G., Flagan, R. C., and Seinfeld, J. H.: Particulate organic acids and overall water-soluble aerosol composition measurements from the 2006 Gulf of Mexico Atmospheric Composition and Climate Study (GoMACCS), J. Geophys. Res., 112, D13201, doi:10.1029/2007JD008537, 2007b.

Spittler, M., Barnes, I., Bejan, I., Brockmann, K. J., Benter, T., and Wirtz, K.: Reactions of $\mathrm{NO}_{3}$ radicals with limonene and alphapinene: Product and SOA formation, Atmos. Environ., 40, S116S127, 2006.

Stanier, C. O., Pathak, R. K., and Pandis, S. N.: Measurements of the volatility of aerosols from alpha-pinene ozonolysis, Environ. Sci. Technol., 41, 2756-2763, 2007.

Stemmler, K. and von Gunten, U.: OH radical-initiated oxidation of organic compounds in atmospheric water phases: part 1. Reactions of peroxyl radicals derived from 2-butoxyethanol in water, Atmos. Environ., 34, 4241-4252, 2000a.

Stemmler, K. and von Gunten, U.: OH radical-initiated oxidation of organic compounds in atmospheric water phases: part 2. Reactions of peroxyl radicals with transition metals, Atmos. Environ. 34(25), 4253-4264, 2000b.

Stemmler, K., Ammann, M., Donders, C., Kleffmann, J., and George, C.: Photosensitized reduction of nitrogen dioxide on humic acid as a source of nitrous acid, Nature, 440, 195-198, 2006.

Stokes, R. H. and Robinson, R. A.: Interactions in aqueous nonelectrolyte solutions. I. Solute-solvent equilibria, J. Phys. Chem., 70, 2126-2130, 1966.

Streibel, T., Weh, J., Mitschke, S., and Zimmermann, R.: Thermal desorption/pyrolysis coupled with photoionization time-of-flight mass spectrometry for the analysis of molecular organic compounds and oligomeric and polymeric fractions in urban particulate matter, Anal. Chem., 78, 5354-5361, 2006.

Subramanian, R., Khlystov, A. Y., Cabada, J. C., and Robinson, A. L.: Positive and negative artifacts in particulate organic carbon measurements with denuded and undenuded sampler configurations, Aerosol Sci. Technol., 38, 27-48, 2004.

Sullivan, A. P., Weber, R. J., Clements, A. L., Turner, J. R., Bae, M. S., and Schauer, J. J.: A method for on-line measurement of water-soluble organic carbon in ambient aerosol particles: Results from an urban site, Geophys. Res. Lett., 31, L13105, doi:10.1029/2004GL019681, 2004.

Sullivan, A. P., Peltier, R. E., Brock, C. A., de Gouw, J. A., Holloway, J. S., Warneke, C., Wollny, A. G., and Weber, R. J.: Airborne measurements of carbonaceous aerosol soluble in water over northeastern United States: Method development and an investigation into water-soluble organic carbon sources, J. Geophys. Res., 111, D23S46, doi:10.1029/2006JD007072, 2006.

Sullivan, R. C. and Prather, K. A.: Recent advances in our understanding of atmospheric chemistry and climate made possible by on-line aerosol analysis instrumentation, Anal. Chem., 77, 38613886, 2005.

Sun, J. and Ariya, P. A.: Atmospheric organic and bio-aerosols as cloud condensation nuclei $(\mathrm{CCN})$ : A review, Atmos. Environ., 40, 795-820, 2006.

Surratt, J. D., Murphy, S. M., Kroll, J. H., Ng, N. L., Hildebrandt, L., Sorooshian, A., Szmigielski, R., Vermeylen, R., Maenhaut, W., Claeys, M., Flagan, R. C., and Seinfeld, J. H.: Chemical composition of secondary organic aerosol formed from the photooxidation of isoprene, J. Phys. Chem. A, 110, 9665-9690, 2006.

Surratt, J. D., Kroll, J. H., Kleindienst, T. E., Edney, E. O., Claeys, M., Sorooshian, A., Ng, N. L., Offenberg, J. H., Lewandowski, 
M., Jaoui, M., Flagan, R. C., and Seinfeld, J. H.: Evidence for organosulfates in secondary organic aerosol, Environ. Sci. Technol., 41, 517-527, 2007a.

Surratt, J. D., Lewandowski, M., Offenberg, J. H., Jaoui, M., Kleindienst, T. E., Edney, E. O., and Seinfeld, J. H.: Effect of acidity on secondary organic aerosol formation from isoprene, Environ. Sci. Technol., 41, 5363-5369, 2007b.

Surratt, J. D., Gómez-González, Y., Chan, A. W. H., Vermeylen, R., Shahgholi, M., Kleindienst, T. E., Edney, E. O., Offenberg, J. H., Lewandowski, M., Jaoui, M., Maenhaut, W., Claeys, M., Flagan, R. C., and Seinfeld, J. H.: Organosulfate formation in biogenic secondary organic aerosol, J. Phys. Chem, A., 112, 8345-8378, 2008.

Svenningsson, B., Rissler, J., Swietlicki, E., Mircea, M., Bilde, M., Facchini, M. C., Decesari, S., Fuzzi, S., Zhou, J., Mønster, J., and Rosenørn, T.: Hygroscopic growth and critical supersaturations for mixed aerosol particles of inorganic and organic compounds of atmospheric relevance, Atmos. Chem. Phys., 6, 1937-1952, 2006,

http://www.atmos-chem-phys.net/6/1937/2006/.

Swietlicki, E., Hansson, H.-C., Hämeri, K., Svenningsson, B., Massling, A., McFiggans, G., McMurry, P., Petäjä, T., Tunved, P., Gysel, M., Topping, D., Weingartner, E., Baltensperger, U., Rissler, J., Wiedensohler, A., and Kulmala, M.: Hygroscopic properties of sub-micrometer atmospheric aerosol particels measured with H-TDMA instruments in various environments - a review, Tellus B, 60, 432-469, 2008.

Szidat, S., Jenk, T. M., Synal, H.-A., Kalberer, M., Wacker, L., Hajdas, I., Kasper-Giebl, A., and Baltensperger, U.: Contributions of fossil fuel, biomass burning, and biogenic emissions to carbonaceous aerosols in Zurich as traced by ${ }^{14} \mathrm{C}$, J. Geophys. Res., 111, D07206, doi:10.1029/2005JD006590, 2006.

Szidat, S., Prévôt, A. S. H., Sandradewi, J., Alfarra, M. R., Synal, H.-A., Wacker, L., and Baltensperger, U.: Dominant impact of residential wood burning on particulate matter in Alpine valleys during winter, Geophys. Res. Lett., 34, L05820, doi:10.1029/2006GL028325, 2007.

Szidat, S., Ruff, M., Perron, N., Wacker, L., Synal, H.-A., Hallquist, M., Shannigrahi, A. S., Yttri, K. E., Dye, C., and Simpson, D.: Fossil and non-fossil sources of organic carbon (OC) and elemental carbon (EC) in Göteborg, Sweden, Atmos. Chem. Phys., 9, 1521-1535, 2009,

http://www.atmos-chem-phys.net/9/1521/2009/.

Szmigielski, R., Surratt, J. D., Vermeylen, R., Szmigielska, K., Kroll, J. H., Ng, N. L., Murphy, S. M., Sorooshian, A., Seinfeld, J. H., and Claeys, M.: Characterization of 2-methylglyceric acid oligomers in secondary organic aerosol from the photooxidation of isoprene using trimethylsilylation and gas chromatography/ion trap mass spectrometry, J. Mass Spectrom., 42, 101116, 2007a.

Szmigielski, R., Surratt, J. D., Gómez-González, Y., Van der Veken, P., Kourtchev, I., Vermeylen, R., Blockhuys, F., Jaoui, M., Kleindienst, T. E., Lewandowski, M., Offenberg, J. H., Edney, E. O., Seinfeld, J. H., Maenhaut, W., and Claeys, M.: 3-methyl1,2,3-butanetricarboxylic acid: An atmospheric tracer for terpene secondary organic aerosol, Geophys. Res. Lett., 34, L24811, doi:10.1029/2007GL031338, 2007b.

Tabazadeh, A., Djikaev, Y. S., and Reiss, H.: Surface crystallization of supercooled water in clouds, P. Natl. Acad. Sci. USA, 99,
$15873-15878,2003$.

Tagliavini, E., Moretti, F., Decesari, S., Facchini, M. C., Fuzzi, S., and Maenhaut, W.: Functional group analysis by $\mathrm{H}$ $\mathrm{NMR} / \mathrm{chemical}$ derivatization for the characterization of organic aerosol from the SMOCC field campaign, Atmos. Chem. Phys., 6, 1003-1019, 2006,

http://www.atmos-chem-phys.net/6/1003/2006/.

Takahama, S., Davidson, C. I., and Pandis, S. N.: Semicontinuous measurements of organic carbon and acidity during the Pittsburgh Air Quality Study: Implications for acid-catalyzed organic aerosol formation, Environ. Sci. Technol., 40, 2191-2199, 2006.

Takahama, S., Pathak, R. K., and Pandis, S. N.: Efflorescence transitions of ammonium sulfate particles coated with secondary organic aerosol, Environ. Sci. Technol., 41, 2289-2295, 2007.

Takegawa, H., Minoura, H., and Yamazaki, S.: Temperature dependence of secondary organic aerosol formation by photo-oxidation of hydrocarbons, Atmos. Environ., 37, 3413-3424, 2003.

Takegawa, N., Miyakawa, T., Kondo, Y., Jimenez, J. L., Zhang, Q., Worsnop, D. R., and Fukuda, M.: Seasonal and diurnal variations of submicron organic aerosols in Tokyo observed using the Aerodyne aerosol mass spectrometer (AMS), J. Geophys. Res., 111, D11206, doi:10.1029/2005JD006515, 2006.

Taraniuk, I., Graber, E. R., Kostinski, A., and Rudich, Y.: Surface tension and diffusion coefficients of atmospheric and model humic like species (HULIS), Geophys. Res. Lett., 34, L16807, doi:16810.11029/12007GL029576, 2007.

Temime, B., Healy, R. M., and Wenger, J. C.: A denuder-filter sampling technique for the detection of gas and particle phase carbonyl compounds, Environ. Sci. Technol., 41, 6514-6520, 2007.

Tilgner, A., Wolke, R., and Herrmann, H.: CAPRAM modeling of the physico-chemical cloud processing of tropospheric aerosols, in environmental simulation chambers - Application to atmospheric chemical processes: Proceedings of the NATO Advanced Research Workshop on Simulation and Assessment of Chemical Processes in a Multiphase Environment, Alushta, Ukraine 1 September 2007, edited by: Barnes, I. and Kharytonov, M., Springer, Berlin, Heidelberg, New York, 540 pp., 2008.

Tobias, H. J. and Ziemann, P. J.: Compound identification in organic aerosols using temperature-programmed thermal desorption particle beam mass spectrometry, Anal. Chem., 71, 34283435, 1999.

Tobias, H. J., Docherty, K. S., Beving, D. E., and Ziemann, P. J.: Effect of relative humidity on the chemical composition of secondary organic aerosol formed from reactions of 1-tetradecene and $\mathrm{O}_{3}$, Environ. Sci. Technol., 34, 2116-2125, 2000.

Tobias, H. J. and Ziemann, P. J: Thermal desorption mass spectrometric analysis of organic aerosol formed from reactions of 1-tetradecene and $\mathrm{O}_{3}$ in the presence of alcohols and carboxylic acids, Environ. Sci. Technol, 34, 2105-2115, 2000.

Tobias, H. J. and Ziemann, P. J.: Kinetics of the gas-phase reactions of alcohols, aldehydes, carboxylic acids, and water with the $\mathrm{C} 13$ stabilized Criegee intermediate formed from ozonolysis of 1-tetradecene, J. Phys. Chem. A, 105, 6129-6135, 2001.

Tolocka, M. P., Jang, M., Ginter, J. M., Cox, F. J., Kamens, R. M., and Johnston, M. V.: Formation of oligomers in secondary organic aerosol, Environ. Sci. Technol., 38, 1428-1434, 2004.

Topping, D. O., McFiggans, G. B., and Coe, H.: A curved multicomponent aerosol hygroscopicity model framework: Part 1 - Inorganic compounds, Atmos. Chem. Phys., 5, 1205-1222, 2005a, 
http://www.atmos-chem-phys.net/5/1205/2005/.

Topping, D. O., McFiggans, G. B., and Coe, H.: A curved multicomponent aerosol hygroscopicity model framework: Part 2 Including organic compounds, Atmos. Chem. Phys., 5, 12231242, 2005b, http://www.atmos-chem-phys.net/5/1223/2005/.

Tsigaridis, K. and Kanakidou, M.: Global modelling of secondary organic aerosol in the troposphere: a sensitivity analysis, Atmos. Chem. Phys., 3, 1849-1869, 2003, http://www.atmos-chem-phys.net/3/1849/2003/.

Tsigaridis, K. and Kanakidou, M.: Secondary organic aerosol importance in the future atmosphere, Atmos. Environ., 41, 46824692, 2007.

Tulet, P., Grini, A., Griffin, R. J., and Petitcol, S.: ORILAM-SOA: A computationally efficient model for predicting secondary organic aerosols in three-dimensional atmospheric models, J. Geophys. Res., 111, D23208, doi:10.1029/2006JD007152, 2006.

Tunved, P., Hansson, H.-C., Kerminen, V.-M., Ström, J., Dal Maso, M., Lihavainen, H., Viisanen, Y., Aalto, P. P., Komppula, M., and Kulmala, M.: High natural aerosol loading over boreal forests, Science, 312, 261-263, 2006.

Turpin, B. J. and Huntzicker, J. J.: Identification of secondary organic aerosol episodes and quantitation of primary and secondary organic aerosol concentrations during SCAQS, Atmos. Environ., 29, 3527-3544, 1995.

Turpin, B. J., Saxena, P., and Andrews, E.: Measuring and simulating particulate organics in the atmosphere: problems and prospects, Atmos. Environ., 34, 2983-3013, 2000.

Turpin, B. J. and Lim, H. J.: Species contributions to PM2.5 mass concentrations: Revisiting common assumptions for estimating organic mass, Aerosol Sci. Technol., 35, 602-610, 2001.

Ulbrich, I. M., Canagaratna, M. R., Zhang, Q., Worsnop, D. R., and Jimenez, J. L.: Interpretation of organic components from positive matrix factorization of aerosol mass spectrometric data, Atmos. Chem. Phys., 9, 2891-2918, 2009,

http://www.atmos-chem-phys.net/9/2891/2009/.

VanReken, T. M., Ng, N. L., Flagan, R. C., and Seinfeld, J. H.: Cloud condensation nucleus activation properties of biogenic secondary organic aerosol, J. Geophys. Res., 110, D07206, doi:10.1029/2004JD005465, 2005.

VanReken, T. M., Greenberg, J. P., Harley, P. C., Guenther, A. B., and Smith, J. N.: Direct measurement of particle formation and growth from the oxidation of biogenic emissions, Atmos. Chem. Phys., 6, 4403-4413, 2006,

http://www.atmos-chem-phys.net/6/4403/2006/.

Varutbangkul, V., Brechtel, F. J., Bahreini, R., Ng, N. L., Keywood, M. D., Kroll, J. H., Flagan, R. C., Seinfeld, J. H., Lee, A., and Goldstein, A. H.: Hygroscopicity of secondary organic aerosols formed by oxidation of cycloalkenes, monoterpenes, sesquiterpenes, and related compounds, Atmos. Chem. Phys., 6, 23672388, 2006, http://www.atmos-chem-phys.net/6/2367/2006/.

Veltkamp, P. R., Hansen, K. J., Barkley, R. M., and Sievers, R. E.: Chromatographic measurement of molecular markers of sources of atmospheric aerosol particles, Environ. Geochem. Health, 18, 77-80, 1996.

Vereecken, L. and Peeters, J.: Non-traditional (per)oxy ring-closure paths in the atmospheric oxidation of isoprene and monoterpenes, J. Phys. Chem. A, 108, 5197-5204, 2004.

Vereecken, L., Muller, J. F., and Peeters, J.: Low-volatility polyoxygenates in the $\mathrm{OH}$-initiated atmospheric oxidation of alpha- pinene: impact of non-traditional peroxyl radical chemistry. Phys. Chem. Chem. Phys., 9, 5241-5248, 2007.

Verheggen, B., Mozurkewich, M., Caffrey, P., Frick, G., Hoppel, W., Sullivan, W.: $\alpha$-pinene oxidation in the presence of seed aerosol: estimates of nucleation rates, growth rates, and yield, Environ. Sci. Technol., 41, 6046-6051, 2007.

Vesterinen, M., Lehtinen, K. E. J., Kulmala, M., and Laaksonen, A.: Effect of particle phase oligomer formation on aerosol growth, Atmos. Environ., 41, 1768-1776, 2007.

Volkamer, R., Platt, U., and Wirtz, K.: Primary and secondary glyoxal formation from aromatics: experimental evidence for the bicycloalkyl-radical pathway from benzene, toluene and pxylene, J. Phys. Chem. A, 105, 7865-7874, 2001.

Volkamer, R., Klotz, B., Barnes, I., Imamura, T., Wirtz, K., Washida, N., Becker, K. H., and Platt, U.: OH-initiated oxidation of benzene - Part I. Phenol formation under atmospheric conditions, Phys. Chem. Chem. Phys., 4, 1598-1610, 2002.

Volkamer, R., Jimenez, J. L., Martini, F. S., Dzepina, K., Zhang, Q., Salcedo, D., Molina, L. T., Worsnop, D. R., and Molina, M. J.: Secondary organic aerosol formation from anthropogenic air pollution: Rapid and higher than expected, Geophys. Res. Lett., 33, L17811, doi:10.1029/2006GL026899, 2006.

Volkamer, R., San Martini, F., Molina, L. T., Salcedo, D., Jimenez, J. L., and Molina, M. J.: A missing sink for gas-phase glyoxal in Mexico City: Formation of secondary organic aerosol, Geophys. Res. Lett., 34, L19807, doi:10.1029/2007GL030752, 2007.

Volkamer, R., Ziemann, P. J., and Molina, M. J.: Secondary organic aerosol formation from acetylene $\left(\mathrm{C}_{2} \mathrm{H}_{2}\right)$ : seed effect on SOA yields due to organic photochemistry in the aerosol aqueous phase, Atmos. Chem. Phys., 9, 1907-1928, 2009,

http://www.atmos-chem-phys.net/9/1907/2009/.

von Sonntag, C. and Schuchmann, H. P.: Peroxyl radicals in aqueous solutions, in: Peroxyl Radicals, edited by: Alfassi, Z. B., Wiley, Chichester, UK, 173-234, 1997.

Vutukuru, S., Griffin, R. J., and Dabdub, D.: Simulation and analysis of secondary organic aerosol dynamics in the South Coast Air Basin of California, J. Geophys. Res., 111, D10S12, doi:10.1029/2005JD006139, 2006.

Wagner, V., Jenkin, M. E., Saunders, S. M., Stanton, J., Wirtz, K, and Pilling, M. J.: Modelling of the photooxidation of toluene: conceptual ideas for validating detailed mechanisms, Atmos. Chem. Phys., 3, 89-106, 2003, http://www.atmos-chem-phys.net/3/89/2003/.

Walser, M. L., Park, J., Gomez, A. L., Russell, A. R., and Nizkorodov, S. A.: Photochemical aging of secondary organic aerosol particles generated from the oxidation of d-limonene, J. Phys. Chem. A, 111, 1907-1913, 2007.

Walser, M. L., Desyaterik, Y., Laskin, J., Laskin, A., and Nizkorodov, S. A.: High-resolution mass spectrometric analysis of secondary organic aerosol produced by ozonation of limonene, Phys. Chem. Chem. Phys., 10, 1009-1022, 2008.

Wang, S. Y., Zordan, C. A., and Johnston, M. V.: Chemical characterization of individual, airborne sub-10-nm particles and molecules, Anal. Chem., 78, 1750-1754, 2006.

Wang, W., Vas, G., Dommisse, R., Loones, K., and Claeys, M.: Fragmentation study of diastereoisomeric 2-methyltetrols, oxidation products of isoprene, as their trimethylsilyl ethers, using gas chromatography/ion trap mass spectrometry, Rapid Commun. Mass Sp., 18, 1787-1797, 2004. 
Wang, W., Kourtchev, I., Graham, B., Cafmeyer, J., Maenhaut, W., and Claeys, M.: Characterization of oxygenated derivatives of isoprene related to 2-methyltetrols in Amazonian aerosols using trimethylsilylation and gas chromatography/ion trap mass spectrometry, Rapid Commun. Mass Sp., 19, 1343-1351, 2005.

Warneck, P.: In-cloud chemistry opens pathway to the formation of oxalic acid in the marine atmosphere, Atmos. Environ., 37, 2423-2427, 2003.

Warneck, P.: Multi-phase chemistry of C2 and C3 organic compounds in the marine atmosphere, J. Atmos. Chem., 51, 119-159, 2005.

Warnke, J., Bandur, R., and Hoffmann, T.: Quantification of terpenic acids in atmospheric aerosol samples, J. Aerosol Sci., Supplement, Abstracts of EAC, Budapest 2004, S21-S22, 2004.

Warnke, J., Bandur, R., and Hoffmann, T.: Capillary-HPLC-ESIMS/MS method for the determination of acidic products from the oxidation of monoterpenes in atmospheric aerosol samples, Anal. Bioanal. Chem., 385, 34-45, 2006.

Warscheid, B. and Hoffmann, T.: Structural elucidation of monoterpene oxidation products by ion trap fragmentation using on-line atmospheric pressure chemical ionisation mass spectrometry in the negative ion mode, Rapid Commum. Mass Sp., 15, 22592272, 2001.

Warscheid, B. and Hoffmann, T.: Direct analysis of highly oxidized organic aerosol constituents by on-line ion trap mass spectrometry in the negative-ion mode, Rapid Commun. Mass Sp., 16, 496-504, 2002.

Weber, R. J., Orsini, D., Daun, Y., Lee, Y. N., Klotz, P. J., and Brechtel, F.: A particle-into-liquid collector for rapid measurement of aerosol bulk chemical composition, Aerosol Sci. Technol., 35, 718-727, 2001.

Weber, R. J., Sullivan, A. P., Peltier, R. E., Russell, A., Yan, B., Zheng, M., de Gouw, J., Warneke, C., Brock, C., Holloway, J. S., Atlas, E. L., and Edgerton, E.: A study of secondary organic aerosol formation in the anthropogenicinfluenced southeastern United States, J. Geophys. Res., 112, D13302, doi:10.1029/2007JD008408, 2007.

Weimer, S., Alfarra, M. R., Schreiber, D., Mohr, M., Prévôt, A. S. H., and Baltensperger, U.: Organic aerosol mass spectral signatures from wood burning emissions: Influence of burning conditions and wood type, J. Geophys. Res., 113, D10304, doi:10.1029/2007JD009309, 2008.

Weingartner, E., Gysel, M., and Baltensperger, U.: Hygroscopicity of aerosol particles at low temperatures. 1. new low-temperature H-TDMA instrument: setup and first applications, Environ. Sci. Technol., 36, 55-62, 2002.

Weitkamp, E. A., Sage, A. M., Pierce, J. R., Donahue, N. M., and Robinson, A. L.: Organic aerosol formation from photochemical oxidation of diesel exhaust in a smog chamber, Environ. Sci. Technol., 41, 6969-6975, 2007.

Welthagen, W., Schnelle-Kreis, J., and Zimmermann, R.: Search criteria and rules for comprehensive two-dimensional gas chromatography-time-of-flight mass spectrometry analysis of airborne particulate matter, J. Chromatogr. A, 1019, 233-249, 2003.

Wex, H., Hennig, T., Salma, I., Ocskay, R., Kiselev, A., Henning, S., Massling, A., Wiedensohler, A., and Stratmann, F.: Hygroscopic growth and measured and modeled critical super-saturations of an atmospheric HULIS sample, Geophys. Res. Lett., 34, L02818,
doi:10.1029/2006GL028260, 2007.

Williams, B. J., Goldstein, A. H., Kreisberg, N. M., and Hering, S. V.: An in-situ instrument for speciated organic composition of atmospheric aerosols: Thermal desorption aerosol GC/MS-FID (TAG), Aerosol Sci. Technol., 40, 627-638, 2006.

Williams, B. J., Goldstein, A. H., Millet, D. B., Holzinger, R., Kreisberg, N. M., Hering, S. V., Allan, J. D., Worsnop, D. R., Jimenez, J. L., and White, A. B.: Chemical speciation of organic aerosol during ICARTT 2004: results from in-situ measurements, J. Geophys. Res., 112, D10S26, doi:10.1029/2006JD007601, 2007.

Wise, M. E, Garland, R. M., and Tolbert M. A.: Ice nucleation in internally mixed ammonium sulfate/dicarboxylic acid particles, J. Geophys. Res., 109(D19), D19203, doi:10.1029/2003JD004313, 2004.

Wozniak, A. S., Bauer, J. E., Sleighter, R. L., Dickhut, R. M., and Hatcher, P. G.: Technical Note: Molecular characterization of aerosol-derived water soluble organic carbon using ultrahigh resolution electrospray ionization Fourier transform ion cyclotron resonance mass spectrometry, Atmos. Chem. Phys., 8, 50995111, 2008, http://www.atmos-chem-phys.net/8/5099/2008/.

Xia, X. and Hopke, P. K.: Seasonal variation of 2-methyltetrols in ambient air samples, Environ. Sci. Technol., 40, 6934-6937, 2006.

Yan, W., Topphoff, M., Rose, C., and Gmehling, J.: Prediction of vapor-liquid equilibria in mixed-solvent electrolyte systems using the group contribution concept, Fluid Phase Equilibr., 162, 97-113, 1999.

Yao, X., Lau, A. P. S., Fang, M., Chan, C. K., and Hu, M.: Size distributions and formation of ionic species in atmospheric particulate pollutants in Beijing, China: 2. dicarboxylic acids, Atmos. Environ., 37, 3001-3007, 2003.

Yttri, K., Dye, C., Slordal, L., and Braathen, O.: Quantification of monosaccharide anhydrides by negative electrospray HPLC/HRMS-TOF - application to aerosol samples from an urban and a suburban site influenced by small scale wood burning, J. Air Waste Manage., 55, 1169-1177, 2005.

Yttri, K. E., Dye, C., Braathen, O.-A., Simpson, D., and Steinnes, E.: Carbonaceous aerosols in Norwegian urban areas, Atmos. Chem. Phys., 9, 2007-2020, 2009, http://www.atmos-chem-phys.net/9/2007/2009/.

Yu, J. Z., Flagan, R. C., and Seinfeld, J. H.: Identification of products containing $-\mathrm{COOH},-\mathrm{OH}$, and $-\mathrm{C}=\mathrm{O}$ in atmospheric oxidation of hydrocarbons, Environ. Sci. Technol., 32, 2357-2370, 1998.

Yu, J. Z., Cocker, D. R., Griffin, R. J., Flagan, R. C., and Seinfeld, J. H.: Gas-phase ozone oxidation of monoterpenes: Gaseous and particulate products, J. Atmos. Chem., 34, 207-258, 1999.

Yu, L. E., Shulman, M. L., Kopperud, R., and Hildemann, L. M.: Characterization of organic compounds collected during the southeastern aerosol and visibility study: Water-soluble organic compounds, Environ. Sci. Technol., 39, 707-715, 2005.

Zahardis, J., LaFranchi, B. W., and Petrucci, G. A.: Direct observation of polymerization in the oleic acid-ozone heterogeneous reaction system by photoelectron resonance capture ionization aerosol mass spectrometry, Atmos. Environ., 40, 1661-1670, 2006.

Zahardis, J. and Petrucci, G. A.: The oleic acid-ozone heteroge- 
neous reaction system: products, kinetics, secondary chemistry, and atmospheric implications of a model system - a review, Atmos. Chem. Phys., 7, 1237-1274, 2007, http://www.atmos-chem-phys.net/7/1237/2007/.

Zappoli, S., Andracchio, A., Fuzzi, S., Facchini, M. C., Gelencsér, A., Kiss, G., Krivacsy, Z., Molnar, A., Meszaros, E., Hansson, H. C., Rosman, K., and Zebuhr, Y.: Inorganic, organic and macromolecular components of fine aerosol in different areas of Europe in relation to their water solubility, Atmos. Environ., 33, 27332743, 1999.

Zardini, A. A., Sjogren, S., Marcolli, C., Krieger, U. K., Gysel, M., Weingartner, E., Baltensperger, U., and Peter, T.: A combined particle trap/HTDMA hygroscopicity study of mixed inorganic/organic aerosol particles, Atmos. Chem. Phys., 8, 55895601, 2008, http://www.atmos-chem-phys.net/8/5589/2008/.

Zelenyuk, A., Cai, Y., and Imre, D.: From agglomerates of spheres to irregularly shaped particles: Determination of dynamic shape factors from measurements of mobility and vacuum aerodynamic diameters, Aerosol Sci. Technol., 40(3), 197-217, 2006.

Zhang, J. Y., Huff Hartz, K. E., Pandis S. N., and Donahue, N. M.: Secondary organic aerosol formation from limonene ozonolysis: Homogeneous and heterogeneous influences as a function of $\mathrm{NO}_{\mathrm{x}}$, J. Phys. Chem. A, 110, 11053-11063, 2006.

Zhang, R., Suh, I., Zhao, J., Zhang, D., Fortner, E. C., Tie, X., Molina, L. T., and Molina, M. J.: Atmospheric new particle formation enhanced by organic acids, Science, 304, 1487-1490, 2004.

Zhang, Q., Alfarra, M. R., Worsnop, D. R., Allan, J. D., Coe, H., Canagaratna, M. R., and Jimenez, J. L.: Deconvolution and quantification of hydrocarbon-like and oxygenated organic aerosols based on aerosol mass spectrometry, Environ. Sci. Technol., 39, 4938-4952, 2005a.

Zhang, Q., Worsnop, D. R., Canagaratna, M. R., and Jimenez, J. L.: Hydrocarbon-like and oxygenated organic aerosols in Pittsburgh: insights into sources and processes of organic aerosols, Atmos. Chem. Phys., 5, 3289-3311, 2005b, http://www.atmos-chem-phys.net/5/3289/2005/.

Zhang, Q., Suh, I., Zhao, J., Zhang, D., Fortner, E. C., Tie, X., Molina, L. T., and Molina, M. J.: Atmospheric new particle formation enhanced by organic acids, Science, 304, 1487-1490, 2004.

Zhang, Q., Jimenez, J. L., Worsnop, D. R., and Canagaratna, M. R.: A case study of urban particle acidity and its effect on secondary organic aerosol, Environ. Sci. Technol., 41, 3213-3219, 2007a.

Zhang, Q., Jimenez, J. L., Canagaratna, M. R., Allan, J. D., Coe, H., Ulbrich, I., Alfarra, M. R., Takami, A., Middlebrook, A. M., Sun, Y. L., Dzepina, K., Dunlea, E., Docherty, K., DeCarlo, P. F., Salcedo, D., Onasch, T., Jayne, J. T., Miyoshi, T., Shimono, A., Hatakeyama, S., Takegawa, N., Kondo, Y., Schneider, J., Drewnick, F., Borrmann, S., Weimer, S., Demerjian, K., Williams, P., Bower, K., Bahreini, R., Cottrell, L., Griffin, R. J., Rautiainen, J., Sun, J. Y., Zhang, Y. M., and Worsnop, D. R.: Ubiquity and dominance of oxygenated species in organic aerosols in anthropogenically-influenced Northern Hemisphere midlatitudes, Geophys. Res. Lett., 34, L13801, doi:10.1029/2007GL029979, 2007b.
Zhao, J., Levitt, N. P., and Zhang, R.: Heterogeneous chemistry of octanal and 2, 4-hexadienal with sulfuric acid, Geophys. Res. Lett., 32, L09802, 10.1029/2004GL022200, 2005.

Zhao, J., Levitt, N. P., Zhang, R., and Chen, J.: Heterogeneous reactions of methylglyoxal in acidic media: Implications for secondary organic aerosol formation, Environ. Sci. Technol., 40, 7682-7687, 2006.

Ziemann, P.: Evidence for low-volatility diacyl peroxides as a nucleating agent and major component of aerosol formed from reactions of $\mathrm{O}_{3}$ with cyclohexene and homologous compounds, J. Phys. Chem. A, 106, 4390-4402, 2002.

Ziemann, P. J.: Formation of alkoxyhydroperoxy aldehydes and cyclic peroxyhemiacetals from reactions of cyclic alkenes with $\mathrm{O}_{3}$ in the presence of alcohols, J. Phys. Chem. A, 107, 20482060, 2003.

Ziese, M., Wex, H., Nilsson, E., Salma, I., Ocskay, R., Hennig, T., Massling, A., and Stratmann, F.: Hygroscopic growth and activation of HULIS particles: experimental data and a new iterative parameterization scheme for complex aerosol particles, Atmos. Chem. Phys., 8, 1855-1866, 2008, http://www.atmos-chem-phys.net/8/1855/2008/.

Zobrist, B., Marcolli, C., Koop, T., Luo, B. P., Murphy, D. M., Lohmann, U., Zardini, A. A., Krieger, U. K., Corti, T., Cziczo, D. J., Fueglistaler, S., Hudson, P. K., Thomson, D. S., and Peter, T.: Oxalic acid as a heterogeneous ice nucleus in the upper troposphere and its indirect aerosol effect, Atmos. Chem. Phys., 6, 3115-3129, 2006, http://www.atmos-chem-phys.net/6/3115/2006/.

Zobrist, B., Marcolli, C., Peter, T., and Koop, T.: Heterogeneous ice nucleation in aqueous solutions: The role of water activity, J. Phys. Chem. A, 112, 3965-3975, 2008a.

Zobrist, B., Marcolli, C., Pedernera, D. A., and Koop, T.: Do atmospheric aerosols form glasses?, Atmos. Chem. Phys., 8, 52215244, 2008b, http://www.atmos-chem-phys.net/8/5221/2008/.

Zuend, A., Marcolli, C., Luo, B. P., and Peter, T.: A thermodynamic model of mixed organic-inorganic aerosols to predict activity coefficients, Atmos. Chem. Phys., 8, 4559-4593, 2008, http://www.atmos-chem-phys.net/8/4559/2008/.

Zuo, Y. G. and Hoigné, J.: Formation of hydrogen peroxide and depletion of oxalic acid in atmospheric water by photolysis of iron(III) oxalato complexes, Environ. Sci. Technol., 26, 1014$1022,1992$.

Zuo, Y. G. and Hoigné, J.: Photochemical decomposition of oxalic, glyoxalic and pyruvic acid catalysed by iron in atmospheric waters, Atmos. Environ., 28, 1231-1239, 1994. 